

\section{Winter hydrology and soil erosion processes in an agricultural catchment in Norway}




\section{Thesis committee}

\section{Promotor}

Prof. Dr C.J. Ritsema

Professor of Soil Physics and Land Management

Wageningen University \& Research

\section{Co-promotors}

\section{Dr J. Stolte}

Head of Department Soil and Land Use

Norwegian Institute for Bioeconomy (NIBIO), Ås, Norway

Dr R. Hessel

Senior Researcher, Soil, Water and Land Dynamics

Wageningen University \& Research

\section{Other members}

Prof. Dr A.H. Weerts, Wageningen University \& Research

Dr M. Stähli, Swiss Federal Research Institute WSL, Birmensdorf, Switzerland Prof. Dr J. Poesen, University of Leuven, Belgium

Prof. Dr N. Jarvis, Swedish University of Agricultural Sciences, Uppsala, Sweden

This research was conducted under the auspices of the Research School for SocioEconomic and Natural Sciences of the Environment (SENSE) 


\section{Winter hydrology and soil erosion processes in an agricultural catchment in Norway}

\section{Torsten Starkloff}

Thesis

submitted in fulfilment of the requirements for the degree of doctor at Wageningen University

by the authority of the Rector Magnificus,

Prof. Dr A.P.J. Mol, in the presence of the

Thesis Committee appointed by the Academic Board to be defended in public

on Tuesday 05 December 2017 at 11 a.m. in the Aula. 
Torsten Starkloff

Winter hydrology and soil erosion processes in an agricultural catchment in Norway, 156 pages.

PhD thesis, Wageningen University, Wageningen, the Netherlands (2017)

With references, with summary in English

ISBN: 978-94-6343-220-7

DOI: $10.18174 / 425126$. 


\section{Table of contents}

Chapter

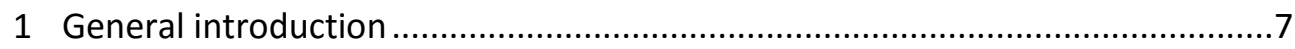

2 Choosing a soil erosion model for southern Norway .......................................15

3 Catchment hydrology and soil erosion during winter and spring: a case study in Norway

4 Understanding snow pack development at catchment scale .67

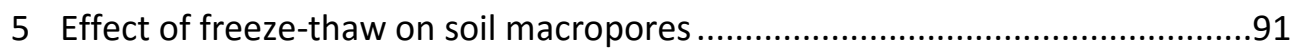

6 Integrated, spatially distributed modelling of surface runoff and soil erosion

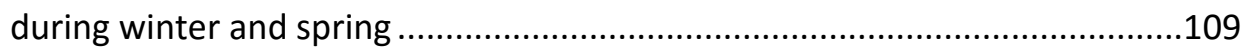

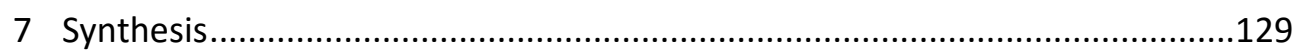

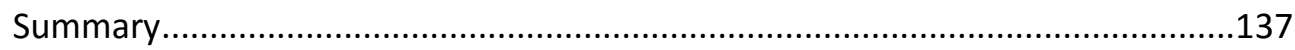

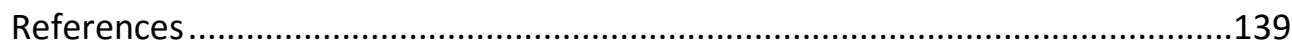

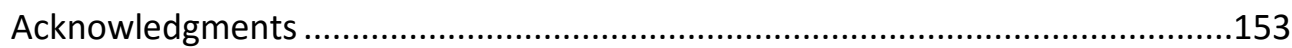


The world, nature, human beings, do not move like machines. The edges are never clearcut, but always frayed. Nature never draws a line without smudging it.

Winston L.S. Churchill (1874-1965)

To my parents, Gabriele and Bernd Starkloff 


\section{General introduction}




\subsection{Introduction}

In regions with a Nordic climate, soil erosion rates in winter and early spring can exceed those during other seasons of the year. In particular, the development of snow pack during winter can have a considerable effect on soils. The temperature-regulating properties of snow are especially important to agricultural soils. Without snow cover, low temperatures can directly affect the soil and result in deep-freezing of the soil profile, which can change the soil hydraulic properties dramatically (Stähli et al., 2001; Al-Houri et al., 2009). In southern Norway this has caused severe soil erosion, through impeded infiltration of snowmelt and rainwater, at the end of winter ( $\varnothing$ ygarden, 2003). The insulating properties of snow, on the other hand, can reduce the impact of freezing and thawing cycles on the soil structure during winter. In southern Norway several freezing and thawing cycles typically occur each winter and the soil structure is affected to a varying degree, depending on the snow cover (Kværnø and Øygarden, 2006). In addition, the amount of snow at the end of winter determines how much meltwater is available for creating overland flow that results in soil erosion on agricultural soils (Lundberg et al., 2016).

Understanding the hydrological processes that occur at catchment scale during winter is challenging. Because of additional factors of soil freezing and thawing and snow pack development and ablation, catchment hydrology is more complex than during other seasons of the year. Water infiltration into frozen soils is more complicated than water infiltration into unfrozen soils, because it involves coupling water and heat transport (temperature of the infiltrating water) with phase change (from liquid to ice and vice versa) (Iwata et al., 2011). In particular, ice blockage of macropores can have a large influence on water transport during freezing and thawing (Seyfried and Murdock. 1997). Furthermore, the changes in pore structure during winter also influence the water transport capacity of soil after winter.

Snow is one of the most changeable elements in the hydrological cycle (Doesken and Robinson, 2009). The air temperature at the time of snowfall is an important factor. It controls the dryness, hardness and crystalline form of fresh snow, and thereby its erodibility by wind. Wind interacting with terrain (e.g. slope and aspect) and vegetation heavily influences the deposition and redistribution of snow, increasing or reducing snow accumulation (Gascoin et al., 2013). Snow packs have a large impact on the development of surface runoff in catchments. A snow pack that is not 'ripe', i.e. the internal temperature has not reached $0^{\circ} \mathrm{C}$, can act as a buffer by retaining incoming rain water (Gray and Male, 1981). However, rain falling on a melting snow pack can accelerate snowmelt and cause large quantities of runoff (Sui and Koehler, 2001), inducing soil erosion and flooding. 
The complexity of the interacting processes, which vary in both time and space make spatial investigation challenging and costly. In spite of the importance of the processes mentioned, they are often neglected or only partly treated in hydrological models (Lundberg et al., 2016), and the spatial and temporal resolution of required data is generally poor as well (Lundberg et al., 2010). In Norway, except for a few attempts using empirical hydrological models (e.g. Lundekvam, 2007), only a few studies have used physically based hydrological models to simulate surface runoff and soil erosion during winter (e.g. Kramer and Stolte, 2009; Grønsten and Lundekvam, 2006), and they have yielded contrasting results.

It was therefore concluded that a better understanding and quantification of the interaction of soil, water and snow at catchment scale was needed in order to reduce the erosion of irreplaceable fertile top soils and related sediment transfer from fields to streams during winter and spring, accounting for a major part of the annual losses of phosphorous and nitrogen in agricultural catchments also (Deelstra et al., 2011; Su et al., 2011). In this context, it was clear that, in addition to the need for better data, physically based models that are able to capture these interlinked processes needed to be tested in more detail under the conditions faced in Norway.

\subsection{Objectives}

The overall aim of this study is to increase our knowledge about winter hydrology and its effect on soil erosion at catchment scale.

Based on the research needs identified above, the specific objectives were to:

1. Investigate the temporal dynamics of soil hydraulic properties during winter conditions, and related effects upon runoff and soil erosion by snowmelt and rain,

2. Quantify and visualise temporal and spatial snow accumulation and melting patterns at catchment scale,

3. Analyse the effect of freeze-thaw cycles upon macropore structural changes in soils,

4. Integrate acquired data and process knowledge with physically based hydrological models for surface runoff and soil erosion simulation at catchment scale during winter and spring conditions. 


\subsection{Outline of the thesis}

The objectives of the PhD study relate to processes, measurements and modelling at both point and catchment scale, which are addressed in detail in subsequent chapters of this thesis. Fig. 1.1 shows the connections between these chapters, and indicates that the work at point scale forms the basis for the measuring strategy and modelling at catchment scale.

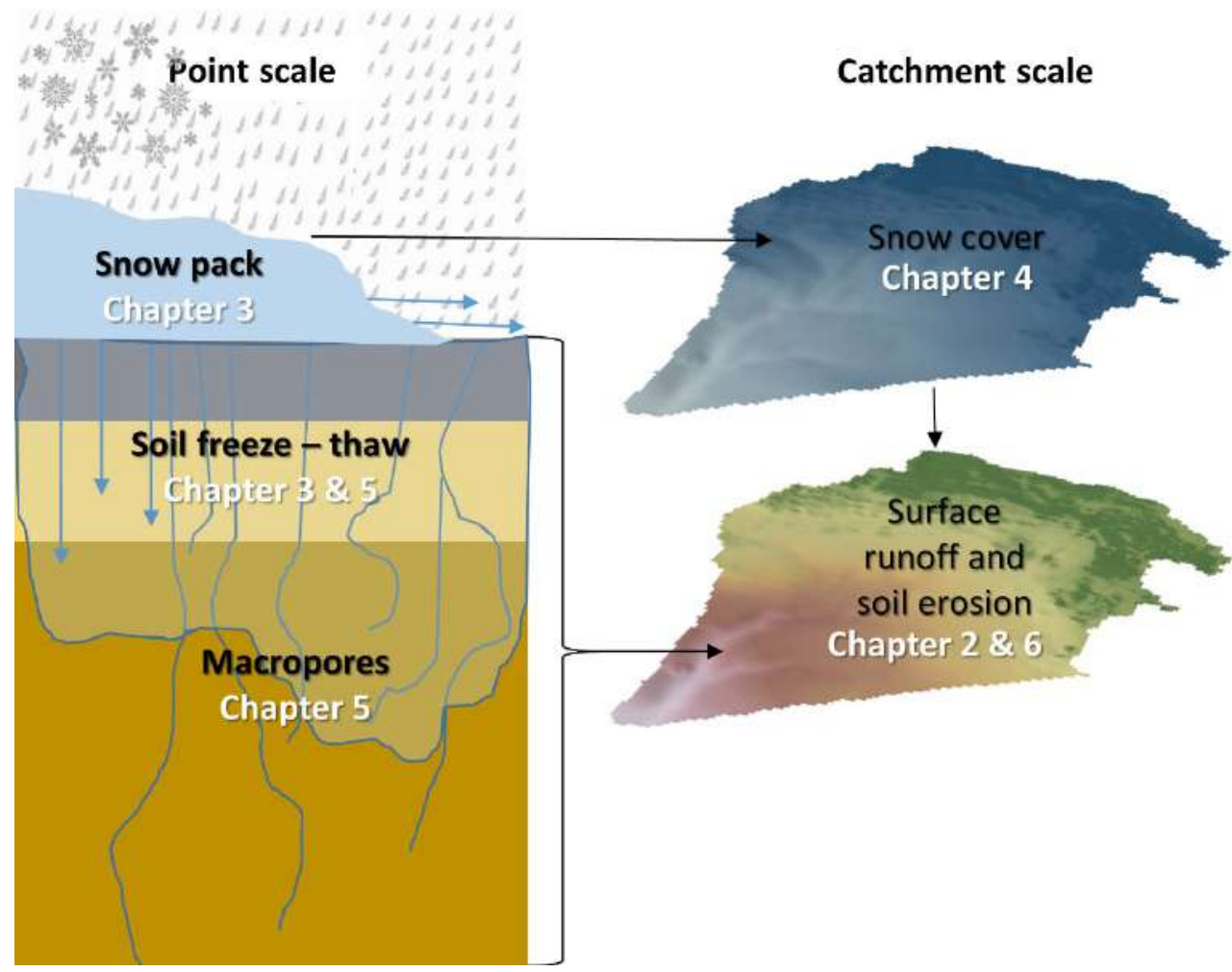

Fig. 1.1: Schematic overview of the structure of the thesis. Black arrows indicate knowledge and data flows, and the blue arrows water pathways.

In Chapter 2, the calibration of the Limburg Soil Erosion Model (LISEM) and the EROSION 3D model for the prediction of surface discharge and soil erosion in the study area is described, and their performance compared. The effects of different resolutions of topological data and of the choice of initial boundary conditions on the modelling results were investigated. This evaluation of models was necessary to bridge the gap caused by the absence of a successfully tested physically based soil erosion model for southern Norway that is suitable for quantifying surface runoff and soil erosion at catchment scale during winter and spring 
conditions (Chapter 6). Based on a set of criteria, the LISEM model was chosen to simulate soil hydrological processes for the study area (Chapter 6).

Chapter 3 focuses on extensive field investigations during three winter periods and subsequent modelling of soil temperature, ice content and snow pack development using the point scale Simultaneous Heat and Water (SHAW) model. This work provided data and process understanding of soil hydraulic property dynamics due to freezing-thawing cycles, and related effects upon runoff and soil erosion generation. Collected data and acquired knowledge were also used to model surface runoff and soil erosion during winter and spring conditions in the respective catchment, as presented in Chapter 6.

Chapter 4 describes the spatially and temporally distributed snow sampling carried out over three winter periods in the study area. In addition, the modelling results of snowmelt at catchment scale using the gridded version of the Utah Energy Balance snow model (UEBGrid) are presented. The snow sampling campaign provided valuable data for calibration and validation purposes. The presented simulations of snowmelt at catchment scale provided necessary input on melt discharge for the soil erosion modelling part described in Chapter 6.

Chapter 5 describes the quantification of temporal changes in soil macropore networks, due to soil freeze-thaw cycles using XRT imaging. This study explains the effects of macropore structural changes upon soil hydraulic parameters in the field, and is closely linked to Chapter 3.

Chapter 6 describes how acquired data and better process understanding were integrated for simulating runoff and soil erosion processes at the catchment scale using the LISEM model during the respective winter and spring conditions.

Finally, Chapter 7 reflects upon the main findings of the thesis in wider perspective, and provides recommendations for further research.

\subsection{Research design}

The field work in this study was carried out in the agricultural area of the Gryteland catchment (Fig. 1.2) between January and April in 2013, 2014 and 2015. Automated measuring of soil water content and soil temperature at different points in the study area was carried out during these periods. Liquid soil water content and soil temperature were measured using frequency domain reflectometry (FDR) sensors (Decagon 5 TM) in up to 
four soil profiles (Fig. 1.2) at four depths: 5, 20, 30 and $40 \mathrm{~cm}$ (see Chapter 3 for more details).

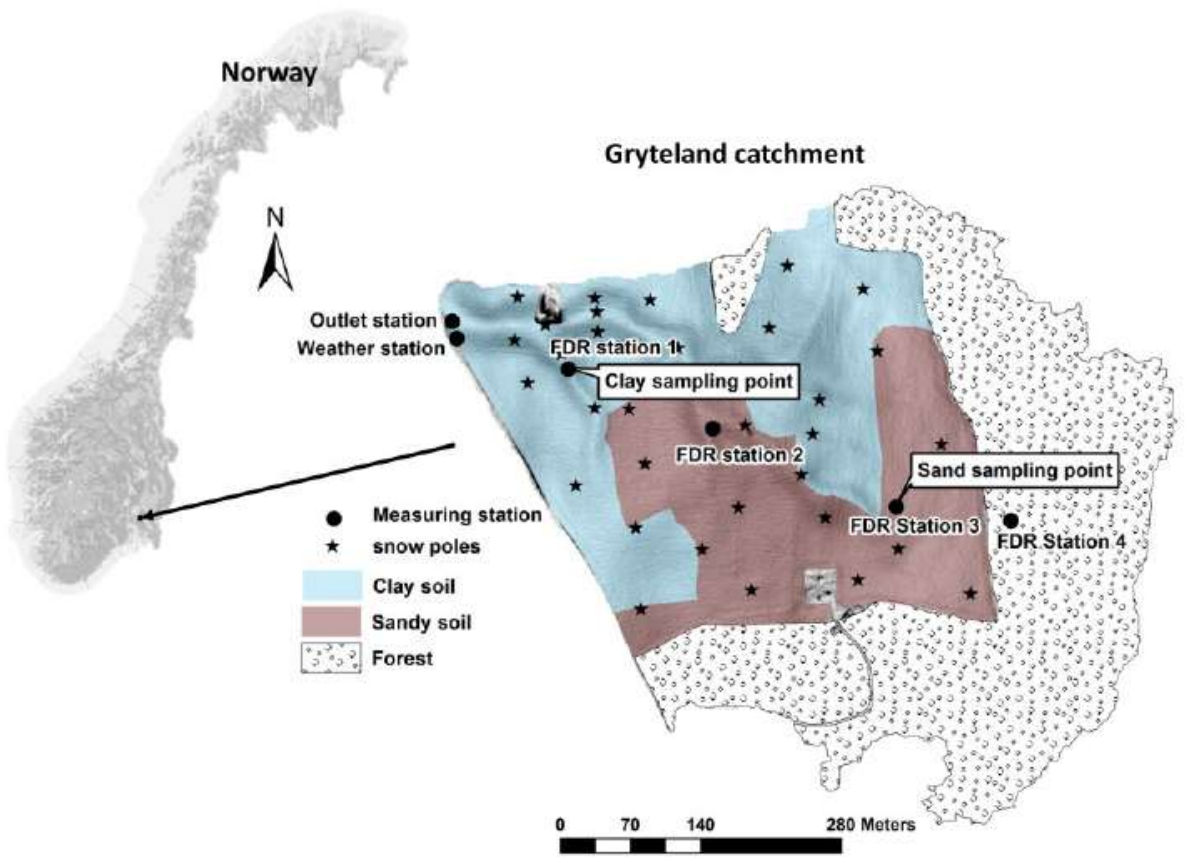

Fig. 1.2: Map showing the location of the Gryteland catchment in Norway, including two points (sand and clay sampling points) where the soil samples for determination of soil hydraulic characteristics and for $X$-ray scanning were taken, and the different measuring stations (FDR station) and snow poles.

A weather station was installed in the study area (Fig. 1.2) at the end of 2013. It provided hourly data on net solar radiation, air temperature, wind speed and wind direction. Since 2008, precipitation has been measured (tipping bucket) in the study area using a time resolution of 10 minutes.

Between January and April of each year, the snow pack was sampled after weather events expected to result in changes in the snow cover. Three to five (volumetric) snow samples were collected at each measuring point, depending on the snow depth. These samples were combined to measure the mass of the snow and to calculate its density (average mass divided by average snow volume). Snow water equivalent (SWE) was calculated from this data. During the winter of 2015, the snow measurements were intensified using marked snow poles distributed across the catchment. These poles allowed snow depth to be measured from a distance by reading the value on the measuring scale of the poles with a spyglass, keeping disturbance of the snow pack within the catchment to a minimum 
(Chapter 4). In the same winter, a drone was used to assess snow patterns across the entire study area in more detail (Chapter 4).

During the field work in 2014, 72 (ensuring enough replicates) undisturbed soil samples of varying size were taken at different depths from two soil profiles, representing the two major soils in the study area (Fig. 1.2). Samples with a volume of $250 \mathrm{~cm}^{3}$ were taken to determine the soil water retention and unsaturated hydraulic conductivity characteristics using the evaporation method (Umwelt-Geräte-Technik $\mathrm{GmbH}$ ), as well as to determine the saturated soil hydraulic conductivity using the constant head method. In addition, samples with a volume of $98 \mathrm{~cm}^{3}$ were taken to determine bulk density and soil organic matter content. These data were used in the modelling simulations presented in Chapters 3 and 6 .

In May 2015 eight undisturbed soil samples (inner diameter $10 \mathrm{~cm}$, length $20 \mathrm{~cm}$ ) were taken, four of each soil type. These samples were scanned several times with an X-ray tomography scanner at the Swedish University of Agricultural Sciences (SLU) in Uppsala, Sweden. Between the scans each sample was exposed to a total of six freeze-thaw-cycles (FTC). The 3D images obtained were processed and analysed using the FIJl distribution of ImageJ and $R$, in order to quantify the change in macropore networks due to the imposed freeze-thaw cycles (Chapter 5).

Four different numerical models were used to describe and quantify different processes in this study. The spatially distributed, physically based hydrological models EROSION 3D and LISEM were tested to obtain a detailed understanding of processes incorporated in these models, to acquire knowledge on parameter sensitivity, and gathering better insights in model weaknesses and strengths. A detailed description of these two models and their performance is provided in Chapter 2. The SHAW model was used to simulate observed changes in soil temperatures during the three winter periods in order to quantify the ice content in two soil types. Furthermore, the development of the snow pack at above the two soil types was simulated with this model (Chapter 3 ). The UEBGrid model was used for the spatially distributed snow modelling (Chapter 4 ). The simulated snowmelt discharge was used as input for the LISEM model for soil erosion modelling at catchment scale (Chapter $6)$. 


\section{Choosing a soil erosion model for southern Norway}

The loss of fertile soil from agricultural areas in Norway is especially harmful because of the thin layer of nutrient rich soil and the limited space where agriculture is possible. Physically based soil erosion prediction models have proved to be good tools to simulate and quantify soil erosion, but are not well established in Norway yet. Due to that this study was undertaken to further improve the knowledge about soil erosion development on agricultural areas and to better establish physically based models as an additional tool for soil research, in Norway. Two models were chosen for this study; the Limburg Soil Erosion Model (LISEM) and the EROSION 3D model. These two models were applied to the Skuterud catchment in the Ås municipality, for which measured discharge data, at the outlet, was available. The goal of this study was to investigate how the differences of two physically based models will influence the result of one and the same problem, to give an in-depth insight of what are the sources of uncertainty in modelling processes. To do that both models were calibrated by comparing the simulated hydrograph with the measured data. Special attention was given to the dependency of the model results on effects of grid cell size and time resolution. The grid cell size of the maps was easily adapted by using digital elevation models (DEM) obtained from airborne light detection and ranging (LIDAR) data. Furthermore the predicted erosion patterns were compared with soil erosion and deposition patterns observed in the field.to validate the simulation results also in a spatial context. With both models, it was possible to simulate a satisfactory accurate hydrograph and total amount of surface discharge. However, the output maps produced by the models showed quite different erosion and deposition features.

Based on:

Starkloff, T., Stolte, J., Applied comparison of the erosion risk models EROSION 3D and LISEM for a small catchment in Norway. Catena, 2014, 118, pp. 154 - 167 


\subsection{Introduction}

In northern countries, erosion rates often follow a seasonal pattern with the highest soil losses occurring during late autumn and early spring. Only a few runoff events are responsible for most of the total soil loss each year ( $\varnothing$ ygarden, 2003). The loss of fertile soil in agricultural areas in Norway is especially harmful because of the thin layer of nutrient rich soil and the limited area in which agriculture is possible. Due to unfavourable conditions for agriculture in large parts of the country, only 3\% (about 1 million ha) of Norway's total land area is cultivated (Lundekvam et al., 2003). Soil erosion and flooding can cause major off-site damage. Studies in Belgium, for example, have estimated the mean annual cost of off-site damage caused by muddy floods to 14-140 million euros per year (Evrard et al., 2007). In addition, it is expected that the extent, frequency and magnitude of soil erosion will increase due to the change in rain fall intensity caused by climate change will increase (Puski and Nearing 2002; Deelstra et al., 2011).

It is important to understand the processes behind discharge development and soil erosion in order to combat negative impacts of extreme weather events. Beside field and laboratory investigation, physically based erosion risk models have proved to be good tools for understanding these processes (e.g. Bhuyan et al., 2002; Nearing et al., 2005; Boardman, 2006). Furthermore, models can help to, e.g., quantify the impact of climate change and land use on soil and water quality, the risk of water pollution by agrochemicals such as nutrients and pesticides, flooding frequency and the efficiency of mitigation measures.

Except for a few modelling attempts using empirical erosion models (e.g. Lundekvam, 2007), only a few studies have used physically based erosion prediction models to simulate erosion in Norway (e.g. Kværnø and Stolte, 2012; Grønsten and Lundekvam, 2006), and they have yielded rather different results. Therefore, this study was undertaken to further improve the knowledge about soil erosion processes in agricultural areas in Norway and to better establish physically based models as an additional tool in soil science in Norway. Two models were chosen for this study: the Limburg Soil Erosion Model (LISEM) (De Roo et al., 1996a, 1996b; Jetten, 2002) and the EROSION 3D model (Schmidt, 1996 and Werner, 2004). These models were chosen for several reasons:

1. Both models have been widely used in different studies; e.g. LISEM in Jetten and De Roo (1999); Takken et al. (1999); Hessel (2005); Hessel and Tenge (2008); Stolte et al. (2005); Hessel et al. (2003); Nearing et al. (2005); Hengsdijk et al. (2005); Sheikh et al. (2010) and EROSION 3D e.g. in Werner (1995); Schmidt and Werner (2000); Michael et al. (2005); Schob et al. (2006); Schindewolf and Schmidt (2009); Köthe (2010); 
2. To continue the evaluation of LISEM for Norway started by Kværn $\varnothing$ and Stolte (2012);

3. To test the EROSION 3D model under the conditions in Norway. To evaluate wether EROSION 3D and its parameter catalogue (DProc software), which was calibrated for a specific region (Saxony) in Germany (Michael, 2000), can be used without major changes because of the different climate of southern Norway.

The main objective of this study was to compare results of two physically based models for calculating discharge and runoff;

(i) To provide in-depth insight into what the sources of uncertainty in the modelling process are, including the model design (i.e. process representation, equations used), to help users to choose the right model for the right purpose,

(ii) To analyse the effect of topographical data at different resolutions,

(iii) To quantify the influence of choices of initial and boundary conditions on modelling results.

Spatial erosion/deposition models should be validated in a spatial context and not just by comparing of the outlet results (Takken et al., 1999). To do so, we compared the soil loss maps produced by the two models with each other and with soil erosion and deposition patterns observed in the field. 


\subsection{Materials and methods}

\subsubsection{Study area}

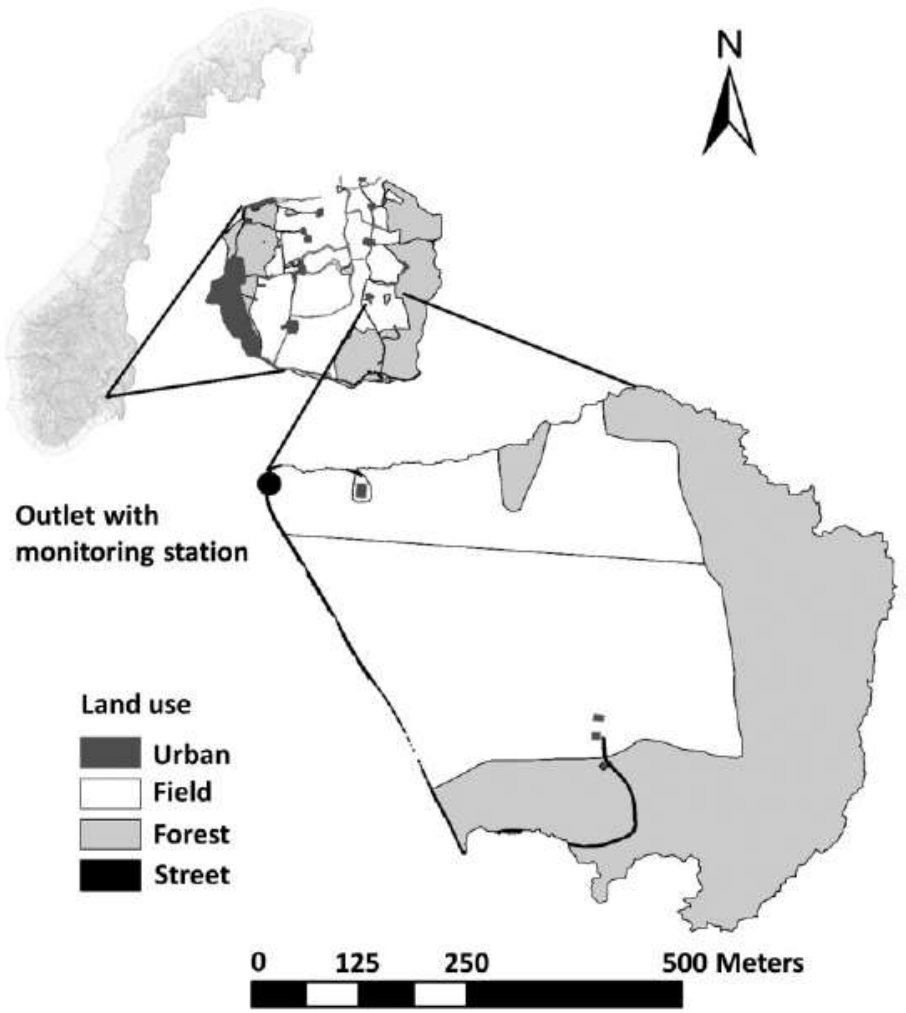

Fig. 2.1: Location of the Gryteland sub-catchment within the Skuterud catchment in Norway.

The study area was the Skuterud catchment, located in Ås and Ski municipalities, approximately $30 \mathrm{~km}$ south of Oslo. The dominating land use is agriculture with cereal production which covers approximately $60 \%$ of the catchment followed by $33 \%$ pine forest and $7 \%$ urban area (Kværnø et al., 2007). The mean annual temperature is $5.3^{\circ} \mathrm{C}$ and the mean precipitation is $785 \mathrm{~mm}$ per year. The catchment size is approximately 450 ha (4.5 $\mathrm{km}^{2}$ ) and the altitude varies from 85 to $150 \mathrm{~m}$ above sea level. The topography can be characterised as undulating.

The soil maps provided by the Norwegian Institute of Bioeconomy Research (NIBIO) only covered the arable land. According to these maps, the main soils in the central parts are 
marine silt loam and silty clay loam, classified in the World Reference Base for soil resources (WRB) as Albeluvisols and Stagnoslos. In the areas surrounding the central marine deposits, sand and loamy sand predominate, classified as Cambisols, Arenosols, Umbrisols, Podzols and Gleysols.

For the calibration of the LISEM and EROSION 3D models, a sub-catchment was chosen in the south-eastern part of the main catchment (Fig. 2.1). After a high erosion risk was recognised within the sub catchment, a monitoring station was installed at the outlet of the sub-catchment in 2008 (Kramer and Stolte, 2009). This station continuously measures precipitation, runoff and soil loss.

\subsubsection{Models}

Both models are physically based, work on a catchment scale and use raster maps as input. These raster maps are created using geo-information system (GIS) based software, ArcGIS (http://www.esri.com/software/arcgis (12.13.2012)) for EROSION 3D and PCRaster (http://www.pcraster.geo.uu.nl/ (12.13.2012)) for LISEM. Furthermore, both models are event-based, which means they are used to predict soil erosion and surface discharge caused by short-term (a few minutes up to a few days) rain events.

The major differences between the models are how they calculate infiltration, overland flow and soil detachment and deposition, This results in different sensitivity to changes in the input parameters and therefore in different calibration procedures as well as different results. The models are described in detail in Schmidt (1996) and Werner (2004), for Erosion 3D, and in De Roo et al. (1996a and 1996b) and Jetten (2002) for LISEM. A good overview of the differences and similarities betweem the two models was provided by Boardman and Poesen (2006).

LISEM and ERSOSION 3D use different approaches to simulate the infiltration and surface runoff. For the LISEM simulations, the Swatre sub-model (Belmans et al., 1983) was used in this study (Kværn $\varnothing$ and Stolte, 2012). In the Swatre sub-model, infiltration and soil water flow in the soil profile are simulated by solving the Richard's equation. Soil hydraulic characteristics (i.e. water retention and (un-) saturated hydraulic conductivity) of each soil layer are needed. They can be either measured or predicted using pedo-transfer functions (PTF).

The infiltration model used for EROSION 3D was developed by Schmidt (1993). It is based on the approach of Green and Ampt (Li et al. 1976). The infiltration rate is calculated with 
the Darcy equation (Schmidt, 1996). The Darcy equation contains variables that can be estimated $\left(\Psi_{m}, K_{s a t}, \vartheta_{s}\right)$ or measured $\left(\vartheta_{i}\right)$ (Schmidt, 1996). The matric potential $\left(\psi_{m}\right)$ of the soil for the initial moisture content $\left(\vartheta_{i}\right)$ is estimated with the equation of Van Genuchten (1980), and the saturated water content $\left(\vartheta_{s}\right)$ was estimated with the pedo-transfer-function of Vereecken (1989), whereas the saturated hydraulic conductivity $\left(K_{\text {sat }}\right)$ is estimated using the PTF of Campbell (1985) (Schmidt, 1996).

The basic concept of the spatial distribution for the overland flow is the same in the two models. Both models use a flow path model that is derived from the digital elevation map (DEM) (Jetten, 2002, Werner, 2004). Furthermore, both models calculate the runoff velocity $\left(v_{q}\right)$ using the approach of Manning-Stickler, as:

$v_{q}=1 / n * \delta^{(2 / 3)} * S^{(3 / 5)}$

where: $v_{q}=$ flow velocity $\left[\mathrm{m} \mathrm{s}^{-1}\right] ; \mathrm{n}=$ Manning $\mathrm{s} \mathrm{n}\left[\mathrm{s} \mathrm{m}^{-1 / 3}\right] ; \delta=$ hydraulic radius $[\mathrm{m}] ; \mathrm{S}=$ slope $[-]$

The hydraulic radius $(\delta)$ is calculated differently in LISEM and EROSION 3D due to the different approaches used to define the surfaces in each model's individual cells.

In LISEM one grid cell can have more than one type of surface, as shown in Fig. 2.2. The infiltration characteristics vary according to the different surfaces in the grid cell, giving an individual water height above each surface type (Fig. 2.2). An average water height is then calculated for the grid cell, which results in an average hydraulic radius ( $\delta_{L}$; Equation 2.2 ) that is used to calculate the flow velocity (Equation 2.1).

$\delta_{L}=A / P_{w}$

where: $A=$ wet cross sectional area $\left[\mathrm{m}^{2}\right] ; P_{w}=$ wet perimeter $[\mathrm{m}]$

The discharge per cell $Q_{\llcorner}\left[\mathrm{m}^{3} \mathrm{~s}^{-1}\right]$ can be calculated using Equation 2.3 for the wet cross section area $(A)$ :

$A=\alpha * Q_{L}^{B}$

where: $\alpha=\left(\left(n / s^{(1 / 2)} * P_{w}\right)^{(2 / 3) b} ; \beta=0.6\right.$

In LISEM, the channel and overland flow are calculated separately with separate kinematic waves. For the distributed overland and channel flow routing, a four-point finite-difference solution of the kinematic wave is used together with Manning's equation. The kinematic wave is calculated over the Local Drain Directions map that forms a network connecting cells in eight directions (Jetten, 2002). 


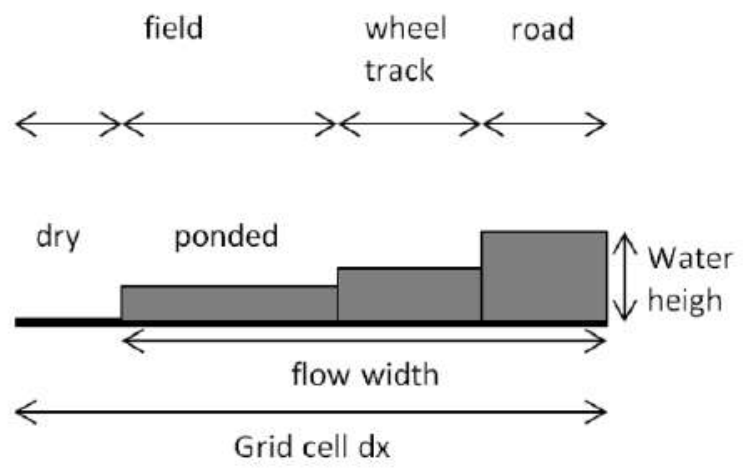

Fig. 2.2: Calculation of the average water height due to different surfaces in a grid cell of LISEM (Jetten, 2002)

The basic version of EROSION 3D does not take the kinematic wave into account (Werner, 2004). A sub-module was later included in EROSION 3D, using a simplification of the kinematic wave approach similar to the one used in LISEM, to improve the results for discharge development over time (Werner, 2004). Unlike LISEM, the approach in EROSION $3 \mathrm{D}$ uses a dynamic reservoir $(M)$ for each grid cell which depends on the hydraulic radius (Equation 2.6) and the size of the grid cell.

$M=\delta_{R} * \partial \mathrm{x}$

where: $M=$ storage capacity of the water film $\left[\mathrm{m}^{3}\right] ; \partial x=$ area of the cell $\left[\mathrm{m}^{2}\right]$

This dynamic reservoir will be filled as long as the runoff increases and it will start to empty when the runoff starts to decrease. The resulting error in velocity is assumed to be small for relatively small catchments if a small time resolution (10 to $60 \mathrm{~s}$ ) is chosen. An increasing error is expected in catchments with small slope angles, due to the increasing diffusion and tailback of the surface water (for more details, see Werner, 2004).

In EROSION 3D, the discharge $\left(Q_{R}\right)$ for each grid cell is calculated as follows:

$Q_{R}=\left(r_{a}-i\right) * \partial x+q_{i n}$

where: $Q_{R}=$ discharge $\left[\mathrm{m}^{3} \mathrm{~s}^{-1}\right] ; r_{a}=$ precipitation intensity in relation to the slope angle $[\mathrm{mm}$ $\left.\mathrm{min}^{-1}\right] ; \quad i=$ infiltration rate $\left[\mathrm{mm} \mathrm{min}^{-1}\right] ; \partial x=$ grid cell length $[\mathrm{m}] ; q_{\text {in }}=$ inflow from other grid cells $\left[\mathrm{m}^{3} \mathrm{~s}^{-1}\right]$

$Q_{R}$ is used to calculate the hydraulic radius $\left(\delta_{R}\right)$ (Equation 2.6), which is used to calculate the flow velocity $\left(v_{q}\right)$ (Equation 2.1 ). 
$\delta_{R}=\left(\left(Q_{R} * n\right) / S^{(1 / 2)}\right)^{(3 / 5)}$

To calculate soil detachment, both models use a combination of detachment processes. One process is the detachment of particles by rain drops, while the second is detachment by overland flow. The models use different approaches to calculate these processes.

In LISEM, the amount of detached particles in the suspension $(e)$ is a balance between the continuous counteracting processes of erosion and deposition $(D p)$, presented in Equation 2.7, where erosion is the sum of splash detachment by raindrops (Ds) and detachment by overland flow $(D f)$.

$e=D s+D f-D p$

The detachment by raindrops in LISEM is related to the kinetic energy of the rainfall $\left(K e_{r}\right.$ and $K e_{t}$, Equation 2.8). This is the case for EROSION 3D as well (Equation 2.15), although different approaches are used in the models. In LISEM the kinetic energy of the rainfall $\left(K e_{r}\right.$ and $\left.K e_{t}\right)$ is calculated as follows:

$K e_{r}=8.95+8.44 * \log (R i)$ (free rain fall) and $K e_{t}=15.8 *\left(h_{p}\right)^{(1 / 2)}-5.87$ (through fall from plant canopy)

where: $R i$ is the rainfall intensity $\left(\mathrm{mm} \mathrm{h}^{-1}\right), h_{p}$ the plant height $[\mathrm{m}]$ and $K e$ in $\mathrm{J} \mathrm{m}^{-2} \mathrm{~mm}^{-1}$.

Two different equations can be used for calculating Ds for LISEM depending on the values of Ke. But in general, the following equation (2.9) is used (Jetten, 2002):

$D s=((2.82 / A s) * K e * \exp (-1.48 * h)+2.96) * P * A$

where: $D s=$ splash detachment $\left[\mathrm{kg} \mathrm{s}^{-1}\right] ; A s=$ aggregate stability $[-] ; h=$ depth of surface water layer $[\mathrm{mm}] ; P=$ precipitation (no plant cover) or through fall (with plant cover) in [mm]; $A$ = surface area over which splash takes place $\left[\mathrm{m}^{2}\right]$

The flow detachment and deposition in LISEM depend on the transport capacity $(T C)$ of the surface runoff (Equation 2.10):

$T c=\chi *\left(s * v_{q} * 100-C S P\right) * \varepsilon$

where: $T c=$ transport capacity $\left[\mathrm{kg} \mathrm{m}^{-3}\right] ; \chi=((\mathrm{D} 50+5) / 0.32)^{-0.6}$, where $D 50$ is the median grain size $[\mu \mathrm{m}] ; \varepsilon=((D 50+5) / 300)^{0.25} ; C S P=$ critical stream power $\left[0.4 \mathrm{~cm} \mathrm{~s}^{-1}\right] ; S=$ slope $[-]$ 
If the transport capacity $(T c)$ is greater than the sediment concentration $(S c)$ in the flow, the flow detachment $(D f)$ is calculated as follows:

$D f=Y *(T c-S c) * S v * \partial t * \partial x * \delta$

where: $D f=$ flow detachment $\left[\mathrm{kg} \mathrm{s}^{-1}\right] ; Y=$ efficiency coefficient; $S c=$ sediment concentration $\left[\mathrm{kg} \mathrm{m}^{-3}\right] ; \mathrm{Sv}=\quad$ settling velocity of the particle according to Stokes 'law [ $\mathrm{m} \mathrm{s}^{-1}$ ]

If the transport capacity $(T c)$ is smaller than the sediment concentration $(S c)$, deposition occurs.

In EROSION 3D the calculation of the detachment of particles depends on a dimensionless factor $E$ (Erodibility), which is calculated as follows:

$E=\left(\varphi_{q}+\varphi_{r}\right) \varphi_{\text {crit }}$

where: $\varphi_{q}=$ impulse current of the surface runoff $[\mathrm{N}] ; \varphi_{r}=$ impulse current of rain drop impact $[\mathrm{N}] ; \varphi_{\text {crit }}=$ critic impulse current of the soil $[\mathrm{N}]$

This factor is used to determine when particles are detached from the soil. If $E>1$, detachment of particles starts and if $E \leq 1$, the sum of the forces of overland flow and splash are not strong enough to detach particles, and no erosion occurs.

The impulse current of the surface runoff $\left(\varphi_{q}\right)$ is calculated as follows:

$\varphi_{q}=\left(Q_{R} * p_{q} * v_{q}\right) / \partial x$

where: $p_{q}=$ liquid density of water $\left[\mathrm{kg} \mathrm{m}^{-3}\right]$

and the impulse current of raindrops $\left(\varphi_{r}\right)$ is defined as follows:

$\varphi_{r}=r_{\alpha} * \partial x * p_{r} * v_{r} * \sin \alpha *\left(1-C_{L}\right)$

where: $r_{\alpha}=$ precipitation intensity in relation to the slope $\alpha\left[\mathrm{m} \mathrm{s}^{-1}\right] ; p_{r}=$ liquid density of the rain $\left[\mathrm{kg} \mathrm{m}^{-3}\right] ; v_{r}=$ mean fall velocity of the raindrops $\left[\mathrm{m} \mathrm{s}^{-1}\right]$, where $v_{r}=4.5 * R i^{0.12} ; \alpha=$ slope angle $\left[{ }^{\circ}\right] ; C_{L}=$ canopy $[\%]$

The critical impulse current $\left(\varphi_{\text {crit }}\right)$ gives an indication of the erosion resistance of the soil. It is determined by irrigation experiments, where it is assumed that a minimum discharge $\left(q_{\text {crit }}\right)$, which depends on the properties of the soil, is necessary to dispatch particles from the soil surface. By inserting the minimum discharge $\left(q_{c r i t}\right)$ into Equation 2.14, the critical impulse current $\left(\varphi_{\text {crit }}\right)$ for a certain soil can be calculated (Equation 2.16). 
$\varphi_{\text {crit }}=\left(q_{c r i t} * p_{q} * v_{q}\right) / \partial x$

As in LISEM the amount of detached particles that can be transported with the discharge depends on the transport capacity $\left(q_{s, \max }\right)$ of the surface discharge, but the transport capacity $\left(q_{s, \text { max }}\right)$ of the surface discharge depends on two processes in EROSION 3D;

1. Deposition of particles due to gravity; and

2. The turbulent current working against this deposition. This turbulent current is a combination of the impulse forces of raindrops and overland flow.

The first process is similar to the LISEM approach (Equation 2.11) described by Stokes` law. By multiplying the value of the sinking velocity of Stokes' law and the mass flow as described in Schmidt (1996), the critical impulse current of the flow $\left(\varphi_{q, \text { crit }}\right)$ is calculated as follows:

$\varphi_{q, \text { crit }}=c^{*} p_{p} * \partial x^{2} * v_{p}^{2}$

where: $c=$ concentration of particles in the suspension $\left[\mathrm{m}^{3} \mathrm{~m}^{-3}\right] ; p_{p}=$ density of the particles $\left[\mathrm{kg} \mathrm{m}^{-3}\right] ; v_{p}=$ sinking velocity $\left[\mathrm{m} \mathrm{s}^{-1}\right]$

If the impulse current in the suspension is below $\varphi_{q, \text { crit }}$ the particle will sink to the ground.

The second process received no consideration in LISEM, but is implemented in the EROSION $3 \mathrm{D}$ model. The vertical turbulent impulse current $\left(\varphi_{q, v e r t}\right)$ is defined as:

$\varphi_{q, v e r t}=1 / K^{*}\left(\varphi_{q}+\varphi_{r}\right)$

where: $K=$ deposition coefficient [-]

According to this, the surface runoff has reached its transport capacity when the vertical impulse current is equal to the critical impulse force of the particles in the suspension.

$\varphi_{q, v e r t}=\varphi_{q, \text { crit }}$

By inserting Equations 2.17 and 2.18 into Equation 2.19, it is possible to calculate the maximal concentration of dispatched particles $c_{\max }\left[\mathrm{m}^{3} \mathrm{~m}^{-3}\right]$ in the discharge:

$c_{\max }=1 / K *\left(\left(\varphi_{q, v e r t}+\varphi_{q, \text { crit }}\right) /\left(p_{p} * \partial x^{2} * v_{p}\right)\right)$

Using Equation 2.20, the transport capacity of the discharge can be calculated:

$q_{s, \max }=c_{\max } * p_{p} * Q_{R}$

where: $q_{s, \max }=$ maximal transport capacity $\left[\mathrm{kg} \mathrm{m}^{-1} \mathrm{~s}^{-1}\right]$ 


\subsubsection{The dataset}

\subsubsection{Calibration event}

A storm event on 13 August 2010 was chosen (Fig. 2.3) for the calibration of the models. Precipitation was monitored at the same location as runoff, i.e. at the sub-catchment outlet, with a resolution of one minute (Kværn $\varnothing$ and Stolte, 2012). The event used in the model calibration had a duration of $12 \mathrm{~h} 50$ minutes and yielded a total of $24.2 \mathrm{~mm}$ of precipitation.

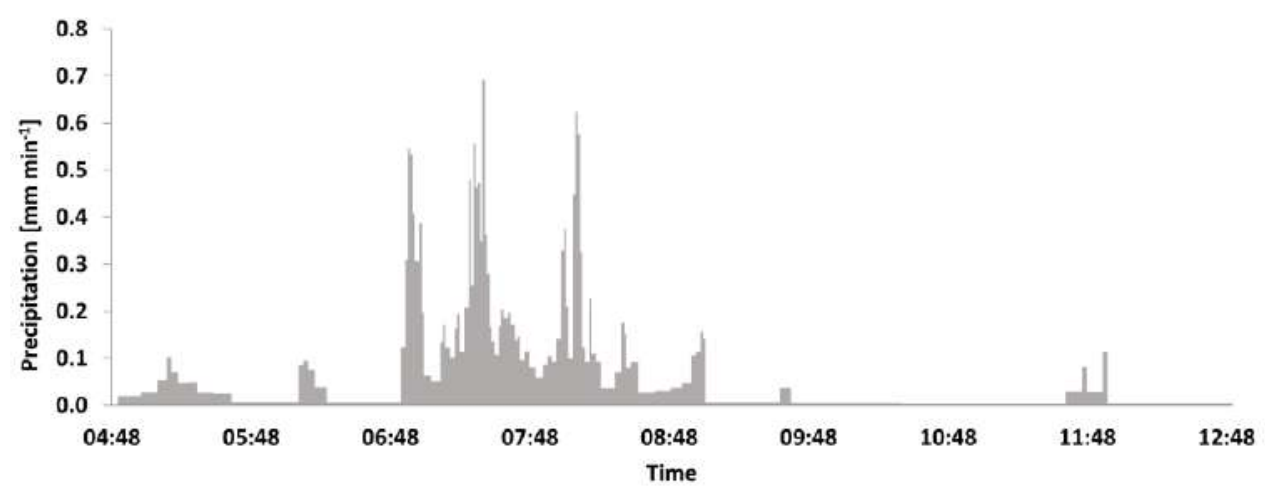

Fig. 2.3: Precipitation graph for the August 13, 2010 event.

\subsubsection{Input parameters}

Soil maps for the LISEM input were available from the Norwegian Forest and Landscape Institute. This soil map covered the arable land only, with a coverage of approximately $94 \%$ ( $6 \%$ of the arable land was not covered by the map), whereas no soil maps exist for the other land use types (forest, urban areas). A geological map was used to determine the soil types in the missing areas, and the soil type for forest and urban area was assumed to be loamy medium sand (Kværnø et al., 2007). From these soil textures the median texture $\left(d_{50}\right)$ was calculated (Kværn $\varnothing$ and Stolte, 2012). LISEM requires input of soil hydraulic tables (text files) containing data about (un-) saturated hydraulic conductivity and soil water retention as a function of matric potential, and maps with other parameter values. These maps include general catchment maps, land use and vegetation maps, soil surface maps, erosion maps, profile maps and channel maps. All these maps were prepared using a digital elevation model (DEM), a land use map, a soil map and a stream map. The soil properties water retention, hydraulic conductivity, cohesion and aggregate stability were calculated from textural composition and soil organic matter using PTFs (Kværn $\varnothing$ and Stolte, 2012) 
The EROSION 3D model requires eight soil input parameters (Michael, 2001). The parameters bulk density, initial moisture, erodibility, Manning's n, cover and skin factor were derived from a parameter catalogue that is included in the DProc software given the soil type, land use, season, soil cover, tillage practice and initial soil water level (Werner, 2010). To use the soil types from the LISEM input for the EROSION 3D model, the Norwegian soil types had to be translated into German soil types. To determine the correlating German soil types, the KA-5 soil types (Ad-hoc-AG BODEN, 2005) were entered into the Norwegian soil texture triangle based on their particle size percentages (based on Scheffer and Schachtschabel, 2010). At the time of the rain event in August 2010, the fields of the catchment had already been harvested and were covered with stubble. For this type of land use, variations in tillage and season are not captured by the DProc software. Crop conditions were set to be of an average stock and the mulch content was set to $0 \%$.

\subsubsection{DEM generation}

The 'Topo-DEM' that was used by Kværn $\varnothing$ and Stolte (2012) for the simulations with LISEM was derived from a topographic map, using the software ESRI/ArcMap 9.3; a grid cell size of $10 \times 10 \mathrm{~m}$ was used. This DEM was also used for one calibration approach performed using EROSION 3D to compare the results with LISEM.

The 'LIDAR-DEMs' used in this study were generated from raw LIDAR-point clouds provided as LAS-files by the company BLOM, which obtained the point clouds through airborne-based LIDAR. LIDAR-point clouds were used to create the DEMs in this study because the high resolution of measurements (the distance between points is less than $1 \mathrm{~m}$ ) enables DEMs to be created that represent the natural terrain more accurately and lead to a more realistic overland flow distribution (as discussed in section 2.4.2 and 2.4.3) than DEMs created from topographic maps. Furthermore, it is easy to create DEMs with high resolutions of up to $1 \times 1$ m.

Gaps in the DEM caused by filtering out vegetation etc. were closed by creating a triangulated irregular network (TIN) from the point cloud using the software ESRI/ArcMap 10. In total, 4 DEMs were created, 2 filtered DEMs with resolutions of $5 \times 5 \mathrm{~m}$ and $10 \times 10 \mathrm{~m}$ and 2 unfiltered DEMs with the same resolutions. The LIDAR-DEMs were filtered using a low

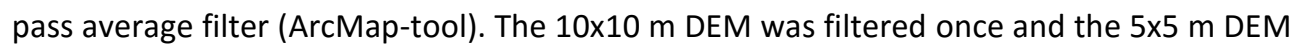
four times. The filtering was undertaken to remove wrong (e.g. short vegetation classified as bare soil) and missing data points that tended to occur most frequently in forest areas (due to vegetation) and led to an unrealistically rough surface (Köthe, 2010). Areas with unrealistically high roughness could lead to slower surface runoff velocities in simulations, 
resulting in less total surface runoff (Köthe, 2010; Werner, 2004). This was investigated during the calibration of EROSION 3D using the $5 \times 5$ m LIDAR-DEM.

The grid sizes $10 \times 10 \mathrm{~m}$ and $5 \times 5 \mathrm{~m}$ were chosen for three reasons:

1. The $10 \times 10 \mathrm{~m}$ grid size was chosen to compare the results of DEMs derived from topographic maps and LIDAR.

2. The $5 \times 5 \mathrm{~m}$ grid size was chosen because the sub-catchment is only (approx.) 0.25 $\mathrm{km}^{2}$, and because the general rule for the EROSION 3D model choose a time resolution of 1 minute and a grid size of $10 \times 10 \mathrm{~m}$ only applies to catchment sizes of $1-10 \mathrm{~km}^{2}$ (Werner, 2004).

3. To investigate whether the more detailed DEMs of $5 \times 5 \mathrm{~m}$ can improve the model results in this study.

\subsubsection{Calibration procedure}

EROSION 3D is highly sensitive to the Manning's $n$ of the surface and the initial moisture content (Werner, 2004). Those two parameters were used for the calibration in this study. Werner (2004) also suggests that bulk density should be a calibrated value. After several test runs, we concluded that changing bulk density did not lead to any improvement in the accuracy of the results. For LISEM several studies (e.g. Hessel et al., 2003; Jetten et al., 1999) have shown that it is most sensitive to the parameters saturated conductivity $\left(K_{\text {sat }}\right)$ and initial matric potential. The initial matric potential was adjusted by Kværn $\varnothing$ and Stolte (2012) and only the saturated conductivity $\left(K_{s a t}\right)$ was used for the calibration in this study. In Fig. 2.4, a calibration scheme for the calibration undertaken for both models is illustrated.

\section{EROSION 3D}

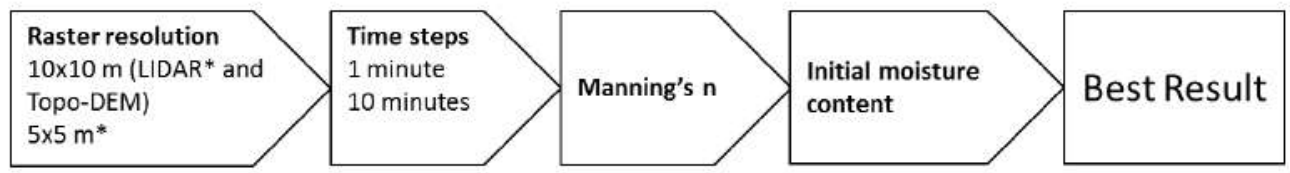

LISEM

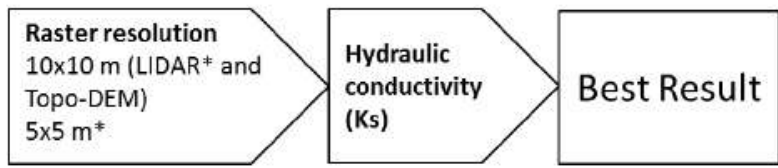

Fig. 2.4: Calibration scheme for the calibration undertaken for both models showing the order in which the calibration steps were undertaken. ( ${ }^{*}$ unfiltered and filtered) 


\subsubsection{Calibration of LISEM}

The LISEM model (version 2.58) was calibrated by Kværnø and Stolte (2012) for the subcatchment with the August 2010 event using measured surface runoff data, (Fig. 2.5). A time resolution of 30 seconds was chosen with a total simulation period of 1000 minutes. $A$ value of 0.01 was used for Manning's $n$ in the channel and the initial pressure head was set to $-5 \mathrm{kPa}$. For the simulation with the DEM derived from the topographic map, the $K_{\text {sat }}$ for the clay soil were multiplied by a factor of 4.51 in order to fit the simulated hydrograph to the measured graph (Kværn $\varnothing$ and Stolte, 2012). An overview of the input parameters used for the LISEM calibrations is shown in Table 2.1.

Table 2.1: Input parameters for the LISEM calibrations (adapted from Kværnø and Stolte, 2011)

\begin{tabular}{|c|c|c|c|c|}
\hline Parameter & Stream & Urban & Forest & Arable \\
\hline Channel cohesion [kPa] & 15000 & - & - & - \\
\hline Channel Manning's $n$ [s m-1/3] & 0.01 & - & - & - \\
\hline Channel width [m] & 1 & - & - & - \\
\hline Slope of channel sides $\left[{ }^{\circ}\right]$ & 45 & - & - & - \\
\hline$K_{\text {sat }}[\mathrm{cm} / \mathrm{d}]$ & - & 81.6 & 81.6 & variable \\
\hline Initial matric potential [cm] & - & -50 & -50 & -50 \\
\hline Random roughness [cm] & - & 0.8 & 3.2 & 0.88 \\
\hline Manning `s $\mathrm{n}\left[\mathrm{s} \mathrm{m}^{-1 / 3}\right]$ & - & 2.4 & 1.2 & 0.6 \\
\hline Fraction of soil covered by vegetation [-] & - & 0.9 & 0.9 & 1 \\
\hline Vegetation height [m] & - & 0.2 & 7 & 0.7 \\
\hline Leaf area index [-] & - & 1.5 & 6 & 2.5 \\
\hline$D 50$ value of the soil $[\mu \mathrm{m}]$ & - & 50 & 50 & 50 \\
\hline Cohesion of bare soil [kPa] & - & 20 & 20 & variable \\
\hline Additional cohesion by roots [kPa] & - & 5 & 10 & 1 \\
\hline Aggregate stability [-] & - & 66 & 66 & variable \\
\hline
\end{tabular}

For the simulations with the filtered $10 \times 10$ m LIDAR-DEM, the same multiplication factor of 4.51 was employed for the $K_{\text {sat }}$ of the clay soils, as used by Kværn $\varnothing$ and Stolte (2012). Only small adjustments had to be made when LISEM was used with the filtered 5x5 m LIDARDEM. To fit the simulated hydrograph to the measured graph the $K_{\text {sat }}$ had to be multiplied by 4.515 . For the test runs with the $5 \times 5 \mathrm{~m}$ unfiltered LIDAR-DEM the $K_{\text {sat }}$ for the clay soils were multiplied by 4.9 . 


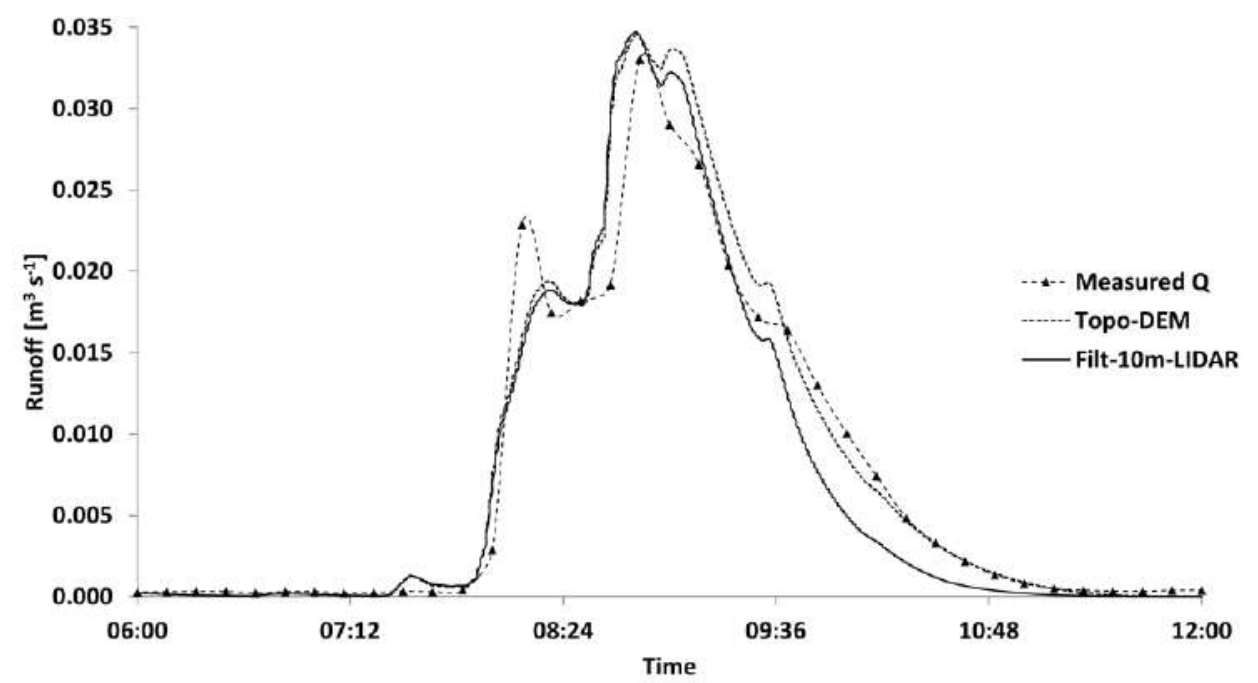

Fig. 2.5: Comparison of the measured discharge with the hydrograph calculated using LISEM, with the TopoDEM and with the $10 \times 10 \mathrm{~m}$ filtered LIDAR-DEM.

\subsubsection{Calibration of EROSION $3 D$}

A one-dimensional sensitivity analysis was conducted to calibrate the EROSION 3D model (version from 2011), as recommended by Werner (2004). This approach assumes that the model's predicted results are linearly dependent on the input parameters. In this study, the focus was on the following interactions:

- The influence of the soil parameters: Manning's $n$ (only for the agricultural land use) and initial moisture (for all land use types) on the surface runoff prediction; and

- The influence of the grid size and calculation time step of the simulation on the surface runoff prediction.

The results of the different analyses were compared with the measured runoff values from the sub-catchment outlet. A selection of important input parameters for the different soil types is shown in Table 2.2 . 
Table 2.2: Input parameters for the EROSION 3D calibration (selection)

\begin{tabular}{|c|c|c|c|c|}
\hline Parameter & Field 1 & Field 2 & Forest & Urban \\
\hline Soil type (German) & Lu & $\mathrm{SI} 3$ & $\mathrm{SI} 3$ & $\mathrm{SI3}$ \\
\hline Bulk density $\left[\mathrm{kg} \mathrm{m}^{-3}\right]$ & 1540 & 1600 & 1000 & 1370 \\
\hline Corg [\%] & 1.5 & 1 & 5 & 2.7 \\
\hline Initial moisture [Vol.-\%] & 36 & 25 & 34 & 34 \\
\hline Erodibility [ $\left.\mathrm{N} \mathrm{m}^{-2}\right]$ & 0.008 & 0.009 & 0.1 & 0.002 \\
\hline Manning's $\mathrm{n}\left[\mathrm{s} \mathrm{m}^{-1 / 3}\right]$ & 0.015 & 0.015 & 0.9 & 0.9 \\
\hline Canopy [\%] & 90 & 90 & 100 & 90 \\
\hline Skin factor [-] & 0.35 & 1 & 20 & 10 \\
\hline
\end{tabular}

\subsection{Results}

\subsubsection{LISEM calibration}

As for the calibration with the Topo-DEM, the hydrograph of the calibration result with the filtered 5x5 m LIDAR-DEM fits rather well with the measured hydrograph. The hydrograph closely follows the shape of the hydrograph calculated with the topographic map (Fig. 2.5). Both curves have the same start time for discharge and the end times also correspond closely. Only small differences can be observed after the second peak. The third peak of the hydrograph calculated with the LIDAR-DEM is slightly smaller than the one calculated with the Topo-DEM. Furthermore, the peak discharge is slightly smaller than the peak of the Topo-DEM-calibration. This resulted in a smaller amount of total discharge (Table 2.3).

Table 2.3: Comparison of the calculated (EROSION 3D) and measured total discharge

\begin{tabular}{ccc}
\hline Simulation runs & total calculated discharge & measured total discharge \\
\hline Topo-DEM & $5.75 \mathrm{~m}^{3}$ & $5.62 \mathrm{~m}^{3}$ \\
Filt-10 m-LIDAR & $5.10 \mathrm{~m}^{3}$ & $5.62 \mathrm{~m}^{3}$ \\
Filt-5 m-LIDAR & $5.04 \mathrm{~m}^{3}$ & $5.62 \mathrm{~m}^{3}$ \\
Unfilt-5 m-LIDAR & $4.94 \mathrm{~m}^{3}$ & $5.62 \mathrm{~m}^{3}$ \\
\hline
\end{tabular}

The hydrograph for the LISEM calibration with the unfiltered $5 \times 5 \mathrm{~m}$ LIDAR-DEM fits the measured graph in shape as well as in size (Fig. 2.6). Compared to the other two calculated graphs the first peak of the measured hydrograph was better simulated, but like the graph for the filtered LIDAR-DEM (5x5 m), discharge declined faster than measured after the discharge peak, which resulted in a smaller total runoff (Table 2.3). 


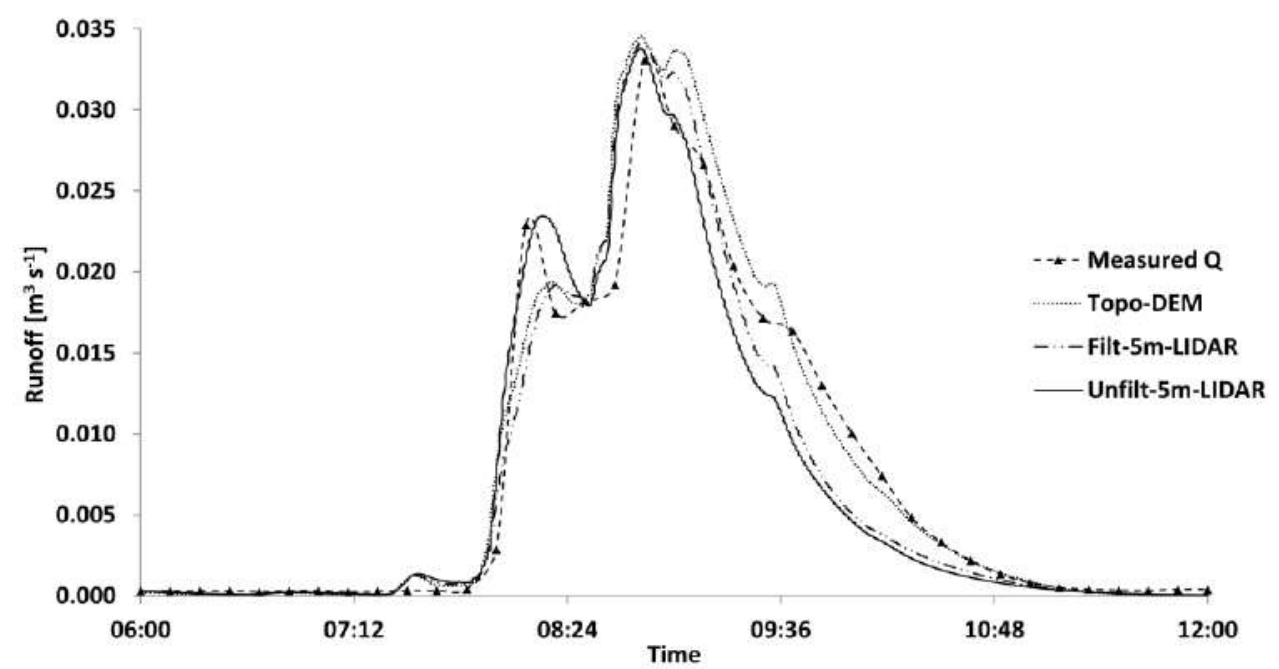

Fig. 2.6: Comparison of the measured discharge with the hydrographs calculated by LISEM, using the TopoDEM and with the $5 \times 5 \mathrm{~m}$ filtered and unfiltered LIDAR-DEM.

\subsubsection{EROSION 3D calibration with the Topo-DEM}

The hydrograph calculated by EROSION 3D using the Topo-DEM did not fit the measured hydrograph (Fig. 2.7); EROSION 3D produced an approximately one magnitude smaller surface discharge. The calibration with $16 \%$ higher initial moisture provided the best result (Fig. 2.7). This increase in the initial moisture content was required to bring the input value closer to the value that was used for the LISEM calibration (Table 2.1). The initial matric hydraulic head for the LISEM input was $-50 \mathrm{~cm}$, which, using the soil water retention curve, leads to an increase of approximately of $16 \%$ of the values given from the DProc program (Table 2.2). Nonetheless, the shape of the modelled hydrograph differs considerably from the measured hydrograph, following the distribution of the rain event more closely. These characteristics could not be substantially modified by introducing changes in the time resolution, initial moisture content or surface roughness (Manning's $n$ ). 


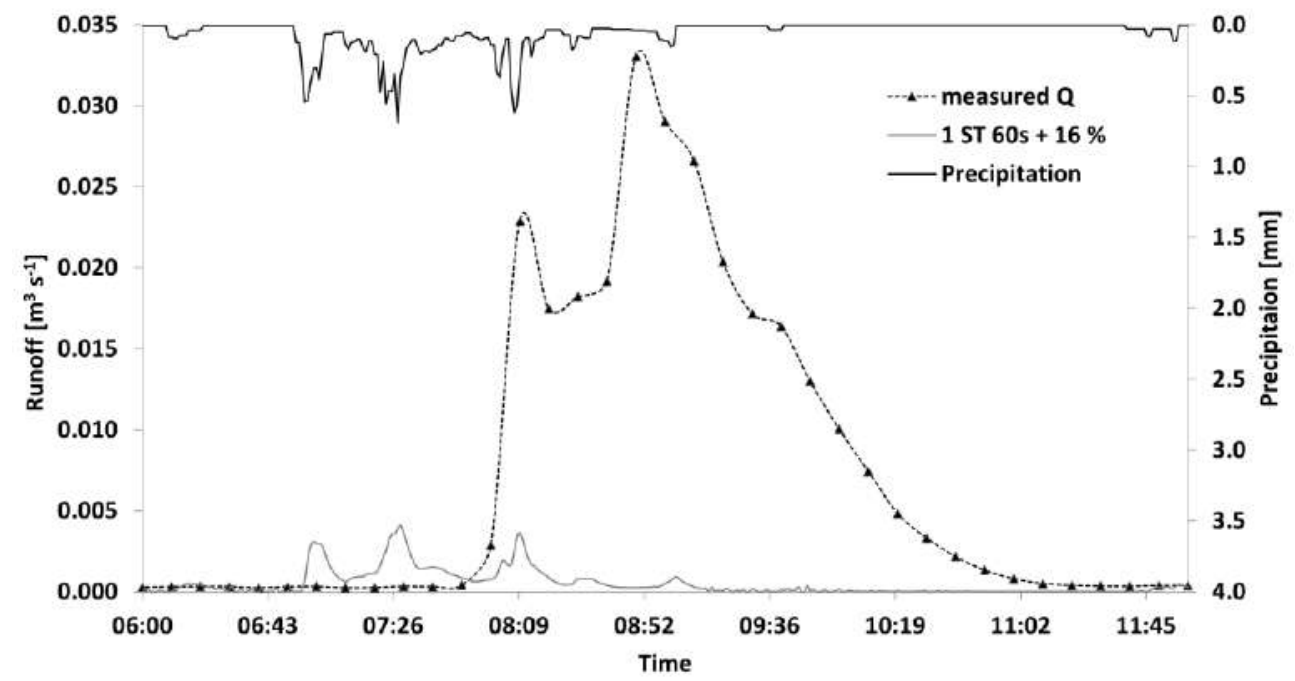

Fig. 2.7: Observed rainfall and measured discharge and surface discharge calculated using EROSION $3 D$ with the Topo-DEM.

\subsubsection{EROSION 3D calibration with the LIDAR-DEMs}

Fig. 2.8 shows the modelled hydrograph using the $10 \times 10 \mathrm{~m}$ LIDAR-DEMs and the two different time resolutions ( 10 minutes and 1 minute).

The predicted hydrograph for the filtered DEM was slightly larger than the predicted hydrograph for the unfiltered DEM, for both time resolutions of 10 minutes and 1 minute, while the predicted hydrograph for the one minute time resolution was not significantly larger than predicted with a 10-minute time resolution. To increase the amount of surface runoff for the 10-minute time resolution, the calibration approach that used $16 \%$ higher initial moisture content, than generated by DProc (Table 2.2) was applied (Fig. 2.8, Case A), resulting in a larger predicted peak discharge (the maximum discharge rate was over 0.03 $\mathrm{m}^{3} \mathrm{~s}^{-1}$ ). The same approach was taken using a 1-minute time resolution, which also produced higher runoff. 


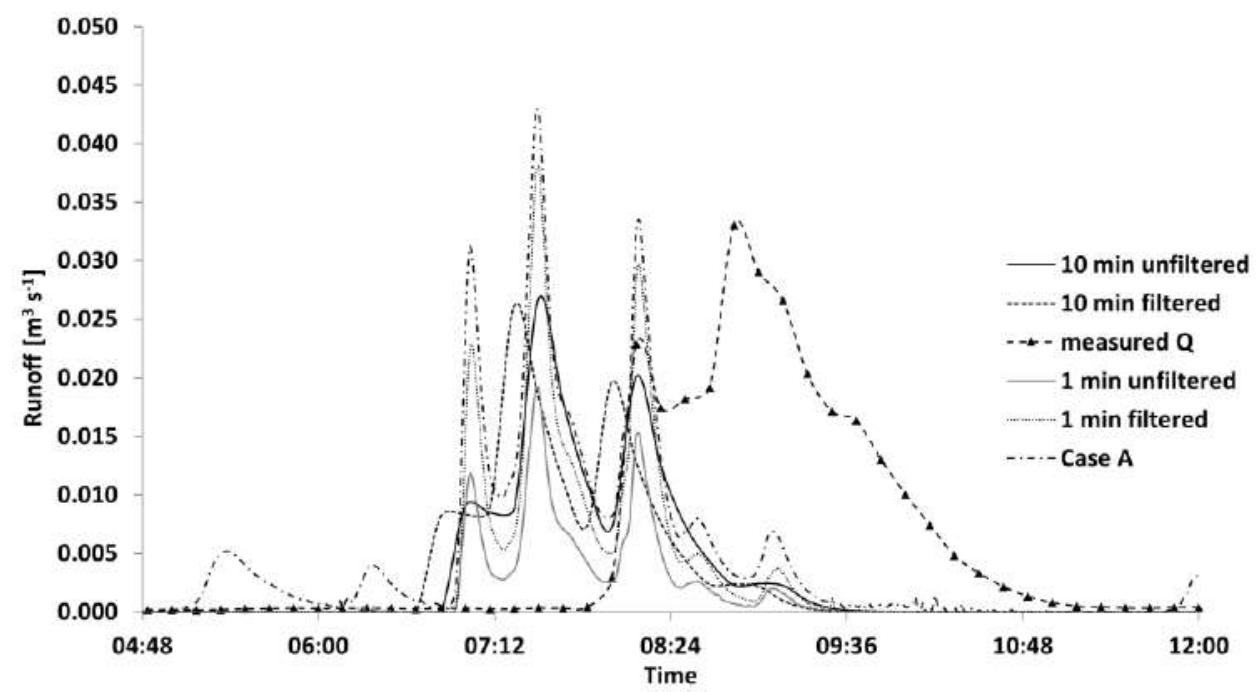

Fig. 2.8: Hydrographs calculated with the filtered and unfiltered $10 \times 10 \mathrm{~m}$ LIDAR-DEMs for a 10-minute and a 1-minute time-resolution compared with the measured hydrograph. The curve 'Case $A$ ' represents the simulation approach with $16 \%$ greater initial moisture content for all land use types (filtered DEM with 10minute time-resolution).

Further calibration, by changing the values for surface roughness and initial moisture, achieved no further improvement in the predicted hydrographs, but showed an increase in the number of peaks with increasing roughness values. Smoother hydrographs (fewer peaks) were calculated using the unfiltered DEM than using the filtered DEM.

The simulations with different time resolutions produced substantially different results with the $5 \times 5 \mathrm{~m}$ unfiltered and filtered LIDAR-DEMs. Fig. 2.9 presents the results of the simulation with 1 minute and 10 minute time resolutions. The predicted surface discharge obtained using the unfiltered DEM was substantially smaller than the predicted surface discharge when filtered DEM was used. As with the predicted surface discharge obtained using the $10 \times 10 \mathrm{~m} \mathrm{DEMs}$, the predicted surface discharge with the 1-minute time resolution was slightly larger than those with the 10-minute resolution. The 1-minute results were not used for further calibration because the hydrographs showed strong fluctuations. 


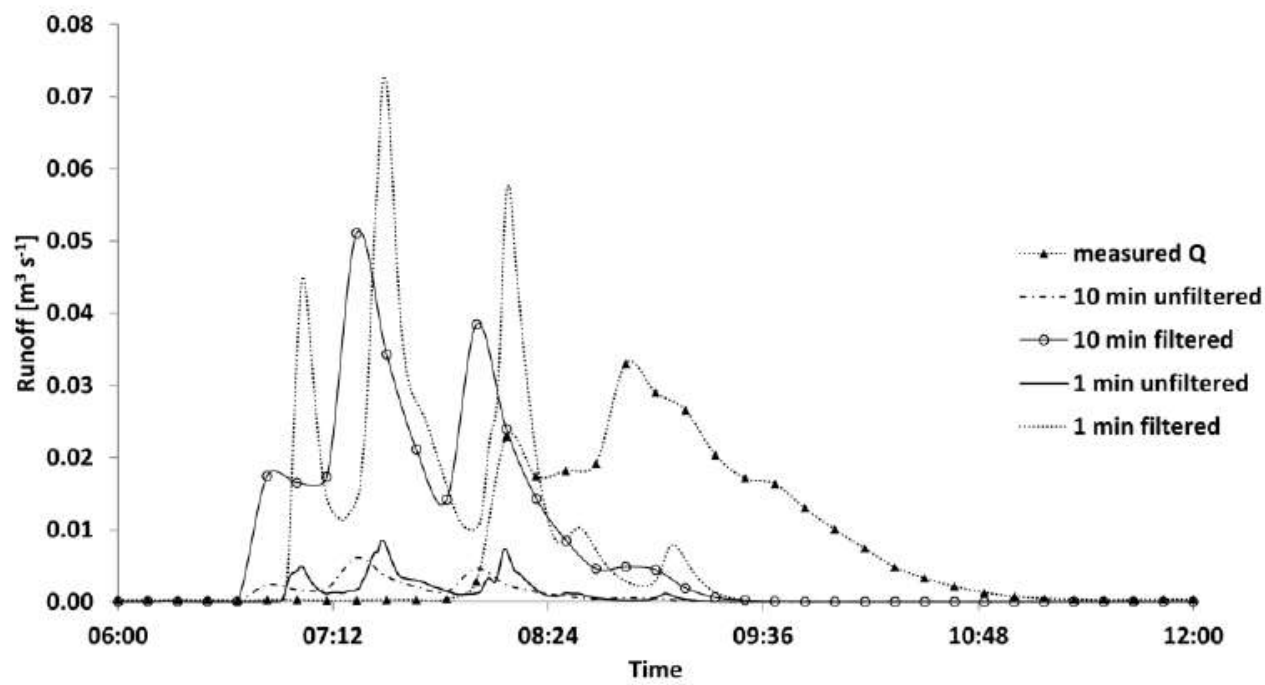

Fig. 2.9: Hydrographs calculated using EROSION $3 D$ with the filtered and unfiltered $5 \times 5 \mathrm{~m}$ LIDAR-DEMs for a 10 minute and a 1-minute time-resolution compared with the measured hydrograph.

After calibrating the value for the surface roughness (Manning's $n$ ) - arriving at two values, 0.2 and $0.25 \mathrm{~s} \mathrm{~m}^{-1 / 3}$, which yielded hydrographs with similar shapes as the measured graph - the initial moisture was slightly adjusted to increase the amount of surface discharge. The best results were achieved by increasing the initial moisture content by 1 and $2 \%$, depending on the value of Manning's n ( $1 \%$ for a Manning's $n$ of $0.25 \mathrm{~s} \mathrm{~m}^{-1 / 3}$; and $2 \%$ for a Manning's $n$ of $0.2 \mathrm{~s} \mathrm{~m}^{-1 / 3}$ ). However, an earlier start of surface discharge was observed for all simulation cases, approximately 50 minutes earlier than was measured in the field.

Both results showed two peaks, which were observed in the measured runoff (Fig. 2.10), but the first peak in each case was approximately $0.005 \mathrm{~m}^{3} \mathrm{~s}^{-1}$ larger than that of the measured surface discharge, and their maxima occurred approximately 10 minutes later than in the measured case (after offsetting the simulated hydrographs by 50 minutes to fit the measured graph, for better comparison (Fig. 2.10)). The two calibration results predicted a slightly larger total surface discharge volume than the measured data (Table 2.4), whereas the total surface discharge for the simulation with $1 \%$ increased initial moisture content correlated more closely with the measured surface discharge.

Table 2.4: Comparison of the calculated (EROSION 3D) and measured total discharge between 00:00 and $13: 50$

\begin{tabular}{ccc}
\hline Simulation runs & $5 \times 5 \mathrm{~m}$ filtered DEM & Measured surface discharge \\
\hline Manning's n $0.25+2 \%$ & $6.63 \mathrm{~m}^{3}$ & $5.62 \mathrm{~m}^{3}$ \\
Manning's n $0.2+1 \%$ & $5.90 \mathrm{~m}^{3}$ & $5.62 \mathrm{~m}^{3}$ \\
\hline
\end{tabular}


In addition, one simulation was carried out using the same values for Manning's $n$ and initial water content as were used for the LISEM calibration (Manning's $\mathrm{n} 0.6 \mathrm{~s} \mathrm{~m}^{-1 / 3}$ and initial moisture increased by $+16 \%$ ). The result was still in the same order of magnitude, but the two peaks that were characteristic of the measured surface discharge were no longer distinguishable and the simulated surface discharge ended much later (20:30 h) than what was measured.

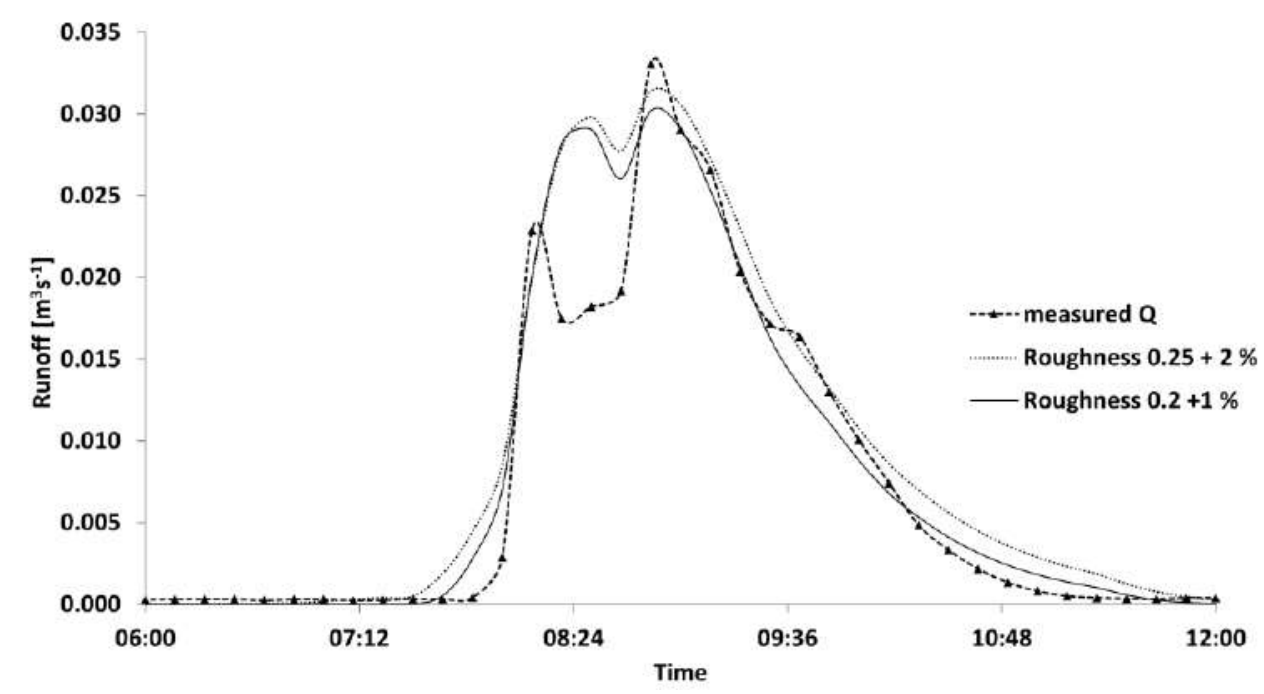

Fig. 2.10: Hydrographs for the two best calibration results with EROSION $3 D$ using the filtered $5 \times 5 \mathrm{~m}$ LIDARDEM (Roughness = Manning's $n$ ) 


\subsection{Discussion}

\subsubsection{LISEM}

Kværn $\varnothing$ and Stolte (2012) offered an explanation for why $K_{\text {sat }}$ had to be increased. $K_{\text {sat }}$ is based on data obtained using the Mualem-van Genuchten equations, which do not take macropore flow into account. However, as observed in the field, clay soils, in particular the Albeluvisols, can be highly macroporous and a greater effective value for $K_{\text {sat }}$ can thus be expected than the matrix $K_{\text {sat }}$ value. After adjusting the $K_{\text {sat }}$, the calculated hydrographs for the simulation with the DEM derived from the topographic map and the DEMs derived from the LIDAR data fitted the measured graph well. In the case of the LIDAR-DEMs, differences between the filtered and unfiltered DEMs had no major influence on the simulation results. The multiplication factor for the $K_{\text {sat }}$ of the clay soils did not differ much, by only 0.4 , between the test runs with the filtered and unfiltered 5x5 m LIDAR-DEM; and not at all between the calibrations with the topographic DEM and the 10x10 m LIDAR-DEM. In a relatively flat agricultural landscape with small variations in elevation, the change in resolution between 10 and $5 \mathrm{~m}$ has no great influence on the runoff character of the catchment. However, using a rougher surface was expected to have some influence, at least in the test runs with the unfiltered $5 \times 5 \mathrm{~m}$ LIDAR-DEM, due to larger vegetation-related errors in the LIDAR, but the data showed otherwise (Fig. 2.6). The simulation time (with an Intel ${ }^{\circledR}$ Core $^{\mathrm{TM}} 2$ Duo CPU P8700 @ $2.53 \mathrm{GHz}$ ) increased, however, from about 10 min (filtered $\mathrm{DEM}$ ) to $30 \mathrm{~min}$ (unfiltered DEM).

\subsubsection{EROSION 3D}

The simulations with the LIDAR-DEMs produced substantially different results depending on the grid size, slope (filtered vs. unfiltered) and time resolution. Some of the differences in these results were caused by the properties of the DEMs, and some by the surface runoff approach used in EROSION 3D.

The strong fluctuations that were observed in the hydrographs obtained using the $10 \times 10 \mathrm{~m}$ DEMs was the result of the inappropriateness of this grid size for such a small catchment area. As shown by Werner (2004), a grid size of $10 \mathrm{~m}$ is recommended for a $1-10 \mathrm{~km}^{2}$ catchment. The calibration area in this study was $\sim 0.25 \mathrm{~km}^{2}$ in size. As a result the runoff velocity increased because of the increasing runoff amount per grid cell (Equation 2.5) and the excessive smoothing of the surface (decrease of slope angle). This issue can be explained by looking at Equations 2.1, 2.6 and 2.4 in the runoff module for EROSION 3D, where the 
hydraulic radius $\left(\delta_{R}\right)$ depends on the slope angle (Equation 2.6). As a result, the runoff velocity $\left(v_{q}\right)$ (Equation 2.1) and capacity of the water film $(M)$ (Equation 2.4) is strongly associated with the slope angle. To investigate whether the $10 \mathrm{~m}$ DEMs contain a high number of grid cells with small slope angles the ArcMAP-tool 'slope' was used to measure the slope angles (Fig. 2.11).

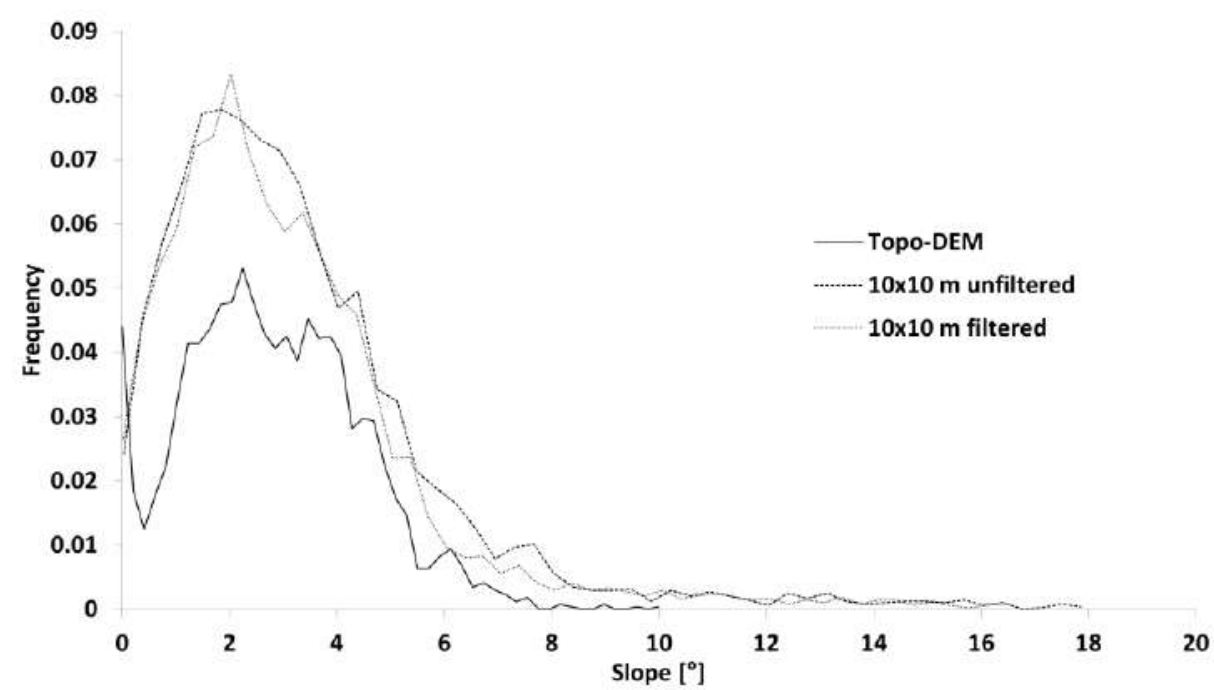

Fig. 2.11: The frequency of different slope angles per grid cell in the filtered and unfiltered $10 \times 10 \mathrm{~m}$ LIDARDEMs and the Topo-DEM.

For both DEMs, most slope angles were between $1^{\circ}$ and $4^{\circ}$ for each grid cell, which indicates a very flat surface. Such flat surfaces result in reduced runoff velocities and discharge per cell which could lead to numerical instability in the runoff prediction (Werner, 2004).

The calibration approach with the $5 \times 5 \mathrm{~m}$ DEMs showed substantially better results than with the 10x10 m DEMs. Problems did occur, however, especially when the 1-minute time resolution was used. The predicted discharges for both time resolutions ( 1 and 10 minutes) for the unfiltered $5 \times 5 \mathrm{~m}$ DEM were much smaller than the predicted discharge using the filtered DEM, which was a result of the rougher surface in the unfiltered DEM. In the unfiltered DEM, all the classification errors from the LIDAR processing, such as vegetation, tillage rills etc. acted as barriers (Köthe, 2010), which increased, for example, the length of the flow path. Filtering the DEM five times proved to be adequate to remove classification errors in the LIDAR data and create a DEM that was smooth enough to show a realistic runoff pattern. When examining the hydrographs (Fig. 2.10) and the predicted runoff volumes for the filtered DEMs (Table 2.4), a grid size of $5 \times 5 \mathrm{~m}$ was necessary to achieve a satisfactory simulation approach for the sub-catchment. The observed differences between 
the start and end times of the simulated surface discharge and the measured runoff could have had several causes. Werner (2004) observed that, by increasing the raster resolution, the predicted runoff starts and ends earlier. Furthermore, complete modelling of detailed water movement with velocity changes and kinematic wave is not included in the approach taken by EROSION 3D to simulate water runoff (Werner, 2004). Therefore, not all factors that influence the surface water flow, and that may delay the start of measurable surface discharge at the catchment outlet were taken into account. Nonetheless, the predicted hydrographs in Fig. 2.10 give a good approximation of the measured surface discharge the form of the graphs shows similar characteristics to those of the measured surface discharge (both peaks exist).

\subsubsection{Comparison of the calibration results of LISEM and EROSION 3D}

The simulation results obtained using EROSION 3D with the DEM that was used for the LISEM modelling correlated poorly with the measured runoff (Fig. 2.7). To investigate whether the DEM itself caused the poor simulation results, the slope angles of each grid cell were examined. As is evident from Fig. 2.11, the investigation showed that the Topo-DEM had a flatter surface than the 10x10 m LIDAR DEMs.

According to Werner (2004), a flatter surface leads to numerical instability in the predictions made by the EROSION 3D model. The Topo-DEM contained a number of $0^{\circ}$ slope values, whereas the LIDAR-DEMs had a minimum slope angle of $0.134^{\circ}$ (Fig. 2.11). The small slope angle values in the Topo-DEM grid cells produced very slow runoff velocities and low water storage capacities for the water film, which can be explained by Equations 2.4, 8 and 9, where a value of zero for the slope angle always produces a zero results. A subroutine is included in EROSION 3D that prevents zero values for the flow velocity, but the predicted amount of surface runoff will nonetheless be substantially smaller than the measured surface discharge in these cases.

There are several possible reasons for the LISEM calibration results fitting the measured runoff characteristics better (Fig. 2.5), despite the mentioned errors in the DEM;

- Instead of calculating only the surface runoff, the total discharge is calculated as a combination of surface runoff that drains into the channel and the channel runoff itself;

- A different approach to calculating the overland flow is applied in LISEM than in EROSION 3D; and

- A different infiltration module is used in LISEM than in EROSION 3D. 
The runoff produced from channel cells was used for the LISEM calibration. The water from the overland flow usually drains into the channel cells and then flows to the outlet of the catchment (Jetten, 2002). Such channel formation by the eroding forces of surface water runoff was observed in the selected catchment. To allow better comparison of the results, the channel runoff was simulated using EROSION 3D as well (a possible, but not recommended option in the model (Werner, 2004)). However, the peak discharge $\left(0.14 \mathrm{~m}^{3}\right.$ $\left.\mathrm{s}^{-1}\right)$ was significantly larger than the measured peak discharge $\left(0.033 \mathrm{~m}^{3} \mathrm{~s}^{-1}\right)$. This discrepancy between the results produced by LISEM and EROSION 3D was because of the second of the reasons presented above: the different approaches taken in the calculation of overland flow. Firstly, the approach taken by EROSION 3D was not recommended for use in simulating channel runoff since it does not properly represent the geometry and runoff resistance of the channel (Werner, 2004). Secondly, the simplified approach in EROSION 3D is much more sensitive to changes in time and spatial resolution (Table 2.5). The more sophisticated approach in LISEM makes it less dependent on time resolution, which the user can freely change independently of the time resolution of the input precipitation file (Table 2.5).

Table 2.5: Overview of the simulation runs undertaken and the final values of the calibration parameters (grey: calibration run with the best simulated surface discharge using EROSION 3D; LISEM yielded satisfying results for all four calibrations)

\begin{tabular}{|c|c|c|c|c|c|c|c|c|c|c|c|c|c|}
\hline \multirow[t]{3}{*}{ Parameters } & \multicolumn{2}{|c|}{ Topo-DEM } & \multicolumn{5}{|c|}{ LIDAR-DEMs 10×10 m } & \multicolumn{6}{|c|}{ LIDAR-DEMs $5 \times 5 \mathrm{~m}$} \\
\hline & \multirow[b]{2}{*}{$\mathrm{L}$} & \multirow[b]{2}{*}{$E$} & \multicolumn{2}{|c|}{ Unfiltered } & \multicolumn{3}{|c|}{ Filtered } & \multicolumn{3}{|c|}{ Unfiltered } & \multicolumn{3}{|c|}{ Filtered } \\
\hline & & & $E$ & $E$ & $\mathrm{E}$ & $E$ & $\mathrm{~L}$ & $E$ & $E$ & $\mathrm{~L}$ & $\mathrm{E}$ & $E$ & $\mathrm{~L}$ \\
\hline $\begin{array}{c}\text { Time } \\
\text { steps [sec] }\end{array}$ & 30 & 60 & 600 & 60 & 600 & 60 & 30 & 600 & 60 & 30 & 600 & 60 & 30 \\
\hline $\mathrm{K}_{\mathrm{sat}}\left[\mathrm{cm} \mathrm{d} \mathrm{d}^{-1}\right]^{\left(^{*}\right.}$ & 4.51 & - & - & - & - & - & 4.51 & - & - & 4.9 & - & - & 4.515 \\
\hline $\begin{array}{c}\text { Manning's } n \\
{\left[\mathrm{~s} \mathrm{~m}^{-1 / 3}\right]}\end{array}$ & - & - & - & $\begin{array}{c}+0.05 \\
+0.1 \\
\end{array}$ & - & $\begin{array}{c}+0.05 \\
+0.1 \\
\end{array}$ & - & - & - & - & - & $\begin{array}{l}+0.2 \\
+0.25 \\
\end{array}$ & - \\
\hline $\begin{array}{c}\text { Initial moisture } \\
\text { content [\%] }\end{array}$ & - & - & - & $+16 \%$ & - & $+16 \%$ & - & - & - & - & - & $\begin{array}{l}+1 \% \\
+2 \% \\
\end{array}$ & - \\
\hline
\end{tabular}

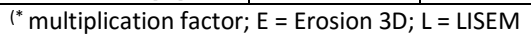

Furthermore the spatial resolution of the DEM of a relatively uniform catchment has a smaller influence on the simulation results of LISEM. The different approaches taken to calculate infiltration were another difference that could lead to significantly different runoff results. For example, in the LISEM calibration, $K_{\text {sat }}$ was changed for the clay soil by multiplying it by 4.51 (Kværnø and Stolte, 2012), whereas 'initial moisture' and Manning's $\mathrm{n}$ are the calibration parameters used by EROSION 3D. The total discharge for the three different simulations is presented in Table 2.6, where there are no substantial differences between the results of LISEM and EROSION 3D. The simulated hydrographs of LISEM and EROSION 3D fitted the measured graph well, but, while LISEM underestimated the first peak, EROSION 3D overestimated the first peak. 
Table 2.6: Comparison of measured and calculated total amount of surface discharges

\begin{tabular}{ccc}
\hline EROSION 3D & LISEM & measured Runoff \\
\hline $5.90-6.63 \mathrm{~m}^{3}$ & $4.94-5.75 \mathrm{~m}^{3}$ & $5.62 \mathrm{~m}^{3}$ \\
\hline
\end{tabular}

\subsubsection{Spatial comparison}

The $5 \times 5 \mathrm{~m}$ filtered LIDAR DEM was chosen for the spatial comparison of the model results of LISEM and EROSION 3D, because EROSION 3D only showed satisfactory results with this DEM. For LISEM, the simulation with a multiplication factor of 4.515 for the $K_{\text {sat }}$ (Fig. 2.6) was chosen, while the simulation with a Manning's $n$ of 0.2 , and an initial moisture increase by $1 \%$ (Fig. 2.10) was chosen for EROSION 3D.

The maps produced by the two models were compared with erosion and depostition patterns that were observed in the field after the rain event. The amount of eroded or deposited soil was not measured in the field. The following comparison is therefore only qualitative.

Where EROSION 3D directly delivers a map with both the erosion and deposition values, LISEM (vers. 2.58) provides two maps, one with the erosion values and one with the deposition values. To arrive at the sediment budget the cell values of the two maps were added together. The results for the spatial distribution of soil erosion and deposition are quite different for the two models (Fig. 2.12). Where LISEM only predicted erosion/deposition in the channel that was predefined (marked with the number 1 in Fig. 2.12), the erosion/deposition map produced by EROSION 3D shows a much more diverse distribution of erosion and deposition patterns. EROSION 3D predicted the observed erosion/deposition structures better than LISEM. The second channel that was observed in the catchment, can be seen in the map provided by EROSION 3D (marked with the number 2 in Fig. 2.12).

However, the comparison showed that the two models produced rather different erosion and deposition maps, even though they calculated the same amount and time distribution of discharge. One reason for the differences is most likely the inclusion of channel flow in the LISEM model, where most of the soil loss is produced in the simulation. Soil loss from the EROSION 3D model has to come from the surface, since channel erosion is not included in these runs. A test run without the channel was performed for the LISEM model, which produced almost no runoff and no erosion. Furthermore, the models calculate deposition and erosion quite differently as presented in section 2.2.2., which probably results in different erosion/deposition patterns as well. However, in both models the flow velocity 
has an important role in relation to the amount of flow detachment (e.g. see Equations: $2.10,2.11,2.14,2.16,2.17,2.20$ ), which is strongly influenced by the Manning's $n$ of the soil surface. Looking at Tables 2.1 and 2.2 it can be seen that different Manning's $n$ were used for the agricultural areas. A much higher Manning's $n\left(0.6 \mathrm{~s} \mathrm{~m}^{-1 / 3}\right)$ was chosen for LISEM than for EROSION 3D $\left(0.015 \mathrm{~s} \mathrm{~m}^{-1 / 3}\right)$. Only for the channel was a comparable Manning's $n$ of $0.01 \mathrm{~s} \mathrm{~m}^{-1 / 3}$ used, which can explain why LISEM only produced erosion in the channel in this study. To investigate this, a test run was performed with LISEM, where the channel was switched off and Manning's $\mathrm{n}$ for the fields was set to the value of the best calibration result from EROSION 3D $\left(0.025 \mathrm{~s} \mathrm{~m}^{-1 / 3}\right)$. It produced similar erosion/deposition patterns as EROSION 3D, but the simulated hydrograph was no longer comparable (14.33 $\mathrm{m}^{3}$ modelled total runoff at the outlet vs. $5.62 \mathrm{~m}^{3}$ measured total runoff).

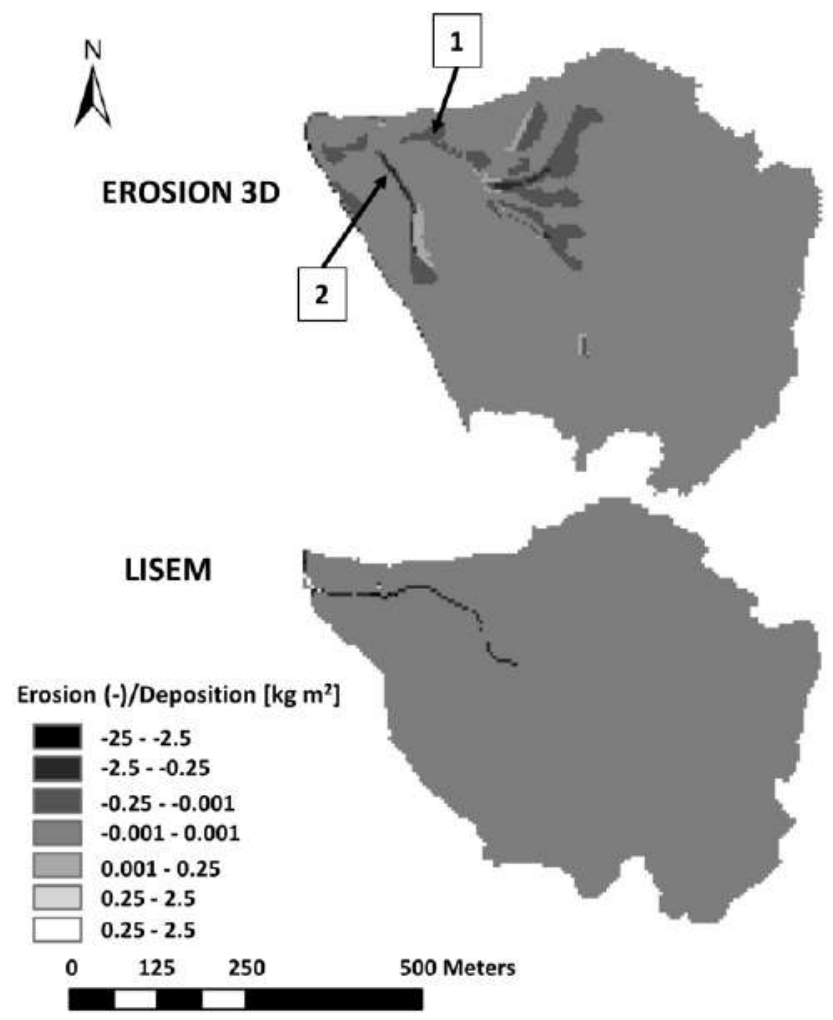

Fig. 2.12: Comparison of the soil-loss-maps provided by EROSION 3D and LISEM. Erosion patters observed in the field are marked with the numbers 1 and 2. 


\subsection{Conclusion}

It was possible with both models to simulate a satisfactory hydrograph and total amount of surface discharge in the sub-catchment for the 2010 rain event. It can therefore be concluded that both LISEM and EROSION 3D can be used as tools to predict surface discharge. However, this conclusion has some limitations: (1) The land use type for agricultural land was 'stubble' in this study. This land use type, which was used as an input for the DProc software, is independent of the season of the year and tillage. Further tests should therefore be carried out to examine whether the input parameters for different land use types and different seasons and tillage practices provided by the DProc software can be used in Norway. (2) This conclusion only applies to areas with characteristics similar to the Skuterud catchment. For areas in Norway with other characteristics as regards to terrain, soil properties and climate, further validation must be undertaken to test the two models under these conditions. (3) The influences of snow cover and soil freezing (important factors in the Norwegian environment) on the prediction capability of the models have not been taken into account in this study, and must therefore be further investigated (see Chapter 6). Furthermore, the comparison of the calibration procedure of the two models showed that EROSION 3D has problems properly predicting the surface discharge using the implemented approach. To calibrate EROSION 3D with measured surface discharge is timeconsuming and entails several difficulties for the user as regards finding the correct calibration values. Several parameters had to be adjusted to arrive at a satisfying result in this study (Table 2.5). During the calibration of the EROSION 3D model in the subcatchment, it was observed that the process of finding the correct grid size and time resolution for such small catchments is not easy and requires experience. A raster resolution of $5 \times 5 \mathrm{~m}$ or higher (e.g. $3 \times 3 \mathrm{~m}$ ) is required to achieve realistic hydrographs for small catchments $\left(<1 \mathrm{~km}^{2}\right)$.

LISEM on the other hand, easily adapted the different raster resolutions and the results were relatively independent of the roughness of the different DEMs (filtered or not) in this study. Only the simulation time increased, although not as much as for EROSION 3D. Furthermore, the results of LISEM were independent of the time resolution of precipitation data. LISEM yielded a much better prediction of runoff behaviour in channels, probably due to the infiltration approach taken in the Richard equation and a better estimation of the kinematic wave in channels and rills. To verify this conclusion, (1) a simulation should be undertaken using the Green and Ampt approach in LISEM, and (2) simulations should be tried with EROSION 3D, using the multiple-layer-infiltration-extension, as that could produce better results, as observed in various studies (e.g. Seidel, 2008; Schindewolf and Schmidt, 2009). This approach could not be used in this study because it requires a considerable amount of measured input data that were not available at the time. 
On the other hand, EROSION 3D requires a relatively small amount of measured input data (if the Green and Ampt infiltration module is used), compared to LISEM, which reduces the operational hours needed to collect the data. EROSION 3D is therefore a good planning tool, while LISEM is probably the better choice for investigating hydrological processes in a catchment.

The differences in the erosion/deposition maps produced showed that the model results do not just have to be compared with outlet measurements, but also with detailed field investigations of the spatial distribution of erosion and deposition patterns. Only with exact knowledge about where and what amount soil loss and sedimentation took place in the catchment, can a more valid comparison and validation of the performance of models be carried out. In this study, the spatial comparison of the results showed that, even if the simulated hydrographs show good results, this does not necessarily means that the modelled erosion and deposition patterns are correct. Especially if estimated input parameters are used (e.g. Manning's n) the user must be aware that the choice of parameters for the calibration can have a strong effect on the performance of the model and the results produced. As Stroosnijder (2005) indicated, it is recommended to measure as many parameters as possible in the field in order to limit the uncertainties during the simulation and calibration procedure. 


\section{Catchment hydrology and soil erosion during winter and spring: a case study in Norway}

In the Nordic countries, soil erosion rates in winter and early spring can exceed those at other times of the year. In particular, snowmelt, combined with rain and soil frost, leads to severe soil erosion, even, e.g., in low risk areas in Norway. In southern Norway, previous attempts to predict soil erosion during winter and spring have not been very accurate owing to a lack of catchment-based data, resulting in a poor understanding of hydrological processes during winter. Therefore, a field study was carried out over three consecutive winters (2013, 2014 and 2015) to gather relevant data. In parallel, the development of the snow cover, soil temperature and ice content during these three winters was simulated with the Simultaneous Heat and Water (SHAW) model for two different soils (sand, clay). The field observations carried out in winter revealed high complexity and diversity in the hydrological processes occurring in the catchment. Major soil erosion was caused by a small rain event on frozen ground before snow cover was established, while snowmelt played no significant role in terms of soil erosion in the study period. Four factors that determine the extent of runoff and erosion were of particular importance: (1) soil water content at freezing; (2) whether soil is frozen or unfrozen at a particular moment; (3) the state of the snow pack; and (4) tillage practices prior to winter. SHAW performed well in this application and proved that it is a valuable tool for investigating and simulating snow cover development, soil temperature and extent of freezing in soil profiles.

Based on:

Starkloff, T., Hessel, R., Stolte, J., Ritsema, C.J., Catchment hydrology during winter and spring and the link to soil erosion: A case study in Norway. Hydrology, 2017, 15, doi: 10.3390/hydrology4010015 


\subsection{Introduction}

In the Nordic countries, soil erosion rates in winter and early spring can exceed those occurring during other seasons of the year. A factor of particular importance is the incidence of frozen soil, which modifies surface runoff generation and also the erosivity of the soil material (Ollesch et al., 2005). In addition, water infiltration into frozen soils is more complicated than water infiltration into unfrozen soils, because it involves coupling water and heat transport (temperature of the infiltrating water) with phase change (from liquid to ice and vice versa) (Iwata et al., 2011).

A large number of laboratory studies has investigated different processes occurring in soils during freezing and thawing. Using a rain simulator, Edwards and Burney (1987) showed that soil freezing and thawing can significantly increase soil erosivity. They concluded that only plant cover is effective in reducing soil losses due to rain and overland flow on frozen ground. Other more recent studies, e.g., Ban et al. (2016), have shown that water flows much faster over a frozen slope than over a thawed slope. Watanabe et al. (2013) found that the speed of snowmelt and/or rain infiltration into frozen soils is largely dependent on initial water content, frost depth and temperature of the soil. In addition, Yami et al. (2012) showed that increasing soil moisture and finer soil structure advance the speed and depth of the freezing front.

Al-Houri et al. (2009) added to knowledge about water transport in frozen soils by showing that the amount of time available for soil water redistribution before freezing affects the infiltration capacity of frozen soil, with more time resulting in better infiltration capacity under frozen conditions. In addition to laboratory studies, a great number of studies has investigated infiltration processes under field conditions at the plot or point scale. In a study examining nine different plots in North Dakota, Willis et al. (1961) showed that soils that were dry in autumn freeze faster and deeper than wet soils and that a dry profile thaws upward, while a wet soil thaws both upward and downward. They also recorded less runoff from dry soils.

Stähli et al. (2001) and Nyberg et al. (2001) concluded that frost has little effect on runoff from forest soils, in contrast to reported effects on agricultural soils (Lindström and Löfvenius, 2000), and that forests probably do not increase runoff episodes in winter and spring. Furthermore, they predicted that critical initial conditions, such as high water content and early frost penetration combined with heavy rain on still frozen soil, could have a decisive effect on the amount of runoff. Iwata et al. (2010 and 2011) showed that a frozen soil layer can significantly impede snowmelt infiltration and thus increase runoff of spring snowmelt water. Zhao et al. (2013a) demonstrated that soil freezing can reduce hydraulic 
conductivity by blocking pores and retaining water in the profile, thereby reducing the infiltration capacity during snowmelt.

In a study at five locations in Finland, Sutinen et al. (2008) found that a snow pack with a thickness exceeding $30 \mathrm{~cm}$ can reduce or even prevent soil freezing. In addition, Zhao et al. (2013b) showed that snow pack less than $20 \mathrm{~cm}$ deep can cause deeper soil freezing than no snow cover, due to an increase in ground albedo caused by the snow. The effects of different tillage practices on soil freezing was investigated by Parkin et al. (2013) in a soil profile over 10 years. They found that conventional autumn tillage resulted in lower soil temperatures than no-till.

In a recent five-year field study in Canada, He et al. (2015) presented results that confirmed many of the above-mentioned effects and demonstrated the complexity of the interaction between the topsoil and snow cover, especially during snowmelt. They also pointed out that only a limited amount of field studies to date has taken all of these processes into account in a series of measurements that covers several winter periods. The complexity of the different processes occurring in soil during winter is amplified when all of these interacting processes have to be monitored and interpreted at the catchment scale, where different soil types, terrain and water flow at the surface and in the soils interact (Kormos et al., 2014; Williams et al., 2009). In addition, detailed observations have to be made over several years to identify processes that can only occur during certain conditions or are masked by confounding factors in a catchment (Shanley, 1999).

In Norway, the occurrence of soil erosion from agricultural land is greatest during spring (Lundekvam and Skøien, 1998; Deelstra et al., 2009), and the severity of the erosion is often amplified by preceding winter conditions. Snowmelt, combined with rain and soil frost, can lead to severe gully and rill erosion, even in low risk areas in Norway ( $\varnothing$ ygarden, 2003). In southern Norway, previous attempts to predict soil erosion during winter and spring have not been successful (Grønsten and Lundekvam, 2006), probably owing to a lack of catchment-based studies covering several winters, resulting in a lack of knowledge about the interacting processes described above. In the present study, field measurements covering three winter periods (2013, 2014 and 2015) were carried out, with the aim of improving overall understanding of how soil hydraulic properties behave during winter and affect surface runoff caused by snowmelt and rain and how these processes are linked to soil erosion. Furthermore, the data collected were used to calibrate and validate a hydrodynamic model (Simultaneous Heat and Water (SHAW) model; Flerchinger et al., 2009), in order to acquire better insights into the complex interactions between freezing, thawing, snow pack and runoff and erosion dynamics. 
The focus of this study lies in Norway; however, severe soil erosion on agricultural areas during winter and spring is a problem in several other countries around the world (e.g., USA (Hansen et al., 2000), Belgium (Govers, 1991), the U.K. (Boardman et al., 2009), Germany (Weigert and Schmidt, 2005), and Russia (Yakutina et al., 2015)). In these areas, like in Norway, soil erosion during winter and spring depletes the irreplaceable nutrient-rich top layer of agricultural soils and results in a major part of the annual input of phosphorous and nitrogen from agricultural catchments to fresh water bodies (Su et al., 2011). It is therefore hoped that this study will also contribute to the understanding of winter processes outside of Norway.

\subsection{Materials and methods}

\subsubsection{Study area}

The study area is located in the Skuterud catchment $\left(4.5 \mathrm{~km}^{2}\right)$ in Ås and Ski municipalities, approximately $30 \mathrm{~km}$ south of Oslo, Norway. For the field investigations and sampling, a sub-catchment, Gryteland $\left(0.29 \mathrm{~km}^{2}\right)$, in the southeastern part of the main catchment (Fig. 1.2), was chosen. This area has been used for different hydrological studies in the past, and it can easily be reached under all weather conditions. A monitoring station was installed at the outlet of the sub-catchment in 2008. This station measures precipitation, air temperature, surface runoff and drainage discharge. In addition, five stations (one at the outlet) were installed along a transect in the catchment (Kramer and Stolte, 2009) (Fig. 1.2), in order to measure soil moisture and soil temperature at three depths $(5,10$ and $20 \mathrm{~cm})$.

The sub-catchment is characterized by an undulating landscape (elevation 106-141 m, slope $2 \%-10 \%$ ) covered by approximately $60 \%$ arable land and $40 \%$ coniferous forest. Soil types for the arable land are a levelled clay loam (Stagnosol) and a silty clay loam (Albeluvisol) (Group 1), as well as a sandy silt on clay (Umbrisol) and a sand to loamy medium sand (Histic Gleysol) (Group 2). The two soil groups are often not clearly distinguishable in the field (Solbakken, 2015). Within the groups, the soils have similar physical properties. Hereafter, Groups 1 and 2 are referred to as clay and sand, respectively (Fig. 1.2).

Mean annual temperature in the study area is $5.3^{\circ} \mathrm{C}$, with an average minimum of $-4.8^{\circ} \mathrm{C}$ in January/February and an average maximum of $16.1^{\circ} \mathrm{C}$ in July. Mean annual precipitation is $785 \mathrm{~mm}$, with a minimum monthly amount of $35 \mathrm{~mm}$ in February and a maximum of 100 $\mathrm{mm}$ in October (Thue-Hansen and Grimenes, 2015). Winter is usually relatively unstable, 
with alternating periods of freezing and thawing and several snowmelt events (Kværnø and $\varnothing$ ygarden, 2006).

\subsubsection{Weather data}

A weather station was installed in the catchment outlet at the end of 2013, providing hourly data on net solar radiation, air temperature, wind speed and wind direction for the winters (December-March) of 2014 and 2015. For winter 2013 (January-April), data from a station $6 \mathrm{~km}$ away from the catchment were used (Thue-Hansen and Grimenes, 2015).

\subsubsection{Soil temperature and soil moisture measurements}

To obtain more detailed measurements of soil water content and temperature during winter, the measuring Stations 1 (clay measurements) and 3 (sand measurements) were upgraded to measure soil water content and soil temperature at four depths, 5, 20, 30 and $40 \mathrm{~cm}$, using Decagon 5 TM temperature and Frequency Domain Reflectometry (FDR) sensors. Measurements from these two stations and the outlet station were used in the present study. However, it should be noted that the soil water content, calculated from the dielectricity of the soil matrix, measured with the FDR probes, represents only the liquid soil water content, not water in the form of ice.

\subsubsection{Discharge measurements}

To estimate how the catchment reacted to precipitation and to analyse the infiltration capacity of the soils in the catchment, data on discharge measured at the outlet were analyzed. Besides measuring how much discharge was produced during the winter periods, the runoff coefficient was calculated as:

$D_{r o}=100 * D_{M} / P_{A}$

where: $D_{r o}=$ Runoff coefficient $[\%] ; D_{M}=$ Discharge $\left[\mathrm{m}^{3}\right] ; P_{A}=$ Precipitation on area $\left[\mathrm{m}^{3}\right]$

\subsubsection{Snow cover properties}

Snow has a significant influence on changes in soil temperature and soil water content (Sutinen et al., 2008). Therefore, snow properties (depth and density) were monitored in 
the catchment during the three winters. The measurements taken at the outlet, Stations 1 and 3, are presented in this study. Snow Water Equivalent (SWE) was sampled after weather changes expected to result in changes in SWE (Starkloff et al., 2017a (Chapter 4)). The measured snow depth data were used to validate snow depth values simulated using the SHAW model.

\subsubsection{Erosion mapping}

In addition to the other measurements carried out in the field, soil erosion features were documented. Minor erosion damage was recorded by taking pictures. The extent of any large features observed was mapped using a differential GPS and the depth and width were measured at several points using a ruler.

\subsubsection{SHAW model set-up and calibration}

The SHAW model, which was originally developed to simulate soil freezing and thawing (Flerchinger and Saxton, 1989), simulates heat, water and solute transfer within a onedimensional profile extending downwards from the vegetation canopy to a specified depth within the soil. A layered system is established through the plant canopy, snow, residue and soil, and each layer is represented by an individual node (Flerchinger et al., 2009). Infiltration is calculated using a Green-Ampt approach for a multi-layered soil. Water flow in frozen soil is assumed to be similar to flow in unsaturated soil. Therefore, the relationships for matric potential and hydraulic conductivity of unsaturated soils are assumed to be valid for frozen soils. However, hydraulic conductivity is reduced linearly with ice content, assuming zero conductivity at an available porosity of 0.13 (Li et al., 2012). A detailed description of the model can be found in Flerchinger (2000).

Input to the SHAW model includes: initial conditions for snow, soil temperature and water content profiles; daily or hourly weather conditions (temperature, wind speed, humidity, precipitation and solar radiation); general site information; and parameters describing the vegetative cover, snow, plant residues and soil. General site information includes slope, aspect, latitude and surface roughness parameters. Input soil parameters are bulk density, saturated conductivity, albedo and coefficient for the soil water potential-water content relationship (Flerchinger, 2000).

To obtain the necessary soil input data (Table 3.1), undisturbed samples were taken in April 2014 at three different depths $(0,25$ and $35 \mathrm{~cm})$ at Stations 1 and 3 . These depths 
corresponded to the depth between FDR probes, avoiding the disturbed area around the probes. For determination of saturated soil hydraulic conductivity $\left(K_{\text {sat }}\right)$ and saturated water content $\left(\vartheta_{s}\right)$, two samples (volume of sample ring $250 \mathrm{~cm}^{3}$ ) were taken. Two additional samples (volume of sample ring $98 \mathrm{~cm}^{3}$ ) were used for determination of bulk density and soil organic matter. In total, 12 samples were taken at each of the two stations.

Saturated soil hydraulic conductivity was determined using the constant head method (Black et al., 1965). The two soil profiles defined for SHAW are presented in Table 3.1, with the corresponding depths of the simulation nodes (same as the installation depth of the FDR/temperature probes). For the simulations of winter 2013 , only the clay was included, as a three-layered soil profile with the location of the nodes at 5, 10 and $20 \mathrm{~cm}$, due to missing data for the sand and only three FDR/temperature probes in the clay.

Table 3.1: Input parameters for the SHAW model. Only the three layers marked with an asterisk (*) were used for the 2013 simulation and the depth was reduced from 15 to $10 \mathrm{~cm}$ and from $25 \mathrm{~cm}$ to $20 \mathrm{~cm}$

\begin{tabular}{|c|c|c|c|c|c|c|c|c|}
\hline Soil type & \multicolumn{4}{|c|}{ Clay } & \multicolumn{4}{|c|}{ Sand } \\
\hline Location & \multicolumn{4}{|c|}{$\begin{array}{c}59^{\circ} 40^{\prime} \mathrm{N} \text {, North facing }\left(22.5^{\circ}\right) \text {, Slope } 12^{\circ}, \\
\text { Elevation ASL } 100 \mathrm{~m}\end{array}$} & \multicolumn{4}{|c|}{$\begin{array}{c}59^{\circ} 40^{\prime} \mathrm{N}, \text { North west facing }\left(330.5^{\circ}\right) \text {, Slope } 0^{\circ}, \\
\text { Elevation ASL } 140 \mathrm{~m}\end{array}$} \\
\hline Surface & \multicolumn{8}{|c|}{$\begin{array}{c}\text { Albedo of dry soil: } 0.15 \\
\text { Wind profile surface roughness: } 0.1 \mathrm{~cm} \\
\end{array}$} \\
\hline Depth & $5 \mathrm{~cm}^{*}$ & $15 \mathrm{~cm}^{*}$ & $25 \mathrm{~cm}^{*}$ & $35 \mathrm{~cm}$ & $5 \mathrm{~cm}$ & $15 \mathrm{~cm}$ & $25 \mathrm{~cm}$ & $35 \mathrm{~cm}$ \\
\hline Campbell's b & 20 & 20 & 20 & 20 & 3 & 1 & 1 & 1 \\
\hline $\begin{array}{c}\text { Air entry } \\
\text { potential }[\mathrm{hPa}]\end{array}$ & -31 & -31 & -34 & -35 & -31 & -31 & -34 & -35 \\
\hline$K_{\text {sat }}\left[\mathrm{cm} \mathrm{hr}^{-1}\right]$ & 2.60 & 1.86 & 1.00 & 0.60 & 16.80 & 18.00 & 22.00 & 24.00 \\
\hline $\begin{array}{l}\text { Bulk density } \\
{\left[\mathrm{kg} \mathrm{m}^{-3}\right]}\end{array}$ & 1331 & 1400 & 1535 & 1537 & 1190 & 1346 & 1346 & 1347 \\
\hline$\theta_{\mathrm{s}}$ & 0.40 & 0.40 & 0.40 & 0.35 & 0.43 & 0.40 & 0.40 & 0.31 \\
\hline Sand [\%] & \multicolumn{4}{|c|}{13} & \multicolumn{4}{|c|}{70} \\
\hline Silt [\%] & \multicolumn{4}{|c|}{58} & \multicolumn{4}{|c|}{13} \\
\hline Clay [\%] & \multicolumn{4}{|c|}{29} & \multicolumn{4}{|c|}{7} \\
\hline $\begin{array}{l}\text { Organic matter } \\
\text { content [\%] }\end{array}$ & 4.5 & 4.0 & 3.7 & 3.5 & 3.4 & 3.4 & 2.7 & 2.0 \\
\hline
\end{tabular}

The model was calibrated to fit the measured snow depth and soil temperature by adjusting the site-specific parameters maximum temperature at which precipitation is snow $\left(T_{\max }\right)$ (only for winter 2015) and the wind profile roughness for momentum transfer of the snow cover $\left(z_{m}\right)$ (for all three winters). 


\subsection{Results}

\subsubsection{Weather measurements}

Measured air temperature and precipitation are presented in Fig. 3.2. Periods with continuous snow cover, indicated with blue bands in the diagram, were of differing duration in the different years.

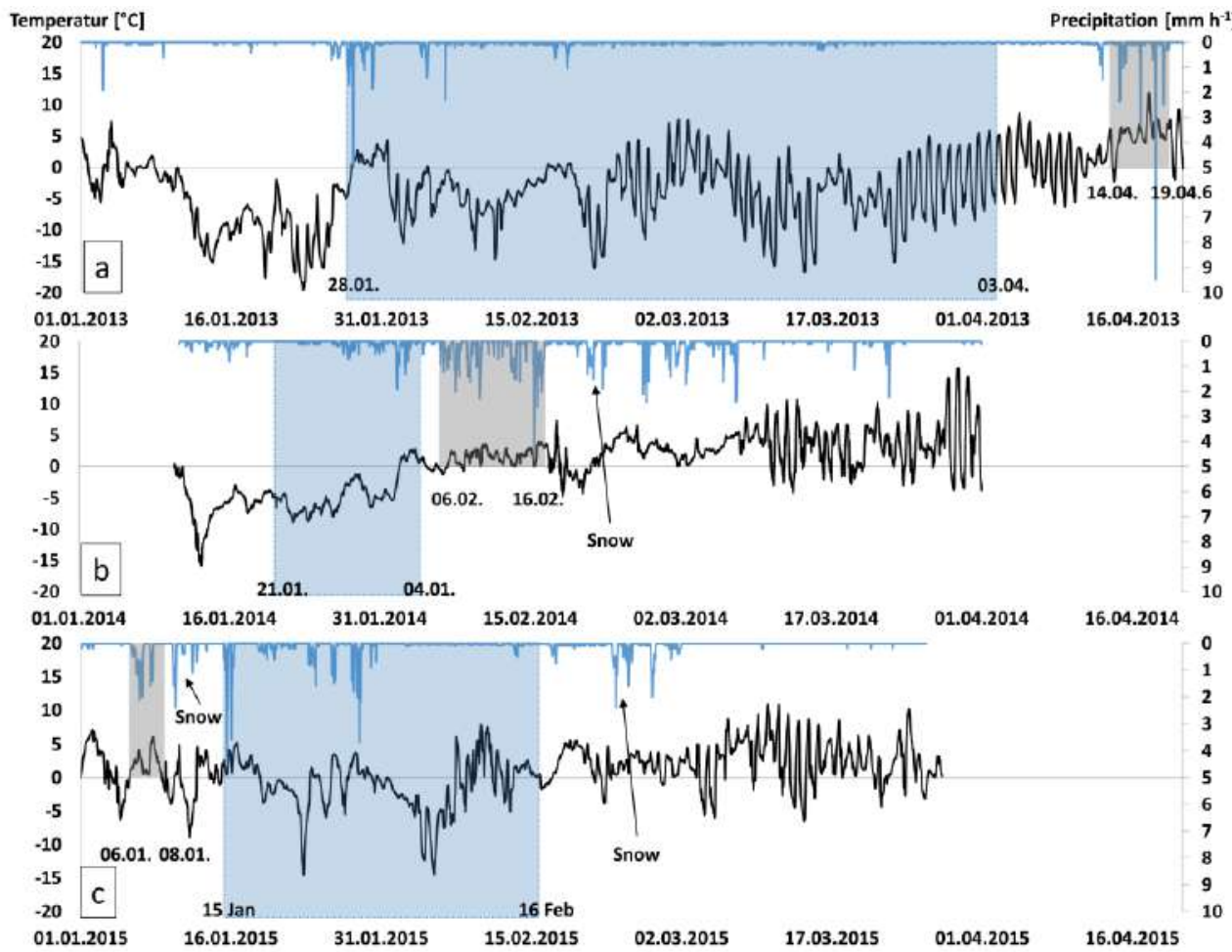

Fig. 3.2: Measured air temperature and precipitation for the three winter periods: 2013 (a); 2014 (b); and 2015 (c). Rain events of interest for this study with start and end dates are marked with grey bands. The duration of unbroken snow cover with start and end dates is indicated with blue bands. Snow events outside the unbroken snow cover period are marked as 'snow'.

The number, duration and intensity of rain events during the three winter periods also differed considerably. For each winter period, rain events of interest were selected (grey bands in Fig. 3.2) for detailed analysis. A rain event was classified as 'interesting' for this study when the precipitation fell as rain on completely or partially frozen ground. The total 
amount of rain and the duration of the 'main event' when the highest measured intensities occurred are shown in Table 3.2.

Table 3.2: Start and end date of the rain events of interest, with measured total amount of precipitation, highest measured intensity and the duration and amount of precipitation of the main event within the whole event

\begin{tabular}{cccc}
\hline Date & Total $[\mathrm{mm}]$ & Main event & Highest intensity $\left[\mathrm{mm} \mathrm{h}^{-1}\right]$ \\
\hline $14.04 .2013-19.04 .2013$ & 42.1 & $15.8 \mathrm{~mm}$ in 2 h & 9.3 \\
$06.02 .2014-16.02 .2014$ & 105 & $10 \mathrm{~mm}$ in 4 h & 4.6 \\
$06.01 .2015-08.01 .2015$ & 28 & $7 \mathrm{~mm}$ in 4 h & 2.0 \\
\hline
\end{tabular}

In terms of intensity, the 2013 event listed in Table 3.2 would be classified as heavy rain and the other events as moderate rain. The rain event in 2014 occurred on top of ongoing snowmelt after 4 February.

\subsubsection{Surface discharge measurements}

Measured surface discharge for the selected rain events is presented in Table 3.3, together with the estimated discharge coefficients. The main discharge events in the three winter periods occurred during these rain events, rather than as a result of snowmelt. While the rain event in 2013 was the largest of the three events, the rain event in 2015 produced the highest amount of discharge and had the highest discharge coefficient. During winter 2014, little discharge was produced by the rain event of interest $\left(1008 \mathrm{~m}^{3}\right)$ compared with the other two years (2594-3096 $\mathrm{m}^{3}$ ) (Table 3.3). However, it should be noted that some tunnelling below the flume was observed, resulting in by-pass of water and too low discharge values. This was repaired and did not happen in 2015.

Table 3.3: Start and end date of measured discharge during the selected rain events, total measured discharge, precipitation per area and percentage of precipitation water which reached the outlet. Values in brackets show discharge coefficient for the agricultural area only. Values marked with an asterisk (*) are incorrect measurements due to by-pass of water below the flume.

\begin{tabular}{|c|c|c|c|}
\hline Date & Discharge $\left[\mathrm{m}^{3}\right]$ & Precipitation $\left[\mathrm{m}^{3}\right]$ & Discharge coefficient [\%] \\
\hline 14.04.2013-19.04.2013 & 3096 & 12180 & $25(50)$ \\
\hline 06.02.2014-16.02.2014 & $1008^{*}$ & 30450 & $4^{*}$ \\
\hline $06.01 .2015-08.01 .2015$ & 2594 & 8120 & $32(63)$ \\
\hline
\end{tabular}

By comparing the discharge measured at the Gryteland sub-catchment outlet with discharge measured at the outlet of the main Skuterud catchment, it was determined that 
a surface discharge coefficient of about $12 \%$, rather than $4 \%$, was more realistic for the event in 2014.

\subsubsection{Liquid soil water content and soil temperature}

A malfunction in stations 1 and 3 created a gap in the data for winter 2013. The two stations were repaired just before the extreme event at the end of the winter period, so that soil moisture and soil temperature measurements for the clay and sand were available for this event (insert diagram in Fig. 3.3). For the clay, measured data were taken close by the outlet station, where undisturbed soil moisture and soil temperature data were obtained throughout winter 2013 (Fig. 3.3).

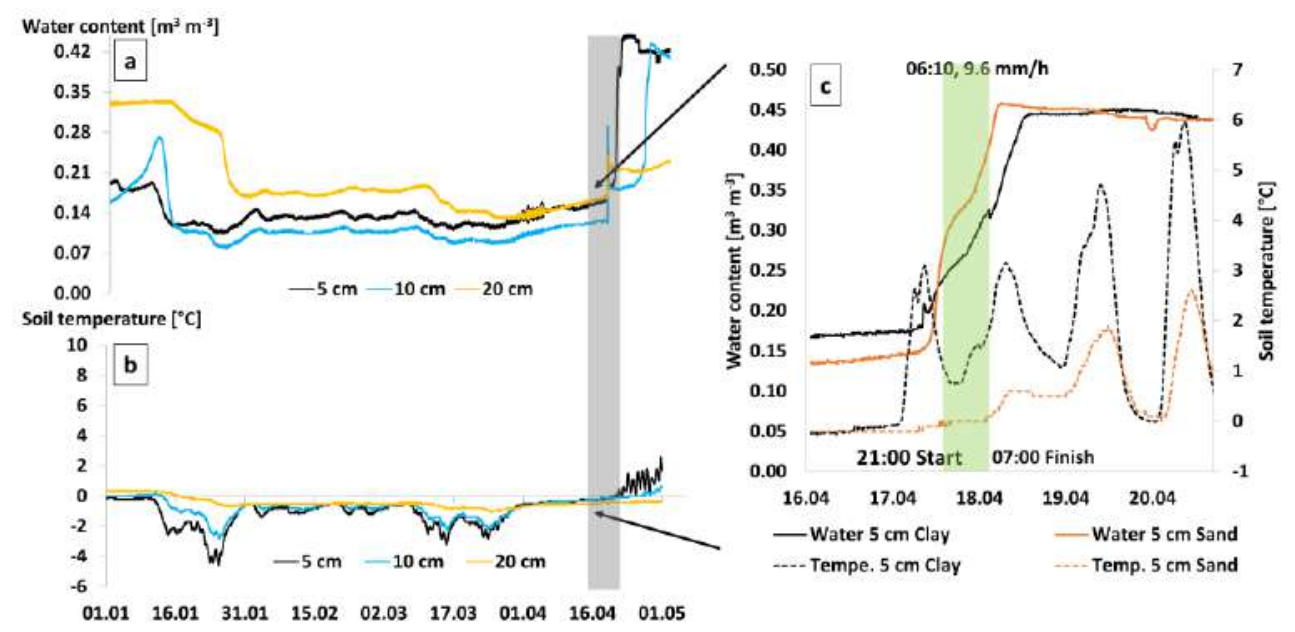

Fig. 3.3: Measured soil water content (a) and soil temperature (b) in the clay during winter 2013 with the insert diagram (c) showing measured soil water content and soil temperature at $5 \mathrm{~cm}$ depth in the clay and sand during the rain event of interest in 2013 (duration marked with grey band in $(a, b)$ ). The period with the highest precipitation intensities is marked with a green band in (c).

During winter 2013, the soil temperature and liquid soil water content measurements were characterized by a long period of soil frost at all soil depths (Fig. 3.3). Shortly after 2 December, the soil started to freeze at 5 and $10 \mathrm{~cm}$ and stayed frozen until the highest precipitation intensities (9.6 $\mathrm{mm} \mathrm{h}^{-1}$ ) occurred on 18 March (Fig. 3.3). Frozen soil was indicated by a low liquid soil water content $\left(\sim 0.12 \mathrm{~m}^{3} \mathrm{~m}^{-3}\right)$ compared with pre-freezing $\left(\sim 0.38 \mathrm{~m}^{3} \mathrm{~m}^{-3}\right.$ in November 2012$)$ and soil temperature below $0^{\circ} \mathrm{C}$. As can be seen in Fig. 3 , the soil was still frozen after the first rain event on 14 April. The liquid soil water content was still low in both soils ( $0.17 \mathrm{~m}^{3} \mathrm{~m}^{-3}$ in the clay and $0.13 \mathrm{~m}^{3} \mathrm{~m}^{-3}$ in the sand), and the 
measured soil temperature was below $0{ }^{\circ} \mathrm{C}$ in both soils. On $17 \mathrm{April}$, the soil temperature in the top $5 \mathrm{~cm}$ in the clay soil started to rise above $0{ }^{\circ} \mathrm{C}$, followed by a continuous increase in liquid soil water content at 5 and $10 \mathrm{~cm}$ depth. The soil temperature in the topsoil dropped to about $0.8{ }^{\circ} \mathrm{C}$ when the major rain event started in the evening of 17 April. However, the liquid soil water content continued to increase steadily and more rapidly in the sand than in the clay. When the highest precipitation rates occurred, the clay soil had reached a liquid soil water content of about $0.25 \mathrm{~m}^{3} \mathrm{~m}^{-3}$. The temperature in the sand soil rose much more slowly than in the clay soil, but the liquid soil water content increased rapidly in the sand topsoil layer at the same rate as in the clay soil, reaching a liquid soil water content of $0.34 \mathrm{~m}^{3} \mathrm{~m}^{-3}$ when the highest precipitation intensities occurred. During the final period of the high intensity rain, the soil water content continued to rise to about $0.45 \mathrm{~m}^{3} \mathrm{~m}^{-3}$ in both the clay and the sand. No further increase in soil water content occurred during the rest of the rain event, probably because both soils were fully saturated.

Measured soil water content during winter 2014 for the clay and sand is shown in Fig. 3.4 and measured soil temperature is presented in Fig. 3.5. 

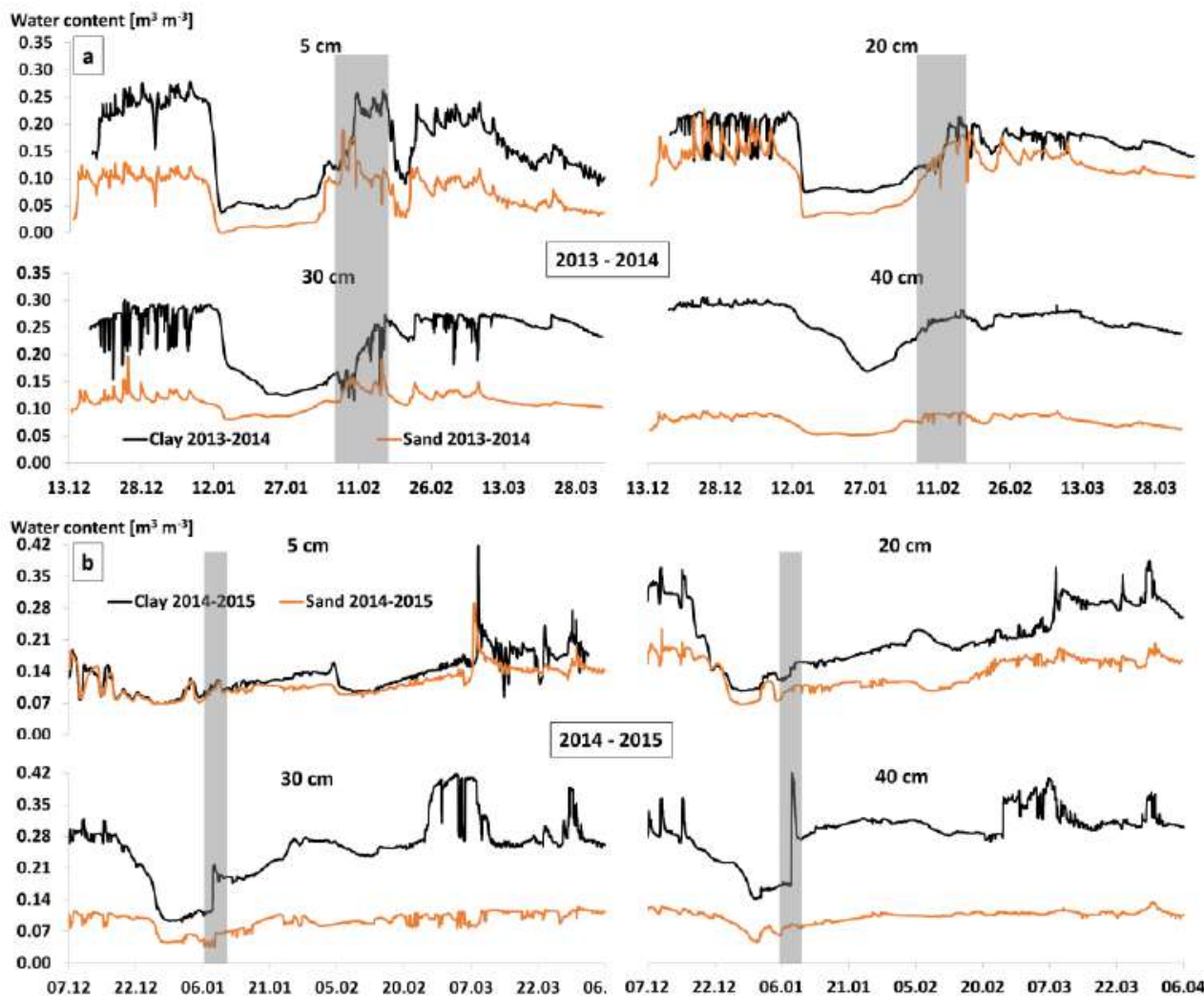

Fig. 3.4: Measured soil water content in the clay and sand for the winter periods 2014 (a) and 2015 (b) at four depths: 5, 20, 30 and $40 \mathrm{~cm}$. Durations of the rain events of interest (according to Table 3.2) are marked with grey bands. 


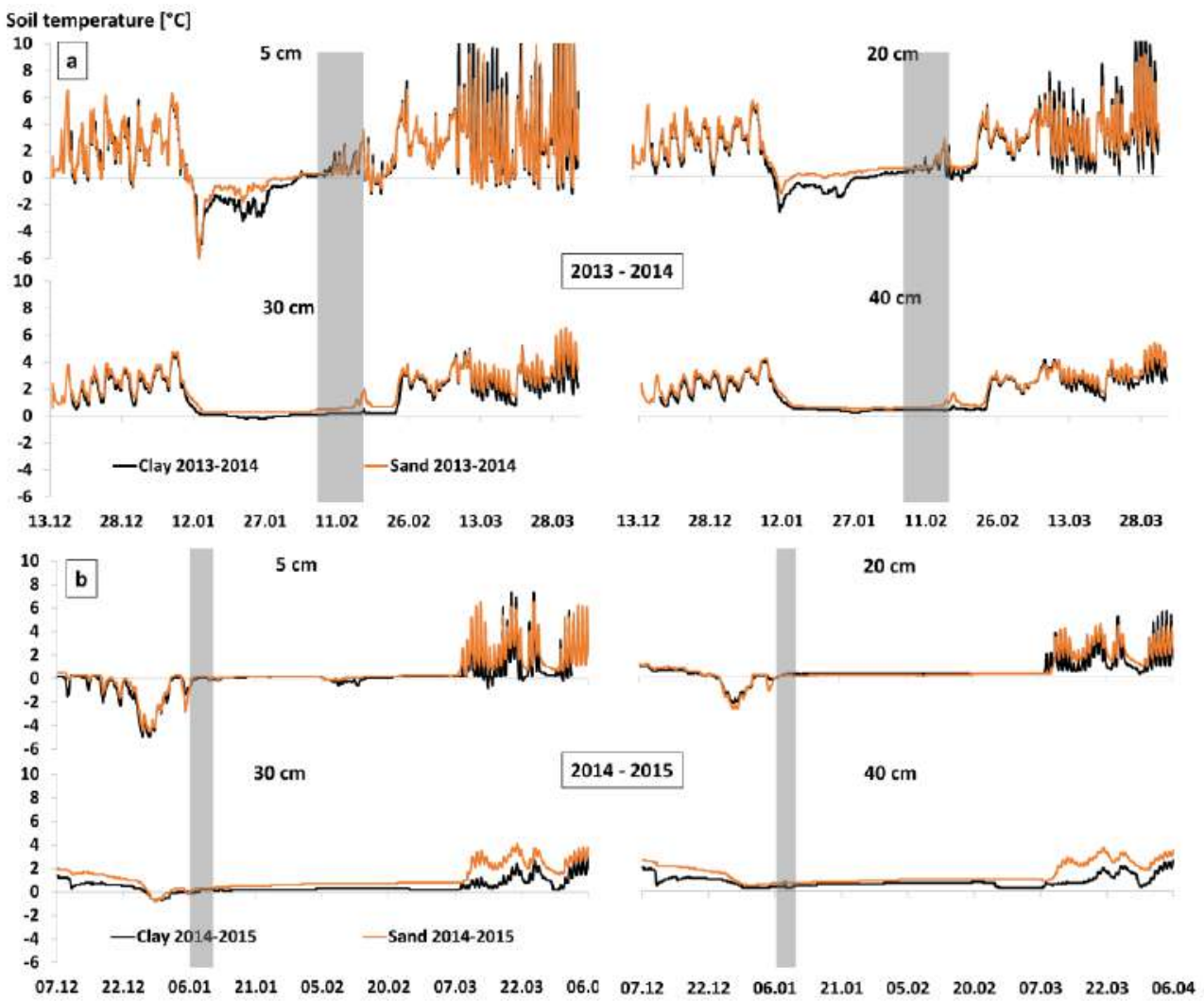

Fig. 3.5: Measured soil temperature in the clay and sand for the winter periods 2014 (a) and 2015 (b) at four depths: 5, 20, 30 and $40 \mathrm{~cm}$. Durations of the rain events of interest (according to Table 3.2) are marked with grey bands.

Measured soil water content and temperature declined significantly in both the clay and sand immediately after the air temperature started to drop below zero (Figs. 3.4 and 3.5) around 6 January. Measured soil water content did not change much after 13 January, whereas soil temperature followed the changes in air temperature, although this effect decreased with increasing depth for both soil types. After 27 January, the liquid soil water content rose slowly until it increased rapidly beginning on 3 February. While the soil water content did not change much in the sand at 30 and $40 \mathrm{~cm}$ depth, a decrease in liquid soil water content was observed at these depths in the clay. Both soils showed similar temperature profiles for all four depths (Fig. 3.5). The soil water content at all depths was much lower in the sand than in the clay, reducing the penetration depth of freezing (Yami et al., 2012). Furthermore, at 30 and $40 \mathrm{~cm}$ depth in the sand there was little water left to freeze (30 cm: $\left.0.08 \mathrm{~m}^{3} \mathrm{~m}^{-3}, 40 \mathrm{~cm}: 0.06 \mathrm{~m}^{3} \mathrm{~m}^{-3}\right)$. 
When the combined rain and snowmelt event occurred in 2014 , both soils had just started to thaw. During the event, similar soil water contents as measured before freezing $(\sim 0.25$ $\mathrm{m}^{3} \mathrm{~m}^{-3}$ ) were reached in the clay. In the sand, soil water content at $5 \mathrm{~cm}$ depth initially rose rapidly above $\left(\sim 0.18 \mathrm{~m}^{3} \mathrm{~m}^{-3}\right)$ pre-freezing values $\left(\sim 0.10 \mathrm{~m}^{3} \mathrm{~m}^{-3}\right)$, but decreased to prefreezing values during the event, while at the other three depths studied the soil water content continued to increase during the whole event. At all four soil depths in both soils, the soil temperature rose significantly to above $0{ }^{\circ} \mathrm{C}$, reaching the highest temperature (3.6 $\left.{ }^{\circ} \mathrm{C}\right)$ at $5 \mathrm{~cm}$.

The change in liquid soil water content in winter 2015 (Fig. 3.4) was characterised by low values at $5 \mathrm{~cm}$ in both soils (minimum of $0.07 \mathrm{~m}^{3} \mathrm{~m}^{-3}$ ) due to early freezing in the beginning of December. This was followed by a decrease in liquid soil water content at 20, 30 and 40 $\mathrm{cm}$ in the clay on 17 December, reaching a minimum of $0.10 \mathrm{~m}^{3} \mathrm{~m}^{-3}$ at 20 and $30 \mathrm{~cm}$ and $0.14 \mathrm{~m}^{3} \mathrm{~m}^{-3}$ at $40 \mathrm{~cm}$. A sudden increase in liquid soil water content occurred on $7 \mathrm{March}$ at all depths in the clay and at $5 \mathrm{~cm}$ in the sand. When the air (Fig. 3.2) and soil temperature (Fig. 3.5) rose significantly to above $0^{\circ} \mathrm{C}$, as in 2014 , the liquid soil water content was lower in the sand than in the clay.

In winter 2015 the rain event (Table 3.2) was preceded by freezing temperatures at $5-30 \mathrm{~cm}$ soil depth and low liquid soil water content at all soil depths in both soils (Figs. 5 and 6). During the event, the liquid soil water content rose rapidly at 30 and $40 \mathrm{~cm}$ depth in the clay, reaching its highest value $\left(0.42 \mathrm{~m}^{3} \mathrm{~m}^{-3}\right)$ at $40 \mathrm{~cm}$ depth. At 5 and $20 \mathrm{~cm}$ depth the change in liquid soil water content was less pronounced. Soil temperature rose in the upper three depths in both soils to about $0{ }^{\circ} \mathrm{C}$, while at $40 \mathrm{~cm}$ depth the soil temperature stayed above $0^{\circ} \mathrm{C}$ at all times in both soils.

\subsubsection{SHAW modelling}

The simulated snow depth, soil temperature and ice content values for the clay during winter 2013 are presented in Fig. 3.6, for the clay and sand during winter 2014 in Figs. 3.7, 3.8 and for winter 2015 in Figs. 3.9 and 3.10. As mentioned, due to missing continuous measurements for the sand during winter 2013 , the sand was not modelled for that year.

As can be seen from Fig. 3.6, the SHAW model simulated the changes in the snow pack very accurately for 2013. To fit the simulated snow depth to the measured values, the $z_{m}$ parameter was set to $0.15 \mathrm{~cm}$. The simulated soil temperature at 5 and $10 \mathrm{~cm}$ showed some fluctuations around the measured temperature, which increased after the snow pack disappeared in the end of March, when the air temperature fluctuated between -7 and 8 
${ }^{\circ} \mathrm{C}$ on a daily basis (Fig. 3.2). However, it should be noted that the soil temperature was measured below a thick grass layer at the outlet station, and this grass layer probably acted as insulation (Flerchinger et al., 2003), buffering the soil from the fluctuating air temperature. The model results show soil temperatures for bare ground, for comparison with the other winters. Due to the satisfactory simulation of snow depth and soil temperature, it was assumed that SHAW also performed well in simulating ice content in the soil profile. Simulated ice content was high $\left(0.35 \mathrm{~m}^{3} \mathrm{~m}^{-3}\right)$ at 5 and $10 \mathrm{~cm}$ depth and zero at $20 \mathrm{~cm}$ depth, indicating that almost all of the water at these depths was frozen. The ice at these depths was apparently formed during the low soil temperatures in January, before the snow pack was established. SHAW was able to simulate the rise in soil temperature after the snow pack reached a depth of about $20 \mathrm{~cm}$ in February and predicted a decrease in ice content to zero at all depths by 12 April. The SHAW model was also able to simulate the observed decrease in soil temperature in the middle of April.

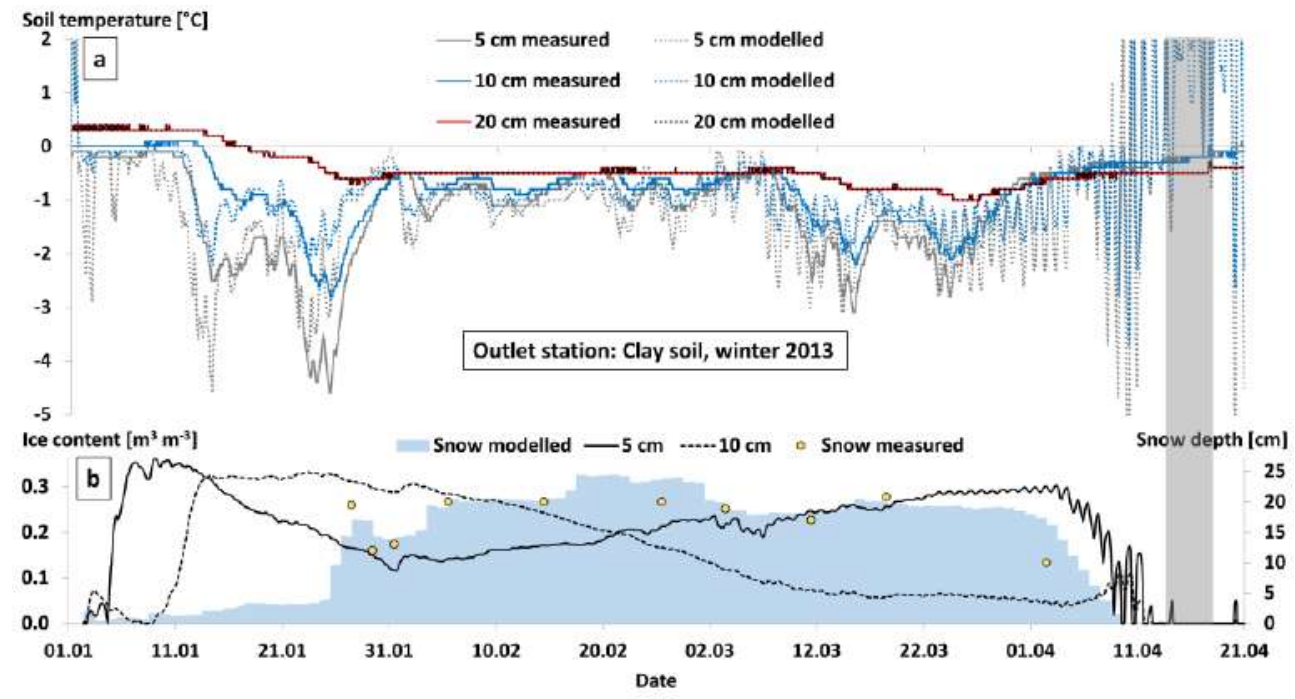

Fig. 3.6: Diagram of (a) modelled and measured soil temperature at three depths $(5,10$ and $20 \mathrm{~cm})$ in the clay soil (at outlet station) during winter 2013; diagram of (b) measured and modelled snow depths at the outlet station and modelled ice content at the three depths in the clay soil (was zero at $20 \mathrm{~cm}$ ). The duration of the rain event of interest is marked with a grey band.

Because only four snow depth measurements were possible in 2014, it was difficult to compare the simulated and measured snow depth values. However, it can be seen that SHAW underpredicted the snow depth above the clay soil during January and overpredicted it above the sand soil (Figs. 3.7 and 3.8). The $z_{m}$ parameter was adjusted to $0.5 \mathrm{~cm}$ for the clay and $1.5 \mathrm{~cm}$ for the sand. 


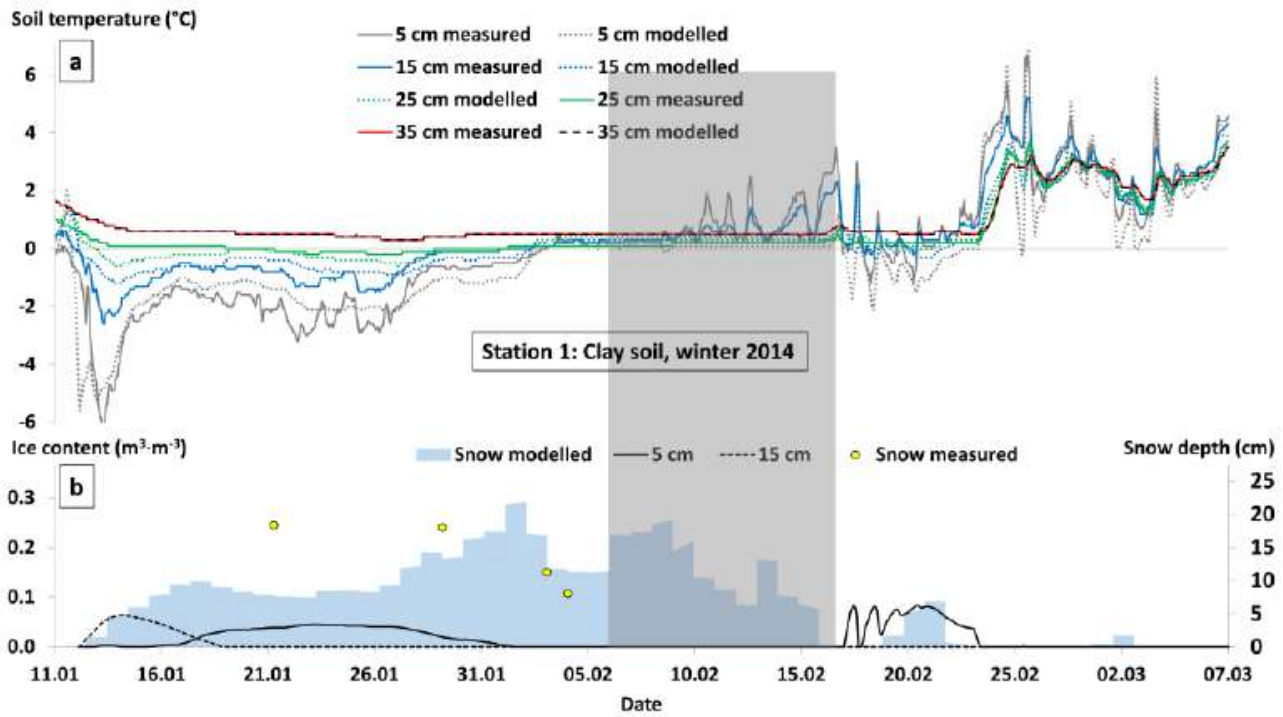

Fig. 3.7: Diagram of (a) modelled and measured soil temperature at four depths $(5,10$ and $20 \mathrm{~cm})$ in the clay soil (at Station 1) during winter 2014; diagram of (b) measured and modelled snow depths at Station 1 and modelled ice content at four depths in the clay soil (was zero at 25 and $35 \mathrm{~cm}$ ). The duration of the rain event of interest is marked with a grey band.

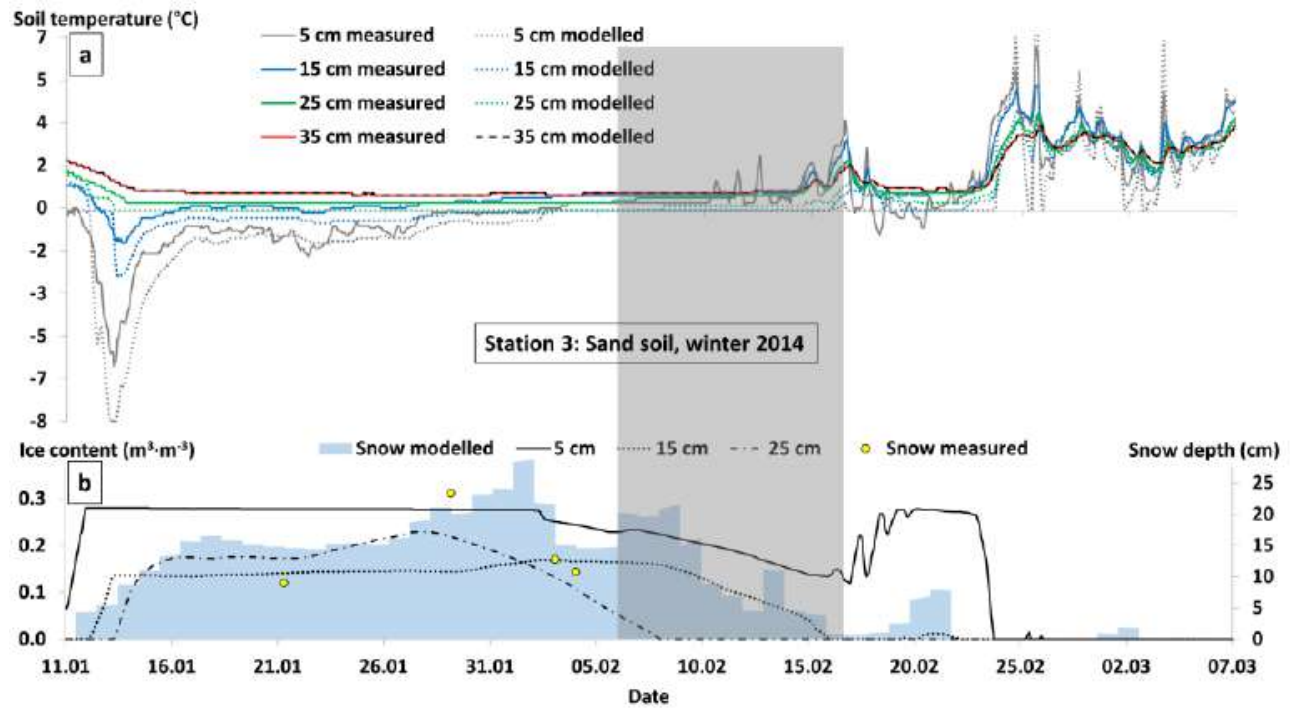

Fig. 3.8: Diagram of (a) modelled and measured soil temperature at four depths $(5,15,25$ and $35 \mathrm{~cm})$ in the sand soil (at Station 3) during winter 2014; diagram of (b) measured and modelled snow depths at Station 3 and modelled ice content at four depths in the sand soil (was zero at $35 \mathrm{~cm}$ ). The duration of the rain event of interest is marked with a grey band. 
The simulated soil temperature in the clay soil (Fig. 3.7) followed the measured temperature rather closely during the freezing period in January, but during the start of the snowmelt in the middle of February, the measured temperature showed a higher fluctuation than the simulated temperature. For the sand, SHAW simulated slightly lower temperature $\left(-8^{\circ} \mathrm{C}\right.$ at $5 \mathrm{~cm}$ ) than the measured values $\left(-6^{\circ} \mathrm{C}\right.$ at $\left.5 \mathrm{~cm}\right)$, but in general, the simulated temperature followed the trend in the measured data quite well (Fig. 8). SHAW predicted low ice content for the clay at 5 and $15 \mathrm{~cm}$ ( $\max .0 .06 \mathrm{~m}^{3} \mathrm{~m}^{-3}$ at $15 \mathrm{~cm}$ ) and no ice at lower depths, while for the sand, it predicted an ice content of $0.28 \mathrm{~m}^{3} \mathrm{~m}^{-3}$ at $5 \mathrm{~cm}$ and $0.22 \mathrm{~m}^{3} \mathrm{~m}^{-3}$ at $25 \mathrm{~cm}$ depth. At 5 and $15 \mathrm{~cm}$, the model predicted that all the available water was frozen, which can be seen as the constant ice contents between 12 January and 2 February. Moreover, the period with frozen water in the sand profile was considerably longer (11 January-23 February at $5 \mathrm{~cm}$ ) than that in the clay (12 January-1 February at $5 \mathrm{~cm}$ ).

Except for a slight underprediction of the snow depth for the period when the first two snow measurements were taken in 2015, SHAW simulated the snow depth well for winter 2015 (Fig. 3.10). To obtain this fit, $z_{m}$ was set to $0.05 \mathrm{~cm}$ for the clay and $0.08 \mathrm{~cm}$ for the sand. In addition, $T_{\max }$ had to be set to $3.8^{\circ} \mathrm{C}$ to fit the modelled snow thicknesses to the measured, which resulted in the simulation of a thin snow cover, which did not occur in the field, during the rain event of interest in 2015. This adjustment of $T_{\max }$ was in accordance with Kramer and Stolte (2009), who used a comparable snow model for the study area and had to make a similar adjustment to this parameter.

The simulated soil temperature showed similar low fluctuations as the measured (Figs. 3.9 and 3.10), and the first negative peak was also simulated, with a good fit in the sand and slightly lower temperature in the clay $\left(-5.8^{\circ} \mathrm{C}\right.$ simulated compared with $-3^{\circ} \mathrm{C}$ measured at $5 \mathrm{~cm}$ ).

For both the clay and the sand, SHAW predicted high ice content at $5 \mathrm{~cm}$ depth, mainly during the period when the snow pack was between 10 and $20 \mathrm{~cm}$ thick (Figs. 3.9 and 3.10). The predicted values were $0.39 \mathrm{~m}^{3} \mathrm{~m}^{-3}$ in the clay and $0.45 \mathrm{~m}^{3} \mathrm{~m}^{-3}$ in the sand. For both soils, SHAW simulated an increase in ice content at $5 \mathrm{~cm}$ with growing snow thickness and a decrease in ice content with decreasing snow thickness. 


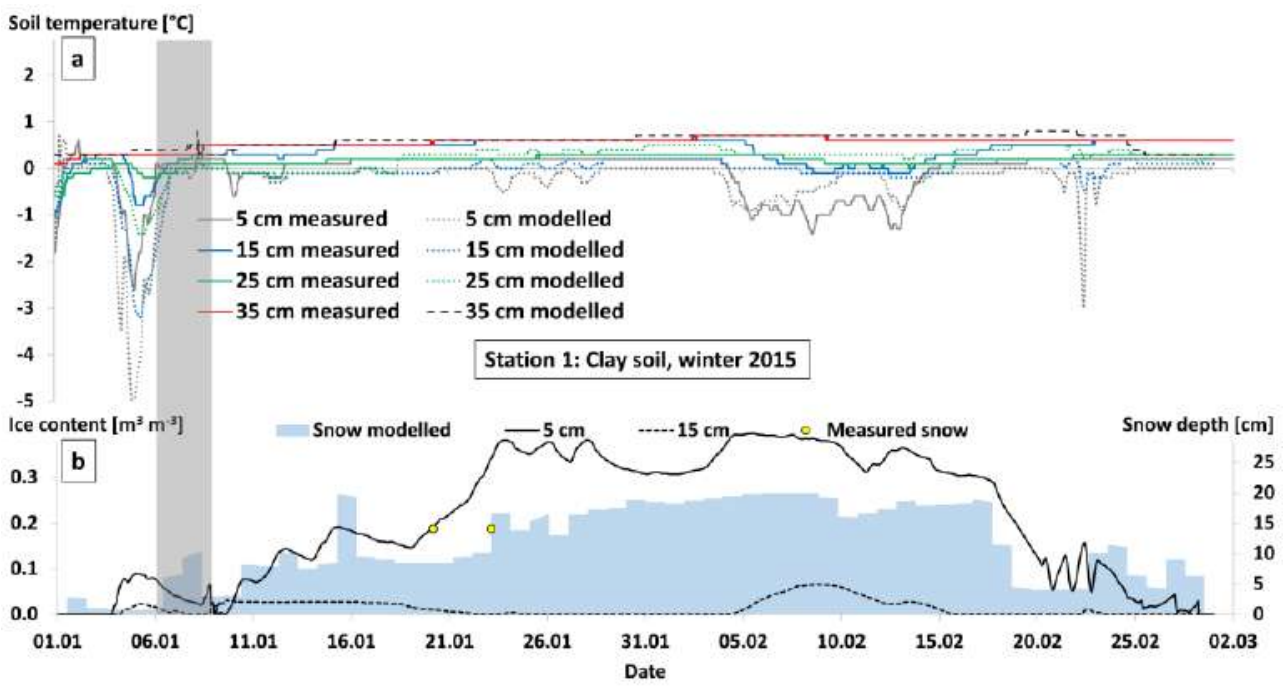

Fig. 3.9: Diagram of (a) modelled and measured soil temperature at four depths $(5,15,25$ and $35 \mathrm{~cm})$ in the clay soil (at Station 1) during winter 2015; diagram of (b) measured and modelled snow depths at Station 1 and modelled ice content at four depths in the clay soil (was zero at 25 and $35 \mathrm{~cm}$ ). The duration of the rain event of interest is marked with a grey band.

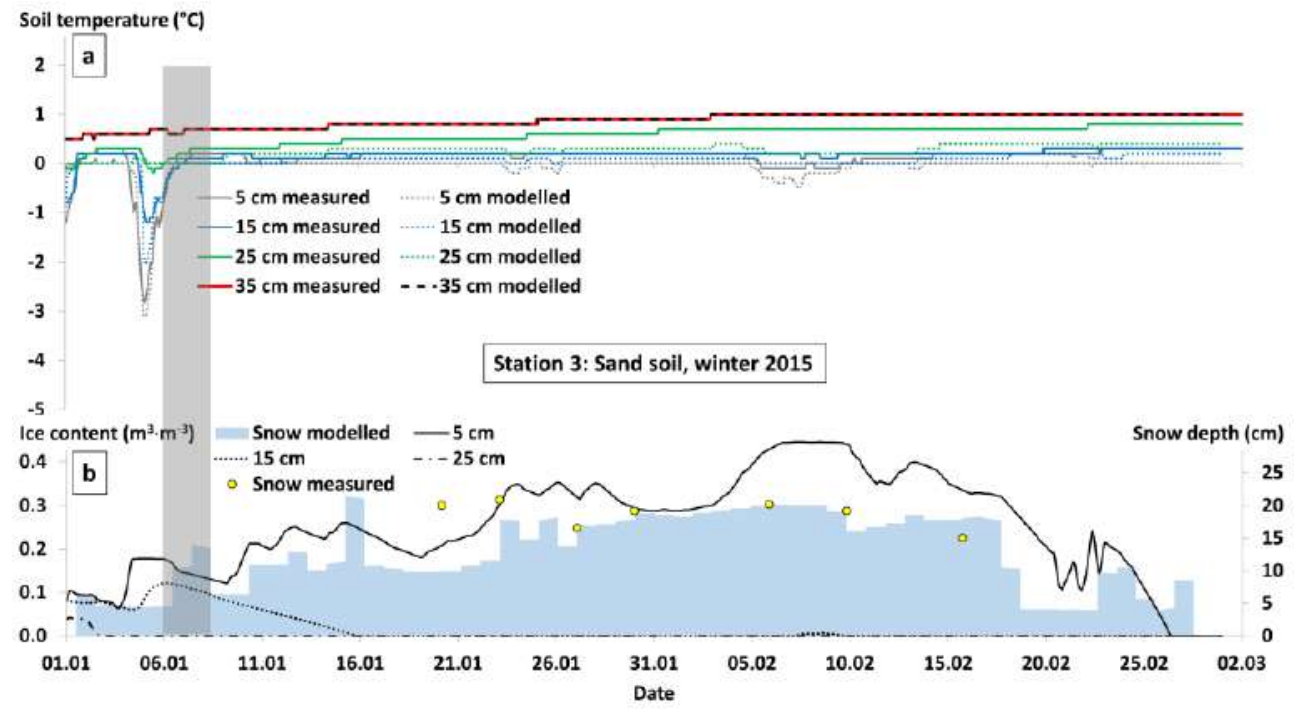

Fig. 3.10: Diagram of (a) modelled and measured soil temperature at four depths $(5,15,25$ and $35 \mathrm{~cm})$ in the sand soil (at Station 3) during winter 2015; diagram of (b) measured and modelled snow depths at Station 3 and modelled ice content at four depths in the sand soil (was zero at $35 \mathrm{~cm}$ ). The duration of the rain event of interest is marked with a grey band. 


\subsubsection{Erosion mapping}

During winter 2013, no erosion was observed anywhere in the catchment. The combined snowmelt and rain event in 2014 formed several small rills with a maximum width of $20 \mathrm{~cm}$ and 5-10 cm deep on two slopes in the catchment (Fig. 3.11). The observed rills were formed mainly in the tracks created by the cultivator.

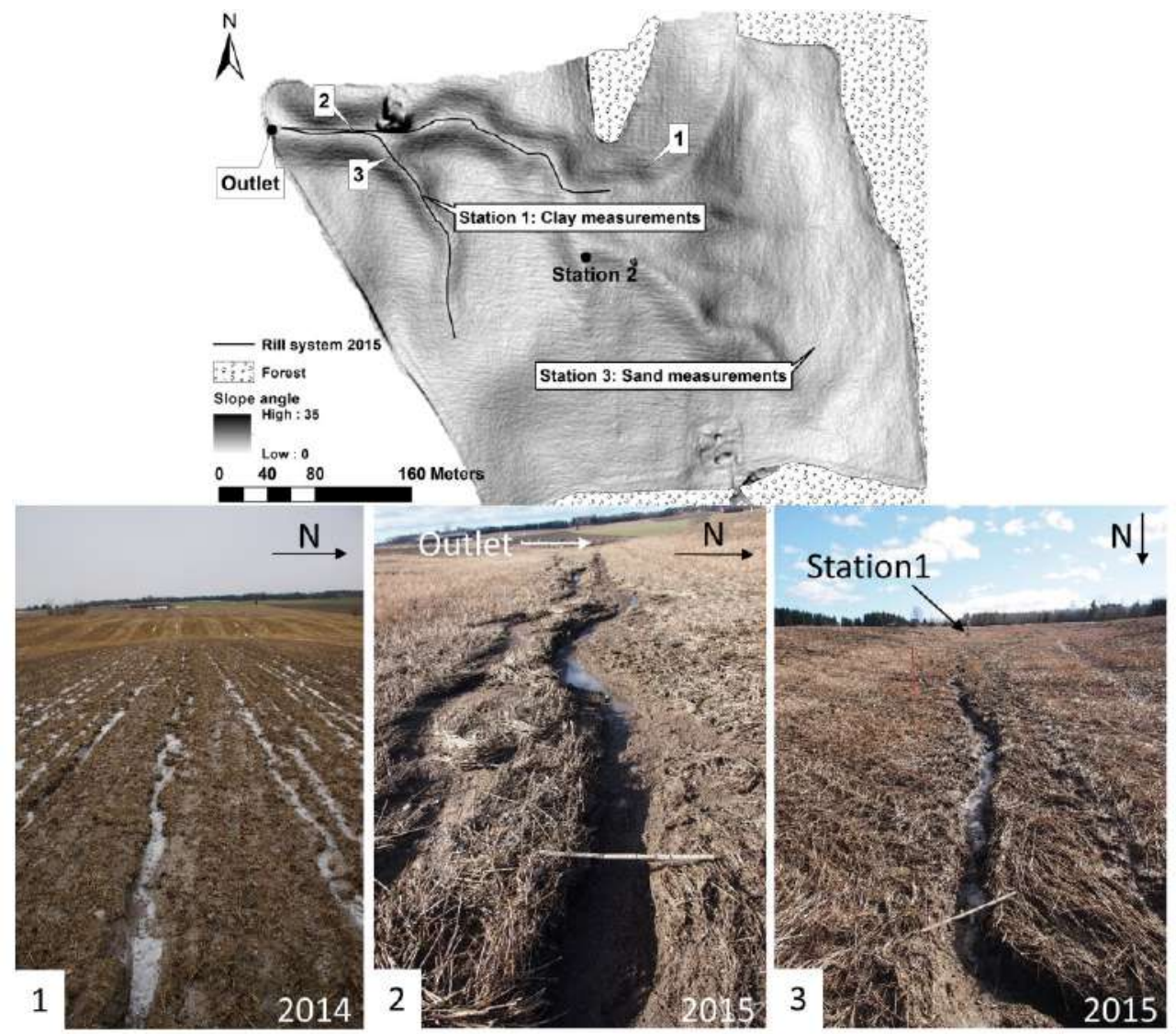

Fig. 3.11: Slope angle map showing; the extent of the rill system, which formed during winter 2015 and the location where images 1-3 were taken. Image 1 shows rills which formed during the combined snowmelt and rain event in 2014 and images 2,3 show rills that formed during winter 2015.

In winter 2015, a continuous rill system (total length $493 \mathrm{~m}$ ) was formed in depressions, where surface runoff was concentrated, during the main rain event. The rills varied in width and depth (Fig. 3.11, Images 2, 3), with measured maximum width of $40 \mathrm{~cm}$ and depth of $20 \mathrm{~cm}$. Several sedimentation areas were observed where the surface runoff was slowed down, due to reduced slope angle and increased flow width, indicating that not all of the 
eroded soil reached the outlet. At the other slope where rills were observed in 2014 (Fig. 3.11, Image 1), the rills were connected to the gully system in 2015.

\subsection{Discussion}

The winters of 2013, 2014 and 2015 differed significantly from each other in terms of the number of freezing periods, the length of period with a continuous snow cover and the number of rain events (Fig. 2). The soils stayed frozen throughout the whole time with a continuous snow cover in the three winter periods, confirming the finding by Zhao et al. (2013b) that a thin $(<25 \mathrm{~cm})$ snow pack can increase soil freezing, e.g., due to an increase in ground albedo.

The amount of water that can infiltrate depends on the water permeability of the soil and the speed of surface runoff. In frozen soil, the water permeability depends on pre-freezing conditions (McCauley et al., 2002), i.e., what the soil water content was before freezing started. In saturated soils the macropores are filled with water, which when frozen, clogs the pores. In the sand studied here, the initial soil water content was similar in 2013, 2014 and 2015 , at between 0.10 and $0.25 \mathrm{~m}^{3} \mathrm{~m}^{-3}$, which is far below the measured saturation of $0.40-0.43 \mathrm{~m}^{3} \mathrm{~m}^{-3}$. Therefore, it can be assumed that the sand areas in the catchment contributed little to surface runoff during these three winters. This could explain why no erosion occurred in the depression on the sand soil in the catchment (Fig. 1.2).

In the clay, however, the conditions differed between the years. In clays, water transport and infiltration capacity are highly dependent on macropores, particularly in the levelled clays found in the study area (Øygarden et al., 1997). When freezing started in 2014, the clay had a soil water content of $0.25-0.30 \mathrm{~m}^{3} \mathrm{~m}^{-3}$, which according to the soil hydraulic characteristic curve for the clay represents a matric potential of $32 \mathrm{kPa}(5 \mathrm{~cm}$ depth) to 315 $\mathrm{kPa}$ (20 cm depth), at which macropores are filled with air (Lundberg et al., 2015). Furthermore, the rain event of interest in 2014 was less intensive than that in 2013 (Table 3.2), and the thawed soil allowed more water to infiltrate, resulting in a smaller amount of water reaching the outlet (Table 3.3). The SHAW results suggested that the clay was completely thawed by the time the rain event occurred (Fig. 3.7).

However, despite a smaller discharge coefficient compared with 2013, the 2014 event caused erosion (Fig. 3.11), in the tracks created by the cultivator.

Similarly to 2013 , in winter 2015 the soil water content was $0.40-0.45 \mathrm{~m}^{3} \cdot \mathrm{m}^{-3}$ at all soil depths in the clay when freezing started in November 2014, resulting in macropores filled 
with ice. Both events had a high discharge coefficient, of $25 \%$ ( $50 \%$ when forest area was excluded) in 2013 and 32\% (63\%) during the first event in 2015 (Table 3). This, together with the low liquid soil moisture values, suggests that infiltration was restricted due to frozen soil during both events. Therefore, the fact that erosion did not occur in 2013 , but did occur in 2015, cannot be explained by the infiltration capacity of the soil during the events. Moreover, the stability of the soils cannot explain the differences between 2013 and 2015, as confirmed by shear strength measurements carried out on the clay immediately before the event in 2013, which revealed low shear strength of 5-10 kPa at the soil surface (vane shear test, Eijkelkamp, The Netherlands).

Another process that could explain the differences between 2013 and 2015 is the speed of surface runoff, which determines the erosivity of surface runoff (Boardman and Poesen, 2006). In 2013, the whole catchment was covered with stubble, but in 2015, only the depressions had intact stubble, while secondary tillage with a cultivator reduced the amount of plant residues on slopes. This tillage created a loose and smoother surface, probably causing higher speed of surface runoff, in freezing conditions in particular, as previously shown by Ban et al. (2016). This assumption was supported by the occurrence of soil erosion in the form of rills on the tilled slopes in 2014 (Fig. 3.11). These findings were also in agreement with Edwards and Burney (1987), who concluded that only a plant cover can significantly reduce soil losses by rain and overland flow on frozen ground, e.g., through reduced runoff speeds and increased soil stability by roots. Our finding that the selected rain events on saturated and frozen soil produced a large amount of surface discharge confirmed the prediction by Stähli et al. (2001) and Nyberg et al. (2001) that high water saturation and early frost penetration, combined with heavy rain on still frozen soil, cause a marked increase in the amount of runoff.

Contrary to observation made by other studies (e.g., Lundekvam and Skøien, 1998; Deelstra et al., 2009; Øygarden, 2003), in all three winters studied, snowmelt played no significant role in terms of soil erosion. During snowmelt in 2014, the snow layer acted as a buffer for incoming rain. The rain infiltrated into the snow pack and surface runoff was delayed by the snow, reducing the erosive forces of the rain event. In 2013, no erosion occurred, and in 2015, the major soil erosion features had occurred before the first snow fell (Fig. 3.2).

The performance of the SHAW model was satisfactory for all three winter periods. The change in soil temperature and snow pack was well reproduced, and the simulated ice content was in agreement with the measured liquid soil water content. In general, SHAW predicted ice in the soil for the periods when the FDR probes measured low liquid soil water contents. With the adjustment of two snow-related parameters in the model, it was possible to obtain reasonable results for the three different winter periods. Adjustment of 
$T_{\max }$ for winters when snow falls at temperatures above $0{ }^{\circ} \mathrm{C}$, as was the case in 2015 , allows the model to partition incoming precipitation into snow and rain based on field observations, rather than using linear interpolation. The performance of SHAW in this study proved that it can be a valuable tool for investigating and predicting: (1) water content at freezing; (2) whether soil is frozen or unfrozen at a particular moment; and (3) the state of the snow cover. These are three important factors that control the amount of runoff during winter and are indispensable for predicting when soil erosion can be expected.

\subsection{Conclusions and implications}

Field observations carried out during three winters in a catchment in southern Norway showed how soil hydraulic properties changed due to freezing-thawing, affecting surface runoff caused by snowmelt and rain, and how these processes are linked to soil erosion. The largest amount of soil erosion was caused by a small rain event on frozen ground, before the snow cover was established, while snowmelt played no significant role in terms of soil erosion. Four factors that determine the extent of runoff and erosion were of particular importance: (1) soil water content at freezing; (2) whether soil was frozen or unfrozen at a particular moment; (3) the state of the snow cover; and (4) tillage operations prior to winter. The simulation results showed that the SHAW model, with its accurate snow pack routine, is a useful tool that can help to investigate and identify non-tillage factors (e.g., 1, 2 and 3) influencing erosion. 


\section{Understanding snow pack development at catchment scale}

Shallow (<1 $\mathrm{m}$ deep) snow packs on agricultural areas are an important hydrological component in many countries, which determines how much meltwater is potentially available for overland flow, causing soil erosion and flooding at the end of winter. Therefore, it is important to understand the development of shallow snow packs in a spatially distributed manner. This study combined field observations with spatially distributed snow modelling using the UEBGrid model, for three consecutive winters (2013-2015) in southern Norway. Model performance was evaluated by comparing the spatially distributed SWE measurements over time with the simulated SWE. UEBGrid replicated SWE development at catchment scale with satisfactory accuracy for the three winters. The different calibration approaches which were necessary for winter 2013 and 2015 showed the delicacy of modelling the change in shallow snow packs. Especially the refreezing of meltwater and prohibited runoff and infiltration of meltwater by frozen soils and ice layers can make simulations of shallow snow packs challenging

\section{Based on:}

Starkloff, T., Stolte, J., Hessel, R., Ritsema, C.J., Investigating the development of shallow snowpacks, using comprehensive field observations and spatially distributed snow modelling. Hydrology Research, 2017, doi: 10.2166/nh.2017.269 


\subsection{Introduction}

In countries were a snow pack develops during winter, the snow packs on agricultural areas are usually shallow (i.e. $<1 \mathrm{~m}$ deep) as in most cases the agricultural areas are located at low altitude. Shallow snow packs are much more sensitive to changes in air temperature and fluctuations between precipitation as rain or snow than deep snow packs and have a reduced ability to dampen peak outflows compared to deep snow packs (Wever et al., 2014). Furthermore, snow packs less than $20 \mathrm{~cm}$ deep cannot insulate the soil from low air temperatures, but can amplify deep-freezing of soils due to an increase in ground albedo caused by the snow (Zhao et al., 2013b). This deep-freezing of the soil profile can change the soil hydraulic properties dramatically (Stähli et al., 2001; Al-Houri et al., 2009). In southern Norway this causes severe soil erosion, through impeded infiltration of snowmelt and rainwater, at the end of winter ( $\varnothing$ ygarden, 2003). The amount of snow at the end of winter determines how much meltwater is available for creating overland flow and soil erosion on agricultural soils (Lundberg et al., 2016). Besides damaging the nutrient rich top layer of agricultural soils, sediment transfer from fields to streams during winter and spring represents a major part of the annual loss of phosphorous and nitrogen from agricultural catchments (Su et al., 2011). Therefore, it is important to better understand the development of shallow snow packs during winter, including the spatial distribution of snow water equivalent (SWE).

Snow is one of the most changeable elements in the hydrological cycle and poses a great range of challenges for monitoring and measuring (Doesken and Robinson, 2009). Below, the main factors influencing snow processes of interest for this study are summarised. $A$ more detailed description can be found in Gray and Male (1981) and Lundberg et al. (2016).

Catchment properties such as slope, aspect and vegetation cover have a major influence on the condition and morphology of snow pack. Slope, curvature and aspect determine exposure to wind (Lapen and Martz, 1996), precipitation and solar radiation (Gray and Male, 1981). Wind interacting with terrain and vegetation heavily influences the deposition and redistribution of snow, enhancing or reducing snow accumulation (Gascoin et al., 2013). More snow is usually accumulated on leeward slopes and forest edges than on windward sides, due to reduced exposure to higher wind speeds. Snow depth is often greater in depressions due to reduced wind speeds and increased turbulence. Furthermore, vegetation (e.g. crop residues) enhances the roughness of the surface during the exposed period before total snow cover, resulting in increased turbulent wind flow and causing complex snow structures and patterns. Another important factor is the air temperature at the time of snowfall, which controls the dryness, hardness and crystalline form of new snow, and thereby its erodibility by wind. For instance, heavy wet snow falling at temperatures 
close to $0{ }^{\circ} \mathrm{C}$, is less susceptible to wind transport and is common for low altitude areas in the temperate zone (Richard and Brun, 2008), like southern Norway, where this study was conducted.

The main process responsible for differential melting of snow in a catchment is energy exchange. Important energy inputs and outputs are solar radiation, rain, incoming longwave radiation, outgoing long-wave radiation and sensible and latent heat fluxes such as evaporation, condensation and sublimation of ice (Tarboton et al., 2000).

The complexity of snow accumulation, distribution and melt processes and the speed of change, which is typical for shallow snow packs, make spatial investigation of snow properties challenging and costly (Gascoin et al., 2013). Therefore, the spatial resolution of snow-related data is often poor or no data on spatial distribution are available (Tarboton et al., 2000). Distributed snow pack models, using physically-based one-dimensional mass and energy balance, have been successfully used for describing spatial variability in properties (Luce and Tarboton, 2001). However, most studies have focused on snowmelt modelling in mountainous, high altitude areas with usually deep snow packs (e.g. Blöschl et al., 1991; Cline et al., 1998; Hiemstra et al., 2006; Bernhardt et al., 2010; Zwaaftink et al., 2011) and forested areas (Lundberg et al., 2016). Little research has been done on modelling shallow snow pack processes with high spatial and time resolution for agricultural areas. These areas are often neglected due to the focus of most studies on water recharge (for hydropower and drinking water) by snow and ice (Lundberg et al., 2016). The effect of snow packs on freeze-thaw and water transport in agricultural soils has received great attention (e.g. Parkin et al., 2013, Flerchinger, 2000), however most of these studies were conducted at point scale. Some studies have investigated distributed soil erosion induced by snowmelt in agricultural areas, but have either focused on a single snowmelt event (Weigert and Schmidt, 2005; Ollesch et al., 2005; Ollesch et al., 2006) or could not produce satisfactory results for the whole winter period due to lack of incorporation of snow pack development in the model (Grønsten and Lundekvam, 2006).

The need to better mitigate soil erosion and peak discharge during winter and spring from agricultural areas requires a better understanding of the temporal and spatial changes of shallow snow packs and that spatial distributed snow models can simulate these changes, to provide continuous datasets, e.g. for soil erosion models. Therefore, the aims of this study were to 1) quantify and visualise the temporal and spatial changes of shallow snow packs (during three winter periods) on arable land; and 2) test a spatially distributed snow model on observed snow cover patterns. For this aim the UEBGrid model (Sen Gupta and Tarboton, 2013) was applied. 


\subsection{Materials and methods}

\subsubsection{Study area and weather data}

The study area, Gryteland (Fig. 4.1), is located in the Ski municipality, approximately $30 \mathrm{~km}$ south of Oslo, Norway. The catchment covers an area of $0.29 \mathrm{~km}^{2}$ (106-140 m a.s.I.). In this area, snow cover processes have been monitored since 2008 , with the main focus on arable land. A monitoring station was installed at the outlet of the sub-catchment in 2008 (Kramer and Stolte, 2009). This station measures precipitation, runoff and the suspended solids content by means of automated sampling. The catchment is characterised by undulating landscape (altitude: $106-141 \mathrm{~m}$, slope $2-10 \%$ ) covered by approx. $60 \%$ arable land and $40 \%$ coniferous forest. All aspects are represented except east-facing slopes.

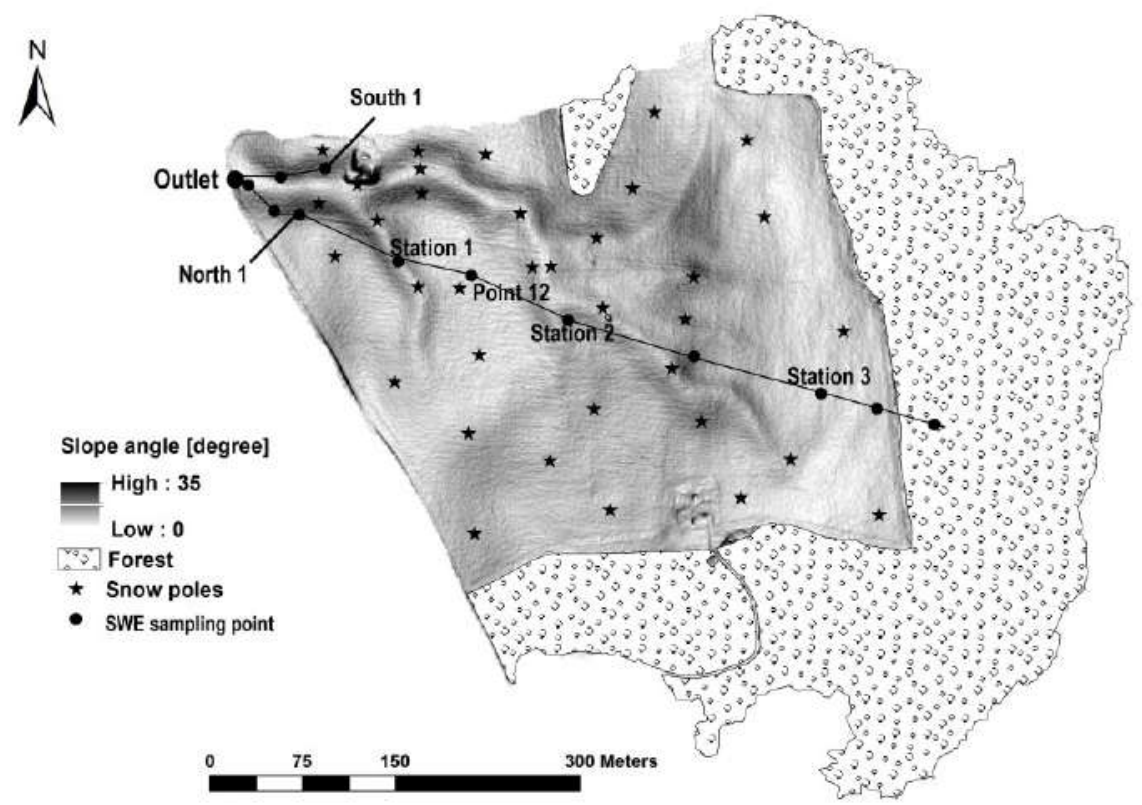

Fig. 4.1: Slope map for the arable land of the Gryteland catchment, showing the locations of the snow poles and the SWE sampling point transect. The six SWE sampling points used for the calibration of the model are named in the map.

Mean annual temperature is $5.3^{\circ} \mathrm{C}$, with minimum average daily temperatures of $-4.8^{\circ} \mathrm{C}$ in January/ February and maximum average daily temperatures of $16.1^{\circ} \mathrm{C}$ in July. Mean annual precipitation is $785 \mathrm{~mm}$, with a minimum monthly amount of $35 \mathrm{~mm}$ in February and a 
maximum of $100 \mathrm{~mm}$ in October (Thue-Hansen and Grimenes, 2015). Winter is usually relatively unstable, with alternating periods of freezing and thawing and several snowmelt events (Kværn $\varnothing$ and $\varnothing$ ygarden, 2006). Snow data have been collected in the area since 2009 and show maximum snow depth of around 55-60 cm in the years 2009-2011 (Stolte and Kværnø, 2013).

As input for modelling and for understanding the snow accumulation and melting processes, detailed measured weather data were necessary. A weather station (106 m a.s.l) was installed in the catchment at the end of 2013, providing data for the winters 2014 and 2015. Data from a station (96 m a.s.l.) $6 \mathrm{~km}$ from the catchment was used for winter 2013 (ThueHansen and Grimenes, 2015).

\subsubsection{Field measurements}

During the three winters, SWE was sampled after weather changes expected to result in changes in SWE. Three to five samples were collected at each measuring point, depending on the snow depth. These samples were combined to measure the mass of the snow and to calculate its density (average mass divided by average snow volume). SWE was calculated by dividing the product of average snow density and average depth of the snow pack by the density of water $\left(1000 \mathrm{~kg} \mathrm{~m}^{-3}\right)$. The samples were taken along transects that covered all aspects and slopes angles occurring in the catchment (Fig. 4.1). To get a better understanding of the spatial development of the snow cover, snow poles (Fig. 1) marked with a measuring scale were installed for winter 2015. These poles allowed snow depth to be measured from a distance by reading the value on the poles with a spyglass, keeping the disturbance of the snow pack to a minimum. Due to the strong correlation of snow depth to SWE, it has been recommended to substitute the time consuming SWE measurements with snow depth measurements (Jonas et al., 2009).

On each measuring occasion, the SWE at each pole was estimated by multiplying the measured snow depth (at the pole) by the average snow density measured along the snow sampling transect. These spatially distributed pole measurements were then compared with the SWE maps produced by the model. In addition, aerial pictures were taken with a drone to visualise snow patterns in the catchment. 


\subsubsection{UEBGrid}

In southern Norway the point version of the Utah Energy Balance snow model (UEB) (Tarboton and Luce, 1996; You, 2004; Luce and Tarboton, 2010; Mahat and Tarboton, 2012; Mahat et al., 2013) has been used successfully (Kramer and Stolte, 2009). To extend its application in this area for spatial distributed modelling, the grid version of UEB (UEBGrid) (Sen Gupta and Tarboton, 2013; Brown et al., 2014; Sen Gupta and Tarboton, 2016) was used in this study. It models the snow pack as a single layer to avoid over-parameterisation (Sen Gupta and Tarboton, 2013). The snow pack is characterized by state variables, SWE, energy content $\left(E_{s}\right)$ and the age of the snow, which is only used for albedo calculations. $E_{s}$ is defined as the energy content of the snow pack plus a top layer of soil with depth (i.e. thermal active depth of the soil $\left.\left(D_{e}\right)\right)$. Soil temperature measurements at different depths in the catchment showed that major fluctuations usually happened between 10 and $40 \mathrm{~cm}$ depth (depending on the winter). Therefore, $D_{e}$, which interacts with the snow was initially set to $10 \mathrm{~cm}$ (Table 4.1). Es represents energy content including this soil depth. High frequency oscillating ground heat fluxes above $D_{e}$ are absorbed into $E_{s}$. This procedure provides a simple approximation of the effects of frozen and unfrozen ground on the snow pack.

$E_{s}$ of the snow pack is determined by incoming longwave radiation, advected heat from precipitation, ground heat flux, sensible heat flux, latent heat flux due to sublimation/condensation, advected heat removed by meltwater and outgoing longwave radiation. The change in SWE depends on the rainfall rate $\left(P_{r}\right)$, snow fall rate $\left(P_{s}\right)$, meltwater outflow $(M r)$ and sublimation from the snow pack (E) (Eq. 4.1).

$S W E / t=P_{r}+P_{s}-M_{r}-E$

$P_{s}$ is determined according to Equations 4.2.

$P_{s}=\left(P-P_{r}\right) * d f$

where: $P_{s}=$ precipitation falling in the form of snow $\left[\mathrm{m} \mathrm{h}^{-1}\right] ; P=$ total (measured) precipitation $\left[\mathrm{m} \mathrm{h}^{-1}\right] ; P_{r}=$ precipitation falling in the form of rain $\left[\mathrm{m} \mathrm{h}^{-1}\right] ; d f=$ drift factor $[-]$

In Equation 4.2, the amount of $P_{r}$ is determined by the threshold temperatures for which all precipitation is rain $\left(T_{r}\right)$ or snow $\left(T_{s}\right)$. According to the following relations (3) precipitation is partitioned based on the measured air temperature $(T)$. 
$P_{r}=P$

if $T \geq T_{r}$

$P_{r}=P^{*}\left(\left(T-T_{s}\right) /\left(T_{r}-T_{s}\right)\right) \quad$ if $T_{s} \leq T<T_{r}$

$P_{r}=0$

if $T \leq T_{s}$

To initiate snowmelt in UEBGrid the temperature of the snow pack $\left(T_{a}\right)$ has to reach $0{ }^{\circ} \mathrm{C}$. By using $E_{s}$ as a state variable the model does not explicitly predict the temperature of the snow pack. $T_{a}$ is therefore obtained from the following equations (Eq. 4.4, 4.5 and 4.6).

If $E_{s}<0$

$T_{a}=E_{s} /\left(p_{w} * S W E * C_{s}+p_{g} * D_{e}^{*} C_{g}\right)$ All solid phase

If $0<E_{S}<p_{w} * S W E * h_{f} \quad T_{a}=0{ }^{\circ} \mathrm{C}$ Solid and liquid mixture

If $E_{s}>p_{w} * S W E * h_{f}$

$T_{a}=\left(E_{s}-p_{w} * S W E * h_{f}\right) /\left(p_{g} * D_{e}^{*} C_{g}+p_{w} * S W E * C_{w}\right)$ All

liquid

where: $p_{w}=$ density of water $\left[1000 \mathrm{~kg} \mathrm{~m}^{-3}\right] ; \quad C=$ specific heat of ice $\left[2.09 \mathrm{~kJ} \mathrm{~kg}^{-1}{ }^{\circ} \mathrm{C}^{-1}\right] ; p_{g}=$ soil density $\left[\mathrm{kg} \mathrm{m}^{-3}\right] ; C_{g}=$ specific heat of soil $\left[1.4 \mathrm{~kJ} \mathrm{~kg}^{-1}{ }^{\circ} \mathrm{C}^{-1}\right] ; h_{f}=$ heat of fusion $\left[333.5 \mathrm{~kJ} \mathrm{~kg}^{-}\right.$ $\left.{ }^{1}\right] ; C_{w}=$ specific heat of water $\left[4.18 \mathrm{~kJ} \mathrm{~kg}^{-1}{ }^{\circ} \mathrm{C}^{-1}\right]$

According to these equations, $E_{s}$ determines the liquid content of the snow pack. Together with Darcy's law for flow through porous media $M_{r}$ is determined (Eq. 4.7).

$M_{r}=K_{s a t} * S^{3}$

where: $K_{\text {sat }}=$ snow saturated hydraulic conductivity $\left[\mathrm{m} \mathrm{h}^{-1}\right] ; S=$ relative saturation in excess of water retained by capillary forces [-]

The model is driven by input of air temperature, precipitation, wind speed, humidity and solar radiation at time steps sufficient to resolve the diurnal cycle (six hours or less). Sen Gupta and Tarboton (2013) reorganised the input-output workflow of UEB to use network Common Data Form map files (netCDF) to allow the model to be run over a grid with input varying in space and time, resulting in the UEBGrid model used in this study. The model runs separately at each grid cell and the melt outputs are accumulated for predefined subwatersheds.

Measured weather data (precipitation, wind speed, solar radiation, air temperature, humidity) at hourly time intervals were used here as input for the model (Figs. 4.2 and 4.3). For the different years the monthly Bristow-Campbell B parameter was given as an input (Table 4.1) for the model to calculate atmospheric transmissivity. Required maps for watershed delineation (Fig. 4.1), slope and aspect were derived in ArcMap 10.2.2 from a digital elevation model (DEM), created from light detection and ranging data (LIDAR) (Starkloff and Stolte, 2014 (Chapter 2)). The calculations for the agricultural area were done 
with a raster resolution of $5 \mathrm{~m} \times 5 \mathrm{~m}$. The forest was not further considered in this study, because in all three winters the snow depth was negligible.

UEBGrid allows definition of grid cells for which detailed output can be produced. In this study, grid cells containing the location of a snow pole or SWE measuring point were selected for output, resulting in a total of 41 points. Six points were chosen for calibration and are discussed in detail in this paper. These six points represent the major characteristics of the catchment, with a north facing slope ('North 1'), a south facing slope ('South 1'), a northwest facing plain ('Point 12'), two depressions ('Station 1' and 'Station 2') and a point influenced by the forest ('Station 3') (Fig. 4.1).

The spatial distributed snow observations of 2015 allowed to evaluate the performance of the model for all locations in the study area. Therefore, the best calibration results for 2015 were spatially and temporal compared with the measured SWE measurements. To statistically evaluate the spatial performance of UEBGrid for 2015 the Nash-Sutcliffe model efficiency coefficient (NSE) was calculated for each measuring occasion.

For calibrating the model the user guide of UEBGrid (Tarboton and Luce, 1996) suggests adjusting the parameters surface aerodynamic roughness height $\left(z_{0}\right)$, surface head conductance $\left(K_{s}\right), K_{\text {sat }}$ and new snow visible band reflectance $\left(a_{v o}\right)$. A previous study carried out using the point version of UEB for the same area as used in this study (Kramer and Stolte, 2009) showed that the parameters $K_{s}$ and $a_{v o}$ had no significant effect on the modelling results and suggested that correction of the threshold temperatures $T_{r}$ and $T_{s}$ might be necessary. In a later study Tarboton et al. (2000) suggested to adjust the drift factor ( $d f$ ) to better account for snow transport by wind. Additionally, due to the importance of the thermal interaction of shallow snow packs with the underlying soils (Norum et al., 1975) the parameter $D_{e}$ was chosen as a calibration parameter. Considering this, the parameters $K_{\text {sat }}$, $z_{0}, d f, T_{r}, T_{s}$, and $D_{e}$ were used for calibrating the model. The initial input parameters used for this study are presented in Table 4.1. 
Table 4.1: Input parameters used for the three simulations (winter 2013, 2014, 2015)

\begin{tabular}{|c|c|c|c|c|}
\hline Parameter & $\begin{array}{l}\text { Same for all three } \\
\text { simulations }\end{array}$ & 2013 & 2014 & 2015 \\
\hline $\operatorname{Tr}\left[{ }^{\circ} \mathrm{C}\right]$ & 3 & & & \\
\hline$T_{s}\left[{ }^{\circ} \mathrm{C}\right]$ & -1 & & & \\
\hline$z_{0}[\mathrm{~m}]$ & 0.01 & & & \\
\hline$d f[-]$ & 1 & & & \\
\hline$K_{\text {sat }}\left[\mathrm{m} \mathrm{h}^{-1}\right]$ & 20 & & & \\
\hline Liquid holding capacity of snow $\left(L_{h}\right)[-]$ & 0.05 & & & \\
\hline Average atmospheric pressure [Pa] & 101325 & & & \\
\hline Canopy coverage fraction map values [-] & 0 & & & \\
\hline Canopy height map value $[\mathrm{m}]$ & 0 & & & \\
\hline Subtype map value [-] & Ground $(0)$ & & & \\
\hline$D_{e}[\mathrm{~m}]$ & 0.1 & & & \\
\hline Bristow-Campbell B parameter for January $\left[{ }^{\circ} \mathrm{C}\right]$ & & 5.8 & 3.1 & 5.0 \\
\hline Bristow-Campbell B parameter for February $\left[{ }^{\circ} \mathrm{C}\right]$ & & 7.1 & 3.1 & 4.9 \\
\hline Bristow-Campbell B parameter for March $\left[{ }^{\circ} \mathrm{C}\right]$ & & 10.9 & - & - \\
\hline Bristow-Campbell B parameter for April $\left[{ }^{\circ} \mathrm{C}\right]$ & & 9.2 & - & - \\
\hline Longitude [degrees] & 10.84 & & & \\
\hline Latitude [degrees] & 59.67 & & & \\
\hline
\end{tabular}

The parameter $z_{0}$ gives the height below which the wind speed is zero in the logarithmic wind profile layer of the model. It effects the calculation of the heat conductance $\left(K_{h}\right)$ between snow surface and air (Eq. 4.8) and the vapour conductance $\left(K_{e}\right)$ at the snow surface (Eq. 4.9).

$K_{h}=k^{2} * V / \ln \left(z / z_{0}\right)^{2}$

where: $k=$ von Kármán's constant $[0.4] ; V=$ wind speed $\left[\mathrm{m} \mathrm{s}^{-1}\right] ; z=$ measuring height of wind speed [m]

$K_{e}=k^{2} * V / \ln \left(z / z_{0}\right)^{2}$

The $d f$ parameter is used in the model to assign different cells a multiplication factor (Eq. 4.2) to account for spatially differences in SWE due to snow drift by wind. 


\subsection{Results and discussion}

\subsubsection{Weather data}

Measured air temperature, precipitation and wind speed and direction are presented in Figs. 4.2 and 4.3, respectively. Solar radiation and relative humidity are not presented, because no significant difference was observed between the years, which means that differences in snow cover properties were not caused by these factors.

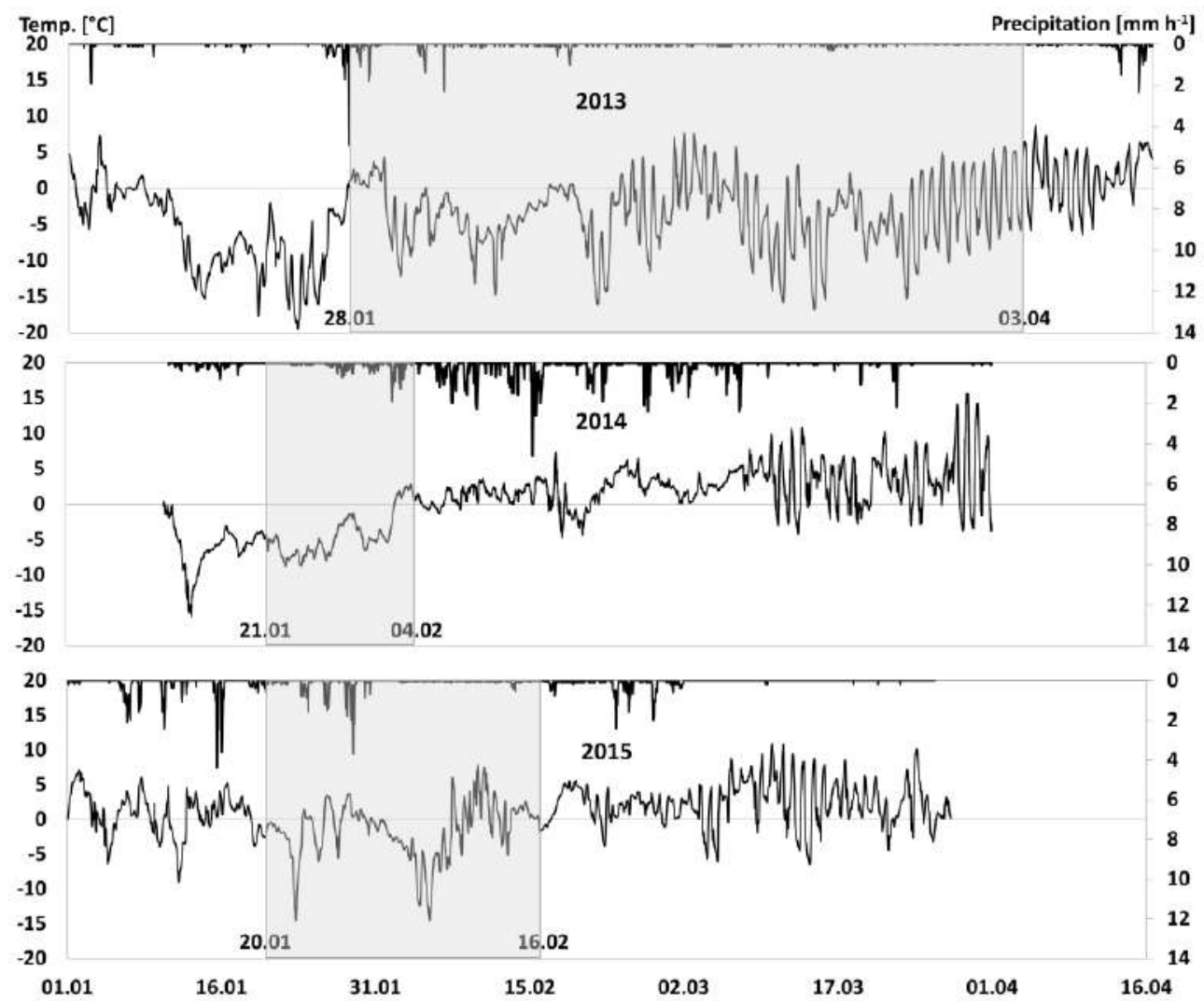

Fig. 4.2: Measured air temperature and precipitation in winter 2013, 2014 and 2015. The grey rectangles, with start and end dates, indicate the periods with measurable snow cover.

As can be seen in Fig. 4.2, the periods with measurable snow cover had different durations in different years. 
Wind speed and wind direction are important factors for the distribution and shape of snow packs, especially during snowfall and immediately after deposition. Wind speeds of about 3 $\mathrm{m} \mathrm{s}^{-1}$ can already redistribute light and dry snow crystals (Gray and Male, 1981). In Fig. 4.3 measured wind speed together with measured precipitation for the snow measuring periods in the three winters are presented. As can be seen occurred the highest (hourly average; $8 \mathrm{~m} \mathrm{~s}^{-1}$ ) measured wind speed in winter 2015, possibly resulting in the redistribution and densification of deposited snow. Furthermore, during the main snow fall episodes in 2015 the wind speeds exceeded $4 \mathrm{~m} \mathrm{~s}^{-1}$, reaching 5-6 $\mathrm{m} \mathrm{s}^{-1}$. In comparison during the winters 2013 and 2014 wind speeds reached only $3.5 \mathrm{~m} \mathrm{~s}^{-1}$ during snowfall.
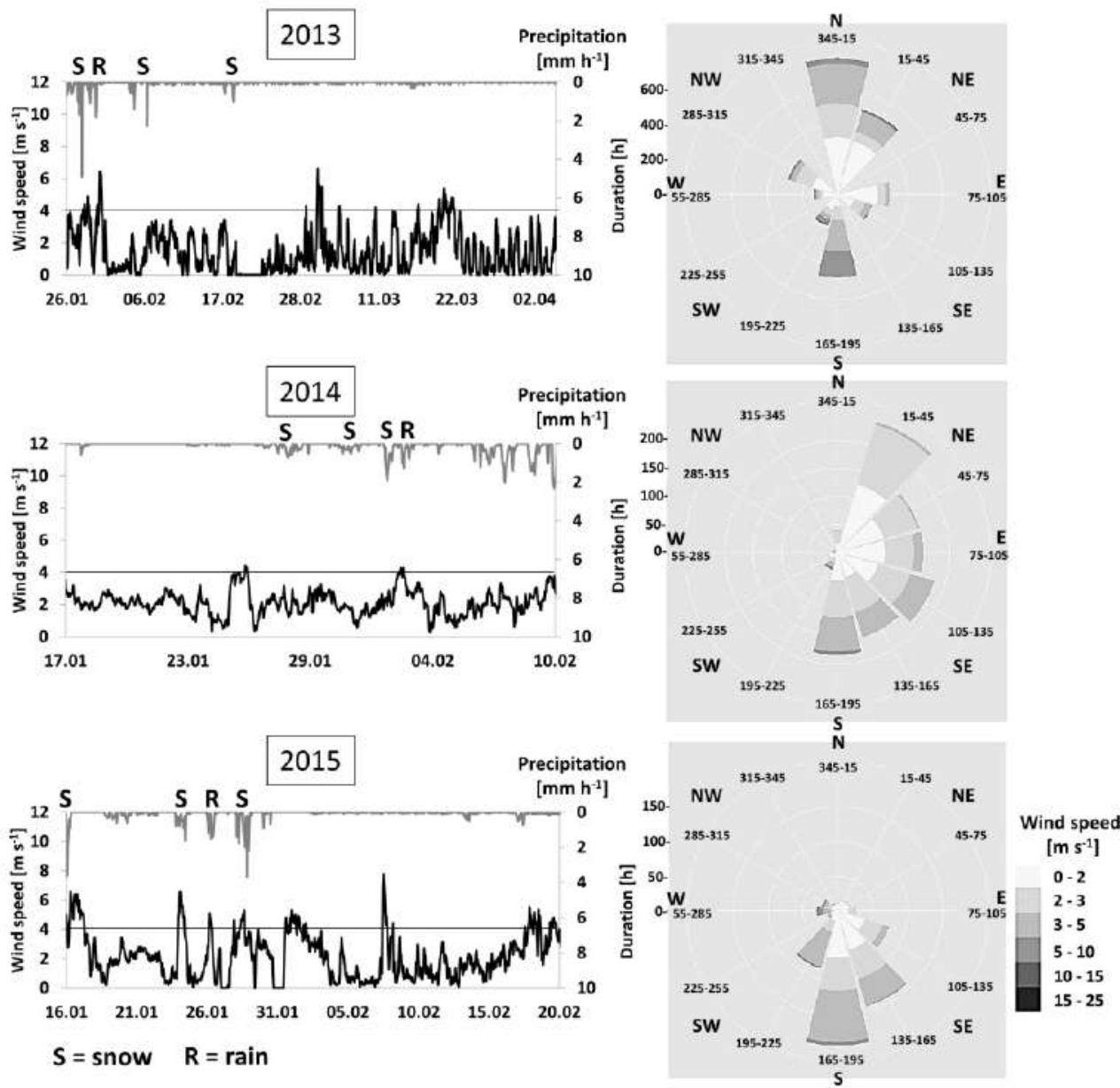

Fig. 4.3: Diagrams of measured wind speed and precipitation per hour, with marked precipitation as snow $(S)$ and rain (R) and wind roses of wind speed and direction in winter 2013, 2014 and 2015. The radial durations are in hours with the wind speeds $\left[\mathrm{m} \mathrm{s}^{-1}\right]$ in each cardinal direction covering 30 degrees. For illustration purposes a horizontal line, marking wind speeds of $4 \mathrm{~m} \mathrm{~s}^{-1}$ was included in the diagrams. 
These measurements confirmed the observations in the field that wind strongly shaped the snow pack in winter 2015, which had to be considered in the modelling.

\subsubsection{Field measurements}

Measured snow depth and SWE for the three winter periods are presented in Fig. 4.4, which shows results from the six locations used for model calibration and validation.
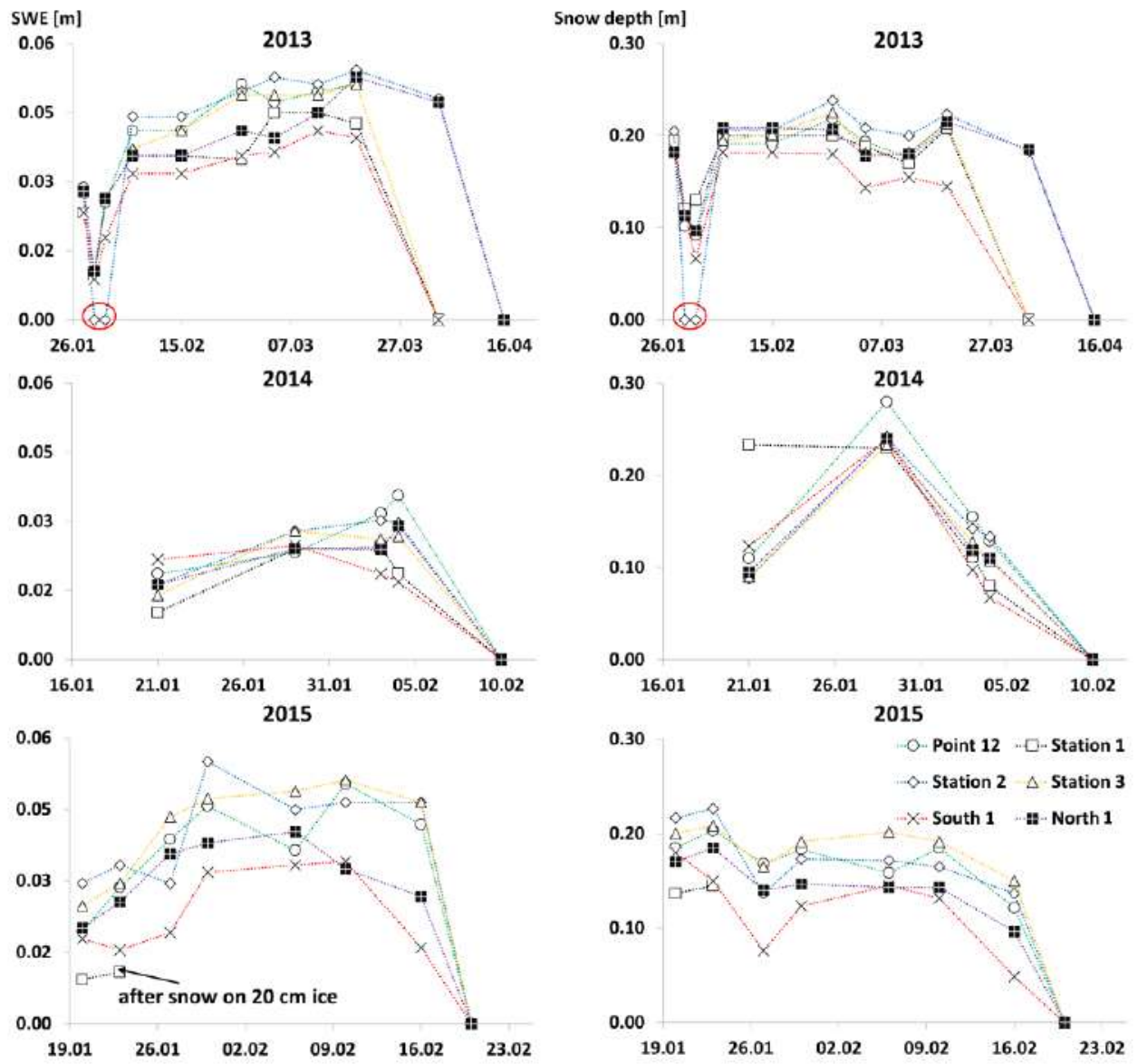

Fig.4.4: Measured snow water equivalent (SWE) and snow depth at the same six locations in winter 2013, 2014 and 2015. Red circle mark measurements at Station 2, which were set to zero because running meltwater on snow and ice made correct measuring impossible. The last measuring points for 2014 and 2015 show the dates when snow had disappear at all measuring location. However some location were snow free earlier, but no exact dates could be given due to rapid melting. 
The smallest snow depths and SWEs measured at Station 2 in 2013 were set to zero because running meltwater on snow and ice made it impossible to measure during these dates (Fig. 4.4). The measurements at Station 1 after the second measuring occasion in winter 2015 were not representative because of a thick $(10-20 \mathrm{~cm})$ ice layer on top of the soil, that established after snowmelt followed by refreezing. Any SWE or snow depth measurements carried out at this location afterwards represent measurements on top of this ice layer until the end of winter.

The development of snow depth and SWE differed between the three winters (Fig. 4.4). In winter 2013, there was an early decrease in snow depth and SWE due to a melting event at the end of January (Fig. 4.2), followed by a sudden increase in snow depth and SWE, and a constant snow depth and slow increase of SWE over time until the spring melt. In total, 10 measuring occasions were possible in 2013.

The short winter of 2014 resulted in only four measuring occasions (Note: the unusually high first snow depth value at Station 1, might be a measuring mistake). While the snow depth decreased already after the second measuring occasion, SWE continued to increase until all snow melted rapidly after the fourth measuring occasion. An increase in SWE followed by rapid snowmelt is typical behaviour of snow pack before each melting episode (Gray and Male, 1981). As the snow depth decreases, the snow density increases due to retention of water (meltwater, often supplied by rain) in the snow pack, until the snow pack reaches a point where it is saturated with water (generally $3-5 \%$ water by weight) and the internal temperature of the pack reaches $0{ }^{\circ} \mathrm{C}$ (Gray and Male, 1981). When the snow pack has reached this point, i.e. when it is 'ripe', then all additional water is quickly released and the snow pack collapses. In 2014 no major precipitation events (Fig. 4.2) occurred before all the snow was gone. The air temperature (Fig. 4.2) stayed below $0{ }^{\circ} \mathrm{C}$ for almost the whole period with snow, until melting started (measuring occasions 3 and 4).

During winter 2015, snow cover was established for a longer period than in 2014, resulting in seven measuring occasions. Similar to winter 2013, winter 2015 was more complex than winter 2014 with an extensive melting event before sampling was started, followed by an increase in snow depth and SWE and an additional snowmelt event on 24-26 January. Meltwater which had accumulated in the depression froze during the following cold period beginning on the 26 January resulted in thick ice layers in the depressions (Fig. 4.5)

Fig. 4.5 shows an image of the arable part of the study area patched together from aerial pictures taken at the end of the melting period in 2015. In large parts of the area, all the snow had melted except in the south. 


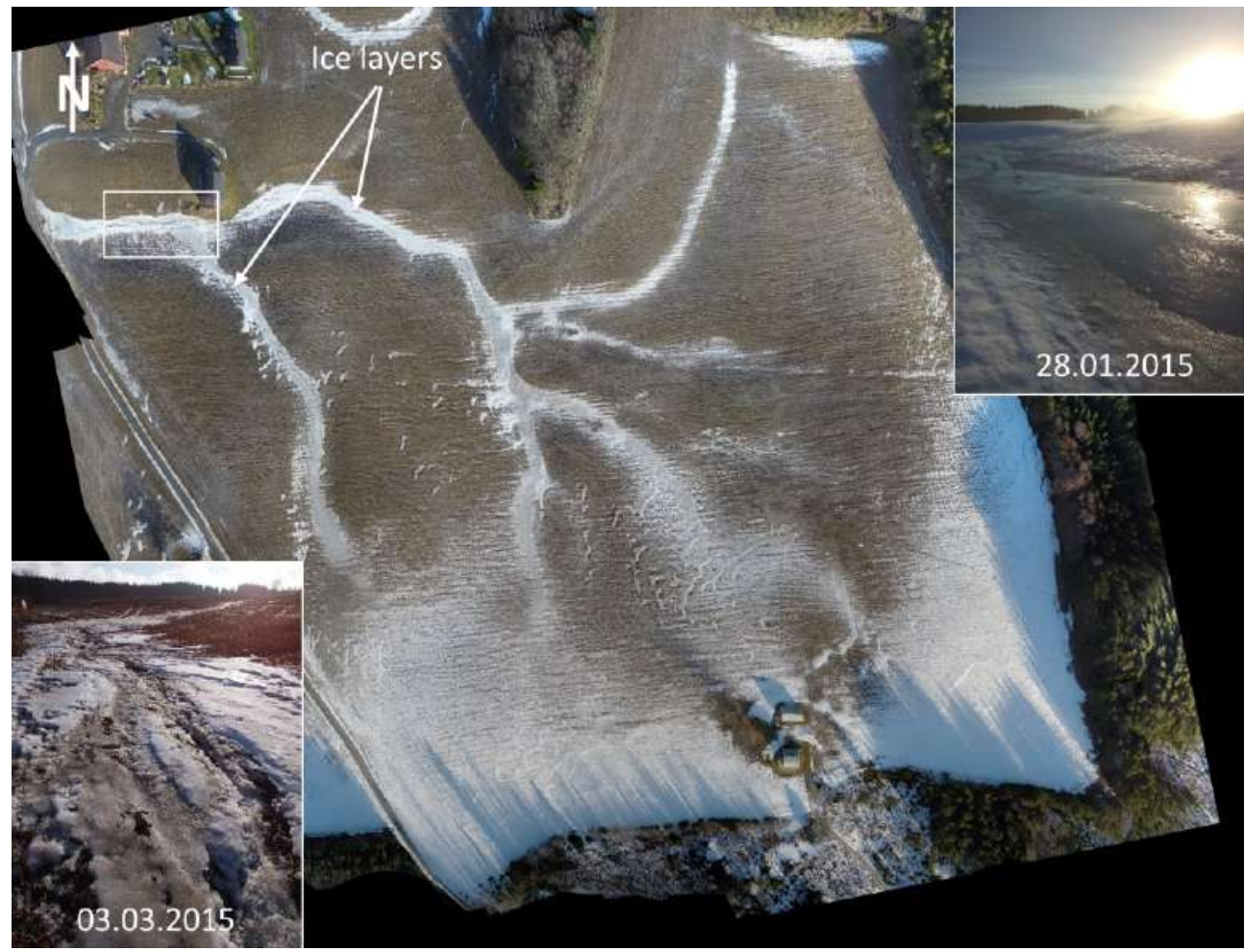

Fig. 4.5: Aerial picture of snowmelt pattern in the study area, 20 February 2015. The white rectangle shows the area covered by the small photos of ice layers, taken 28 January and 03 March 2015.

The aerial images (Fig. 4.5) visualised spatial patterns of the snow cover. From these patterns, it was possible to obtain information about the processes determining the distribution of snow at catchment scale. Examples are: (1) ice development due to refreezing of accumulated meltwater in depressions, which were the main pathways for surface runoff; (2) the closed snow cover in the southern parts of the catchment, on arable land, showing the shadowing effect of the forest against solar radiation and deposition of snow along the forest edge due to reduced wind speeds.

\subsubsection{Modelling}

The modelling results for winter 2013 are presented in Fig. 4.6. Changing the parameters, $d f, I h, K_{s a t}, T_{r}$ and $T_{s}$ did not improve the modelling results. The best possible fit was achieved with a slight change of $z o$ from 0.01 to $0.006 \mathrm{~m}$ and the adjustment of $D_{e}$ to $0.3 \mathrm{~m}$ (Fig 4.6, black line). 


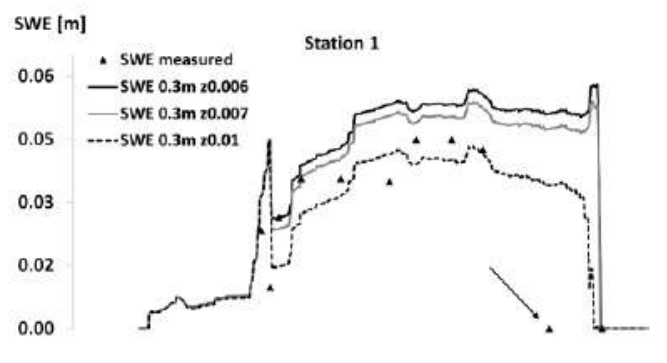

Point 12

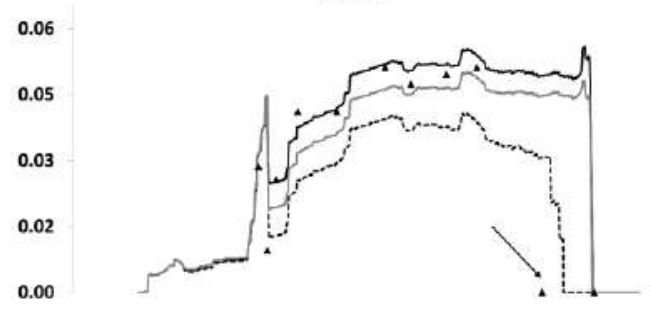

Station 2

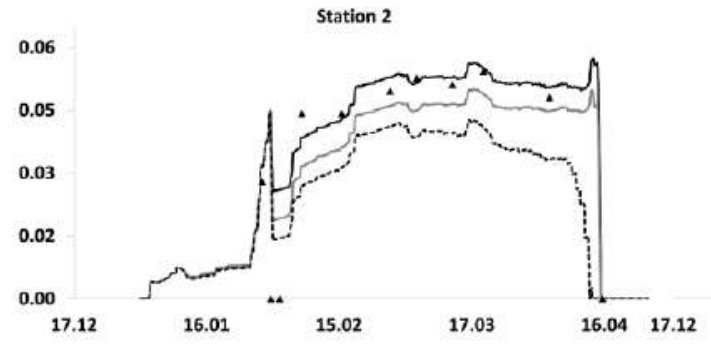

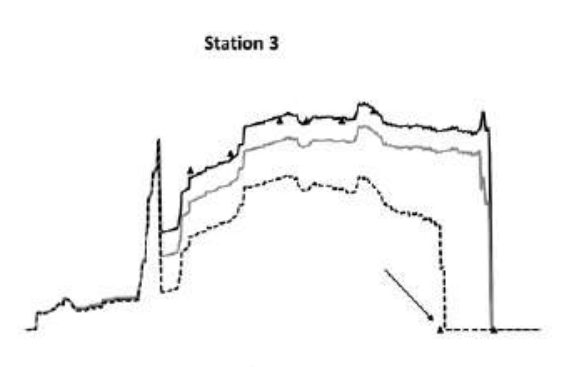

South 1
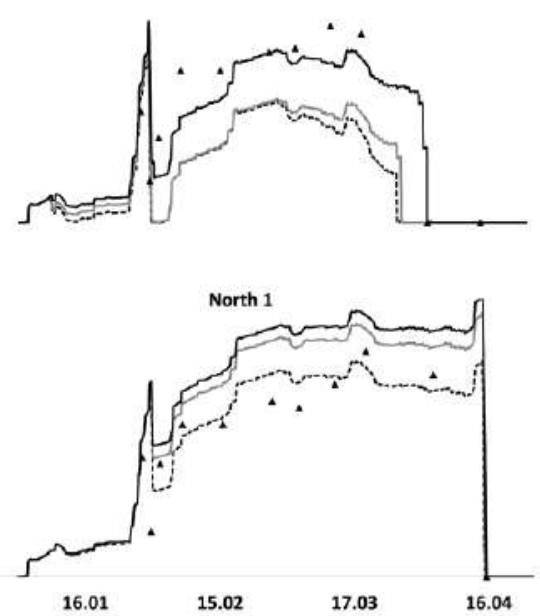

Fig. 4.6: Measured and modelled snow water equivalent (SWE) for winter 2013. The arrows mark false zero measurements (3 April), as discussed in the text. Lines 'SWE $0.3 \mathrm{mz0.006',} \mathrm{'-z0.007'} \mathrm{and} \mathrm{'-z0.01'} \mathrm{present} \mathrm{result}$ of model runs with different values for $z_{0}$.

However, it should be noted that similar fits were achieved with setting the parameters $\mathrm{Ih}$, $T_{s}$ and $T_{r}$ to values of $0.8,3$ and $3.8^{\circ} \mathrm{C}$ respectively. Snow fall at temperatures around $3{ }^{\circ} \mathrm{C}$ have been observed in the study area, however setting $T_{s}$ to $3^{\circ} \mathrm{C}$ alone did not change the modelling results and the highest measured $I h$ in soaked snow cannot greatly exceed 0.15 (Kinar and Pomeroy, 2015).

That the adjustment of $D_{e}$ was necessary to achieve better modelling results for 2013, indicated that the interaction of the snow pack with the underlying soil was a major process occurring in winter 2013. Observations carried out during winter 2013 supported this assumption. Winter 2013 was characterized by a major melting event during the measuring period (between 30 January and 6 February) (Fig. 4.2). During this event an (approx. $10 \mathrm{~cm}$ thick) ice layer, which had developed earlier in January on the soils prevented infiltration of meltwater (image 3 in Fig. 4.7), resulting in high water contents in the bottom layer of the 
snow pack. During snow sampling on 30 January it was observed that a slight disturbance of the snow resulted in a total collapse of the lower $5 \mathrm{~cm}$ of snow into water (Fig. 4.7). $D_{e}$ directly influences $T_{a}$ of the snow pack in UEBGrid, as can be seen from Equations 4.4 and 4.6. An increasing of $D_{e}$ results in a decrease of $T_{a}$ and therefore in a reduction of the liquid content of the snow pack and a slowdown of melting.

A slight over prediction for the North 1 and Station 1 locations can be seen, but not exceeding $2 \mathrm{~cm}$ difference between measured and modelled SWE. For these location the initial zovalue of $0.01 \mathrm{~m}$ resulted in a better fit (Fig. 4.6). The model predicted a longer period of snow cover for Stations 1 and 3 and Point 12 compared with the measured values (Fig. 4.6, arrow markings). However, these measurements require some explanation. As can be seen from Fig. 4.7, there was still snow present on 3 April 2013.
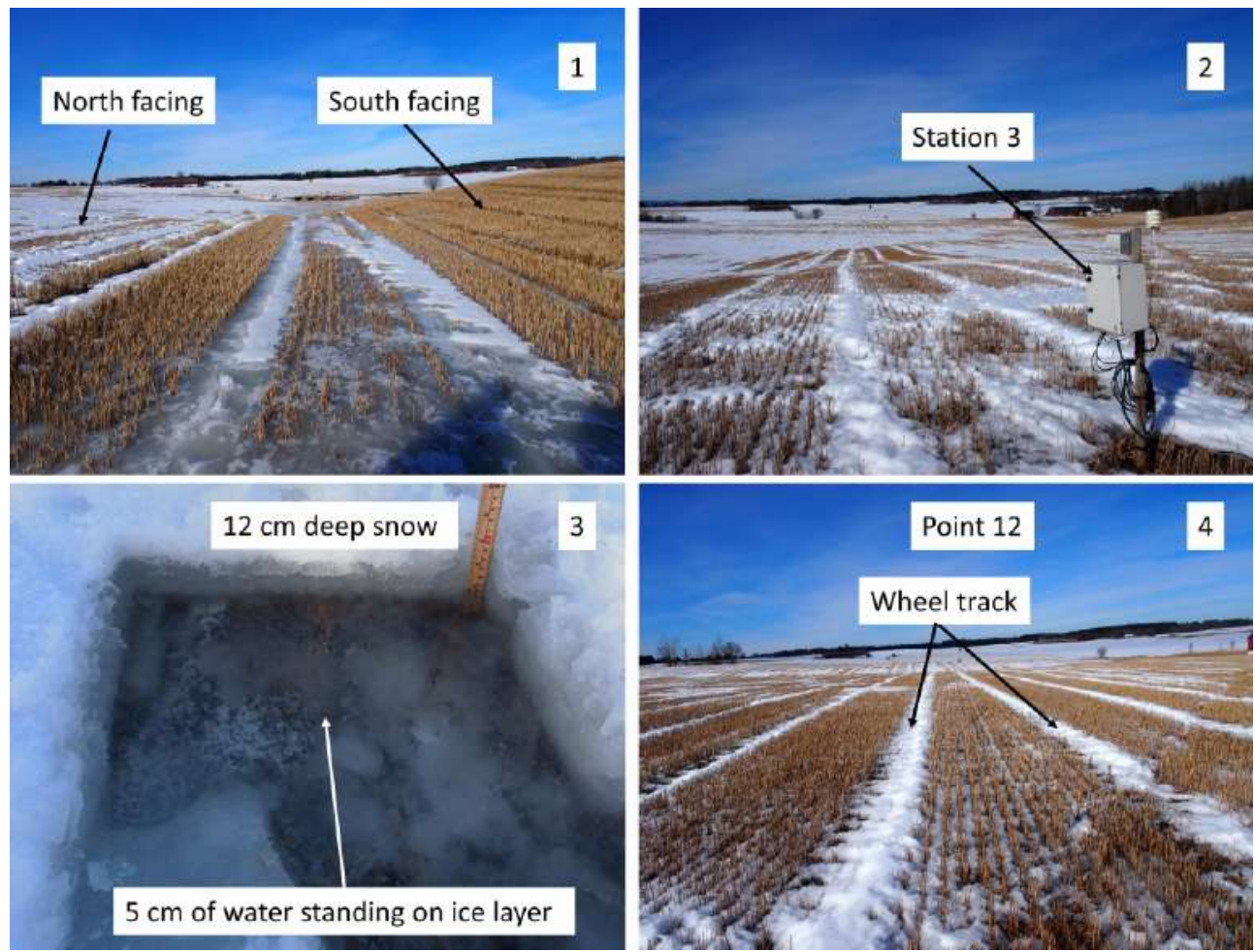

Fig. 4.7: Photos 1, 2 and 4 taken at different measurement points on 3 April 2013. Photo 3 shows water standing on an ice layer on top of the soil during snow sampling on 30 January 2013.

There was no snow on the south facing slopes on 3 April (image 1 in Fig. 4.7), where the model predicted the timing of total exposure correctly. The north facing slopes were still covered with snow (image 1), which the model predicted correctly. At Point 12 (image 4), 
Station 3 (image 2) and Station 1 (not shown), the snow had disappeared in areas where the stubble had broken the snow surface (therefore zero measurements at these locations), but not in the wheel tracks, which had no stubble (images 4 in Fig. 4.7). In comparison, neighbouring areas (not shown) without any plant cover or covered with only poorly developed winter wheat were still completely covered with snow on 9 April. The model was unable to account for the change in albedo and increased heat conductance due to stubble. For bare soil, the model would probably have correctly predicted the timing of total disappearance of snow at all locations. The last measurement points in Fig. 4.6 indicate when all snow had disappeared at all locations ( 3 April at South 1 and 15 April at the other locations), which fits well with the timing predicted by the model.

The modelling results for 2014 are presented in Fig. 4.8. Calibration was done by adjusting $z_{0}$ visually from 0.01 to 0.006 . Increasing $D_{e}$ from 0.1 to $0.3 \mathrm{~m}$, as used for the simulation of winter 2013, did not improve the modelling results.

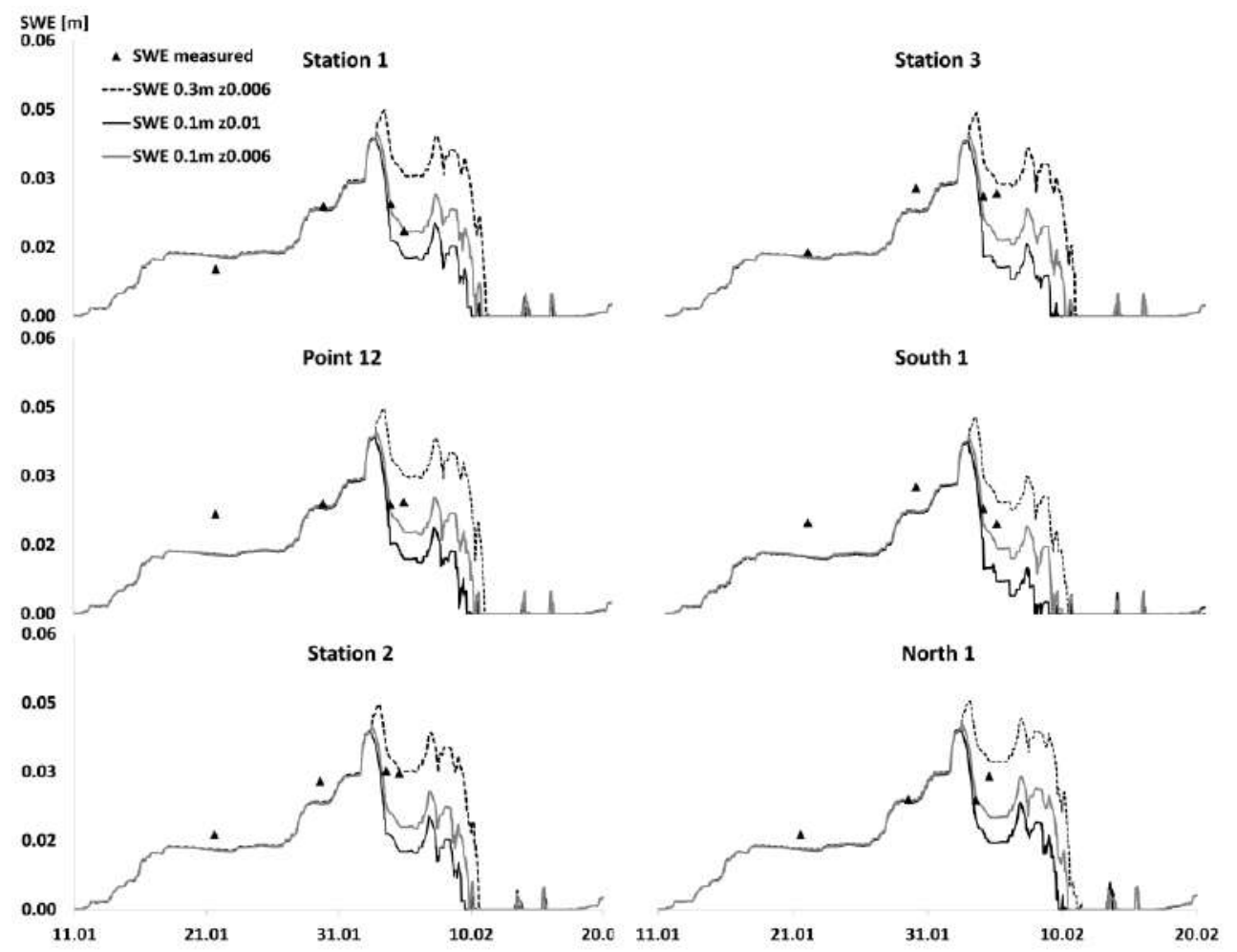

Fig. 4.8: Measured and modelled snow water equivalent (SWE) for winter 2014. Line 'SWE 0.1m z0.01' present the model results with De set to $0.1 \mathrm{~m}$ and $z_{0}$ set to 0.01 and line 'SWE $0.1 \mathrm{~m} \mathrm{z} 0.006$ ' the results with $z_{0}$ set to 0.006 . Line 'SWE $0.3 \mathrm{~m}$ z0.006' presents modelling results with the same input as used for winter 2013. 
However it should be noted that the limited number of measurements in 2014 made detailed evaluation of the model results difficult. But it can be seen that the modelled SWEs had the same magnitude as the measured values and the model simulated the measured increases and decreases in SWE (Fig. 4.8). Winter 2014 was the least complex of the three observed winters, which was also mirrored by the simple calibration necessary.

For winter 2015 no satisfactory fit was achieved with adjusting $D_{e}$ and $z_{0}$ to values used for winter 2013 and 2014 (Fig. 4.9, dotted line). This indicated that other processes which did not occur or had only insignificant effects in 2014 and 2013 needed to be taken into account for the 2015 simulations. That wind played a greater role in winter 2015, compared to the other winters was confirmed by the wind measurements (Fig. 4.3). In addition, during the conducted field measurements it was observed that following interacting processes occurred: (1) different snow patterns due to the redistribution of snow by wind, depending on the terrain (slope, curvature and aspect); (2) the forest acting as an obstacle to wind (reducing wind speeds, causing snow to be deposited along the forest edge); (3) the shading effect of the forest against solar radiation. More snow could accumulate in the southern part of the catchment due to process (2), because the forest edge protected the area against the major wind direction of southwest to southeast in 2015 (Fig. 4.3), contrary to 2014 and 2013 were major wind directions were north to southeast (Fig. 4.3). These interacting processes cannot be directly simulated with UEBGrid or indeed with most available snow models (Essery et al., 2013). However, in UEBGrid the drift factor ( $d f$ ) can be used to account for the effect of process (1) and (2) (Tarboton et al., 2000; Luce and Tarboton, 2001). Accordingly the $d f$ (Fig. 4.8) was calibrated for the six locations (Fig. 4.8). As can be seen were, depending on the location different values for $d f$ necessary to fit the modelled to the measured SWE. 


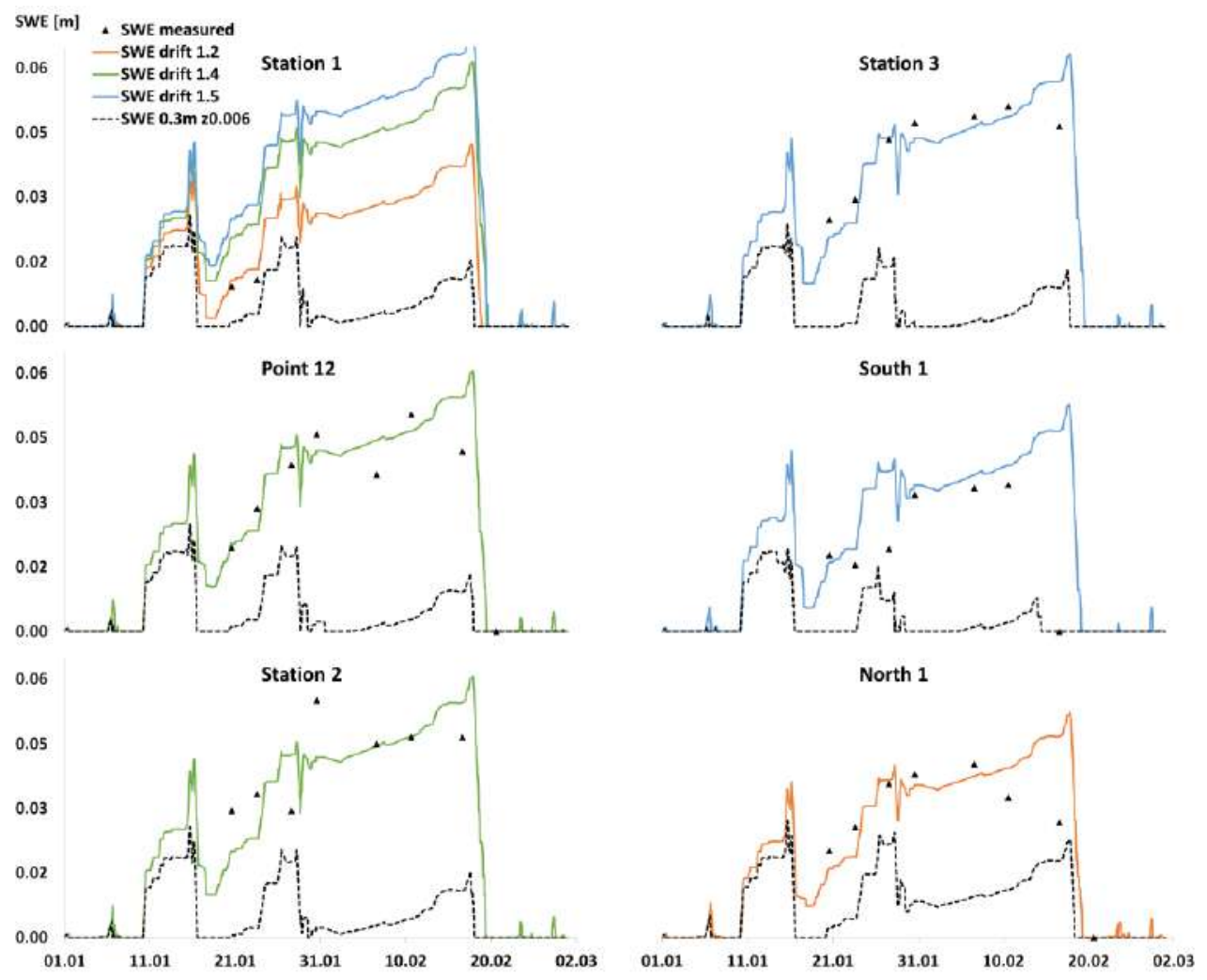

Fig. 4.9: Measured and modelled snow water equivalent (SWE) for winter 2015. Lines 'SWE drift 1.2', '-1.4' and '-1.5' present result of model runs with different values for $\mathrm{df}$. Line 'SWE $0.3 \mathrm{~m}$ z0.006' presents the model run with the same input as used for 2013.

With these adjustments, a satisfactory fit was achieved. However, complete disappearance of snow was two days late for the South 1 location, while for North 1, Station 3 and Point 12 this was one day too early. A slight over prediction occurred at all location, especially after the fifth measuring occasion, with a maximum difference of approx. $0.03 \mathrm{~m}$ for the seventh measuring occasion at the North 1 location.

That the highest $d f$ value (1.5) had to be applied to the areas close to the forest edge (similar to point Station 3) suggested that process (2) played a major role in winter 2015. Also the south facing slopes (similar to point South 1 ) required a value of 1.5 , suggesting increased deposition of snow on these slopes during winter 2015. Based on this calibration, a map with different values for $d f$, depending on the location was created (Fig. 4.10), enabling an evaluation of the model performance for the whole area. Areas with similar characteristics as Point 12 and Station 2 were given a value of 1.4, while north facing slopes with similar characteristics as the points North 1 and Station 1 were given a value of 1.2. 


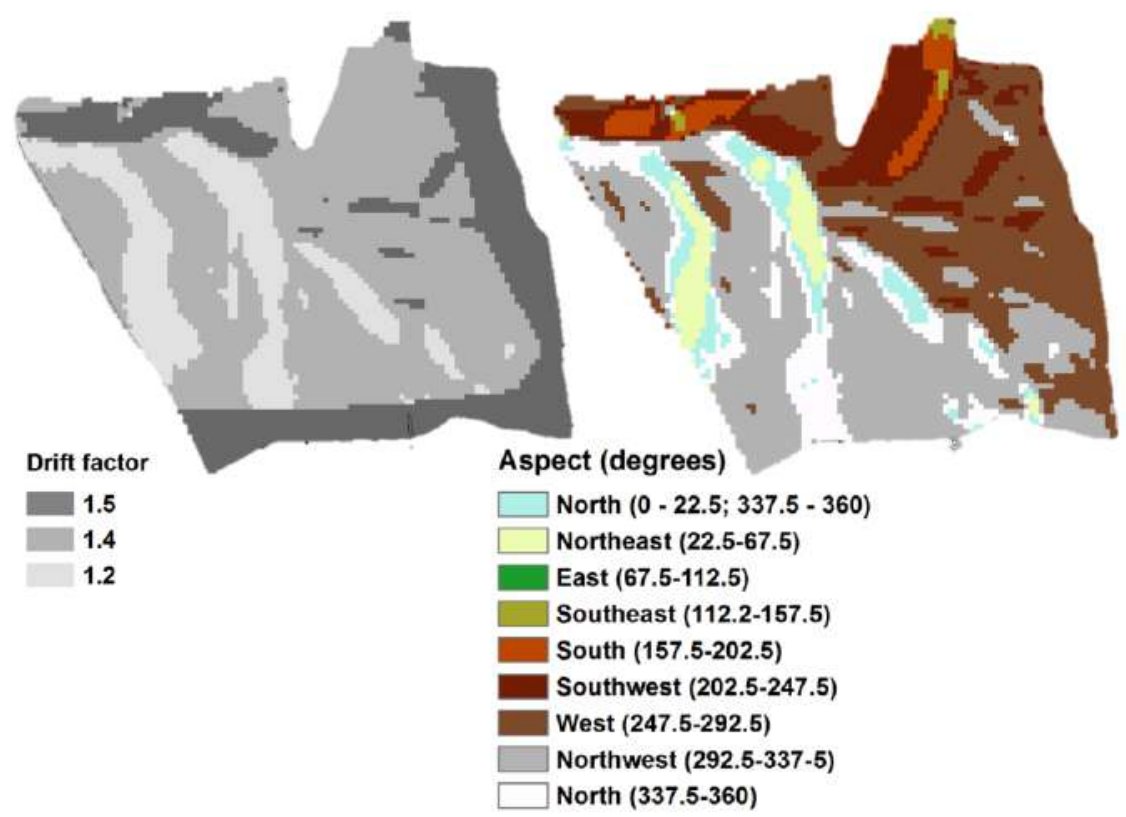

Fig. 4.10: Aspect and drift factor maps used as an input for the 2015 modelling .

Fig. 4.11 shows the modelled SWE maps for the seven measuring occasions in 2015. In addition, for each date the modelled SWE is compared with the measured SWE at the snow pole locations. 


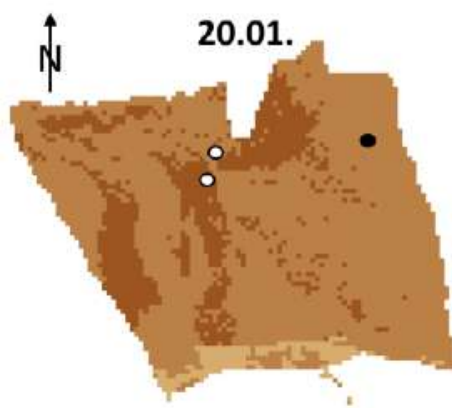

23.01

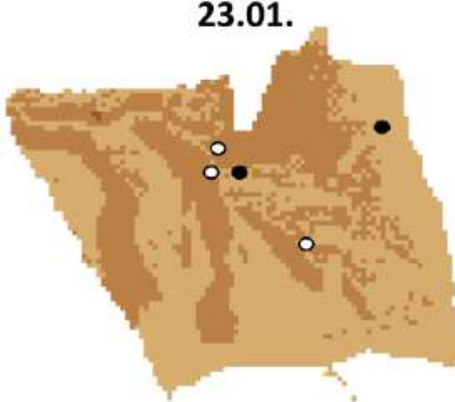

27.01 .

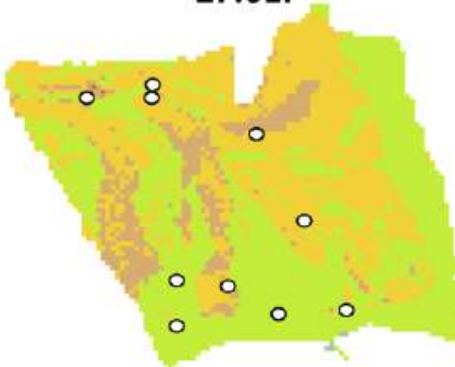

30.01 .

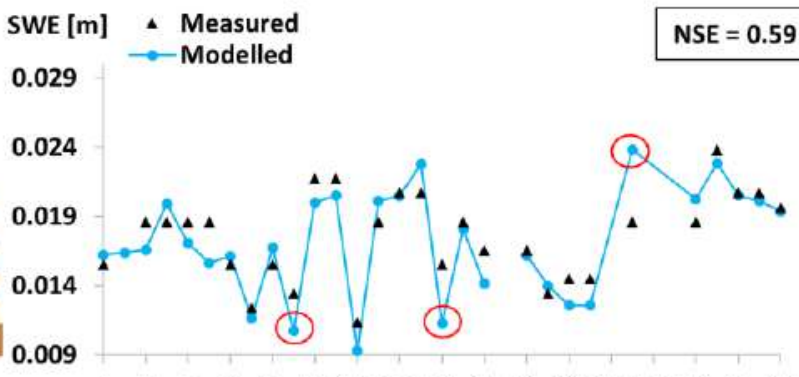

$\begin{array}{lllllllllllllllll}1 & 3 & 5 & 7 & 9 & 11 & 13 & 15 & 17 & 19 & 21 & 23 & 25 & 27 & 29 & 31 & 33\end{array}$

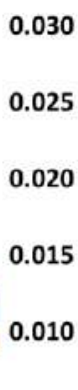

0.030
0.025
0.020
0.015
0.010
1
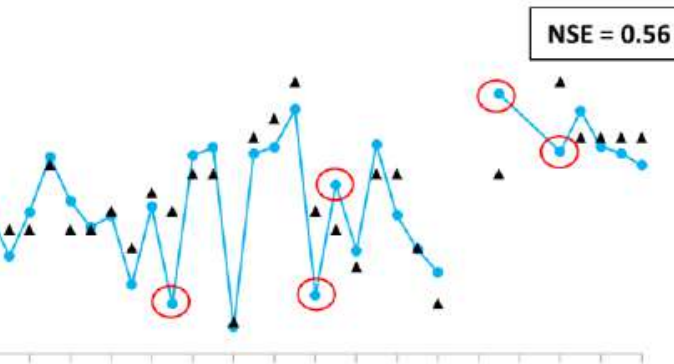

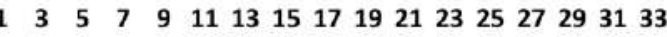
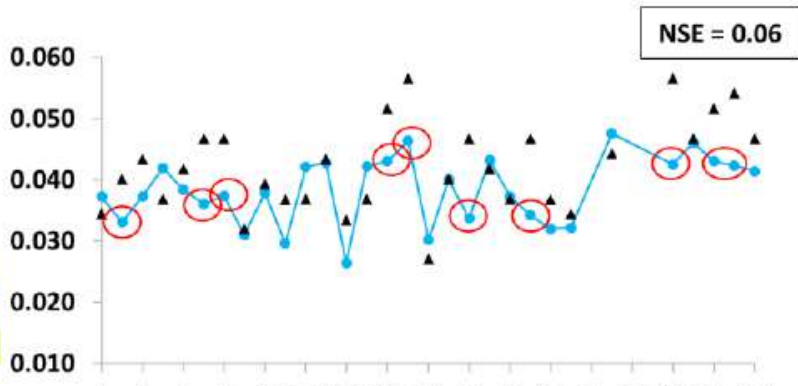

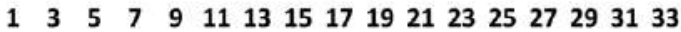

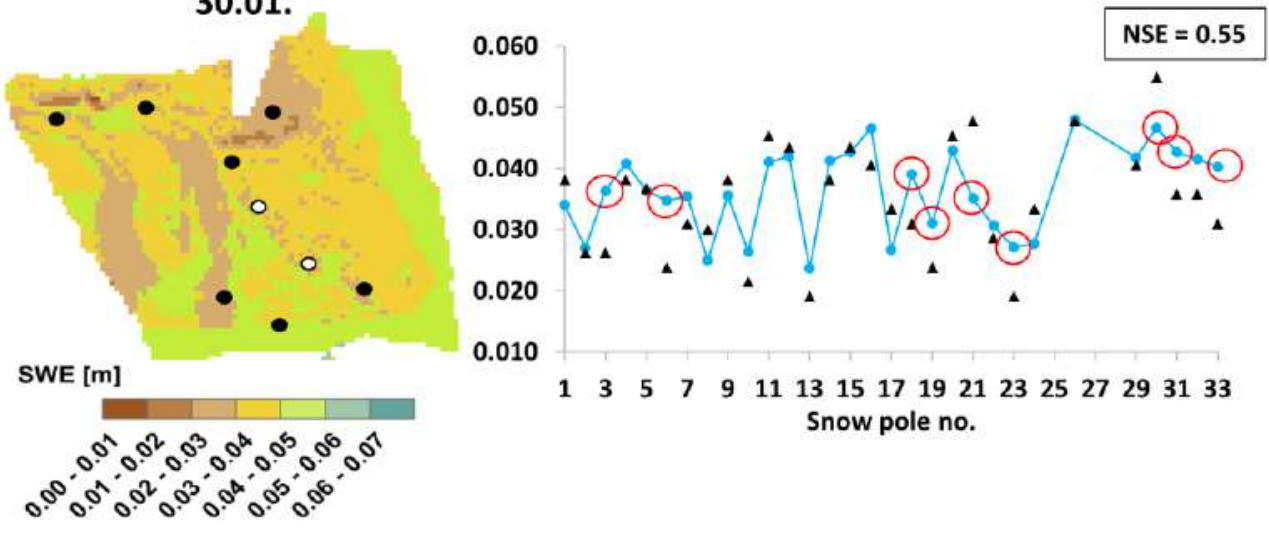

Fig. 4.11: Modelled SWE maps for the seven measuring occasions in 2015 and the corresponding graphs with measured SWE vs. modelled SWE at the snow poles. In the graphs the modelled points are connected for 
better visibility. In each graph the calculated NSE value is presented and snow poles with the larges differences between measured and simulated SWE (i.e. > $0.005 \mathrm{~m}$ SWE) are marked in the graphs. Additionally, the location of these poles are shown in the simulated SWE maps, were black dots indicate overprediction and white dots underprediction of SWE by the model.

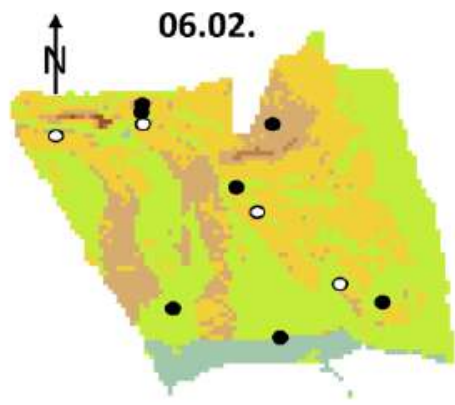

10.02

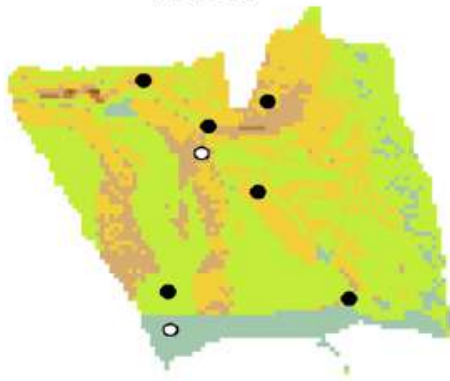

16.02 .

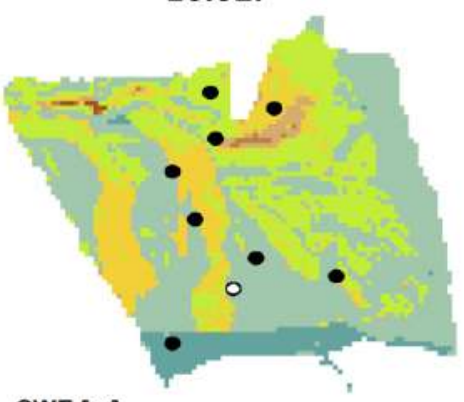

SWE [m]

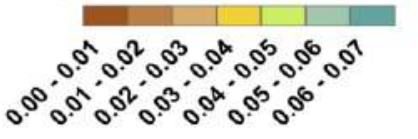

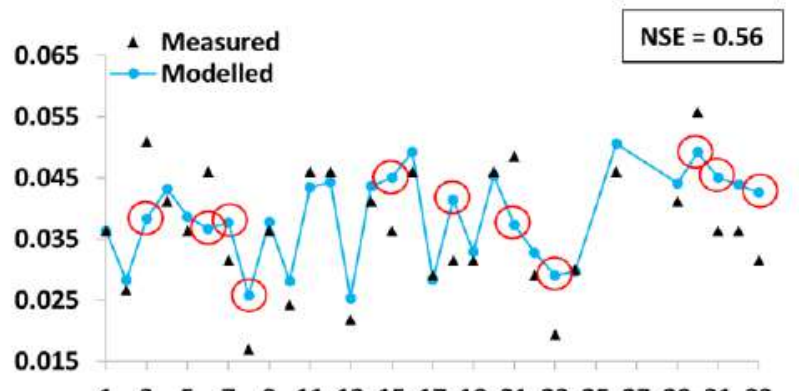

$\begin{array}{lllllllllllllllll}1 & 3 & 5 & 7 & 9 & 11 & 13 & 15 & 17 & 19 & 21 & 23 & 25 & 27 & 29 & 31 & 33\end{array}$

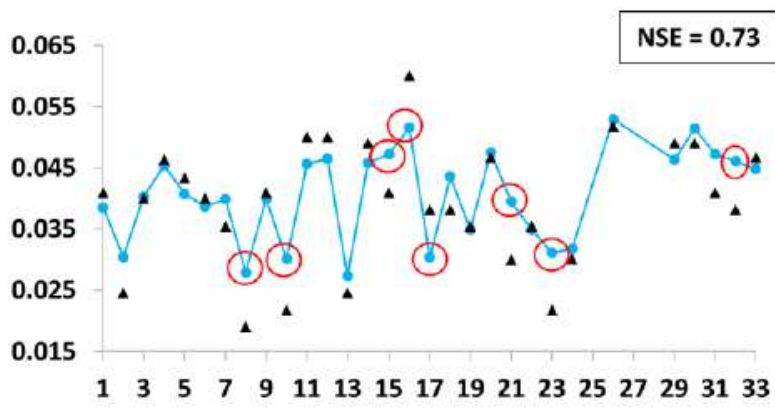

NSE $=0.59$

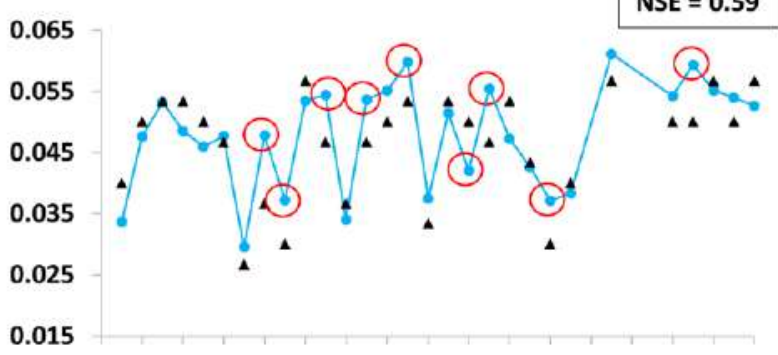

$\begin{array}{lllllllllllllllll}1 & 3 & 5 & 7 & 9 & 11 & 13 & 15 & 17 & 19 & 21 & 23 & 25 & 27 & 29 & 31 & 33\end{array}$ Snow pole no.

Fig. 4.11: (continued)

To better quantify the performance of the model, for each measuring occasion, the calculated NSE is presented in the graphs of Fig. 4.11. Except for 27 January the model performed well with NSE ranging between 0.55 and 0.73 . The NSE for 27 January was 0.06 , 
indicating that the model was only slightly better than the average of the measured data. As can be seen from Fig. 4.11, predicted the model lower SWE at many locations compared with the measurements. The measurements taken 27 January were characterized by a decrease in snow depth, but an increase in SWE compared with 23 January (Fig. 4.4). This suggests that the snow pack contained more water from precipitation (snow and rain at 1.5 ${ }^{\circ} \mathrm{C}$ ), which had occurred 26 January (Fig. 4.2) than UEBGrid anticipated. The parameter $/ \mathrm{h}$ can be used in the model to account for an increased water storage of the snow pack. However, the given value for $I h$ is constant for the whole modelling period, which would have affected all results.

Based on the modelling experiences gathered in this study, four suggestions on how the UEBGrid model could be improved were formulated. (1) To improve the prediction of different snow patterns due to the combination of wind speed, wind direction and terrain the $d f$ could be linked to slope angle, aspect and input of measured wind directions. (2) To account for accumulation of meltwater in snow packs at the bottom of slopes and in depressions a flow routing routine could be implemented in the model. This would also help in the context of soil erosion prediction due to snowmelt. (3) To allow for ice layers within snow packs and on soil surfaces, theoretically, using a multiple layered snow pack and (4) including the possibility of a soil profile below the snow in the model (like it is the case in some non-distributed snow models, e.g. SHAW (Flerchinger et al., 2009)) could improve the simulation results. However, suggestions (3) and (4) could result in a difficult to calibrate, over parameterized and measurement intensive model, reducing its applicability. Therefore, when improving the model a good balance between model complexity and input data requirements, which UEBGrid provides, has to be maintained (Avanzi et al., 2016).

Overall, the UEBGrid model proved capable of simulating the development and spatial distribution of SWE in the shallow snow packs in the three winter periods. However, the different calibration approaches which were necessary for winter 2013 and 2015 showed the delicacy of modelling the change in shallow snow packs. Due to the rapid changes occurring in such snow packs, as shown by the observations and measurements a certain simulation error has to be expected. Especially the refreezing of meltwater, prevention of runoff and infiltration of meltwater by frozen soils and ice layers can make simulations of shallow snow packs challenging. Simulation results therefore have to be treated with care and correct results can probably only be acquired in combination with detailed field observations and measurements. Many additional tools for improving the observation and measurements of rapidly changing snow packs already exist (e.g. Kinar and Pomeroy, 2015; Garvelmann et al., 2013; De Michele et al., 2016; Hopkinson et al., 2012), which should be more widely utilized. 


\subsection{Conclusions}

The three winter periods studied differed in length, amount of snow and processes shaping the snow cover. These interacting processes caused by different weather conditions and state of the soil, resulted in higher $(2013,2015)$ or lower $(2014$,$) complexity of the$ modelling. By considering weather data and quantitative (measurements) and qualitative (aerial and ground images) field observations it was possible to correctly validate the model results. Especially the importance of detailed photographic image and video documentation, as a substitute to quantitative measurements, for process understanding cannot be stressed enough.

UEBGrid proved capable of simulating the development and spatial distribution of SWE in the study area for 2013, 2014 and 2015. The acquired calibration values, especially for $d f$ should be tested in coming winters and in other areas, with similar characteristics, to evaluate how consistent they are. UEBGrid captured the essential physics of accumulation and melt processes of shallow and patchy snow covers. The measurements and calibrations underlined how sensitive such snow packs are to wind, small changes in the composition of precipitation and soil temperature conditions, requiring a greater focus on automated, differentiating precipitation and spatially distributed wind and SWE measurements. Also more research of processes related to shallow snow packs is necessary with the prospect of decreasing snow depths in areas where snow packs now are usually deep due to global warming (Barnett et al., 2005).

However, that it was possible to satisfactory simulate temporal and spatial changes of shallow snow packs made us confident that we are step closer to the overall goal to better quantify and finally reduce soil erosion during winter and spring. 


\section{Effect of freeze-thaw on soil macropores}

In the Nordic countries, changes in pore structure during winter can affect e.g. water transport capacity in soils after winter. A reduction in pore space can cause an increase in runoff volume due to snowmelt and rain, resulting in flooding and soil erosion. This study quantified the effect of freezing-thawing cycles (FTCS) on the macropore structure of a clay and a sandy soil. Six consecutive FTCS were applied to intact soil samples, which were scanned after 0, 1, 2, 4 and 6 FTCs with an industrial X-ray scanner. Using state-of-the-art image processing and analysis techniques, changes in soil macropore network characteristics were quantified. The results showed that freezing-thawing affected the looser sandy soil more than the clay with its more cohesive structure. However, in both soils freezing-thawing had a negative effect on pores. These findings can help improve understanding of how undisturbed soils react to different winter conditions, which can be beneficial in the development of models for predicting flooding and soil erosion.

Based on:

Starkloff, T., Larsbo, M., Stolte, J., Hessel, R., Ritsema, C.J., Quantification of freezingthawing cycles on the pore network of a silty clay loam and a loamy sand topsoil using X-ray tomography. Catena, 2017, 156, pp. 365-374 


\subsection{Introduction}

In the Nordic countries, the incidence of soil erosion from agricultural land is greatest during spring (Lundekvam and Skøien, 1998; Deelstra et al., 2009). The severity of erosion is often exacerbated by winter conditions. During winter and snowmelt, soil hydraulic properties can change dramatically due to freezing and thawing (Stähli et al., 2001; Al-Houri et al., 2009). In particular, ice blockage of macropores can have a large influence on water transport during freezing and thawing (Seyfried and Murdock, 1997). The changes in pore structure during winter also influence the water transport capacity of soil after winter. Following an extensive literature review, Qi et al. (2006) concluded that repeated freezingthawing cycles (FTCs) lead to an increase in pore volume in dense soils (e.g. consolidated clays) and a decrease in loose soils (e.g. uncompacted silts). The hydraulic permeability also increases in dense soils after a number of FTCs, which may be attributable to crack development. However, the influence of FTCs on soil structure (i.e. the arrangement of soil aggregates and pore networks) is still far from being fully understood (Qi et al., 2006).

A number of studies have investigated water flow and soil hydraulic properties under freezing and thawing (e.g. Al-Houri et al., 2009; Iwata et al., 2011; Watanabe et al., 2013) and have attempted to link these to changes in soil structure. Until recently, the structural properties of soils had to be inferred from hydraulic measurements (Bodner et al., 2008) or destructive 2D visualisation methods (e.g. thin section micromorphology) (Taina et al., 2013), which do not allow continuous observations of changes in soil structure. However, improvements in the image resolution of X-ray tomography (XRT) scanners and an increase in computation capacity in the past decade have made it possible to study soils at the pore scale without destroying the samples (De Kock et al., 2015). This option of using XRT for quantitative investigations of soil structure has resulted in a number of recent studies relating water flow and solute transport properties to macropore network characteristics derived from XRT images (Luo et al., 2008, 2010a, 2010b; Garbout et al., 2013a; Larsbo et al., 2014; Koestel and Larsbo, 2014; Katuwal et al., 2015; Zhang et al., 2015).

Some studies have shown that XRT can be used to investigate the effect of freezing and thawing on rocks (Ruiz de Argandoña et al., 1999; De Kock et al., 2015). However, only a few studies have used XRT to study the effects of FTCs on soil structure. One of the first studies in this regard was by Viklander (1998), who examined stone heave in a glacial till exposed to several FTCs. Torrance et al. (2008) carried out a qualitative study (limited by the resolution of the XRT scanner used) on frozen soil and were able to visualise the formation of ice lenses in two soils and show the great potential of XRT to investigate structural change due to FTCs in soils. Taina et al. (2013) carried out a quantitative study to investigate microstructural features formed under annual freezing and thawing and found that, for the 
tillage systems they investigated, no tilled soil formed a clear platy structure. However, all these studies report a lack of data and knowledge about how soil macropore networks behave under the series of consecutive FTCs that are likely to occur during a typical winter in the Nordic countries. Against this background, the aim of the present study was to quantify the effect of FTCs on the pore structure of two different soil types. This was done by applying several consecutive FTCs to intact soil columns and using XRT imaging to quantify the changes in macropore network characteristics.

\subsection{Materials and methods}

\subsubsection{Sampling}

The soil samples were taken in the Gryteland catchment, which is located approximately 30 $\mathrm{km}$ south of Oslo, Norway. This catchment was chosen because FTCs are common at the site during winter and because the soil types are representative of a large proportion of agricultural soils in southern Norway.

The two soil selected for this study were a levelled silty clay loam and a loamy sand, classified according to the world reference base as a Stagnosol and Umbrisol, respectively. The silty clay loam was formed by marine deposition and was artificially levelled and the loamy sand was formed by beach deposition on clay. They are referred to hereafter as clay soil and sand soil, respectively. At the two locations, undisturbed soil samples were taken by hand, through carefully pushing PVC cylinders with an inner diameter of $10 \mathrm{~cm}$ and 20 $\mathrm{cm}$ length, equipped with specially designed aluminium top and bottom rings into the soil. Four topsoil samples (to $15 \mathrm{~cm}$ depth, leaving $5 \mathrm{~cm}$ of air on top of the samples) were taken from each soil on 26 May 2015 (Clay: C1, C2, C3 and C4; Sand: S1, S2, S3 and S4). At the time of sampling, the topsoil had a loose structure due to seedbed preparation (mouldboard ploughed in spring with an approx. plough depth of $30 \mathrm{~cm}$, followed by harrowing) and the soil surface was cropped with newly germinated cereals. At sampling, measured soil water content in the clay was approximately $0.3 \mathrm{~m}^{3} \mathrm{~m}^{-3}$, corresponding to a matric potential of approx. $32 \mathrm{kPa}$, while in the faster-draining sand soil it was approximately $0.17 \mathrm{~m}^{3} \mathrm{~m}^{-3}$ with a matric potential of approx. $13 \mathrm{kPa}$. The soil water content was measured by frequency domain reflectometry (FDR) sensors at two nearby stations). The soil structure and soil water content were comparable to autumn conditions for fields planted with winter cereals. It was therefore assumed that during the experiment, the soil structure would behave similarly to what can be expected during winter. After sampling, the samples were packed in airtight containers, to avoid evaporation loss throughout the experiment, and stored 
under refrigeration at $4{ }^{\circ} \mathrm{C}$ until they were scanned at the Swedish University of Agricultural Sciences (SLU) in Uppsala, Sweden. In addition to soil texture, organic matter content, bulk density, cohesion (at sampling) and soil hydraulic conductivity were determined for the two soils (Table 5.1).

Table 5.1: Characteristics of the two soils investigated

\begin{tabular}{ccc}
\hline Parameter & Clay soil & Sand soil \\
\hline Clay [\%] & 29 & 7 \\
Silt [\%] & 58 & 13 \\
Sand [\%] & 13 & 70 \\
$K_{\text {sat }\left[\mathrm{cm} \mathrm{h}^{-1}\right]}$ & 2.4 & 16.8 \\
Cohesion [kPa] & 40 & 19 \\
Bulk density [g cm $\left.{ }^{-3}\right]$ & 1.32 & 1.18 \\
Organic matter content [\%] & 4.51 & 3.40 \\
\hline
\end{tabular}

\subsubsection{XRT scanning and experimental setup}

Each sample was exposed to six FTCs. Each freeze-thaw cycle (FTC) consisted of freezing the sample at $-15{ }^{\circ} \mathrm{C}$ overnight (approx. 36 hours) and thawing it at $40{ }^{\circ} \mathrm{C}$ in the morning (minimum 5 hours). These extreme temperatures were a compromise based on the restricted time we had available at the XRT scanner. The samples were insulated the base and sides with $5-\mathrm{cm}$ foam boards and glass wool, in order to achieve top to bottom freezing. For thawing, the insulation material was removed to allow complete thawing of the samples within the restricted time frame. Scans were taken as shown in Fig. 5.1.

For the scanning work, the GE Phoenix v/tome/x $m$ XRT scanner at the Department of Soil and Environment, SLU, was used. This scanner consists of a $240 \mathrm{kV} \mathrm{X-ray} \mathrm{tube,} \mathrm{a} \mathrm{tungsten}$ target (beryllium window) and a GE 16" flat panel detector. In order to reduce beamhardening artefacts, the detector was covered with $1.0 \mathrm{~mm}$ thick copper plate. During each scan, 2024 radiographs were taken per 3D image with a discretisation of 1840x1840 pixels, corresponding to a resolution of $70 \mu \mathrm{m}$. The scans were made at a voltage of $150 \mathrm{kV}$ and a current of $320 \mu \mathrm{A}$ for the sand samples and $360 \mu \mathrm{A}$ for the clay samples. The exposure time for each radiograph was $333 \mathrm{~ms}$ and the acquisition time was approximately $45 \mathrm{~min}$ per scan. 3D images were reconstructed from the radiographs using the $G E$ image reconstruction software datos/ $x$, and exported as TIFF (tagged image file format) stacks with 16 bit grayscale resolution. The resulting 3D images had a spatial resolution of $70 \mu \mathrm{m}$ in all directions. 


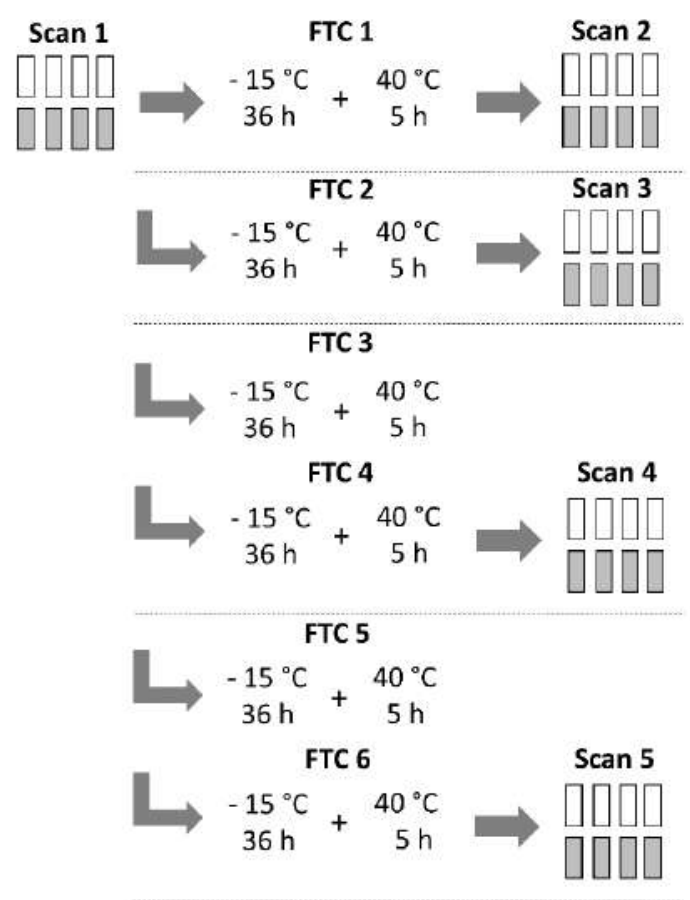

Fig. 5.1: Flow diagram showing the different steps of the experiment. The eight soil samples analysed (four from each soil type) were scanned five times.

\subsubsection{Image processing}

Forty 3D images were obtained during the freeze/thaw experiment. Image processing was carried out with the FIJI distribution (Schindelin et al., 2012) of ImageJ (Abramoff et al., 2004) and $R$ (R core team, 2016). In order to carry out quantitative interpretation of X-ray images, homogeneous illumination is required and objects with known density (e.g. water and air) must have the same grey values over the entire 3D image (Koestel and Larsbo, 2014). To reduce differences in illumination in both the vertical and radial directions, the procedure described in Larsbo et al. (2014) was applied here using an $R$ script developed for the purpose. Using this script grey values were adjusted to the $70^{\text {th }}$ and $0.1^{\text {st }}$ percentile grey values, representing the soil matrix and the air in the sample, respectively. This procedure yielded satisfactory results except at the soil surface and at the base of the column. The corrected images were filtered with the ImageJ 3D median filter with a radius of 1 to reduce noise (i.e. only the 6 neighbouring voxels with a face connection were used in the filtering). These filtered images were then cropped to a 600 voxel diameter to remove the cylinder walls and soil close to the walls, which may have been affected by the field sampling 
procedure. Since some images still showed beam-hardening artefacts at the base and close to the soil surface, sub-stacks were defined. To ensure that the same soil volume was always analysed in each sample, landmarks (e.g. small stones) that appeared in each scan of each sample were used. The image slices above and below these landmarks were removed, resulting in regions of interest of about $9 \mathrm{~cm}$ for the clay samples and 6 (S2) to $9 \mathrm{~cm}$ for the sand samples. Removing visual image slices above and below certain landmarks can result in slightly different image stacks. It was estimated that an error of \pm 2 image slices (i.e. \pm 0.28 $\mathrm{mm}$ ) can be expected when using such a procedure. To reduce the computation time during processing, the image resolution of each frame was reduced by a factor of two in all directions, resulting in an edge length of $140 \mu \mathrm{m}$ of each image voxel. Due to partial volume effects (i.e. a voxel may be located both in pore and solids, giving it an average grey value), pores with diameter larger than approximately $280 \mu \mathrm{m}$ were visible. This resolution allowed quantitative investigation of the macropores, a term usually referring to pores with diameter greater than 300-500 $\mu \mathrm{m}$ (Jarvis, 2007). After this, all 3D images were centred and placed in an upright position. Finally, the images were binarised into soil matrix and macropores using one grey value threshold for all clay images and one threshold for all sand images. These thresholds were determined by visual inspection.

\subsubsection{Quantitative measures of macropore networks}

Quantitative measures of the macropore network were calculated from the binary images. The macroporosity was determined using the tool Volume Fraction of boneJ (Doube et al., 2010). To quantify the homogeneity of the spatial distribution of the macroporosity, the mass fractal dimension (Perret et al., 2003) was calculated with the Fractal Dimension tool of boneJ. This tool scans the 3D image using boxes of diminishing size and the number of boxes of each size containing foreground (pores in this case) is counted (Fazzalari and Parkinson, 1996). The surface area of the macropore network was calculated with the Isosurface tool of boneJ with the resampling parameter set to 6 (default value). This tool constructs a triangular surface mesh by marching cubes, where the sum of the areas of the triangles makes up the mesh (Lorensen and Cline, 1987). The Connectivity tool of boneJ was used to determine the Euler number of the pore network (Odgaard and Gundersen, 1993). This number gives an estimate of the local pore connectivity of the sample (Larsbo et al., 2014), by counting the number of isolated objects minus the number of connections or loops plus the number of cavities (Vogel et al., 2010). To examine whether there were pores connecting the top and bottom of the samples, the different pore clusters were labelled with the Particle Analyser tool in ImageJ (Bolte and Cordelières, 2006). The resulting image was then used to calculate the overall connectivity $(G C ; 1$ if percolating macropores exist, 0 if no percolating macropores exist) and, if $G C$ equalled 1 , the percentage of percolating 
pores (connected porosity) among all pores using $R$. Finally, the pore sizes were estimated with the Thickness tool of boneJ, where the thickness of each macropore voxel is defined as the diameter of the largest sphere that fits into the macropore and contains the voxel. The resulting thickness histograms were used as estimates of pore size distribution. To account for the differences in volume, the measured surface area of the macropores and Euler number were divided by the total volume of the sub-stacks.

To check whether the changes of the different properties of the macropore network in the clay and sand soil due to the six FTCs were significant, the Gerneral Linear Model of ANOVA (GLM) was applied, using the software Minitab 17.2.1. The null hypothesis was that the means of several measurements are equal. In this case, if the means of the four replicates (four sand and four clay samples) for a certain property (e.g. macroporosity) were equal for zero, one, four and six FTCs. With this statistical test is was possible to determine if a significant trend existed and whether it was positive or negative. Trends were considered significant if $\mathrm{P}$-values were less than 0.05 .

\subsubsection{Qualitative analysis of macropore networks}

The effect of the FTCs on individual pores was investigated qualitatively by comparing horizontal cross-sections of the unprocessed ( $70 \mu \mathrm{m}$ resolution) greyscale image stacks of a clay sample (C4) and a sand sample (S1) before and after six FTCs. The depth of these crosssections was 8 and $7 \mathrm{~cm}$ below the soil surface for the clay and sand samples, respectively. Due to space limitations only greyscale images of these two samples, as representatives for the clay and sand soil are presented. 


\subsection{Results and discussion}

\subsubsection{Initial soil characteristics}

Some images of the macropore networks in the clay soil and sand soil before freezing are shown in Fig. 5.2. The initial macroporosity (i.e. before freezing and thawing) estimated from XRT images ranged between 33 and $36 \%$ for the clay soil and between 8 and $10 \%$ for the sand soil. The macroporosity decreased with depth for both soils.
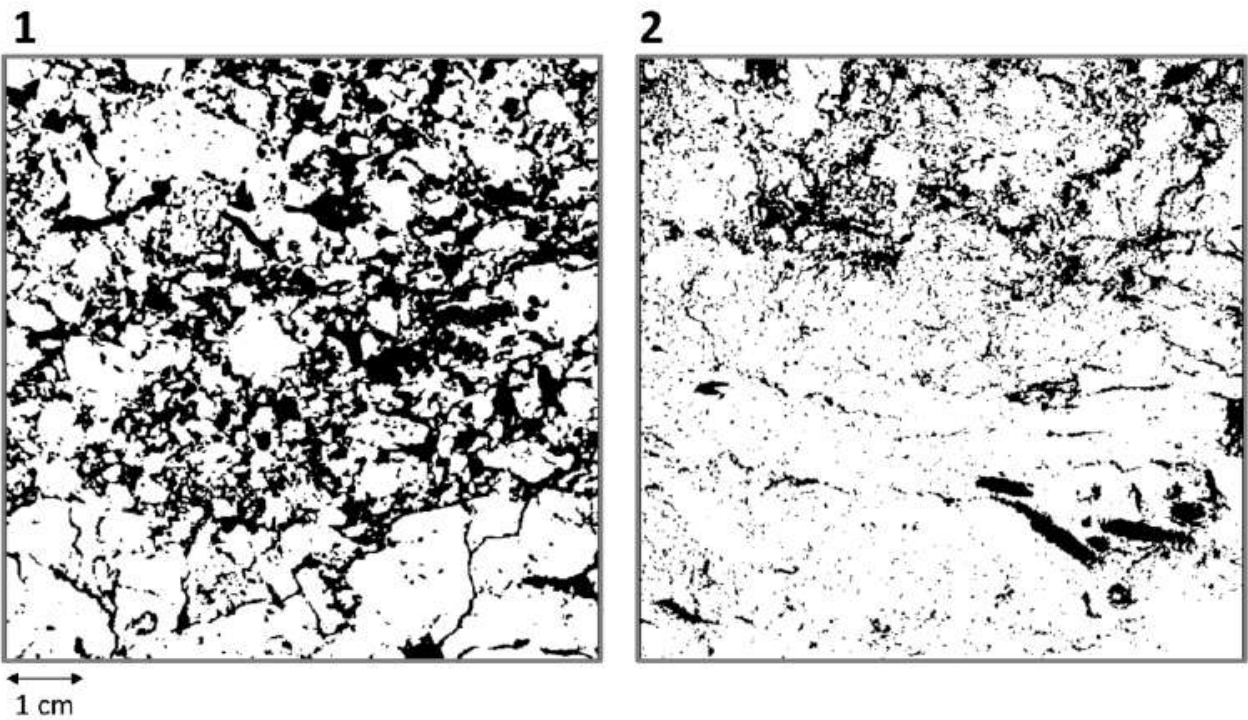

Fig. 5.2: Vertical cross-section of binary images of (1) a clay sample and (2) a sand sample, showing visible pore space (black) in the seedbed.

These values are high for agricultural topsoils (Larsbo et al., 2014), but it should be noted that the samples were taken from the relatively freshly tilled top layer of the Ap horizon of both soils. Garbout et al. (2013b) found similarly high XRT-derived macroporosities two weeks after sowing in a sandy loam. From Fig. 5.2, it can be seen that the pore network was more homogeneously distributed in the clay soil than in the sand soil, which was in accordance with the higher fractal dimensions calculated for the clay soil (2.81-2.86) compared with the sand soil (2.67-2.78). These values matched findings by Perfect (1999), who showed that fine-textured soils had higher fractal dimensions than coarse-textured soils ( 2.8 for a silt loam compared with 2.6 for a sand). The macropore networks of the two soils in the present study also differed in connectivity. GC was 1 for all clay samples, resulting in a connected porosity of $33-35 \%$, while all sand samples had GC of 0 and therefore no 
percolating macropore network. Moreover, average pore thickness differed between the clay and sand soil. Based on the XRT images of the samples, the average pore thickness was calculated to be 1.0-1.3 $\mathrm{mm}$ for the clay soil and 0.6-0.8 $\mathrm{mm}$ for the sand. The largest pore size calculated for the clay soil and sand soil was 7.4 and $4.8 \mathrm{~mm}$, respectively. However, it should be noted that pores important for water storage and for plant growth $(30-75 \mu \mathrm{m})$, especially between the coarser particles in the sand soil, were too fine to be detected by the image resolution (i.e. $140 \mu \mathrm{m}$ ) used in this study.

\subsubsection{Quantitative measures of freezing-thawing effects on macropore networks}

The length of the sub-stacks analysed, as defined by the landmarks, is shown in Fig. 5.3. The error bars in the diagrams show the length differences due to \pm 2 images slices. By comparing the different lengths, with consideration of the error, to that of the initial stack (0 FTC), it was determined whether the change in length, and thereby in volume, was due to uncertainties in determination of length of the sub-stacks or to the effect of FTCs.

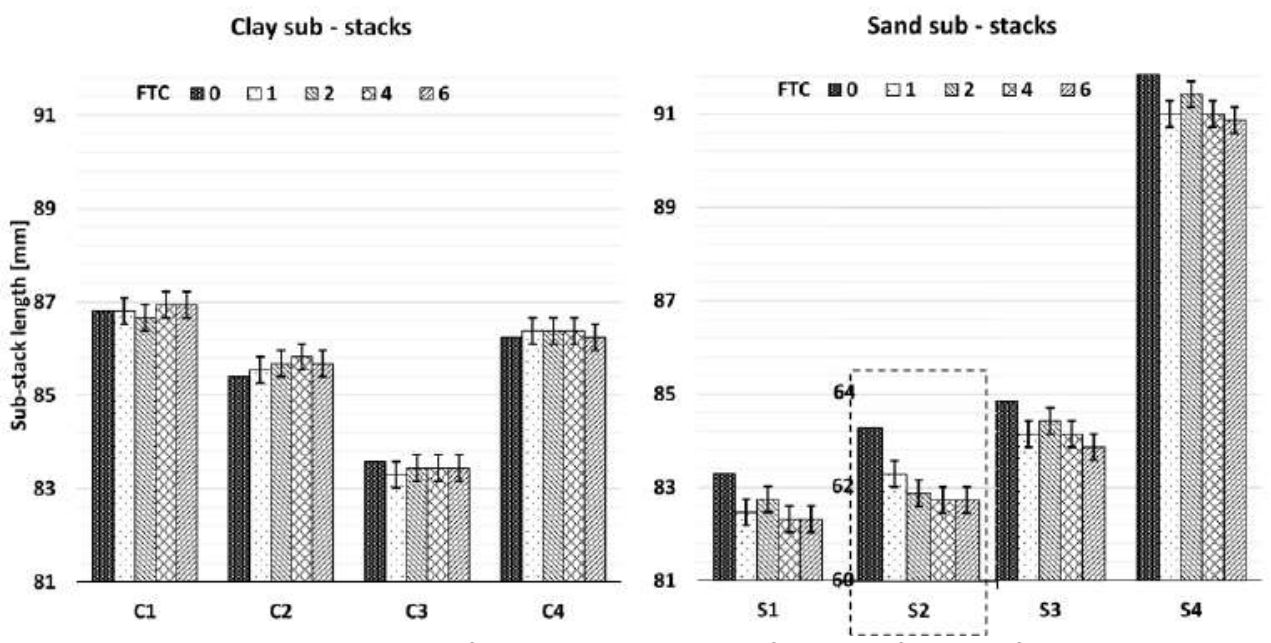

Fig. 5.3: Graphs showing the length of the image-sub-stack before and after each freezing-thawing cycle (FTC: $0,1,2,4,6)$ for the clay and sand samples. The error bars indicate the uncertainties ( \pm 2 image slices, i.e. $\pm 0.28 \mathrm{~mm}$ ) in the sub-stack definition procedure. For better visibility, a different scale was applied to S2.

As can be seen, the length differences between the FTCs were small in the clay and therefore probably due to the uncertainty in estimation of sub-stack length, while in the sand the differences were larger than the estimated error and therefore probably due to the freezing and thawing. This reduction in volume suggested that the FTCs increased the density of the 
The results of the six measurements performed for each clay sample through the six FTCS are shown in Fig. 5.4. The changes were slightly different in the four samples, probably due to small differences in structure. The four samples showed a slight negative trend for total macroporosity (Fig. 5.4). Samples C1, C2 and C3 first showed an increase in macroporosity after the first FTC, followed by a decrease through the following five FTCs. A negative trend and similar development as for the macroporosity were observed for the connected porosity (Fig. 5.4). All samples showed a negative trend ( $C 3$ after the first FTC) in mean pore thickness, with a continuous reduction until the last FTC (Fig. 5.4). No trend was observed for the surface area of the macropores or for the Euler number (Fig. 5.4), suggesting that the freezing and thawing had no effect on the internal connectivity of the pore networks. Furthermore, no clear trend was observed for the fractal dimension of the pore networks in the clay soil (Fig. 5.4). Peyton et al. (1994) and Luo (2009) found a strong, positive correlation between macroporosity and fractal dimension of pore networks, but for our samples that was not the case. In samples C3 and C4 the fractal dimension decreased and in samples $\mathrm{C} 1$ and $\mathrm{C} 2$ it increased slightly between the first and last measurement. However, it should be noted that all differences and changes occurring during the six FTCs were minor for the clay and the GLM results suggested no significant trends within the different measurements. 

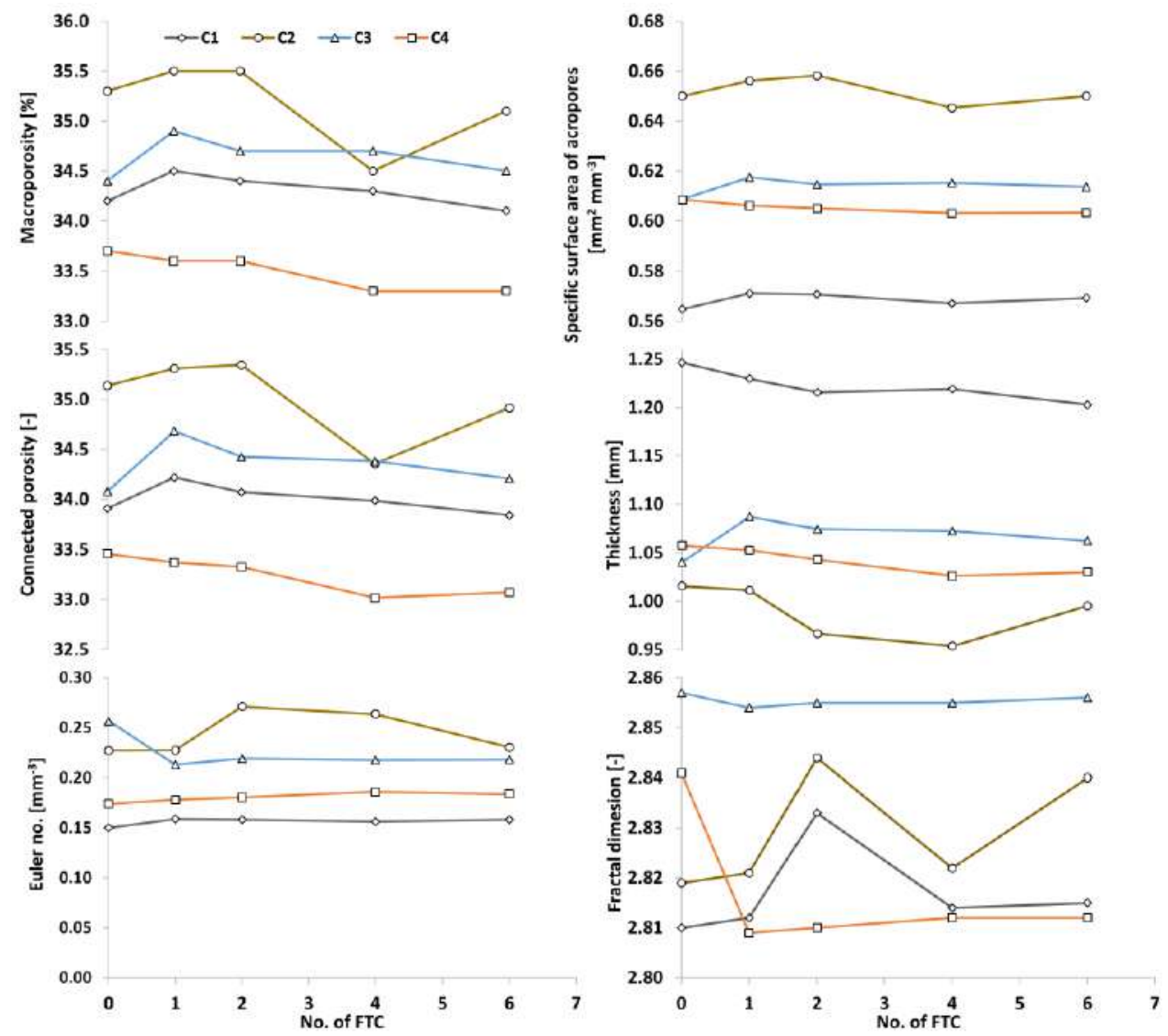

Fig. 5.4: Measured macropore characteristics in the four replicate samples of the clay soil in the five scans.

The pore thickness distribution in the four clay samples is shown in Fig. 5.5. The images illustrate how the different pores changed during the six FTCs. All four samples showed a reduction in the number of pixels for pore thicknesses between approx. 2 and $5 \mathrm{~mm}$. 

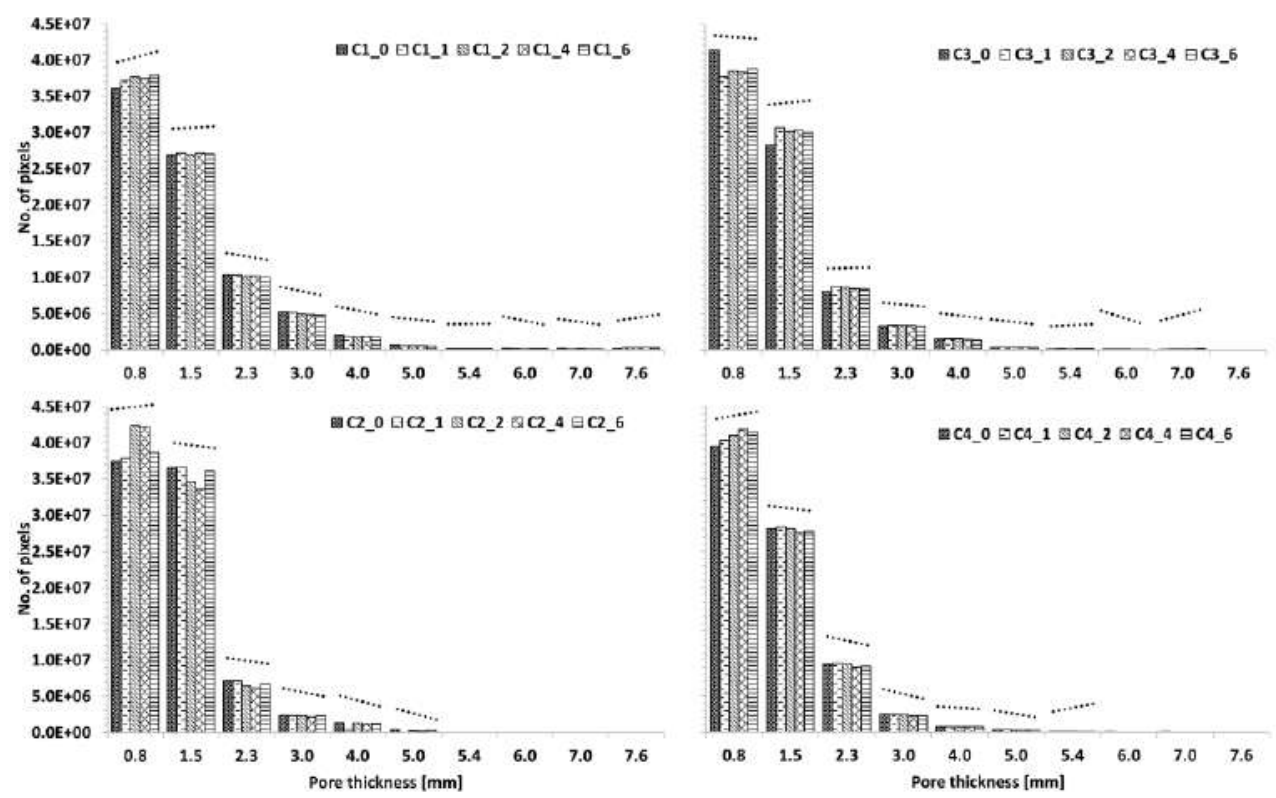

Fig. 5.5: Pore size distribution in the four replicate samples of the clay soil $(C 1, C 2, C 3, C 4)$ measured after each freeze-thaw cycle $(0,1,2,4,6)$. The calculated trend within each class is presented as a dotted line above each class.

Samples C2 and C4 also showed a reduction in pixels for their largest pores $(5.0 \mathrm{~mm}$ thickness in C2 and 6.0 and $7.0 \mathrm{~mm}$ in C4), while samples C1 and C3 showed an increase in number of pixels for their largest pores $(7.6 \mathrm{~mm}$ in $\mathrm{C} 1$ and $7.0 \mathrm{~mm}$ in C3). The increase in number of pixels in the smaller pores ( $\sim 0.5-1 \mathrm{~mm}$ ) in all four samples was probably due to the initial larger pores becoming thinner, giving an increasing number of pixels for thinner pore classes.

Similarly to the clay soil, the four sand samples reacted somewhat differently to freezing and thawing. However, applying the GLM showed that the changes in macroporosity and surface area of the macropores were statistically significant in contrary to the clay soil (Fig. 5.6). 

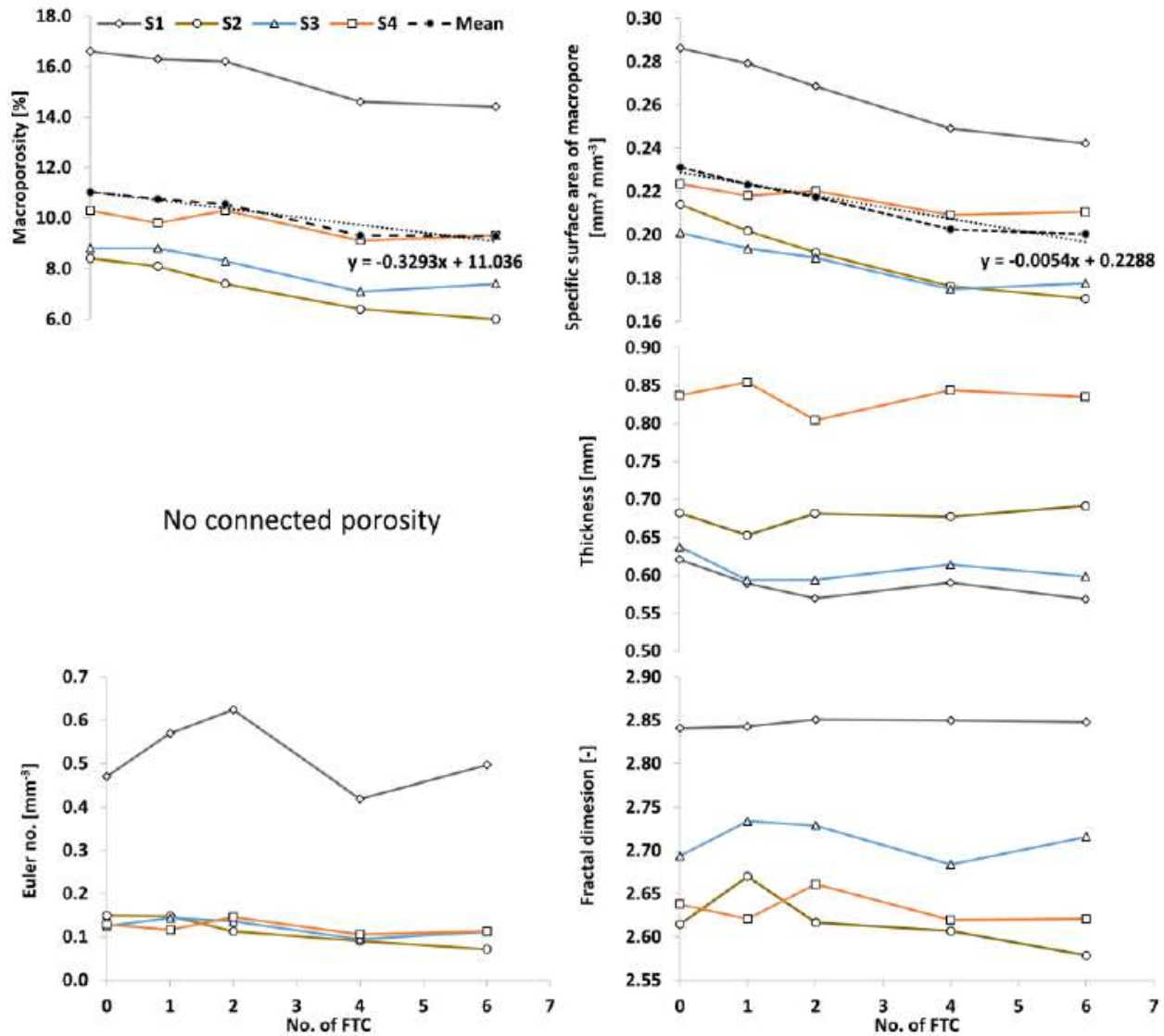

Fig. 5.6: Measured macropore characteristics in the four replicate samples of the sand soil for the five scans. For measurements where the GLM showed significant differences the trend line, with regression equation, through the mean values for each no. of FTC is presented.

Clear negative trends were observed for these two properties (Fig. 5.6), indicating that the FTCs had an effect on these characteristics of the pore network of the sand soil, but not in the clay soil. The reduction in surface area of macropores and macroporosity correlated well with the observed reduction in sample volume (Fig. 5.3). For the measurements pore thickness, Euler number and fractal dimensions the GLM showed no significant trends (Fig. 5.6), suggesting that freezing and thawing had no significant effect on these properties for the sand. 

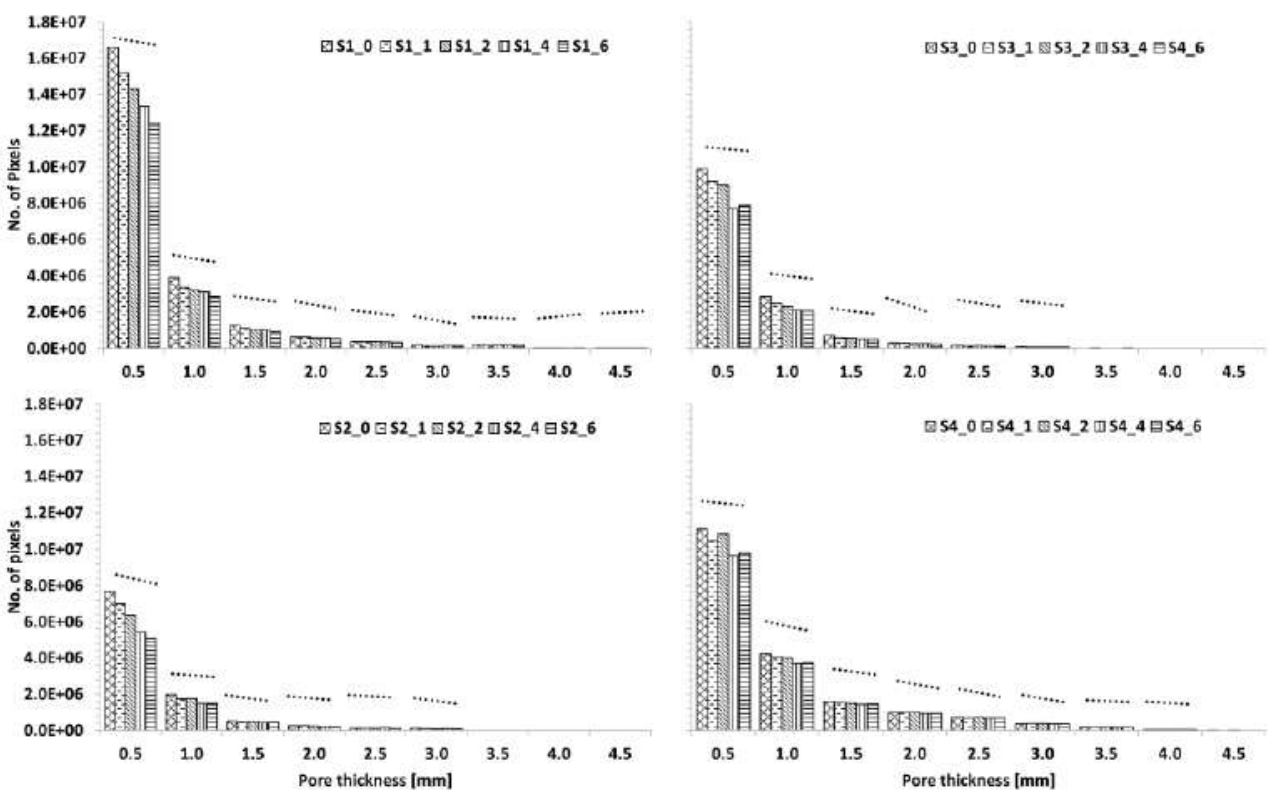

Fig. 5.7: Pore size distribution in the four replicate samples of the sand soil (S1, S2, S3, S4) measured after each freeze-thaw cycle $(0,1,2,4,6)$. The calculated trend within each class is presented as a dotted line above each class.

As can be seen in Fig. 5.7, all sand samples showed a decrease in the number of pixels for the pores with thickness between 0.5 and $3.5 \mathrm{~mm}$. In samples S3 and S4 the largest measured pore thickness was reduced, while in sample S1 it was increased. As found for the clay soil, no clear trend was observed for the largest pores.

To better distinguish how the macropore structure was affected at different depths of the soil columns, the change in macroporosity with soil depth between the initial distribution and after six FTCs was compared (Fig. 5.8). In general, the macroporosity was slightly reduced in the upper layers of the clay samples $(\sim 0-30 \mathrm{~mm})$ and slightly increased in the lower layers ( 45-90 mm), but these changes were small. Because no clear trends were observed in the quantitative measurements for the clay and all observed changes were small, no conclusions could be drawn about the reasons for these differences. The differences were not sufficiently great to differentiate between changes induced by limitations in image processing and the possible effect of freezing and thawing. 


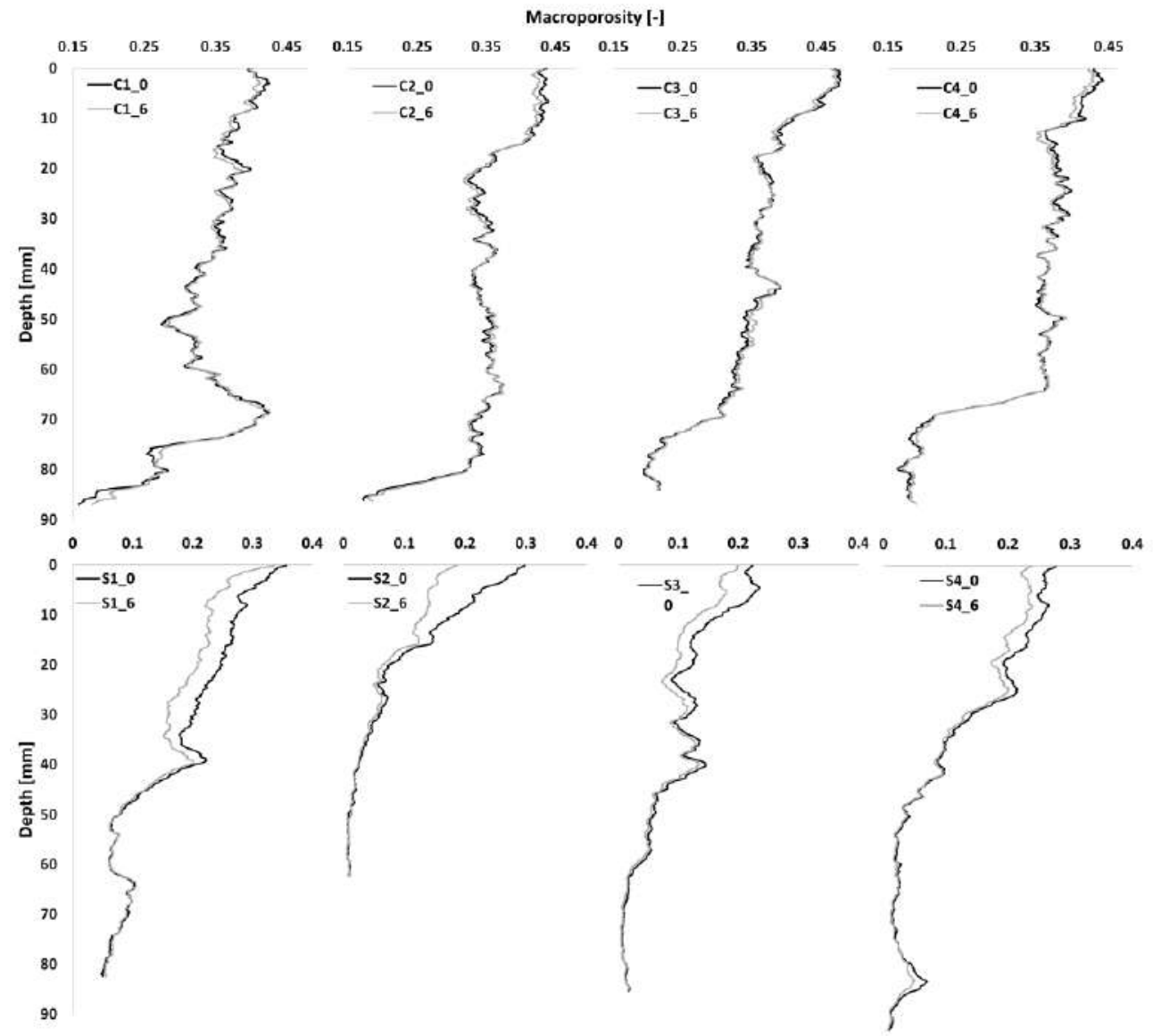

Fig. 5.8: Macroporosity distribution per depth in the eight soil samples.

The significant reduction in macroporosity that occurred for the sand can also be seen in Fig. 5.8. The six FTCs decreased the macroporosity mainly in the upper $3 \mathrm{~cm}$, while in the lowest $2 \mathrm{~cm}$ the effect was insignificant. The greatest changes were observed in the upper layers of the sand soil. Reasons for this could be the exposure to the great temperature fluctuations $\left(-15\right.$ to $40^{\circ} \mathrm{C}$ ) at the surface and the initially looser structure of the upper layers due to the recent tillage operations.

\subsubsection{Qualitative measures of freezing-thawing effects on macropore networks}

Chamberlain et al. (1990) found that freezing and thawing reduced the mean radius of macropores, but that the hydraulic conductivity increased, which they attributed to an increase in microscopic voids. The image resolution limit in this study was too coarse for 
quantitative analyses of these voids, but creation of new small voids was observed in the clay soil at a depth of $8 \mathrm{~cm}$. Such qualitative analysis of the greyscale images of soils is recommended by Baveye et al. (2010). From Fig. 5.9, it can be seen that new small voids were created in the clay soil (rectangles), while the thickness of larger pores was reduced in both soils (arrows). Interestingly, in the images it can also be seen that some large pores became smaller in the clay, while the quantitative measurements did not show a significant decrease in macroporosity or mean thickness for the clay. A reason for this could be that such changes were only observed in greyscale images of the lower regions of the clay soil (7 to $9 \mathrm{~cm}$ ), where macroporosity was small (Fig. 5.8). Changes in these regions would therefore result only in small differences in total measured macroporosity. However, these images show that the FTCs had an effect, at least on parts of the pore network of the clay soil. Therefore, further experiments with samples from lower regions of the clay soil should be undertaken to quantify how freezing and thawing influences the macropore network of the less porous layers of the clay soil.

For quantitative analyses of the small voids created during FTCs, thinner $(\varnothing<10 \mathrm{~cm})$ samples than used in this study would be necessary, allowing higher XRT image resolutions. However, the sample size used in this study allowed for a more representative soil volume with respect to structure and freeze-thaw conditions.

Due to the fact that the greatest differences in macroporosity and surface area of the pores were observed in the sand soil, it can be assumed that FTCs affect the pore structure of looser soils more than that of more cohesive soils. Similarly, Viklander (1998) showed that looser soils are consolidated by freezing and thawing, resulting in a reduction in total porosity. The impact of FTCs depends on the soil water content (e.g. Torrance et al., 2008). It would therefore be desirable to conduct similar experiments as done in this study with different soil water contents and possibly more FTCs. However, it should be noted that at present, high resolution XRT scanners are still rare and expensive and the scanning and the necessary image processing are still time consuming (Schlüter et al., 2014).

More research is also necessary to investigate how freezing and thawing affects soils under different conditions, like changing soil water content. Similar experiments should be carried out with smaller samples or an XRT scanner, which can provide higher image resolution than possible in this study, to quantify the effect of FTCs on thin pores $(<140 \mu \mathrm{m})$. 


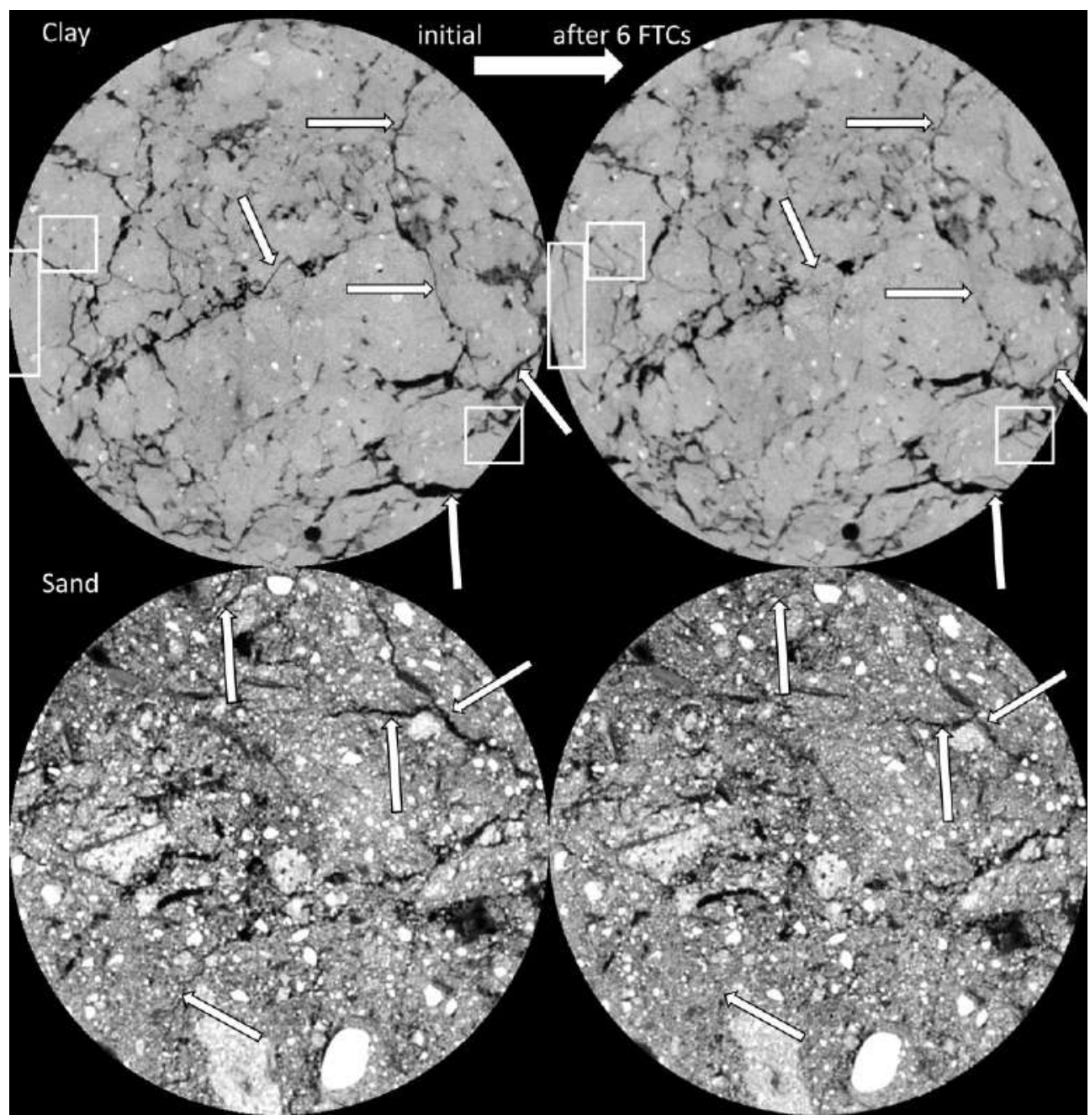

Fig. 5.9: Horizontal cross-section through four greyscale images. The upper two are images of the more compacted lower regions (approx. $9 \mathrm{~cm}$ depth) of a clay sample before the first FTC (left) and after six FTCs (right). The lower images show the same for a sand sample. Arrows show pores which became thinner and rectangles show where new voids occurred. 


\subsection{Conclusions}

In this study we were able to quantify the effect of six consecutive freezing-thawing cycles (FTCs) on the macropore structure of two different soil types, using XRT imaging. Under the given conditions, the sand soil was more affected than the clay soil by the six FTCs applied. It can be concluded that freezing and thawing affects looser soils more than soils with a more cohesive structure. However, the qualitative analysis also suggested that the FTCs had an (decreasing) effect on the pores in the lower layers of the clay. To quantify the effect of FTCs on thin pores $(<140 \mu \mathrm{m})$ studies using higher image resolution than possible in this study would be needed. Furthermore, the observed changes in this study were small and further research should be undertaken to investigate how these changes affect infiltration and water transport in these soil. However, a changing climate with winters characterised by a reduction in snow cover thickness and coverage length, as it is the case in southern Norway (Hanssen-Bauer et al., 2015), might result in an increase in the number of freezing and thawing episodes. This could have a negative impact on water permeability of loose soils due to the reduction in macroporosity, and possibly a positive impact on more cohesive soils due to an increase in permeability through the creation of small voids and cracks. 


\section{Integrated, spatially distributed modelling of surface runoff and soil erosion during winter and spring}

In cold climate regions a significant fraction of annual soil erosion in agricultural land occurs during snowmelt and rain on partially frozen soils. Physically based and spatially distributed soil erosion models have proved to be good tools for understanding the processes occurring at catchment scale during rainfall erosion. However, most existing erosion models do not account for snow in a suitable way. A combination of the UEBGrid snow pack model and the LISEM erosion model was therefore used in this study. The aim was to test and validate this model combination and to assess its utility in relation to quantification and process understanding. Applying this model combination to simulate surface runoff and soil erosion showed that, in principle, it is possible to satisfactorily simulate surface runoff and observed soil erosion patterns during winter. The values for the calibration parameters were similar for the two chosen winter periods when the rainfall and snowmelt episodes occurred. However, the calibration procedure showed that the utility of this combination had several limitations. It is hoped that this study can help to improve existing models and trigger new developments in including snow pack dynamics and soil freezing and thawing in soil erosion models.

Based on:

Starkloff, T., Stolte, J., Hessel, R., Ritsema, C.J., Jetten, V., Integrated, spatially distributed modelling of surface runoff and soil erosion during winter and spring. 2017, submitted to Catena 


\subsection{Introduction}

In cold climate regions a significant fraction of annual soil erosion in agricultural land occurs during snowmelt and rain on partially frozen soils (Lundekvam and Skøien, 1998; Deelstra et al., 2009; Su et al., 2011). Snow packs have a large impact on the development of surface runoff in catchments. A snow pack that is not 'ripe', i.e. the internal temperature has not reached $0^{\circ} \mathrm{C}$, can act as a buffer by retaining incoming rain water (Gray and Male, 1981). However, rain falling on a melting snow pack can accelerate the snowmelt process and cause large quantities of runoff (Sui and Koehler, 2001). In addition, partially or completely frozen soil modifies surface runoff generation and also the erodibility of the soil (Ollesch et al., 2005). Soil freezing can reduce soil hydraulic conductivity $\left(k_{h}\right)$ by blocking pores and retaining water in the profile, thereby reducing infiltration capacity during snowmelt (Nyberg et al., 2001). Iwata et al. (2011) showed that a frozen soil layer can significantly impede snowmelt infiltration and thus increase runoff of spring snowmelt water. Water flows much faster over a frozen slope than over a thawed one, as shown by Ban et al. (2016). This runoff water can easily erode soil that has been weakened by repeated freezing and thawing (Kværn $\varnothing$ and $\varnothing$ ygarden, 2006). In Norway, the occurrence of snowmelt, combined with rain and soil frost, has led to severe gully and rill erosion, even in low risk areas (Øygarden, 2003). Sediment transfer from fields to streams during winter and spring accounts for a major part of the annual loss of phosphorous and nitrogen from agricultural catchments (Su et al., 2011), resulting in loss of the irreplaceable nutrient-rich top layer of agricultural soils. Runoff during winter and spring also needs to be examined with regard to hazardous floods and as a triggering factor for landslides (Bayard et al., 2005).

Physically based and spatially distributed soil erosion models have proved to be good tools for understanding the processes occurring at catchment scale during rainfall erosion (e.g. Bhuyan et al., 2002; Nearing et al., 2005; Starkloff and Stolte, 2014 (Chapter 2)). Such models are widely used to quantify the impact of climate change and tillage, and the efficiency of mitigation measures. To provide reliable tools for researchers and policy makers who deal with the problems caused by runoff and soil erosion during winter and spring, models have to be capable of reproducing winter hydrology processes (Deelstra et al., 2009). However, most existing erosion models do not account for snow in a suitable way (Weigert et al., 2003; Grønsten and Lundekvam, 2006; Ollesch et al., 2006), because it is one of the most changeable elements in the hydrological cycle and presents a large range of challenges as regards monitoring and measuring (Doesken and Robinson, 2009).

Spatially distributed snow pack models, using a physically-based one-dimensional mass and energy balance have been successfully used to describe spatial variability in snow pack properties (Luce and Tarboton, 2001; Starkloff et al., 2017a (Chapter 4)). Combining such a 
snow pack model with a physically based erosion model could be a solution to quantifying and better understanding the complex processes occurring at catchment scale during winter. A combination of the UEBGrid snow pack model and the LISEM erosion model was therefore used in this study. The first aim was to test and validate this model combination and to assess its utility in relation to quantification and process understanding. A second aim was to evaluate whether this model combination can be a tool for helping to reduce the risk and damage by soil erosion and surface runoff during winter.

\subsection{Methods}

\subsubsection{Winter periods}

For this study, two winter periods were chosen from the long-term monitoring that has been carried out in the study area since 2008. The winter periods of 2012-2013 and 20142015 were chosen because they enabled a comparison to be made between a winter in which erosion was observed (2014-2015) and one in which this was not the case (20122013). This made it possible to investigate which processes lead to soil erosion during winter. Hereafter these winter periods are referred to as winter 2015 and winter 2013, respectively.

\subsubsection{Study area}

The field investigations were carried out in the Gryteland catchment $\left(0.29 \mathrm{~km}^{2}\right)$, located approximately $30 \mathrm{~km}$ south of Oslo, Norway. This area (Fig. 1.2) can be easily reached under all weather conditions. A monitoring station was installed at the outlet of the subcatchment in 2008 and enhanced with a weather station in 2013. This station measures precipitation, air temperature, relative humidity, solar radiation, wind direction and speed, and surface runoff and drainage discharge. In addition, five stations (one at the outlet) were installed in the catchment (Kramer and Stolte, 2009) along a transect (Fig. 1.2) to measure soil moisture and soil temperature at four depths $(5,10,20$ and $40 \mathrm{~cm})$.

The sub-catchment is characterised by undulating landscape (elevation: 106-141 m, slope $2-10 \%$ ) covered by approx. $60 \%$ arable land and $40 \%$ coniferous forest. Soil types in the arable land (Fig. 1.2), are a levelled clay loam (Stagnosol), and silty clay loam (Albeluvisol) (Group 1), and sandy silt on clay (Umbrisol) and sand to loamy medium sand (Histic Gleysol) (Group 2). Hereafter, the two groups are referred to as clay and sand, respectively. 
The mean annual temperature is $5.3^{\circ} \mathrm{C}$, with a minimum average daily temperature of -4.8 ${ }^{\circ} \mathrm{C}$ in January/February and a maximum average daily temperature of $16.1^{\circ} \mathrm{C}$ in July. The mean annual precipitation is $785 \mathrm{~mm}$, with a minimum monthly amount of $35 \mathrm{~mm}$ in February and a maximum of $100 \mathrm{~mm}$ in October (Thue-Hansen and Grimenes, 2015). Winter is usually relatively unstable, with alternating periods of freezing and thawing and several snowmelt events (Kværnø and Øygarden, 2006).

Tillage practices were no-till after harvest in 2013, leaving the fields covered in stubble. In 2015 , secondary tillage was carried out after harvest with a cultivator on the slopes, leaving the depressions covered with stubble.

\subsubsection{Field investigations}

The detailed field investigations carried out during the two winters included spatially distributed measuring of snow water equivalent (SWE) after weather changes that were expected to result in changes in SWE. These measurements were used to calibrate the snow pack model used in this study. A detailed description of the snow measuring set-up that was used can be found in Starkloff et al. (2017a (Chapter 4)). Changes in soil water content and soil temperature were monitored at the measuring stations in the catchment (Fig. 1.2). With these measurements, it was possible to estimate the depth of freezing in the soil profiles. Soil erosion features were also documented. Minor erosion damage was recorded by taking pictures. The extent of any large features observed was mapped using a differential GPS, and the depth and width were measured at several points using a ruler. A detailed description of these field measurements can be found in Starkloff et al. (2017b (Chapter 3)).

\subsection{Model description}

For this study, the grid version of the Utah Energy Balance snow model (UEBGrid) was used to calculate the distributed snow pack development. The surface discharge and soil erosion were modelled using the Limburg Soil Erosion Model (LISEM). This section describes the two models and how they were combined.

\subsubsection{UEBGrid}

UEBGrid (Sen Gupta and Tarboton, 2013) was selected based on the physical characterisation of the snow pack and energy and mass fluxes within the model, and its 
ability to calculate spatially distributed snow-pack dynamics. The model uses snow-pack energy content, and snow water equivalent as two state variables. The energy content of the snow pack is relative to ice at $0^{\circ} \mathrm{C}$ and is determined by atmospheric input, advective heat removed by meltwater, outgoing longwave radiation and thermal interaction (ground heat flux) with the soil layer beneath it. Snow surface temperature is considered as a third state variable, with the main purpose of estimating the snow surface albedo. The snow pack is represented as a single layer to avoid over-parameterisation (Sen Gupta and Tarboton, 2013). The model is driven by (atmospheric) input of air temperature, precipitation (rain and snow), wind speed, humidity and solar radiation at time steps sufficient to resolve the diurnal cycle (six hours or less). The model uses physically based calculations of radiative, sensible, latent and advective heat exchanges. A force-restore approach (driving flux at the surface is sinusoidal) is used to represent surface temperature, accounting for differences between snow surface temperature and average snow pack temperature without having to introduce additional state variables. The melt outflow rate from the snow pack is determined by the liquid content of the snow pack, using Darcy's law for porous media. Rain is added to the snow pack by increasing the SWE until the internal temperature of the snow pack reaches $0^{\circ} \mathrm{C}$. Until this temperature is reached no meltwater output will be released from the snow pack. After that any additional rain is directly added to the meltwater output of the melting snow pack. Sen Gupta and Tarboton (2013) reorganised the input-output workflow of UEB to use network Common Data Form map files (netCDF) to enable the model to be run over a grid with input varying in space and time. This resulted in the UEBGrid model used in this study. In Starkloff et al. (2017a (Chapter 4)), a detailed description of the set-up and calibration of the UEBGrid model for winter 2013 and 2015 is given. The model runs separately at each grid cell. With the applied $5 \times 5 \mathrm{~m}$ grid cell size it was possible to simulate the spatial and temporal heterogeneity of the snow cover during the two winter periods (Starkloff et al., 2017a (Chapter 4)).

\subsubsection{LISEM}

LISEM (De Roo et al., 1996; Jettern and De Roo, 2001) was selected for this study because it allows the input of snowmelt discharge and it has previously been used successfully for the study area (Starkloff and Stolte, 2014 (Chapter 2)). LISEM is a spatial hydrological and erosion model that simulates runoff, sediment dynamics and shallow floods. The model works at catchment scale and is event-based, which means that it predicts soil erosion and surface discharge caused by short-term (a few minutes up to a few days) rain events. LISEM uses input maps to model the physical characteristics of the watershed. Many of these characteristics are based on a digital elevation model (DEM), which is then used to determine maps such as LDD (local drain direction), gradient (steepness of path along LDD), 
and the position of the watershed outlet. Land use maps include surface cover, leaf area index, plant height, roads, and grass strips. Soil surface maps include random roughness, Manning's $n$, and maps for including soil crust, compaction and stone fraction. Erosion is computed using maps with values for soil cohesion, additional cohesion provided by plant roots, aggregate stability for splash erosion, and median particle diameter. The soil profile can be divided into layers, and the corresponding soil water characteristic curves for each soil type are read from tables provided by the user. The initial hydraulic potential of each layer is provided by the user. Rainfall is handled by the model by first removing a fraction of the precipitation due to plant interception. The kinetic energy of the raindrops striking the soil surface is then taken into account to simulate splash erosion. Water that reaches the soil surface is then ponded there, and can become surface storage, infiltration or runoff.

In this study, the raster maps ( $5 \times 5$ m cells), were created using PCRaster and ESRI ArcMap 10.2.2. Because the time step length can have an effect on the numerical stability of the calculations in LISEM (Hessel, 2005), different time step resolutions were tested (5 sec, 30 sec, 10 minutes, 30 minutes and 60 minutes) to make sure that this did not influence the simulation results. As no effect of time step length was found, a time step of 60 minutes was chosen, since this resulted in the shortest duration of the simulations. The openLISEM version 2.01 (23.08.2015) was used.

The principles of LISEM have been discussed in several studies (De Roo et al., 1996; Jetten and De Roo, 2001; Starkloff and Stolte, 2014 (Chapter 2)).

\subsubsection{Combining UEBGrid and LISEM}

In Fig. 6.2, the basic structure of LISEM is presented together with the additional meltwater input calculated using UEBgrid. The figure also shows which parameters were used for the calibration, and which data were used for the validation of the performance of the combined LISEM/UEBGrid.

The snowmelt input option in LISEM was used to process the meltwater output from the snow pack, calculated using UEBGrid. Snowmelt is handled differently from rainfall in LISEM; it is simply ponded on the soil surface during every time step, while for rainfall both interception by vegetation and splash erosion are calculated. 


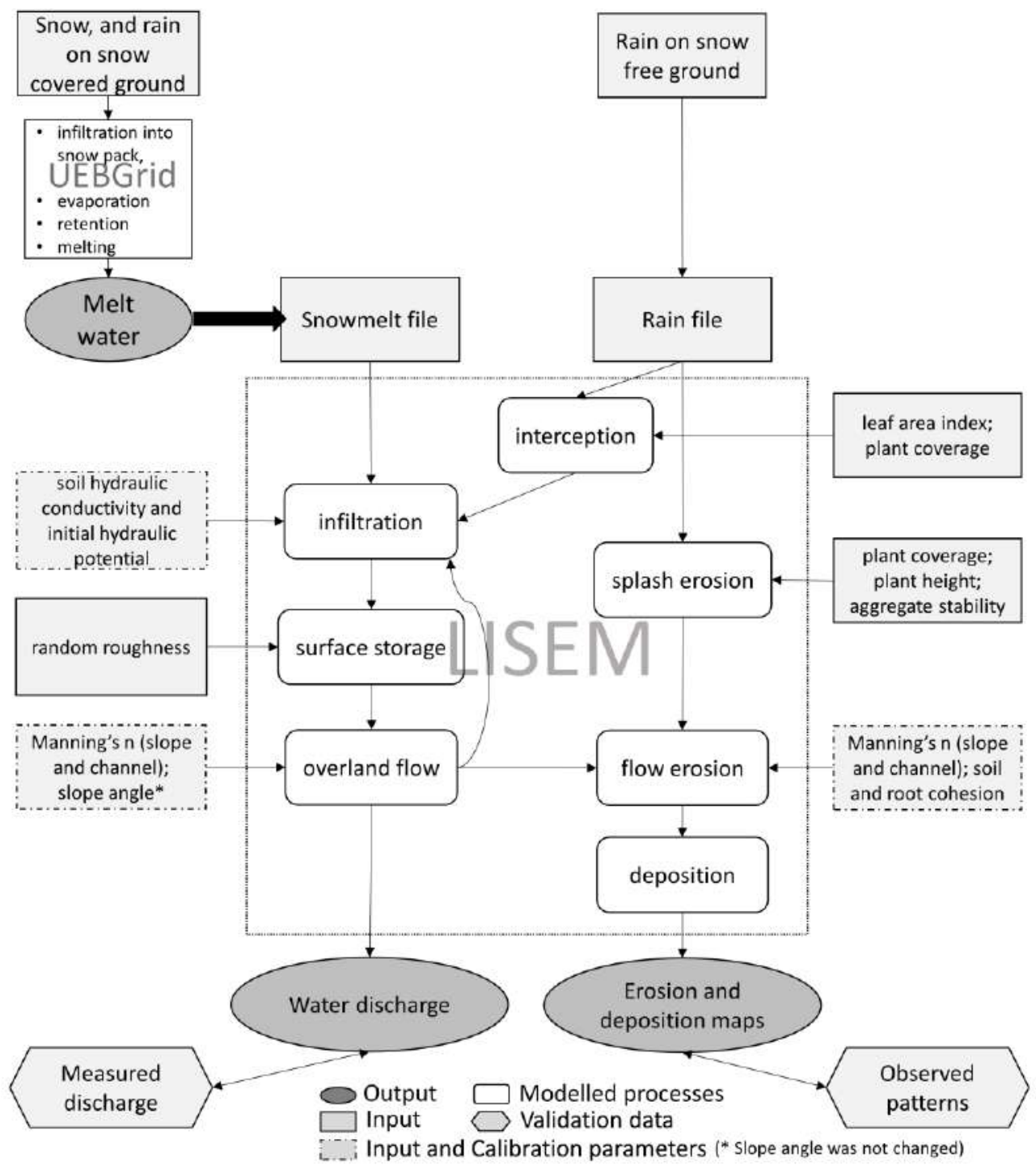

Fig. 6.2: Workflow of the modelling and the basic structure of LISEM.

When a snow cover existed or when precipitation was snow, the snowmelt input file was used. This file allows the input of the total meltwater outflow from predefined subwatersheds (the sum of the output from each grid cell within the watershed) for each time step. The meltwater inputs for the predefined areas of the catchment (ID map, Fig. 6.3) were calculated using UEBGrid. These areas were aggregated based on slope, curvature and aspect. 
Measurements existed for this area for all input parameters (Table 6.1), except for the parameters 'root cohesion' and 'Manning's $n$ for the channel'. Different input values were used for the two years because of the differences in tillage practice.

Table 6.1: LISEM input parameters for the simulations in 2013 and 2015. (1) Thomsen et al., (2015); (2) Linden (2016); (3) Starkloff et al., (2017b); (4) Schols (2016); * adjusted during calibration

\begin{tabular}{|c|c|c|c|c|c|c|c|}
\hline \multirow{2}{*}{ Parameters } & \multicolumn{3}{|c|}{2013} & \multicolumn{4}{|c|}{2015} \\
\hline & $\begin{array}{l}\text { Sandy } \\
\text { soil }\end{array}$ & $\begin{array}{l}\text { Clay } \\
\text { soil }\end{array}$ & Forest & $\begin{array}{l}\text { Sandy } \\
\text { soil }\end{array}$ & $\begin{array}{l}\text { Clay } \\
\text { soil }\end{array}$ & Forest & $\begin{array}{l}\text { Depre } \\
\text { ssion }\end{array}$ \\
\hline LAI $\left[\mathrm{m}^{2} \mathrm{~m}^{-2}\right]$ & 0.4 & 0.4 & 6 & 0.3 & 0.3 & 6 & 0.4 \\
\hline Plant cover [-] & 0.43 & 0.43 & 1 & 0.3 & 0.3 & 1 & 0.43 \\
\hline Plant height [m] & 0.2 & 0.2 & 15 & 0.1 & 0.1 & 15 & 0.17 \\
\hline Random roughness $[\mathrm{cm}]^{(1)}$ & 1.25 & 1.25 & 1.22 & 1.3 & 1.3 & 1.22 & 1.25 \\
\hline Manning's n [-] ${ }^{*(2)}$ & 0.17 & 0.17 & 1.2 & 0.2 & 0.2 & 1.2 & 0.17 \\
\hline $\begin{array}{l}\left.\text { Initial hydraulic potential ( } h_{\text {init }}\right) \\
{[\mathrm{cm}]^{*}}\end{array}$ & -50 & -50 & -50 & -50 & -50 & -50 & -50 \\
\hline$K_{\text {sat }}\left[\mathrm{cm} \mathrm{day} \text { da }^{-1}\right]^{*(3)}$ & 432 & 62.4 & 450 & 432 & 62.4 & 450 & 62.4 \\
\hline Cohesion [kPa] & 60 & 60 & 500 & 19 & 40 & 500 & 60 \\
\hline Plant root cohesion [kPa] & 1 & 1 & 200 & 1 & 1 & 200 & 1 \\
\hline Aggregate stability $[-]^{(4)}$ & 34 & 161 & 202 & 34 & 161 & 202 & 161 \\
\hline Channel width [m] & - & - & - & - & - & - & 0.5 \\
\hline Manning's n of channel [-] & - & - & - & - & - & - & 1.5 \\
\hline
\end{tabular}

To simulate infiltration and water flow in the soil profile, the Swatre sub-model (Belmans et al., 1983), which solves the Richard's equation, was chosen in this study. Based on soil profiles excavated in the field, four soil layers were defined for the clay and sand soil (0-25 $\mathrm{cm}, 25-55 \mathrm{~cm}, 55-80 \mathrm{~cm}$ and $80-100 \mathrm{~cm})$. Measured soil water retention curves were available for the upper layer $(0-25 \mathrm{~cm})$ of the clay and sand soil, from which unsaturated hydraulic conductivities were estimated using the software RETC (van Genuchten et al., 1991). For the deeper soil layers, the soil hydraulic characteristics were estimated using pedo-transfer-functions (Kværnø and Stolte, 2012). The values of the parameters, 'initial hydraulic potential' $\left(h_{\text {init }}\right)$ and $k_{h}$ were based on Starkloff et al. (2017b (Chapter 3$)$ ). They measured low soil water contents when soil temperatures were below and around $0{ }^{\circ} \mathrm{C}$, indicating the occurrence of ice in the soil, which can reduce water infiltration due to blockage of pores. 
To account for the differences in tillage between the two years, two different land unit maps were produced for 2013 and 2015 (Fig. 6.3). In 2015 the depressions were covered with stubble. The depressions were therefore defined as a separate unit to enable these areas to be given different values for the input parameters (Table 6.1). In addition, a channel was defined (Fig. 6.3) that was used for the model runs after the first rain event (06.01.-08.01.) in 2015 in order to account for a rill that was formed during this event (Starkloff et al., 2017b (Chapter 3)).

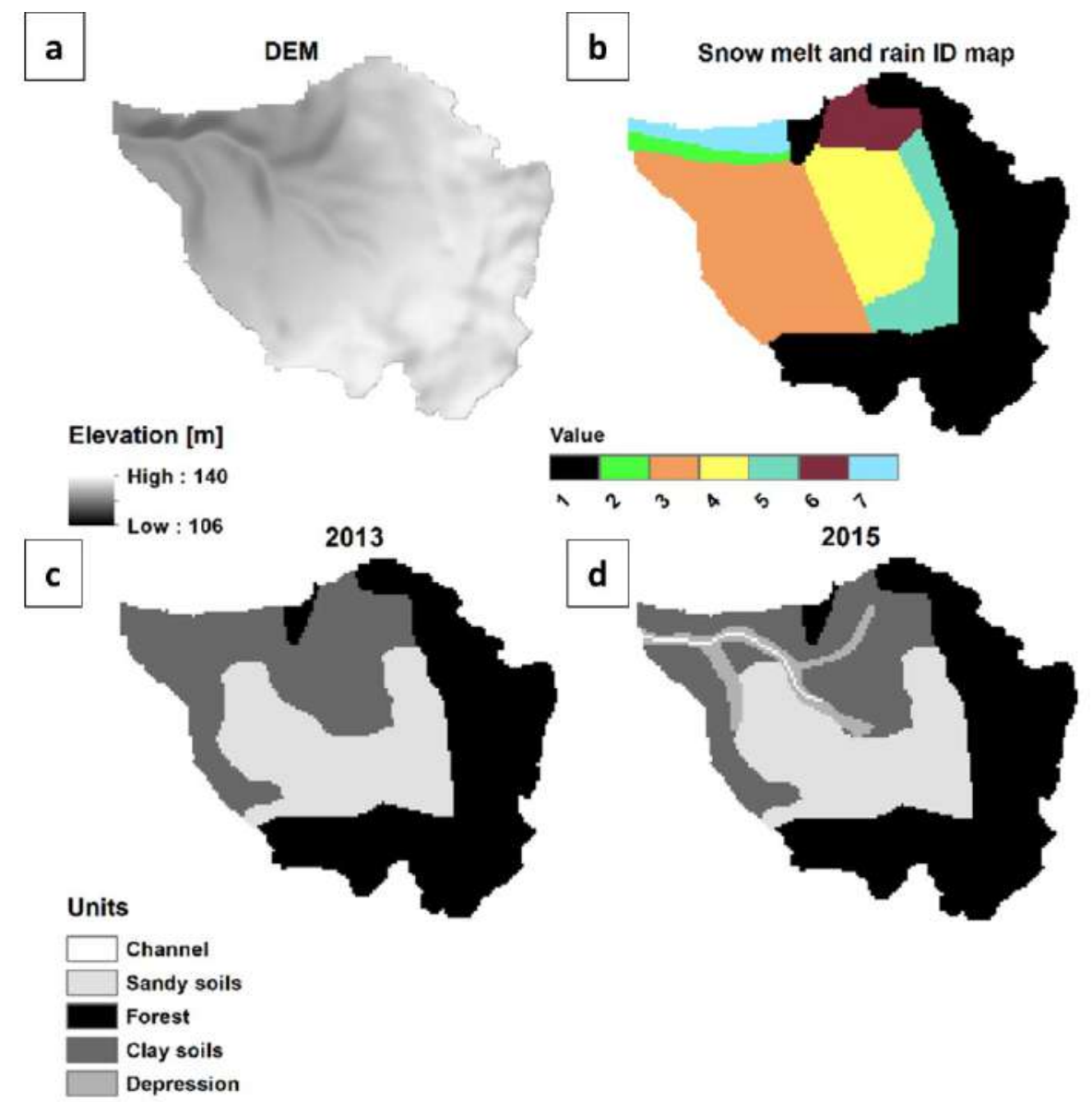

Fig. 6.3: The DEM (a), snowmelt and rain ID map (b) and the land unit maps for winter 2013 (c) and winter 2015 (d) created for the LISEM simulations.

In Fig. 6.3 the snowmelt and rain ID map is shown. It corresponded to the areas used for the meltwater output calculated using UEBGrid. Area no. 1 was the forest for which no 
snowmelt was simulated using UEBGrid (because of too shallow snow pack (Starkloff et al., 2017a (Chapter 4)), but which was included for the rain events.

Because LISEM was developed as an event based model the two winter periods had to be split into several shorter episodes, to adjust the calibration parameters to the changing conditions, e.g. changes in (un- and saturated) soil hydraulic conductivity ( $k_{h}$ and $k_{\text {sat }}$ ) due to freezing and thawing soils. Furthermore, the winter periods had to be split into episodes with runoff triggered by snowmelt and episodes with runoff caused by rain on snow-free ground. For the former episodes, meltwater discharge calculated using UEBGrid was used as input for LISEM, while for the latter episodes, measured precipitation was used as input. To define suitable periods, the measured precipitation and calculated snowmelt from each ID map area $(2,3,4,5,6$ and 7$)$, simulated using UEBGrid were compared with the measured runoff for both years (Fig. 6.4 and 6.5).
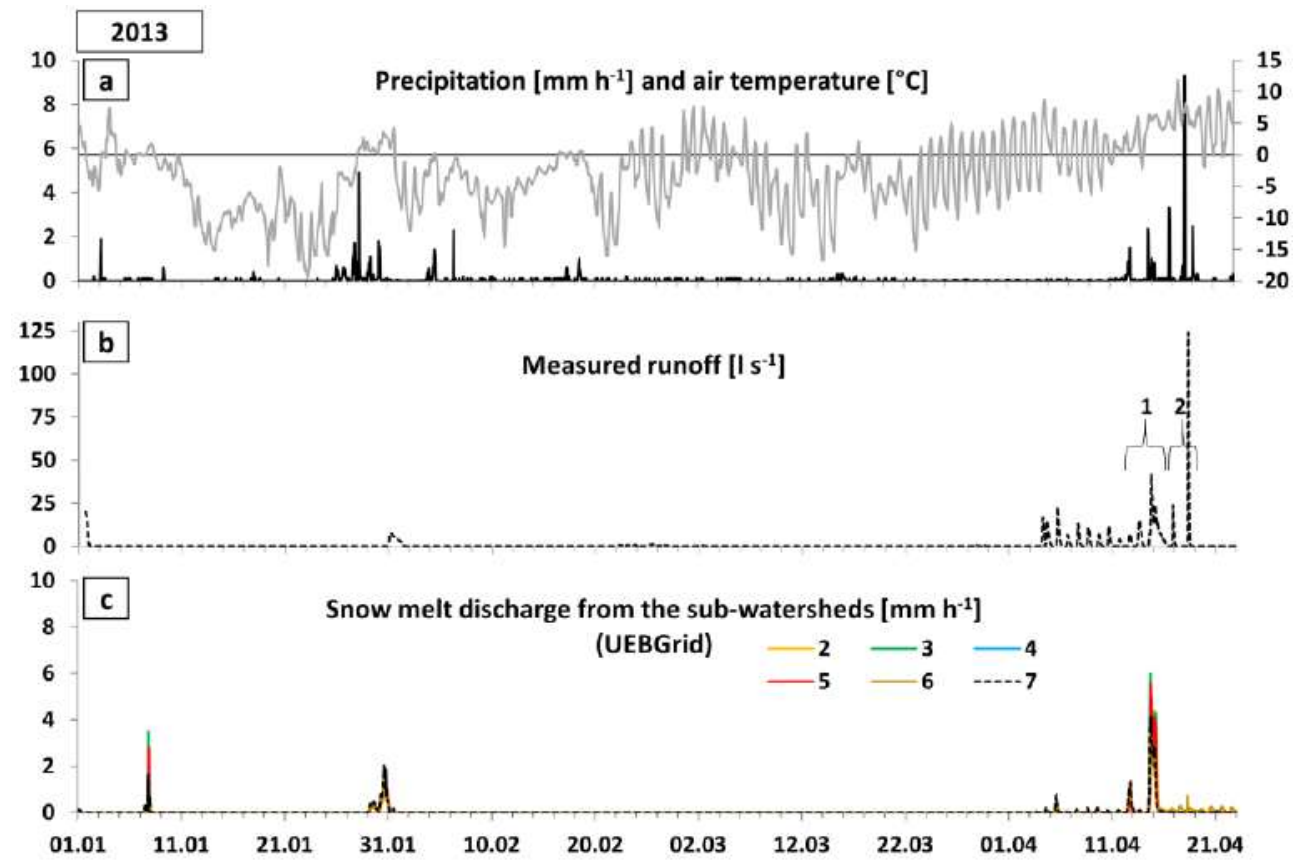

Fig. 6.4: Measured precipitation and air temperature (a), and measured surface runoff (b) for winter 2013. The runoff episodes simulated with LISEM are numbered in the measured runoff graph. Snowmelt from the ID map areas (2-7) was simulated using UEBGrid (c).

In winter 2013, significant runoff only occurred at the end of the winter, where the first peaks were mainly triggered by snow melt discharge and the last two peaks by rain. The LISEM modelling was therefore split into two episodes: the first was the major snowmelt 
episode (14 April 2013-16 April 2013) and the second was the last rain event (17 April 201319 April 2013). The rest of the winter period of 2013 was not considered further for LISEM, due to the lack of significant runoff. However, to simulate the development of the snow pack the whole winter period was simulated using UEBGrid.

Winter 2015 was more complex than winter 2013, with five runoff episodes (Fig. 6.5), resulting in the LISEM simulations being split into five episodes. The first episode was a rain event (6 Jan. 2015-8 Jan. 2015), the second episode a combination of rain and snowmelt (15 Jan. 2015-17 Jan. 2015), the third episode was also a combination of rain and snowmelt (26 Jan. 2015-30 Jan. 2015), the fourth episode was a snowmelt event (18 Feb. 2015-28 Feb. 2015 ) and the fifth episode was a rain event that occurred after the snow had gone (28 Feb. 2015-1 Mars 2015).

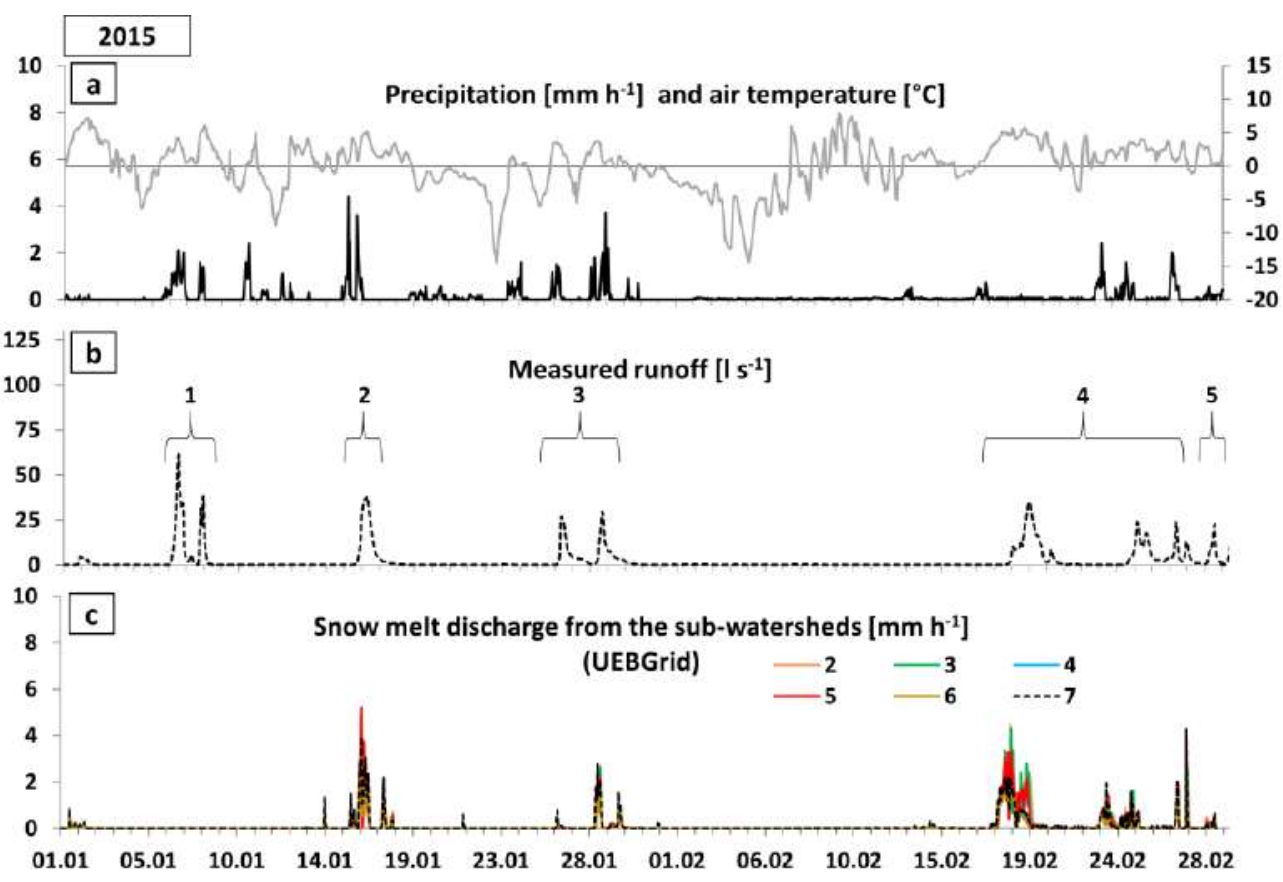

Fig. 6.5: Measured precipitation and air temperature (a), and measured surface runoff (b) for winter 2015. The runoff episodes simulated using LISEM are numbered in the measured runoff graph. Snowmelt from the ID map areas (2-7) was simulated using UEBGrid (c). 


\subsection{Results and discussion of the surface runoff and soil erosion modelling}

The resulting hydrographs of the LISEM simulations for winter 2013 are shown in Fig. 6.6. A selection of calibration curves are presented for each episode. A reduction of the initial $k_{h}$ values by $60 \%$ resulted in the best fit for the snowmelt episode in 2013 (Fig. 6.6a), thus accounting for reduced soil permeability due to ice in the soils. In addition, the initial $h_{\text {init }}$ had to be increased from -50 to $-150 \mathrm{~cm}$ to account for a reduction in liquid water in the soil profiles due to freezing.

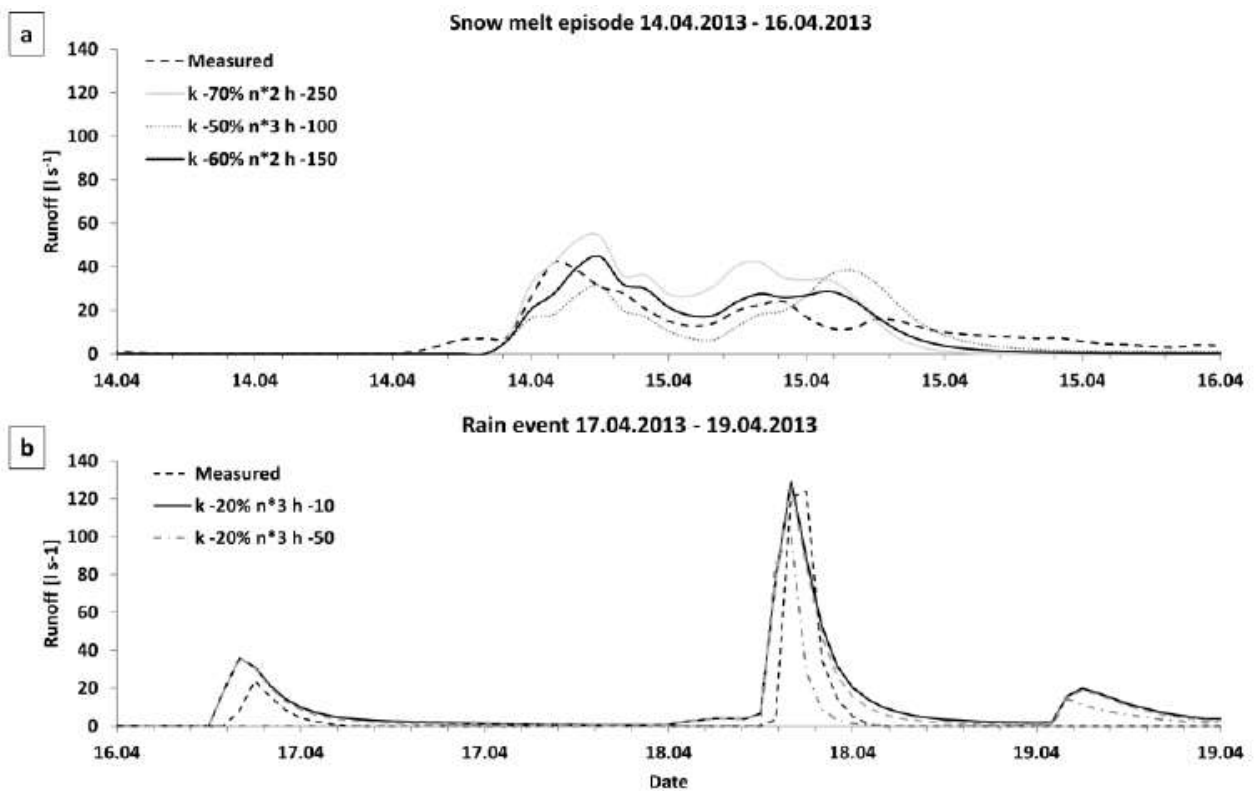

Fig. 6.6: Measured and simulated hydrographs for the snowmelt (a) and rainfall event (b) simulated with the LISEM model for winter 2013. The black curve presents the best fit. $k=k_{h}, n=$ Manning's $n$ of the slopes, $h$ $=h_{\text {init }}$

The Manning's $\mathrm{n}$ value of the slopes was increased by a factor 2 to simulate a reduction in surface runoff speed, which can be expected from a melting snow pack. UEBGrid considers delays in meltwater output due to vertical water movement through the snow pack. The horizontal water movement is not included in the model.

Fig. 6.6b shows the simulation results for the rain event at the end of winter 2013. To achieve a satisfactory fit to the measured hydrograph $h_{\text {init }}$ had to be decreased to $-10 \mathrm{~cm}, k_{h}$ was reduced by $20 \%$ and Manning's $n$ was increased by a factor of three. The lower $h_{\text {init }}$ reflects the increase in soil water content due to thawing of the soils and infiltrating water 
from the previous snowmelt episode. Soil water content measurements showed that the soils had almost reached saturation when the final rain event occurred (Starkloff et al., 2017b (Chapter 3)). The increase in $k_{h}$ compared with the previous snowmelt event reflected that the soils had started to thaw. Manning's $n$ had to be increased for the rain event caused by the state of the surface cover. The initial Manning's $n$ values were measured for stubbles (Linden, 2016). In the 2013 situation, however, straw residuals were left on the ground in addition to the stubbles. Where the surface runoff accumulated, these residuals created dams (Fig. 6.7), often where ice and snow residues occurred, which decelerated the surface runoff and caused ponding. Such processes are difficult for standardised Manning's n measurements to take into account.

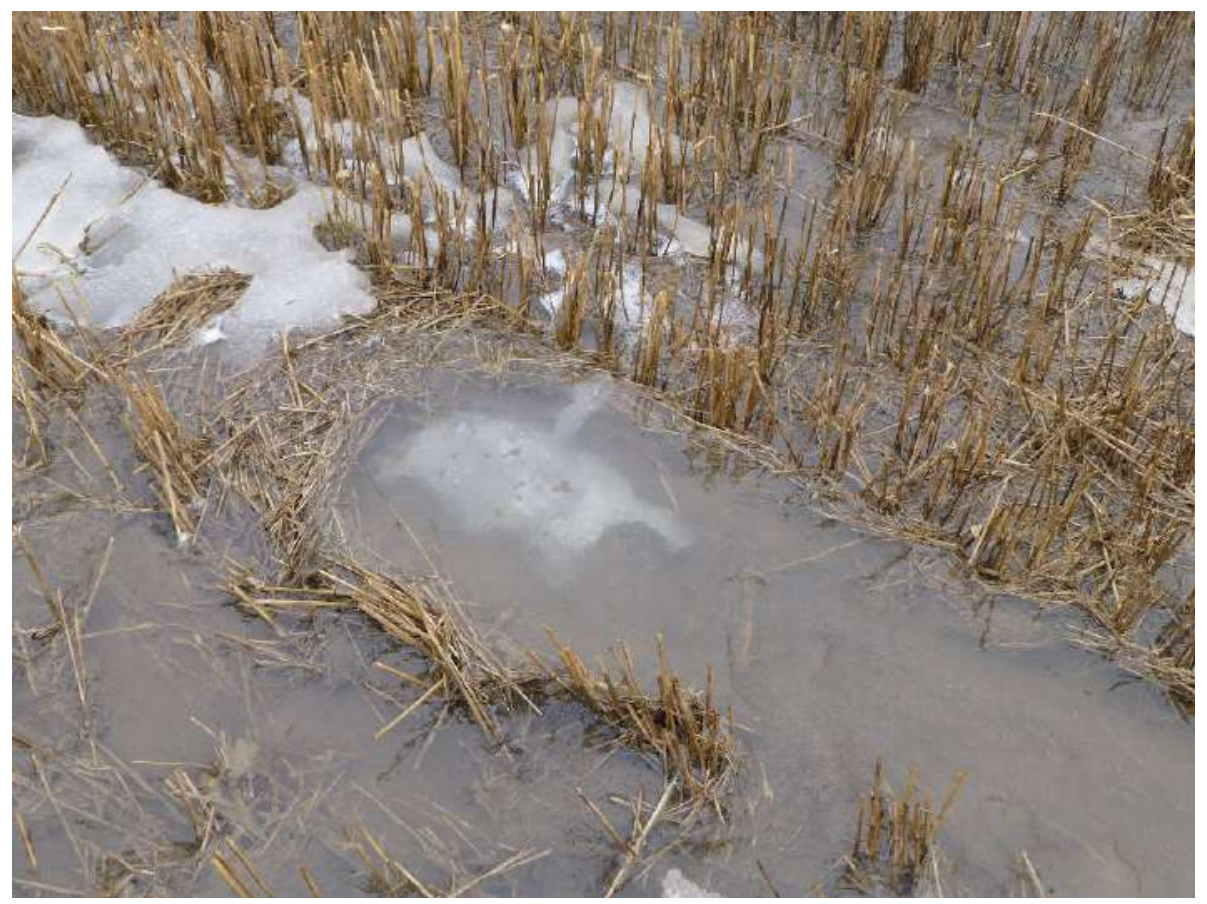

Fig. 6.7: Runoff accumulation at a small dam created by residual straw and residual ice. The photo was taken on 15 April 2013.

Soil loss maps for the best calibration simulations (Fig. 6.6, black curves) are shown in Fig. 6.8. LISEM predicted no significant erosion for the snowmelt episode in 2013 (Fig. 6.8a), which was in agreement with what was observed in the field. For the rain event of 2013, LISEM predicted considerable erosion in several areas of the catchment (Fig. 6.8b). No erosion was observed in the catchment in winter 2013, however. 

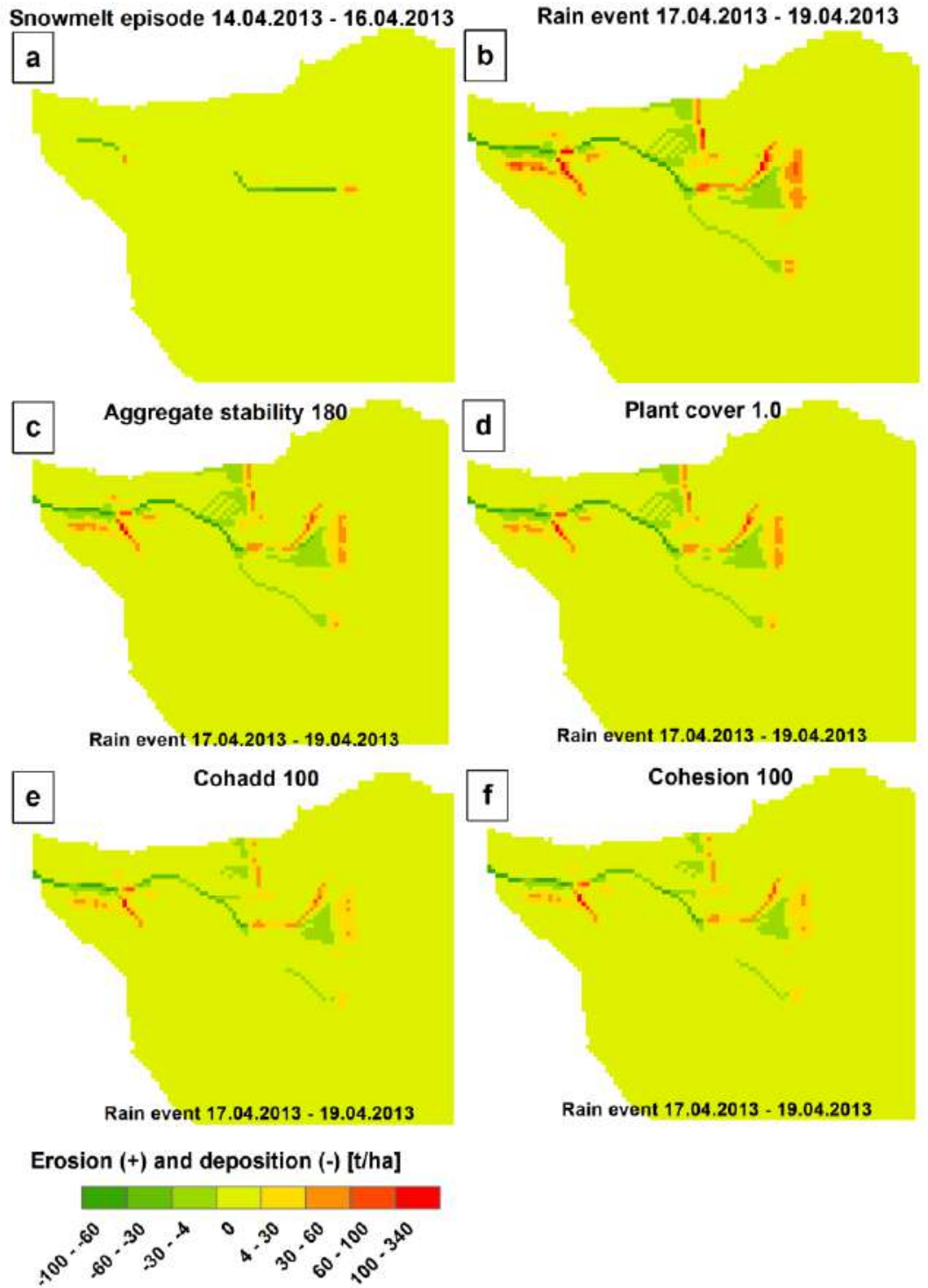

Fig. 6.8: Simulated soil loss maps calculated using LISEM for the two episodes ( $a$ and $b$ ). In addition soil loss maps for model runs (for the rain event) with an aggregate stability adjusted to 180 (c), a plant cover adjusted to 1.0 for the agricultural areas (d), an additional root cohesion of $100 \mathrm{kPa}(e)$ and a soil cohesion adjusted to $100 \mathrm{kPa}(\mathrm{f})$ are presented.

Erosion is triggered in LISEM by the force of surface runoff and the kinetic impact of the raindrops. To check how the plant cover influenced erosion for the simulated rain event in winter 2013 the parameters 'aggregate stability' and 'plant cover', as well as the parameters 
'root cohesion' (Cohadd) and 'soil cohesion', were adjusted separately. Increasing of the first two parameters (aggregate stability to 180 and the plant cover to 1) only had insignificant effects on the erosion rates simulated by LISEM (Fig. 6.8c and d respectively), suggesting that splash erosion was negligible for this episode. However, the increase in Cohadd and cohesion to $100 \mathrm{kPa}$, reduced the amount of erosion simulated by LISEM (Fig. $6.8 \mathrm{e}$ and $\mathrm{f}$ respectively). When the soil cohesion and Cohadd were further adjusted to values used for the forest ( $500 \mathrm{kPa}$ and $200 \mathrm{kPa}$ respectively), no erosion was simulated. Starkloff et al. (2017b (Chapter 3)) concluded that the dense surface cover by stubble and straw residues prevented any soil erosion in the area in winter 2013. The effect of increasing the Cohadd parameter suggested that the roots of the stubbles might possibly have reduced soil detachment.

A selection of simulated hydrographs for the snowmelt and rain events during winter 2015 is shown in Fig. 6.9. The highest amount of runoff was measured during the first rain event (Fig. 6.9a). For the best fit, $k_{h}$ had to be reduced to $1 \%$ of the initial values (Table 6.1) and $h_{\text {init }}$ had to be adjusted to $-150 \mathrm{~cm}$ to account for soil freezing. Manning's $\mathrm{n}$ for the slopes was multiplied by a factor of two to improve the shape of the hydrographs. This calibration result suggested that the infiltration capacity of the soils was largely reduced by freezing, which was confirmed by the large discharge coefficient of 63\% (Starkloff et al., 2017b (Chapter 3 )). The large amount of surface runoff caused erosion and created a rill system. To account for the different flow patterns caused by the rill, a $0.5 \mathrm{~m}$ wide channel was included in the LISEM simulations (Fig. 6.3) for the subsequent episodes in winter 2015.

For the first snowmelt episode (Fig. 6.9b) in winter 2015, similar values were used as for the snowmelt in 2013 (Fig. 6.6a) to account for partially frozen soils. The $k_{h}$ was reduced by $70 \%$ and $h_{\text {init }}$ was adjusted to $-200 \mathrm{~cm}$. As in 2013 Manning's n was multiplied by 3. 

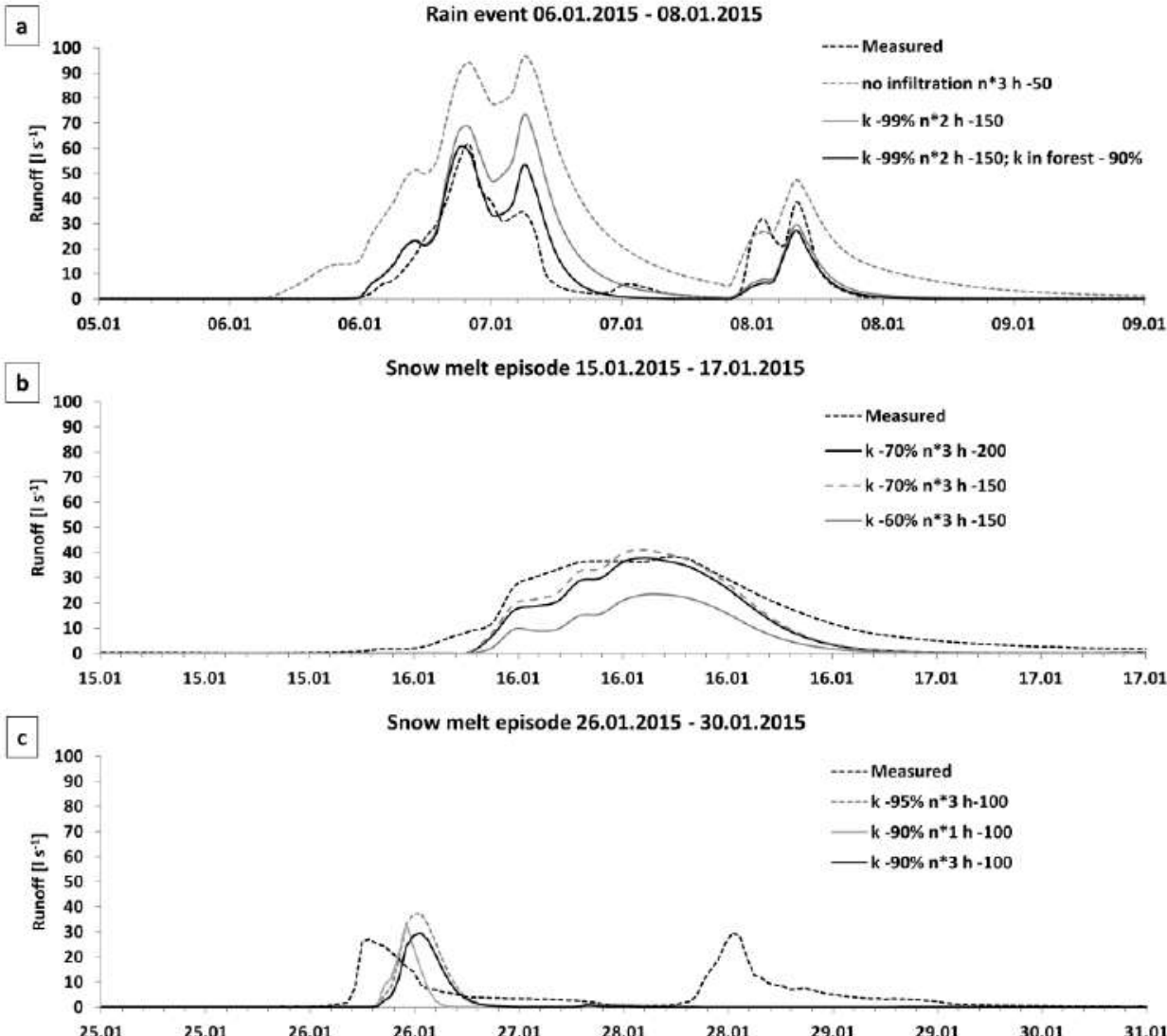

d
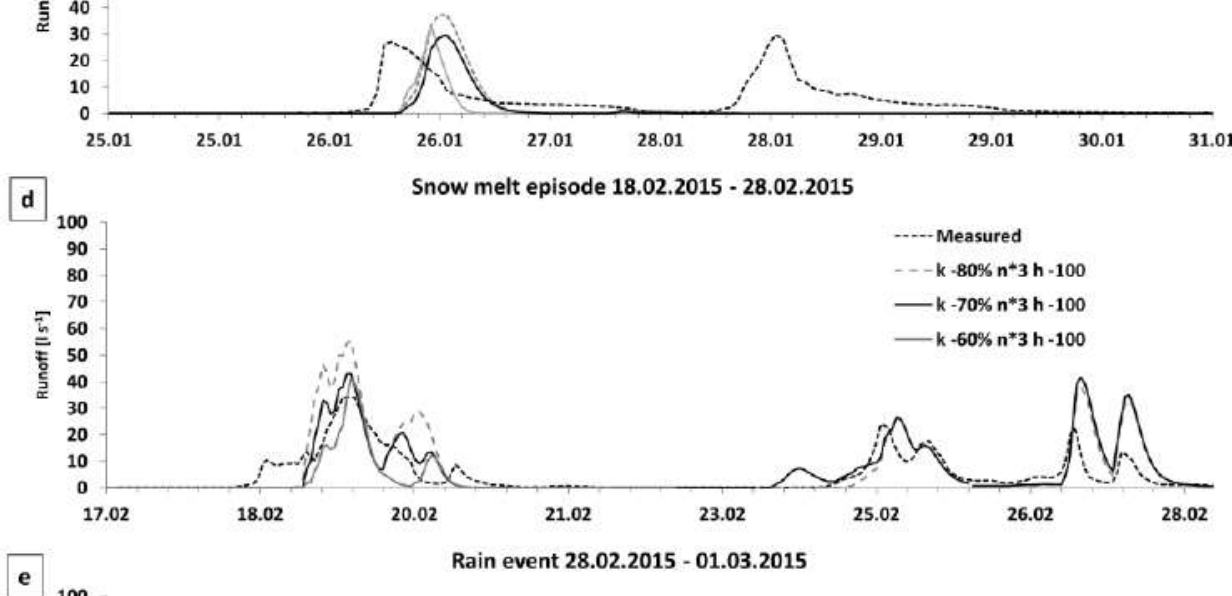

Rain event 28.02.2015 - 01.03.2015

e

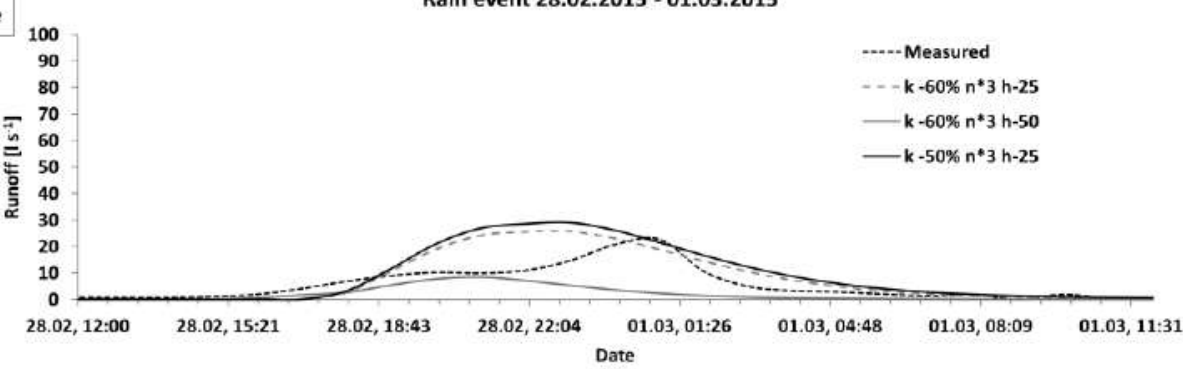


Fig. 6.9: (previous page) Measured and simulated hydrographs for the five episodes (a-e) simulated using LISEM for winter 2015. The black curve presents the best fit. $k=k_{h}, n=$ Manning's $n$ of the slopes, $h=h_{\text {init }}$

The third episode in 2015 (Fig. 6.9c) was characterised by air temperatures fluctuating between $-5^{\circ} \mathrm{C}$ and $+5^{\circ} \mathrm{C}$ (Fig. 6.5), causing snowmelt and refreezing of meltwater. After the first snowmelt episode (Fig. 6.9b), a $15 \mathrm{~cm}$-thick ice layer formed in the depressions due to refreezing of meltwater. This ice layer forced melt water from the second snowmelt episode (Fig. 6.9c) to flow below and on top of this ice crust. In addition, some uncertainties have to be expected in the UEBGrid output due to difficulty of correctly reproducing each of the melting episodes occurring during these temperature changes. Stolte et al. (2003) found that the LISEM model had problems correctly reproducing such low amounts of runoff and, considering the complexity of the occurring processes, these simulations were probably within the error range that can be expected for LISEM. Due to these problems the model did not simulate the second peak measured during the third episode in 2015.

The fourth episode (Fig. 6.9d), a snowmelt event, was satisfactory reproduced by LISEM, applying similar values for $k_{h}, h_{\text {init }}$ and Manning's $n$ as used for the snowmelt event in 2013 and the second episode in 2015. A slight overprediction of the last two peaks occurred (Fig. $6.9 \mathrm{~d})$, suggesting that more infiltration occurred than was calculated, probably due to continuous thawing of the soils during the event, resulting in a continuous increase in $k_{h}$.

The final episode in winter 2015 (Fig. 6.9e) was an event dominated by rain with some snowmelt. Little precipitation occurred and most of the snow had melted, which resulted in little runoff (peak discharge of $21 \mathrm{I} \mathrm{s}^{-1}$ ). To simulate comparable runoff rates, $k_{h}$ was reduced by $50 \%$ and $h_{\text {init }}$ was decreased to $-25 \mathrm{~cm}$. Manning's $\mathrm{n}$ was not changed in comparison to the previous episode because a lot of ice was still in the flow paths of the depressions.

A soil loss map for the first rain event (black curves in Fig. 6.9a) in winter 2015 is shown in Fig. 6.10. No erosion was predicted for the last four episodes, which was in agreement with what was observed in the field, where all major erosion features were created by the first rain event. For this event, LISEM predicted considerable erosion in some parts of the catchment (Fig. 6.10).

The simulated amount of erosion (Fig. 6.10) was of the same order of magnitude as the maximum measured amount of erosion of $267 \mathrm{t} \mathrm{ha}^{-1}$. The location where major erosion occurred was also predicted (Fig. 6.10, areas marked with and ' $E$ '). It corresponded well with what was observed in the field. LISEM mainly predicted deposition in the depression leading to the outlet (Fig. 6.10, line feature marked with a ' $D$ '). In the field, considerable deposition was observed in this depression, but also a shallow rill (approx. 20-40 cm wide and $5-20 \mathrm{~cm}$ 
deep), which LISEM did not predict. The field observations, also from other years, suggest that small differences in the state of the soil surface and crop residual cover determine whether a rill occurs or not (Starkloff et al., 2017b (Chapter 3)). Small differences can be, for example, how much residual straw was left on the ground or where the stubble was flattened in wheel tracks. Such small differences are difficult to account for when modelling at catchment scale, especially in context of increasingly complex processes due to freezethaw.

Rain event 06.01.2015 - 08.01.2015
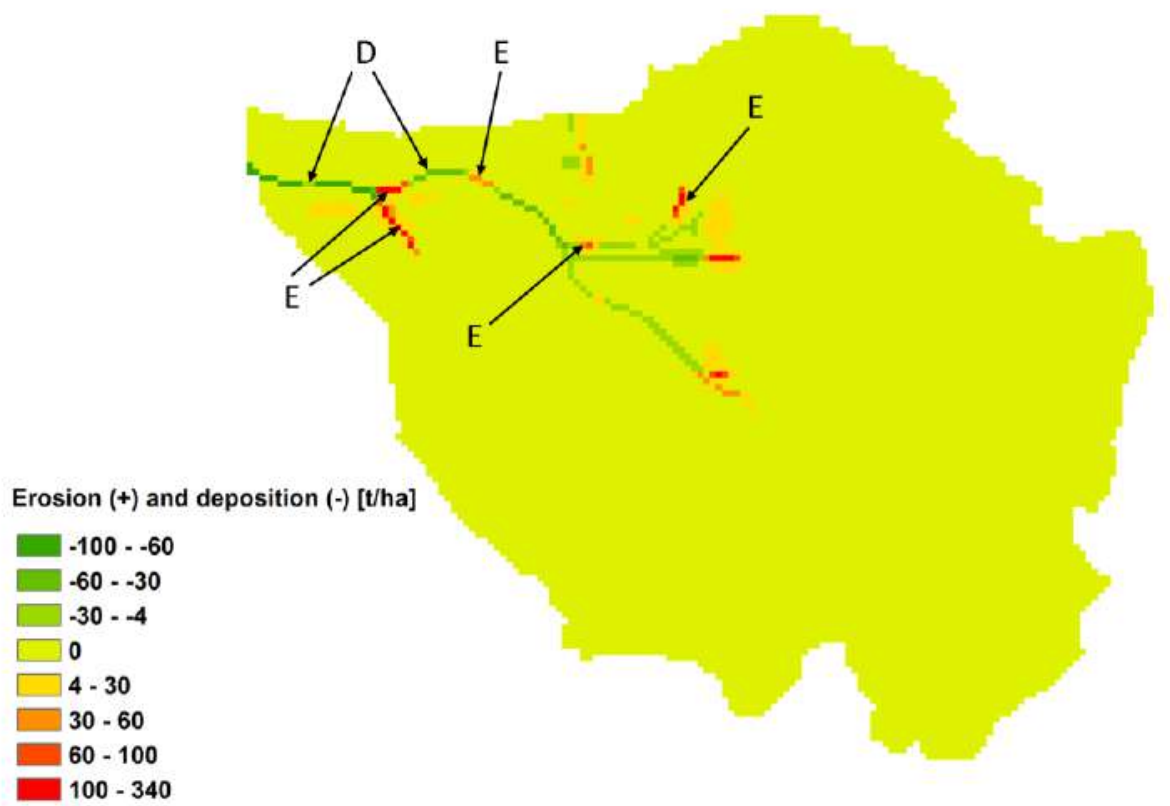

Fig. 6.10: Simulated soil loss maps produced by LISEM for the first rain event of winter 2015. Marked erosion $(E)$ and deposition (D) features are discussed in the text. 


\subsection{General implications and conclusions}

Applying the erosion model LISEM together with the snow model UEBGrid to simulate surface runoff and soil erosion showed that, in principle, it is possible to satisfactorily simulate surface runoff and observed soil erosion patterns during winter. The calibration values for the parameters $k_{h}, h_{\text {init }}$ and Manning's $n$ were similar in the two years when the rainfall and snowmelt episodes occurred. This could suggest that these values for these parameters generally describe the soil conditions during winter and spring and should be tested for other winter periods.

Most of the assumptions made for the calibration and interpretation of modelling results were only possible due to good knowledge of the area and the availability of detailed measuring data. Given this background knowledge, it was possible to adjust the chosen calibration parameters so that a satisfactory fit was achieved, while maintaining plausible values for these parameters given the characteristics of the study area.

Our study shows that, to quantify spatially distributed soil erosion during winter and spring, process understanding is necessary as regards:

- the reduction of water infiltration due to ice (at the surface and in the soil profile)

- the effect of ice and snow layers on surface flow

- the change in soil surface structure due to freeze-thaw

It can therefore be concluded that combining a snow model with an erosion model makes for a useful tool for dealing with problems caused by runoff and soil erosion during winter and spring, but the results will be based on parameter manipulations, and on the users having good knowledge of the modelled area. A good fit between observations and simulations does not necessarily imply that the model captures the processes correctly. Hence there is a need to improve soil erosion models, especially in order to simulate temporal changes of soil permeability and soil structure (i.e. aggregate stability and cohesion) due to freeze-thaw.

The model results suggested that experts could use such an approach to demonstrate to stakeholders the potential of different measures for mitigating soil erosion (e.g. a dense cover of straw and crop residuals). The modelling work illustrated how models can help to identify the processes that trigger runoff and soil erosion during winter and spring, which is often difficult to capture at catchment scale using only observations and measurements. Further testing of model combinations is therefore recommended in areas where major soil erosion and flooding can be expected during winter and spring. In addition, this could help 
to better identify where major uncertainties exist as regards winter hydrology at catchment scale, thus enabling research to be better focused and mitigation strategies to be developed. 


\section{Synthesis}




\subsection{Introduction}

In Nordic countries, the investigation and quantification of hydrological processes occurring during winter is challenging. Compared to other seasons of the year, winter adds an additional 'dimension' to the already complex hydrological processes occurring at catchment scale (Kormos et al., 2014; Williams et al., 2009). The occurrence of temperatures below freezing point allows water to change its phase from liquid to solid. Precipitation turns into snow, and water in streams and soils turns into ice. To further complicate things, these additional variables in the hydrological cycle in the Nordic countries vary spatially and temporally. Snow can be redistributed by wind, and can melt or evaporate (Gray and Male, 1981). In addition, it can store rainwater and thereby act as a buffer, slowly recharging aquifers or acting as a source of large quantities of water during melt, resulting in floods and soil erosion (Sui and Koehler, 2001). However, snow can also act as an insulating layer, protecting crops and soils from extreme low temperatures (Sutinen et al., 2008). The freezing water in soil changes its infiltration capacity and structure (Al-Houri et al., 2009), which can increase the risk of soil erosion and flooding or improve infiltration in successive seasons due to the creation of new small voids and cracks (Qi et al., 2006). These are just a few examples of the increased complexity of winter hydrology, and a research project covering four years can only make a small contribution to increasing our understanding of it. Moreover, during the three winter periods investigated in this thesis, only a limited range of possible winter scenarios have occurred and the experimental field site represented only a part of the agricultural area available in Norway.

The approach adopted in this study of looking into processes at point scale (i.e. infiltration in frozen soils) and catchment scale (i.e. surface runoff, erosion and snow cover development), and simulating these processes with physically based models, provided better insight into the complexity and interactions between these processes. It also resulted in identifying knowledge gaps in this research field.

Through detailed field investigations and laboratory experiments, it was possible to analyse how ice formation changes the infiltration capacities of soils and the structure of macropore networks, subsequently having effects upon runoff and soil erosion dynamics. The spatial and temporal development of snow packs was analysed and, through gathered data and process understanding, it was possible to simulate its development using a numerical model. Furthermore, field observations revealed how the interaction of tillage, state of the soils and snow cover determines possible generation of runoff and soil erosion. Integrating acquired data, observations and better process understanding, made it possible to simulate and quantify runoff and soil erosion during winter and spring conditions at the entire catchment scale. 


\subsection{Research findings}

Fig. 7.1 shows the main findings in the research topics addressed in this study, which are described in this section. The figure illustrates how the findings are related to each other.

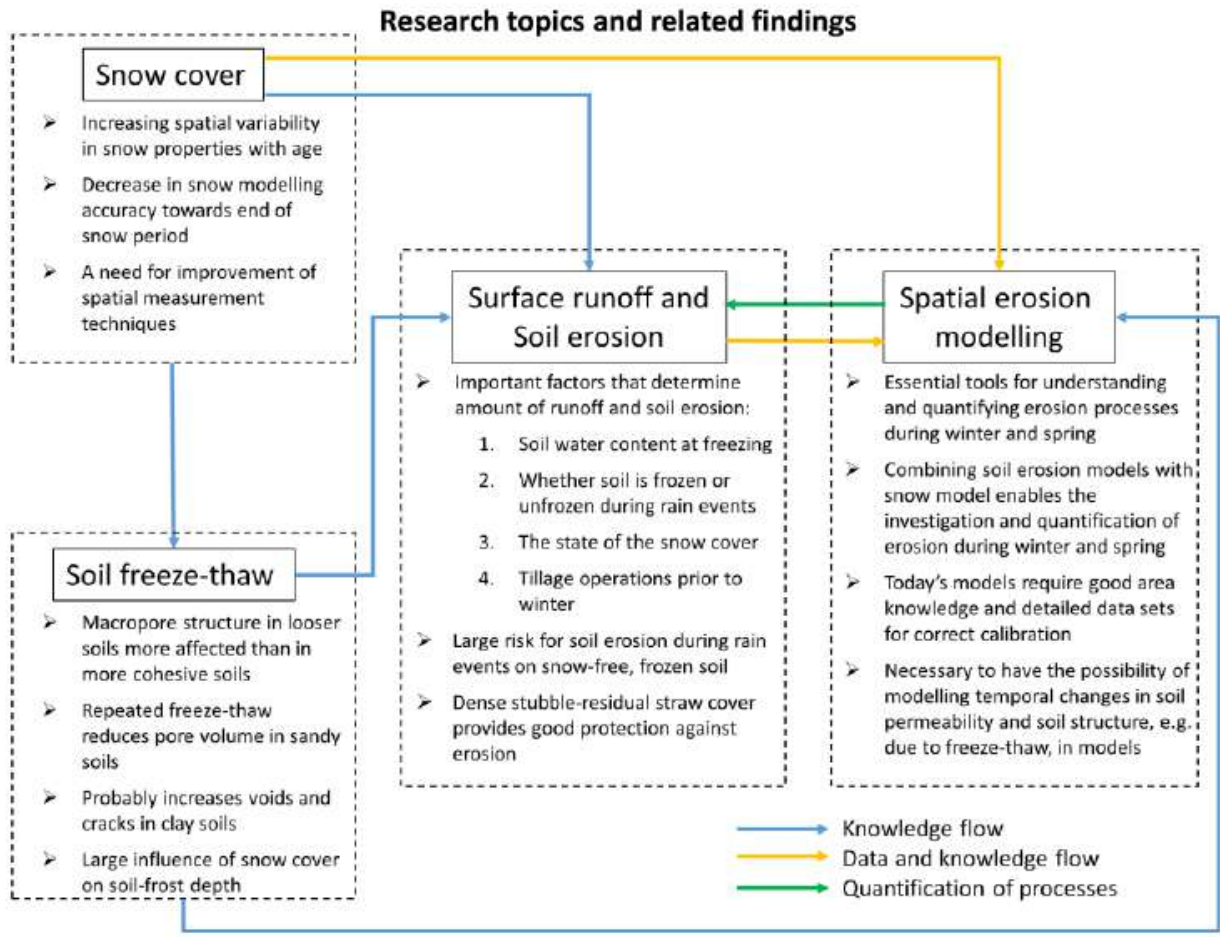

Fig. 7.1: Overview of the main findings within the research topics of this study and how they are related to each other.

\section{Snow cover}

A large part of this study was aimed at understanding changes in snow packs (point scale) and snow cover (catchment scale). The snow measurements carried out during the three winter periods, as described in Chapter 4, showed that spatial differences in snow packs are small at the beginning of the snow cover period and that they become larger with increasing age, e.g. in density, thickness and water content. The temporally and spatially distributed modelling that was undertaken mirrored that, but also showed a decrease in the accuracy of the modelling towards the end of the snow cover period. The measurements and model calibrations underlined how sensitive shallow snow packs are to wind and small changes in the composition of precipitation (rain versus snow), indicating that more attention is 
required for development and use of automated, spatially distributed measurement networks.

The UEBGrid model (Sen Gupta and Tarboton, 2013) satisfactorily captured the essential physics of accumulation and melt processes of shallow and patchy snow covers, but its performance could be improved, e.g. by linking the $d f$ parameter to slope angle, aspect and measured wind direction. However, over-parameterisation of such a model should be avoided as was emphasised by Avanzi et al. (2016). Furthermore, with better knowledge about the composition of precipitation (rain and/or snow) around $0{ }^{\circ} \mathrm{C}$, a non-linear approach could be developed for determining whether precipitation should be counted as snow or rain in the model simulations.

The work described in Chapter 4 was closely linked to the third objective of this thesis: to quantify and visualise temporal and spatial changes in snow accumulation and melting. This was accomplished for the three observed winters. However, the field-work executed in this study showed that the chosen approach is really time-consuming, and it is therefore strongly recommended that more emphasis should be given to development and use of automated monitoring systems capable in providing near-continuous measurement data at high temporal and spatial resolution. From this perspective, use of airborne remote sensing imagery could also be an interesting alternative.

\section{Effects of freeze-thaw on soil macropores}

Because the water transport in the investigated soils, especially in the clay soil, depended greatly on macropores (Kværn $\varnothing$ and Stolte, 2012), the behaviour of such macropores during freeze-thaw cycles was investigated using XRT imaging. X-ray scanning of macropores that were repeatedly exposed to freezing and thawing events, as described in Chapter 5, suggested that looser soils are more affected by freeze-thaw processes than soils with a more cohesive structure. Repeated freeze-thaw cycles reduced the pore volume in the investigated sandy soil, while only minor changes were measured in the investigated clay soil. The occurrence of thin voids and cracks, which possibly developed in the clay soil during the repeated freeze-thaw events, could not be quantified in clear detail using the automated state-of-the-art XRT scanner, however, careful visual inspection of the 3-D images confirmed existence of these features.

The XRT imaging of the two different soils showed that this technology can be of use to quantify the effect of freeze-thaw cycles on macropore structure in soils, although higher spatial resolution and accuracy levels would provide even better results (see Chapter 1 ). XRT scans of smaller samples would allow higher image resolution, and are expected to 
provide more detailed information about the overarching effects of repeated freeze-thaw cycles upon macropore structural changes in soils.

\section{Surface runoff and soil erosion during winter and spring}

Any study intending to understand the linkages between soil erosion, snowmelt and soil freeze-thaw cycles at catchment scale will require detailed spatially and temporally distributed field measurements and observations (Shanley, 1999). For example, during the three observed winter periods (Chapter 3 ), the largest amount of soil erosion was caused by a small rain event on frozen ground, before snow cover was established, so without a significant role of snowmelt. Four factors that determine the extent of runoff and erosion were found to be of particular importance in this particular study: (1) soil water content when freezing starts, (2) whether soil was frozen or unfrozen when rain occurred, (3) the state of the snow cover, and (4) tillage operations prior to winter. In terms of tillage, the most effective protection against soil erosion during these three winters was a dense stubble and residual straw cover in the fields. The observed erosion patterns suggested that covering only the water ways with stubble and straw did not significantly reduce soil erosion. Furthermore, the investigations showed that previously eroded soil is often deposited before reaching the outlet, thereby illustrating the limited value of outlet measurements for determining soil erosion rates in a catchment.

These findings illustrate the improvement in our understanding of processes at catchment scale causing soil erosion during winter and spring conditions, which was the second objective of this thesis (see Chapter 1 ). However, three winter periods are not necessarily sufficient to cover the variety of conditions and resulting hydrological responses occurring on the long term. Therefore, the measurement programme deployed would preferably remain operational during forthcoming winter and spring seasons.

\section{Spatial erosion modelling}

In order to model surface runoff and soil erosion at catchment scale during winter and spring conditions, a suitable GIS-based model had to be selected first. After a literature review, two soil erosion models were chosen and tested (Chapter 2). These tests suggest that EROSION 3D (Schmidt, 1996; Werner, 2004) might perform better as a planning tool, due to rather simplistic representation of processes and small number of required input data. LISEM (Jetten, 2002) appeared to be a better choice for investigating and simulating hydrological processes at catchment scale, because it is less sensitive to changes in grid cell size and time-step length enabling a faster calibration procedure, while, at the same time, processes occurring within a catchment are better represented in the model code. Spatial comparison of both models showed that, even if the simulated hydrographs agree well with 
measured ones, simulated spatial erosion and deposition patterns are not necessarily the same.

The application of the erosion model LISEM in combination with the snow model UEBGrid (see Chapter 6 ) indicated that it is indeed possible to satisfactorily simulate surface runoff and observed soil erosion patterns during subsequent winter and spring conditions. Basis for successful model application is availability of data for careful calibration and validation, accounting and covering important regulating processes in the catchment, as well as good knowledge of the area. However, a good fit between observations and simulations does not necessarily imply that the model captures all processes correctly, as certain processes might not be accounted for in the model while being important in the field. With this respect, including temporal changes in soil permeability and soil structure (i.e. aggregate stability and cohesion) as a result of repeating freeze-thaw cycles would create added value to a new version of LISEM.

Model simulations showed that physically based models indeed can help to better understand and quantify complex and interacting processes during winter conditions at an entire catchment scale (addressing research objective 4 of this thesis). The application of the LISEM model mirrored the observations in the field that soil surface stability, crop residues and infiltration capacity of partially frozen soils are important factors regulating the development of surface runoff and soil erosion during winter and spring. In addition, model results also revealed redistribution of eroded material within the catchment by deposition processes at locations with dense stubble and straw residue cover, similarly as has been observed regularly in the field (Chapter 3). Alternatively, the calibrated and validated LISEM model can be used also for exploring the potential effects of specific conservation management strategies aiming at reducing runoff and erosion rates within the catchment. This could provide valuable information for stakeholders, including land managers, in and related to the study catchment.

\subsection{Outlook and recommendations}

In order to maintain the multiple and valuable functions of agricultural soils in Nordic countries for future generations, and reduce the impact of agriculture practices on fresh water bodies, increased attention is required to prevent runoff generation and soil erosion during winter and spring conditions. In this thesis, field investigations, laboratory trials, and simulation modelling were carried out to better quantify and understand these interlinked and dynamically changing processes. The work undertaken for this thesis provides insight into process complexity and gives indications of how they can be better measured, 
quantified, and simulated. Despite substantial advances in the state of knowledge have been made in this study, specific aspects will need further scientific attention in the future, in particular with regard to achieve better understanding on the following issues:

- Surface runoff mechanisms below and above snow and ice layers

- Lateral water flow dynamics within snow packs

- Time-variant behaviour of soil surface stability during winter and spring field conditions

- The influence of different autumn tillage practices and freeze-thaw cycles on initiation of runoff

- Effects of growing or decreasing soil ice contents on changes in infiltration capacity

- Cause-effect relations between slope angle and aspect upon infiltration capacity differences across watersheds during winter and spring.

- Water infiltration through macropores in field soils during freeze-thaw conditions

- The contribution of gullies and rills to total soil loss during winter and spring erosion events

- The effect of climate change on winter hydrology processes in agricultural catchments, including runoff and erosion

- Evaluation of different measures to mitigate runoff and soil erosion during winter conditions in Nordic countries effectively

To address the knowledge gaps above, acquiring detailed temporally and spatially distributed measurements and observations in the field might be of crucial importance. Models might be a great help further, enabling quantification, integration, and upscaling of processes beyond the scale of observation. Furthermore, long-term, temporally and spatially distributed field studies are urgently needed also, to provide the data and process understanding that is required to develop and evaluate reliable strategies and climatesmart mitigation measures to reduce soil erosion during current and future winter and spring conditions. Several promising and advanced technologies could be helpful for this purpose, such as:

- Drones as platforms for different sensors (e.g. conventional, infrared and spectral cameras), e.g. to measure spatially distributed snow depth and quantify soil loss by rills and gullies through airborne photogrammetry. Trials carried out during this study (not presented in this thesis) produced promising results for snow depth.

- $\quad$ Electric resistivity tomography (ERT), e.g. to investigate freeze-thaw patterns in soils.

- $\quad$ Automated snow water equivalent measurements (Smith et al., 2017). 
- $\quad$ Automated precipitation measurement that distinguishes between rain and snow (Egli et al., 2009).

- Wireless intelligent sensor networks enabling cost-efficient spatially and temporally distributed monitoring, e.g. of soil moisture (Ritsema et al., 2009).

- Permanent installed time lapse and video cameras in experimental sites for observing processes and events on a semi-continuous basis.

Although the knowledge gained in this study advanced our insights in winter hydrology processes and phenomena in agricultural catchments in Nordic countries substantially, it also provides distinct directions and topics for further research in order to achieve an even more complete and in-depth understanding of these complex environments than available to date. 


\section{Summary}

In regions with a Nordic climate, soil erosion rates in winter and early spring can exceed those occurring during other seasons of the year. In this context, this study was initiated to improve our understanding of the interaction between agricultural soils and occurring winter conditions. The main objective was to better understand how hydrological processes in a catchment are influenced by snow, ice, and freeze-thaw cycles of soils, leading to runoff and soil erosion in winter and spring conditions.

For this purpose, detailed spatially and temporally distributed measurements and observations in a small catchment in Norway were executed during three consecutive winter/spring periods. During the winter/spring periods of 2013-2014, 2014-2015 and 20152016, soil water content, soil temperature, and snow cover properties were measured. In addition, numerous soil samples were taken to determine the soil hydraulic characteristics of the investigated soils and to quantify the changes in their macropore networks due to freeze-thaw events, using X-ray imaging.

With the collected data and deduced process understanding, it was possible to model and quantify the spatial and temporal development of snow packs. Furthermore, the field observations revealed how the interaction of tillage, state of the soils and snow cover at a certain time can lead to none or extensive surface runoff and soil erosion.

Integrating acquired data, observations and process knowledge facilitated advances in simulating and quantifying surface runoff and soil erosion rates across the catchment under investigation. The models applied and the maps and output derived are crucial elements for presenting current state and problems in the catchment to stakeholders (such as farmers), providing a starting point for discussing ways to prevent and reduce further runoff and erosion. For model calibration and validation, including interpretation of modelling results, good knowledge of the area and availability of detailed data are essential, especially when processes such as freezing-thawing of soils and ice layer and snow-pack dynamics have to be considered also.

In order to reduce runoff and soil erosion during winter and snowmelt conditions in the future, more targeted research is required in order to address the full range of existing knowledge gaps in this field, as identified in this particular study also. 


\section{References}

Ad-hoc-AG BODEN, Bodenkundliche Kartieranleitung. 5. Aufl., Hannover, 2005, Germany

Al-Houri, Z.M., Barber, M.E., Yonge, D., R., Ullman, J.L., Beutel, M.W. Impact of frozen soils on the performance of infiltration treatment facilities. Cold Regions Science and Technology, 2009, 59, pp. 51 - 57

Abramoff, D., Magalhaes, P. J., Ram, S. J., Image processing with ImageJ, Biophotonics Int., 2004, 11, pp. 36-42

Avanzi, F., De Michele, C., Morin, S., Carmagnola, C.M., Ghezzi, A., Lejeune, Y., Model complexity and data requirements in snow hydrology seeking a balance in practical applications. Hydrological Processes, 2016, 30, pp. 2106-2118

Ban, Y., Lei, T., Liu, Z., Chen, C., Comparison of rill flow velocity over frozen and thawed slopes with electrolyte tracer method. Journal of Hydrology, 2016, 534, pp. 630-637

Barnett, T. P., Adam, J. C., Lettenmaier, D. P., Potential impacts of a warming climate on water availability in snow-dominated regions. Nature, 2005, 438, pp. 303-309

Baveye, P.C., Laba, M., Otten, W., Bouckaert, L., Dello Sterpaio, P., Goswami, R.R., Grinev, D., Houston, A., Hu, Y., Liu, J., Mooney, S., Pajor, R., Sleuter, S., Tarquis, A., Wang, W., Wei, Q., Sezgin, M., Observer-dependent variability of thresholding step in the quantitative analysis of soil images and X-ray microtomography data. Geoderma, 2010, 157, pp. $51-63$

Bayard, D., Stähli, M., Parriaux, A., Flühler, H. The influence of seasonally frozen soil on the snowmelt runoff at two Alpine sites in southern Switzerland. Journal of Hydrology, 2005, 309, pp. 66-84

Belmans, C, Wesseling, J.G., Feddes, R.A., Simulation model of the water balance of a cropped soil: SWATRE. Journal of Hydrology, 1983, 6, pp. 271-286

Bernhard, M., Liston, G. E., Strasser, U., Zängl, G., Schulz, K., High resolution modelling of snow transport in complex terrain using downscaled MM5 wind fields. The Cryosphere, 2010, 4, pp. 99-113

Bhuyan, S.J., Kalita, P.K., Janssen, K.A., Barnes, P.L., Soil loss predictions with three erosion simulation models. Environmental Modelling \& Software, 2002, 17, pp. 137-146

Black, C.A., Evans, D.D., White, J.L., Ensminger, L.E., Clark, F.E. METHODS OF SOIL ANALYSIS Physical and Mineralogical Properties, Including Statistics of Measurement and Sampling. American Society of Agronomy, Madison, Wisconsin, Part 1, Volume 9, pp. $1-770,1965$, USA

Blöschl, G., Kirnbauer, R. \& Gutknecht, D., Distributed Snowmelt Simulations in an Alpine Catchment 1. Model Evaluation on the Basis of Snow Cover Patterns. Water Resources Research, 1991, 27, pp. 3171-3179 
Boardman, J., Soil erosion science: Reflections on the limitations of current approaches. Catena, 2006, 68, pp. 73-86

Boardman, J., Poesen, J. Soil Erosion in Europe. John Wiley \& Sons Inc., 111 River Street, Hoboken, 2006, USA

Bodner, G., Loiskandl, W., Buchan, G., Kaul H.-P., Natural and managment-induced dynamics of hydraulic conductivity along a cover-cropped field slope. Geoderma, 2008, 146, pp. $317-325$

Bolte, S., Cordelières, F.P., A guided tour into subcellular colo-calization analysis in light microscopy. Journal of Microscopy, 2006, 224, pp. 213- 232

Brewer, R., Fabric and mineral analysis of soils. Krieger Publishing Co., Huntington, New York, 1976, USA

Brown, M. E., Racoviteanu, A. E., Tarboton, D. G., Sen Gupta, A., Nigro, J., Policelli, F., Habib, S., Tokay, M., Shrestha, M. S., Bajracharya, S., Hummel, P., Gray, M., Duda, P., Zaitchik, B., Mahat, V., Artan, G. \& Tokar, S., An integrated modelling system for estimating glacier and snow melt driven streamflow from remote sensing and earth system data products in the Himalaya. Journal of Hydrology, 2014, 519, pp. 1859-1869

Chamberlain, E.J., Iskander, I., Hunsiker, S.E., Effect of freeze-thaw on the permeability and macrostructure of soils. Proceedings of the International Symposium on Frozen Soil Impacts on Agriculture, Range, and Forest Lands. Cold Regions Research and Engineering Laboratory, Hanover, New Hampshire, U.S.A. Special Report, 1990, 90-1, pp. $145-155$

Chung, S., Horton, R. Soil heat and water flow with a partial surface mulch. Water Resource Research, 1987, 23, pp. 2175 - 2186

Cline, D. W., Bales, R. C. \& Dozier, J., Estimating the spatial distribution of snow in mountain basins using remote sensing and energy balance modeling. Water Resources Research, 1998, 34, pp. 1275-1285

Deelstra, J., Kværnø, S.H., Granlund, K., Sileika, A.S., Gaigalis, K., Kyllmar, K., Vagstad, N. Runoff and nutrient losses during winter periods in cold climates - requirements to nutrient simulation models. Journal of Environmental Monitoring, 2009, 11, pp. 602 609

Deelstra, J., Øygarden, L., Blankenberg, A.B., Eggestad, H.O., Climate change and runoff form agricultural catchments in Norway. Climate Change Strategies and Management, 2011, 3, pp. 345-360

De Kock, T., Boone, M.A., De Schryver, T., Van Stappen, J., Derluyn, H., Masschaele, B., De Schutter, G., Cnudde, V., A Pore-Scale Study of Fracture Dynamics in Rock Using X-ray Micro-CT Under Ambient Freeze-Thaw Cycling. Environmental Science \& Technology, 2015, 49, pp. $2867-2874$ 
De Michele, C., Avanzi, F., Passoni, D., Barzaghi, R., Pinto, L., Dosso, P., Ghezzi, A., Gianatti, R., Vedova, G. D., Using a fixed-wing UAS to map snow depth distribution: an evaluation at peak accumulation. The Cryosphere, 2016, 10, pp. 511-522

De Roo, A.P.J., Wesseling, C.G., Ritsema, C.J., LISEM: a single event physically-based hydrologic and soil erosion model for drainage basins: I. Theory, input and output. Hydrological Processes, 1996a, 10, pp. 1107-1117

De Roo, A.P.J., Offermans, R.J.E., Cremers, N.H.D.T., LISEM: a single event physically-based hydrologic and soil erosion model for drainage basins: II. Sensitivity analysis, validation and application. Hydrological Processes, 1996b, 10, pp. 1119-1126

Doesken, N. J. \& Robinson, D. A., The Challenge of Snow Measurements. Historical Climate Variability and Impacts in North America, Springer, Heidelberg, 2009, Germany

Doube, M., Klosowski, M.M., Arganda-Carreras, I., Cordelieres, F.P., Dougherty, R.P., Jackson, J.S., Schmid, B., Hutchinson, J.R., Shefelbine, S.J., BoneJ Free and extensible bone image analysis in ImageJ. Bone, 2010, 47, pp. 1076 - 1079

Edwards, L.M., Burney, J.R. Soil erosion losses under freeze/thaw and winter ground cover using a laboratory rainfall simulator. Can. Agric. Eng., 1987, 29, pp. 109 - 115

Egli, L., Jonas, T. \& Meister, R., Comparison of different automatic methods for estimating snow water equivalent. Cold Regions and Technology, 2009, 57, pp. 107-115

Essery, R., Morin, S., Lejeune, Y. \& Menard, C. B., A Comparison of 1701 snow models using observations from an alpine site. Advances in Water Resources, 2013, 55, pp. 131-148

Essery R., Pomeroy J., Ellis C. \& Link T., Modelling longwave radiation to snow beneath forest canopies using hemispherical photography or linear regression. Hydrological Processes, 2008, 22, pp. 2788-2800

Evrard, O., Bielders, C.L., Vandaele, K., v. Wesemael, B., Spatial and temporal variation of muddy floods in central Belgium,off-site impacts and potential control measures. Catena, 2007, 70, pp. 443-454

Fazzalari, N.L., Parkinson, I.H., Fractal dimension and architecture of trabecular bone. Journal of Pathology, 1996, 178, pp. 100 - 105

Flerchinger, G.N., Xiao, W., Sauer, T.J., Yu, Q. Simulation of within-canopy radiation exchange. NJAS - Wageningen Journal of Life Science, 2009, 57, pp. 5 - 15

Flerchinger, G.N., Sauer, T.J., Aiken, R.A., Effects of crop residue cover and architecture on heat and water transfer at the soil surface. Geoderma, 2003, 116, pp. 217 - 233

Flerchinger, G.N., The Simultaneous Heat and Water (SHAW) Model: Technical Documentation. Technical Report NWRC 2000-09, Northwest Watershed Research Center USDA Agricultural Research Service Boise, Idaho, 2000, USA

Flerchinger, G.N., Saxton, K.E., Simultaneous heat and water model of a freezing snowresidue-soil system. I. Theory and development. Trans. Am. Soc. Agric. Eng., 1989, 32, pp. $565-571$ 
Garbout, A., Munkholm, L.J., Hansen, S.B., Temporal dynamics for soil aggregate determined using X-ray CT scanning. Geoderma, 2013a, 204-205, pp. 15 - 22

Garbout A., Munkholm, L.J., Hansen, S.B., Tillage effects on topsoil structural quality assessed using X-ray CT, soil cores and visual soil evaluation. Soil and Tillage Research, 2013b, 128, pp. 104-109

Garvelmann, J., Pohl, S., Weiler, M., From observation to the quantification of snow processes with a time-lapse camera network. Hydrol. Earth Syst. Sci., 2013, 17, pp. 1415-1429

Gascoin, S., Lhermitte, S., Kinnard, C., Bortels, K., Liston, G. E., Wind effects on snow cover in Pascua-Lama, Dry Andes of Chile. Advances in Water Resources, 2013, 55, pp. 25-39

Gray, D.M., Male, D.H. Handbook of Snow. Pergamon Press, Toronto, 1981, Canada

Grønsten, H.A., Lundekvam, H., Prediction of surface runoff and soil loss in southeastern Norway using the WEPP Hillslope model. Soil and Tillage Research, 2006, 85, pp. 186 199

Hanssen-Bauer, I., Førland, E.J., Haddeland, I., Hisdal, H., Mayer, S., Nesje, A., Nilsen, J.E. Ø., Sandven, S., Sandø, A.B., Sorteberg, A., Ådlandsvik, B., Klima i Norge 2100 Kunnskapsgrunnlag for klimatilpasning. NCCS report, 2, pp. 1 - 204, 2015, Norway

He, H., Dyck, M.F., Si, B.C., Zhang, T., Lv, J., Wang, J., Soil freezing - thawing characteristics and snowmelt infiltration in Cryalfs of Alberta, Canada. Geodermal Regional, 2015, 5, pp. $198-208$

Hengsdijk, H., Meijerink, G.W., Mosugu, M.E., Modeling the effect of three soil and water conservation practices in Tigray, Ethiopia. Agriculture Ecosystems \& Environment, 2005, 105, pp. 29-40

Hessel, R., Jetten, V., Baoyuan, L., Yan, Z., Stolte, J., Calibration of the LISEM model for a small Loess Plateau catchment. Catena, 2003, 54, pp. 235-254

Hessel, R., Effects of grid cell size and time step length on simulation results of the Limburg soil erosion model (LISEM). Hydrological Processes, 2005, 19, pp. 3037-3049

Hessel, R., and Tenge, A., A pragmatic approach to modelling soil and water conservation measures with a catchment scale erosion model. Catena, 2008, 74, pp. 119-126

Hiemstra, C. A., Liston, G. E., Reiners, W. A., Observing, modelling and validating snow redistribution by wind in a Wyoming upper treeline landscape. Ecological Modelling, 2006, 197, pp. 35-51

Hopkinson, C., Collins, T., Anderson, A., Pomeroy, J., Spooner, I., Spatial Snow Depth Assessment Using LiDAR Transect Samples and Public GIS Data Layers in the Elbow River Watershed, Alberta. Canadian Water Resource Journal, 2012, 37, pp. 69-87 
IPCC, 2013: Climate Change 2013: The Physical Science Basis. Contribution of Working Group I to the Fifth Assessment Report of the Intergovernmental Panel on Climate Change. Stocker, T.F., D. Qin, G.-K. Plattner, M. Tignor, S.K. Allen, J. Boschung, A. Nauels, Y. Xia, V. Bex and P.M. Midgley (eds.); Cambridge University Press, Cambridge, NY, USA, 2013, 1535 pp.

Iwata, Y., Nemoto, M., Hasegawa, S., Yanai, Y., Kuwao, K., Hirota, T., Influence of rain, air temperature, and snow cover on subsequent spring-snowmelt infiltration into thin frozen soil layer in northern Japan. Journal of Hydrology, 2011, 401, pp. 165 - 176

Iwata, Y., Hayashi, M., Suzuki, S., Hirota, T., Hasegawa, S., Effects of snow cover on soil freezing, water movement, and snowmelt infiltration: A paired plot experiment. Water Resource Research, 2010, 46, pp. 1 - 11

Jarvis, N.J., A review of non-equilibrium water flow and solute transport in soil macropores: principles, controlling factors and consequences for water quality, European Journal of Soil Science, 2007, 58, pp. 523 - 546.

Jetten, V., De Roo, A., Favis-Mortlock, D., Evaluation of field-scale and catchment-scale soil erosion models. Catena, 1999, pp. 521-541

Jetten, V., De Roo, A. Spatial analysis of erosion conservation measures with LISEM. Ch 14. Landscape erosion and evolution modelling, Kluwer Academic/Plenum, New York, pp. 429-45, 2001, USA

Jetten, V., LISEM, Limburg Soil Erosion Model, User's Manual. University of Utrecht, 2002, Netherlands

Jetten, V., Govers, G., Hessel, R., Erosion models: quality of spatial predictions. Hydrological Processes, 2003, 17, pp. 887-900

Jonas, T., Marty, C., Magnusson, J.,. Estimating the snow water equivalent from snow depth measurements in the Swiss Alps. Journal of Hydrology, 2009, 378, pp. 161-167

Katuwal, S., Arthur, E., Tuller, M., Moldrup, P., de Jonge, L.W., Quantification of Soil Pore Network Complexity with X-ray Computed Tomography and Gas Transport Measurements. Soil Science Society of America Journal, 2015, 79, pp. 1577- 1589

Kinar, N.J., Pomeroy, J.W., Measurement of the physical properties of the snowpack. Reviews of Geophysics, 2015, 53, doi:10.1002/2015RG000481

Koestel, J., Larsbo, M., Imaging and quantification of preferential solute transport in soil macropores. Water Resources Research, 2014, 50, pp. 4357 - 4378

Kormos, P.R., Marks, D., Williams, C.J., Marshall, H.P., Aishlin, P., Chandler, D.G., McNamara, J.P., Soil, snow, weather, and sub-surface storage data from a mountain catchment in the rain-snow transition zone. Earth System Science Data, 2014, 6, pp. 165 - 173

Köthe, R., and Wurbs, D., Analyse des digitalen Geländemodells DGM2 für die Erosionsbewertung. ÖA LfULG, Schriftenreihe, Heft XX/2010, 2010, Germany

Kramer, G. J., Stolte, J., Cold-Season Hydrology Modeling in the Skuterud Catchment. Bioforsk Report, Vol. 4, No. 126, 2009, Norway 
Kværnø, S. H. \& Øygarden, L., The influence of freeze-thaw cycles and soil moisture on aggregate stability of three soils in Norway. Catena, 2006, 67, pp. 175-182

Kværnø S.H., Haugen L.E., Børresen T., Variability in topsoil texture and carbon content within soil map units and its implications in predicting soil water content for optimum workability. Soil \& Tillage Research, 2007, 95, pp. 332-347

Kværn $\varnothing$ S.H., Variability and uncertainty in soil physical properties: effects of data source on functional criteria. PhD Thesis 2011:40, Norwegian University of Life Sciences, 2011, Norway

Kværnø, S.H., Stolte, J., Effects of soil physical data sources on discharge and soil loss simulated by the LISEM model. Catena, 2012, 97, pp. 137-149

Lapen, D.R., Martz, L.W., An investigation of the spatial association between snow depth and topography in a Prairie agricultural landscape using digital terrain analysis. Journal of Hydrology, 1996, 184, pp. 277-298

Larsbo, M., Koestel, J., Jarvis, N., Relations between macropore network characteristics and the degree of preferential solute transport. Hydrology and Earth System Sciences, 2014, 18, pp. 5255 - 5269

Li, R., Stevens, M.A., Simons, D.B., Solutions to the Green and Ampt infilttration equation. J. Irrig. Drain. Div., 1976, 2, pp. 239-248

Li, R., Shi, H., Flerchinger, G.N., Akae, T., Wang, C., Simulation of freezing and thawing soils in Inner Mongolia Hetao Irrigation District China. Geoderma, 2012, 173-174, pp. 28 33

Linden, T., Soil surface resistance to runoff. Master thesis, Wageningen University, 2015, Netherlands

Lindström, G., Löfvenius, M.O., Tjäle och avrinning $i$ Svartberget-studier med HBVmodellen. SMHI Hydrologi Nr 84. SMHI, Norrköping, 2000, Sweden

Lorensen, W., Cline, H., Marching cubes: a high resolution $3 \mathrm{~d}$ surface construction algorithm. Computers and Graphics, 1987, 21, 163-169.

Luce, C. H., Tarboton, D. G., Modeling Snowmelt Over Area: Modeling Subgrid Scale Heterogeneity in Distributed Model Elements. Civil and Environmental Engineering, Utah State University, 2001, USA

Luce, C. H., Tarboton, D. G., Evaluation of alternative formulae for calculation of surface temperature in snowmelt model using frequency analysis of temperature observations. Hydrology Earth System Sciences, 2010, 14, pp. 535-543

Lundberg, A., Granlund, N., Gustafsson, D., Towards automated 'Ground truth' snow measurements - a review of operational and new measurement methods for Swede, Norway and Finnland. Hydrological Processes, 2010, 24, pp. 1955-1970

Lundberg, A., Ala-Aho, P., Eklo, O., Klöve, B., Kværner, J., Stumpp, C., Snow and frost: implications for spatiotemporal infiltration patterns - a review. Hydrological Processes, 2016, 30, pp. 1230 - 1250 
Lundekvam, H.E., Plot studies and modelling of hydrology and erosion in southeast Norway. Catena, 2007, 71, pp. 200-209

Lundekvam, H.E., Romstad E., Øygarden L., Agricultural policies in Norway and effects on soil erosion. Environmental Science \& Policy, 2003, 6, pp. 57-67

Lundekvam, H.; Skøien, S., Soil erosion in Norway. An overview of measurements from soil loss plots. Soil Use Manag. 1998, 14, pp. 84-89.

Luo, L., Lin, H., Schmidt, J., Quantitative Relationships between Soil Macropore Characteristics and Preferential Flow and Transport. Soil Science Society of America Journal, 2010 (1), 74, pp. 1929 - 1937

Luo, L., Lin, H., Li, S., Quantification of 3-D soil macropore networks in different soil types and land uses using computed tomography. Journal of Hydrology, 2010 (2), 393, pp. $53-64$

Luo, L., Quantification of soil macropore network and its relationship to preferential flow using combined X-ray computed tomography and breakthrough curve analysis. PhD dissertation, The Pennsylvania State University, Soil Science Graduate Program, 2009, USA

Luo, L., Lin, H., Halleck, P., Quantifying Soil Structure and Preferential Flow in Intact Soils Unsing X-ray Computed Tomography. Soil Science Society of America Journal, 2008, 72, pp. $1058-1069$

Mahat, V., Tarboton, D. G., Molotch, N. P., Testing above- and blow-canopy representations of turbulent fluxes in an energy snowmelt model. Water Resources Research, 2013, 49, pp. 1107-1122

Mahat, V., Tarboton, D. G., Canopy radiation transmission for an energy balance snowmelt model. Water Resources Research, 2012, 48, W01534

McCauley, C.A., White, D.M., Lilly, M.R., Nyman, D.M., A comparison of hydraulic conductivities, permeabilities and infiltration rates in frozen and unfrozen soils. Cold Regions Science and Technology, 2002, 34, pp. 117 - 125

Michael, A., Anwendung des physikalisch begründeten Erosionsprognosemodells EROSION 2D/3D - empirische Ansätze zur Ableitung der Modellparameter. Freiberger Forschungshefte, Bd. 488, 2001, Germany

Michael, A., Anwendung des physikalisch begründeten Erosionsprognosemodells EROSION 2D/3D - Empirische Ansätze zur Ableitung der Modellparameter. PhD Thesis, TU Bergakademie Freiberg, 2000, Germany

Michael, A., Schmidt, J., Enke, W., Deutschländer, T., Malitz, G., Impact of expected increase in precipitation intensities on soil loss - results of comparative model simulations. Catena, 2005, 61, pp. 155-164 
Nearing, M.A., Jetten, V., Baffaut, C., Cerdan, O., Couturier, A., Hernandez, M., Bissonnais, Y. Le, Nichols, M.H., Nunes, J.P., Renschler, C.S., Souche're, V., van Oost, K., Modeling response of soil erosion and runoff to changes in precipitation and cover. Catena, 2005, 61, pp. 131-154

Nyberg, L., Stähli, M., Mellander, P., Bishop, K.H., Soil frost effect on soil water and runoff dynamics along a boreal forest transect: 1. Field investigations. Hydrological Processes, 2001, 15, pp. $909-926$

Odgaard, A., Gundersen H.J.G, Quantification of connectivity in cancellous bone, with special emphasis on 3-D reconstruction. Bone, 1993, 14, pp. $173-182$

Ollesch, G., Sukhanovski, Y., Kistner, I., Rode, M., Meissner, R., Characterization and modelling of the spatial heterogeneity of snowmelt erosion. Erth Surf. Process. Landforms, 2005, 30, pp. 197-211

Ollesch, G., Kistner, I., Meissner, R., Lindenschmidt, K., Modelling of snowmelt erosion and sediment yield in a small low-mountain catchment in Germany. Catena, 2006, 68, pp. 161-176

$\varnothing$ ygarden, L., Rill and gully development during an extreme winter runoff event in Norway. Catena, 2003, 50, pp. 217 - 242

$\varnothing$ ygarden, L., Kværner, J., Jenssen, P.D., Soil erosion via preferential flow to drainage systems in clay soils. Geoderma, 1997, 76, pp. 65 - 86

Parkin, G., von Bertoldi, A.P., McCoy, A.J., Effect of tillage on Soil Water Content and Temperature under Freeze-Thaw Conditions. Vadose Zone Journal, 2013, 12, doi:10.2136/vzj2012.0075

Peppin, S.S.L., Style, R.W., The Physics of Frost Heave and Ice-Lens Growth. Vadose Zone Journal, 2013, 12, doi:10.2136/vzj2012.0049

Perfect, E., Estimating soil mass fractal dimensions form water retention curves. Geoderma, 1999, 88, pp. 221 - 231

Perret, J.S., Prasher, S.O., Kacimov, A.R., Mass fractal dimension of soil macropores using computed tomography: from the box-counting to the cube-counting algorithm. European journal of Soil Science, 2003, 54, pp. 569 - 579

Peyton, R.L., Gantze, C.J., Anderson, S.H., Haeffner, B.A., Pfeiffer, P., Fractal dimension to describe soil macropore structure using $\mathrm{x}$-ray computed tomography. Water Resources Research, 1994, 30, pp. 691 - 700

Qi, J., Vermeer, P.A., Cheng, G., A Review of the Influence of Freeze-thaw Cycles on Soil Geotechnical Properties. Permafrost and Periglacial Processes, 2006, 17, pp. 245 - 252

$\mathrm{R}$ Core Team, R: A language and environment for statistical computing. R Foundation for Statistical Computing, Vienna, 2016, Austria. (http://www.R-project.org/)

Richard, A., Brun, E., Snow and Climate Physical Processes, Surface Energy Exchange and Modeling. Cambridge University Press, New York, 2008, USA 
Ritsema, C.J., Dekker, L.W., Oostindie, K., Moore, D., Leinauer, B, A practical field method for determining soil water repellency and critical soil water content. In : Soil Science: Step-by-step field analyses / Longsdon et al., S.D., Madison, WI, Soil Science Society of America, 2009 USA

Ruiz de Argandoña, V.G., Rodríguez, Rey, A.R., Celorio, C., Suárez del Rio, L.M., Calleja, L., Llavona, J., Characterization by Computed X-ray Tomography of the Evolution of the Pore Strucutre of a Dolomite Rock During Freeze-Thaw Cyclic Tests. Physics and Chemistry of the Earth, 1999, 24, pp. $633-637$

Schindelin, J., Arganda-Carreras, I., Frise, E., Kaynig, V., Longair, M., Pietzsch, T., Preibisch, S., Rueden, C., Saalfeld, S., Schmid, B., Tinevez, J.-Y., White, D. J., Hartenstein, V., Eliceiri, K., Tomancak, P., Cardona, A., Fiji: an open-source platform for biological image analysis, Nat. Methods, 2012, 9, pp. 676-682

Schindewolf, M., Schmidt, W., Prüfung und Validierung des neu entwickelten Oberflächenabflussmoduls des Modells EROSION 3D im Zusammenhang mit Maßnahmen des vorsorgenden Hochwasserschutzes auf landwirtschaftlich genutzten Flächen. Schriftenreihe des Landesamtes für Umwelt, Landwirtschaft und Geologie, Heft 15/2009, 2009, Germany

Schlüter, S., Sheppard, A., Brown, K., Wildenschild, D., Image processing of multiphase images obtained via X-ray microtomography: A review. Water Resource Research, 2014, 50, pp. 3615 - 3639

Schob, A., Schmidt, J., Tenholtern, R., Derivation of site-related measures to minimise soil erosion on the watershed scale in the Saxonian loess belt using the model EROSION 3D. Catena, 2006, 68, pp. 153-160

Schols, A. The influence of natural-simulated freeze-thaw cycles on aggregate stability in sandy and clayey soils in Norway. Master thesis, Wageningen University, 2016, Netherlands

Schmidt, J., Teilmodell zur Simulation der Infiltration. Zwischenbericht zum BMFT-Vorhaben 0339233, 1993, Germany

Schmidt, J., Entwicklung und Anwendung eines physikalisch begründeten Simulationsmodells für die Erosion geneigter landwirtschaftlicher Nutzflächen. Berliner Geogr. Abh., Heft 61, pp. 1-148, 1996, Germany

Schmidt, J., Werner, M., Modeling Sediment and Heavy Metal Yields of Drinking Water Reservoirs in the Osterzgebirge Region of Saxony (Germany). In: SCHMIDT, J. (Ed.): Soil Erosion - Application of Physically Based Models., New York, 2000, USA

Seidel, N., Untersuchung der Wirkung verschiedener Landnutzungen auf Oberflächenabfluss und Bodenerosion mit einem Simulationsmodell. PhD Thesis, TU Bergakademie, Freiberg, 2008, Germany 
Sen Gupta, A. Tarboton, D.G., A tool for downscaling weather data from large-grid reanalysis products to finer spatial scales for distributed hydrological applications. Environmental Modelling \& Software, 2016, 84, pp. 50-69

Sen Gupta, A., Tarboton, D.G., Using the Utah Energy Balance Snow Melt Model to Quantify Snow and Glacier Melt in the Himalayan Region. Proceedings of the Western Snow Conference $81^{\text {st }}$ Annual Meeting. Adaptive Water Management in a Changing Climate, 2013, Jackson Hole, Wyoming, April 15-18, 103-114

Seyfried, M.S., Murdock, M.D., Use of air permeability to estimate infiltrability of frozen soil. Journal of Hydrology, 1997, 202, pp. 95 - 107

Shanley, J.B., Chalmers, A., The effect of frozen soil on snowmelt runoff at Sleepers River, Vermont. Hydrological Processes, 1999, 13, pp. 1843 - 1857

Sheikh, V., van Loon, E., Hessel, R., Jetten, V., Sensitivity of LISEM predicted catchment discharge to initial soil moisture content of soil profile. Journal of Hydrology, 2010, 393, pp. 174-185

Smith, C.D., Kontu, A., Laffin, R., Pomeroy, J.W., An assessment of two automated snow water equivalent instruments during the WMO Solid Precipitation Intercomparison Experiment. The Cryosphere, 2017, 11, pp. 101-116

Solbakken, E., Kartlegging av Gryteland delnedbørfelt. Skog og landskap Report, Ås, 2015, Norway

Starkloff, T., Stolte, J. Applied comparison of the erosion risk models EROSION 3D and LISEM for a small catchment in Norway. Catena, 2014, 118, pp. 154-167

Starkloff, T., Stolte, J., Hessel, R., Ritsema, C.J., Investigating the development of shallow snowpacks, using comprehensive field observations and spatially distributed snow modelling. Hydrology Research, 2017a, doi: 10.2166/nh.2017.269

Starkloff, T., Hessel, R., Stolte, J., Ritsema, C.J., Catchment hydrology during winter and spring and the link to soil erosion: A case study in Norway. Hydrology, 2017b, 15, doi:10.3390/hydrology4010015

Stähli, M., Nyberg, L., Mellander, P., Jansson, P., Bishop, K.H., Soil forst effects on soil water and runoff dynamics along a boreal transect: 2: Simulations. Hydrological Processes, 2001, 15, pp. 927-941

Stolte, J., Liu, B., Ritsema, C.J., van den Elsen, H.G.M., Hessel, R., Modelling water flow and sediment processes in a small gully system on the Loess Plateau in China. Catena, 2003, 54, pp. $117-130$

Stolte, J., Ritsema, C.J., Bouma, J., Developing interactive land use scenarios on the Loess Plateau in China, presenting risk analyses and economic impacts. Agriculture, Ecosystems \& Environment, 2005, 105, pp. 387-399

Stolte, J., Kværnø, S. H., Snowmelt and runoff in two small field-scale catchments. Agriculture and Environment - Long term Monitoring in Norway. Akademika Publishing, Trondheim, 2013, Norway 
Stroosnijder, L., Measurement of erosion: Is it possible? Catena, 2005, 64, pp. 162-173

Su, J.J., van Bochove, E., Thériault, G., Novotma, B., Khaldoune, J., Denault, J.T., Zhou, J., Nolin, M.C., Hu, C.X., Bernier, M., Benoy, G., Xing, Z.S., Chow, L., Effects of snowmelt on phosphorus and sediment losses from agricultural watersheds in Eastern Canada. Agricultural Water Managment, 2011, 98, pp. 867-876

Sui, J., Koehler, G., Rain-on-snow induced flood events in Southern Germany. Journal of Hydrology, 2001, 252, pp. 205-220

Sutinen, R., Hänninen, P., Venäläinen, A., Effect of mild winter events on soil water content beneth snowpack. Cold Regions Science and Technology, 2008, 51, pp. $56-67$

Taina, I.A., Heck, R.J., Deen, W., Ma, E.Y.T., Quantification of freeze-thaw related structures in cultivated topsoils using X-ray computer tomography. Canadian Journal of Soil Science, 2013, 93, pp. 533 - 553

Takken, I., Beuselinck, L., Nachtergaele, J., Govers, G., Poesen, J., Degraer, G., Spatial evaluation of a physically-based distributed erosion model (LISEM). Catena, 1999, 37, pp. 431-447

Tarboton, D. G., Luce, C. H., Utah Energy Balance Snow Accumulation and Melt Model (UEB), Computer model technical description and users guide. Utah Water Research Laboratory and USDA Forest Service Intermountain Research Station, 1996, USA

Tarboton, D. G., Blöschl, G., Cooley, K., Kirnbauer, R., Luce, C., Spatial Snow Cover Processes at Kühtai and Reynolds Creek. Spatial Patterns in Catchment Hydrology: Observations and Modelling. Cambridge University Press, 2000, UK

Thomsen, L.M., Baartman, J.E.M., Barneveld, R., Starkloff, T., Stolte, J., Soil surface roughness: comparing old and new measuring methods and application in a soil erosion model. Soil, 2015, 1, pp. 399-410

Thue-Hansen V., Grimenes A.A. Meteorologiske data for Ås, Norges Miljø og Biovitenskaplige Universitet, Ås, 2013-2015, Norway

Tignor, S.K. Allen, J. Boschung, A. Nauels, Y. Xia, V. Bex and P.M., Midgley. Cambridge University Press, Cambridge, New York, 2013, USA,

Toride, N., Watanabe, K., Hayashi, M., Special Section: Progress in Modeling and Characterization of Frozen Soil Processes. Vadose Zone Journal, 2013, 12, doi:10.2136/vzj2013.01.0001

Torrance, J.K., Elliot, T., Martin, R., Heck, R.J., X-ray computed tomography of frozen soil. Cold Regions Science and Technology, 2008, 53, pp. 75 - 82

Viklander, P., Laboratory study of stone heave in till exposed to freezing and thawing. Cold Regions Science and Technology, 1998, 27, pp. 141 - 152

Vogel, H.-J., Weller, U., Schlüter, S., Quantification of soil structure based on Minkowski functions. Computer and Geosciences, 2010, 36, pp. 1236 - 1245 
Werner, M., GIS-orientierte Methoden der digitalen Reliefanalyse zur Modellierung von Bodenerosion in kleinen Einzugsgebieten. PhD Thesis, Freie Universität Berlin, 1995, Germany

Werner, M., Abschätzung des Oberflächenabflusses und der Wasserinfiltration auf landwirtschaftlich genutzten Flächen mit Hilfe des Modells EROSION 3D. GeoGnostic, Endbericht, Berlin, 2004, Germany

Werner, M., Abflussmodell Benutzerhandbuch. GeoGnostic Software, Ver. 1.0, Berlin, 2005, Germany

Werner, M., Erosion-3D Benutzerhandbuch. GeoGnostic Software, Ver. 3.15, Berlin, 2007, Germany

Werner, M., Data base-Processor User manual. GeoGnostic Software Ver. 1.80, Berlin, 2010, Germany

Watanabe, K., Kito, T., Dun, S., Wu, J.Q., Greer, R.C., Flury, M., Water Infiltration into a Frozen Soil with Simultaneous Melting of the Frozen Layer. Vadose Zone Journal, 2013, 12, doi:10.2136/vzj2011.0188

Weigert, A., Schmidt, J., Water transport under winter conditions. Catena, 2005, 64, pp. 193-208

Wever, N., Jonas, T., Fierz, C., Lehning, M., Model simulation of the modulating effect of the snow cover in a rain-on-snow event. Hydrol. Earth Syst. Sci., 2014, 18, pp. 4657-4669

Williams, C.J., Mcnamara, J.P., Chandler, D.G., Controls on the temporal and spatial variability of soil moisture in a mountainous landscape: the signature of snow and complex terrain. Hydrology and Earth System Science, 2009, 13, pp. 1325 - 1336

Willis, W.O., Carlson, C.W., Alessi, J., Haas, H.J., Depth of freezing and spring run-off as related to fall soil-moisture level. Canadian Journal of Soil Science, 1961, 41, pp. 115 123

Yami, E.R., Khalili A., Rahimi, H., Etemad, A., Investigation of moisture on soil temperature regimes and frost depths in a laboratory model. International Journal of AgriScience, 2012, 2, pp. $717-732$

You, J., Snow Hydrology: The Parameterization of Subgrid Processes within a Physically Based Snow Energy and Mass Balance Model. PhD thesis, Civil and Environmental Engineering, Utah State University, Logan, 2004, USA

Zhang, Z.B., Peng, X., Zhou, H., Lin, H., Sun, H., Characterizing preferential flow in cracked paddy soils using computed tomography and breakthrough curve. Soil \& Tillage Research, 2015, 146, pp. $53-65$

Zhao, Y., Nishimura, T., Hill, R., Miyazaki, T., Determining Hydraulic Conductivity for AirFilled Porosity in an Unsaturated Frozen Soil by the Multistep Outflow Method. Vadose Zone Journal, 2013a, 12, doi:10.2136/vzj2012.0061 
Zhao, Y., Huang, M.B., Horton, R., Liu, F., Peth, S., Horn, R., Influence of winter grazing on water and heat flow in seasonal frozen soil of Inner Mongolia. Vadose Zone Journal, 2013b, 12, doi:10.2136/vzj2012.0059

Zwaaftink, C. D. G., Löwe, H., Mott, R., Bavay, M., Lehning, M., Drifting snow sublimation: A high-resolution 3-D model with temperature and moisture feedbacks. Journal of Geophysical Research, 2011, 116, D16107 


\section{Acknowledgments}

Four challenging years are over and it is time to say thank you to:

Coen Ritsema, Jannes Stolte and Rudi Hessel who made this endeavour possible and helped with tons of advice along the way.

Eva Skarbøvik and Sigrun Kværnø, my always supportive project leaders.

Mats Larsbo for making Chapter 5 possible by helping me in Sweden, and with the image analysis and writing.

Thorsten Heidorn for introducing me to sailing and saying the right words in the dearest hour of my PhD.

Johannes Deelstra for funny stories and hilarious talks about the 'thing' during coffee breaks.

Robert Barneveld for your never subsiding enthusiasm for research, being a helping hand in the field and a never ending supply of videos from dumpert.nl.

My fellow commuters, colleagues and friends I met in Norway.

My family in Norway (including Mira) for making Norway my second home.

The Freiberg gang, without you guys I wouldn't have come so far.

Anett for always being there and 'taking care' of thinks in Germany.

My parents Gabriele and Bernd for always supporting me.

Andrea for your infectious happiness.

Helga for always going with me through high and low. 


\section{Acknowledgements of financial support}

The work undertaken in this study was funded by the SIS-CATCHY project at the Norwegian Institute for Bioeconomy (NIBIO), funded by the Norwegian Ministry of Agriculture and Food. 


\section{SENSE}

Netherlands Research School for the

Socio-Economic and Natural Sciences of the Environment

\section{I P L O M A}

For specialised PhD training

The Netherlands Research School for the

Socio-Economic and Natural Sciences of the Environment

(SENSE) declares that

\section{Torsten Starkloff}

born on 16 November 1986 in Leipzig, Germany

has successfully fulfilled all requirements of the Educational Programme of SENSE.

Wageningen, 5 December 2017

the Chairman of the SENSE board

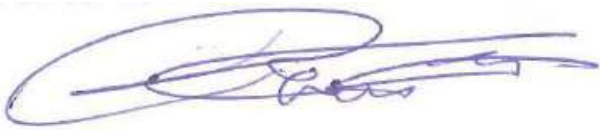

Prof. dr. Huub Rijnaarts the SENSE Director of Education

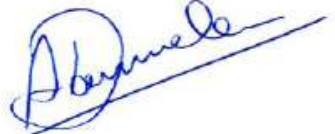

Dr. Ad van Dommelen

The SENSE Research School has been accredited by the Royal Netherlands Academy of Arts and Sciences (KNAW)

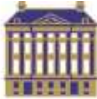

$\begin{array}{llllllllllllllllllllll}K & O & N & I & N & K & L & I & J & K & E & N & E & D & E & R & L & A & N & D & S & E\end{array}$ 


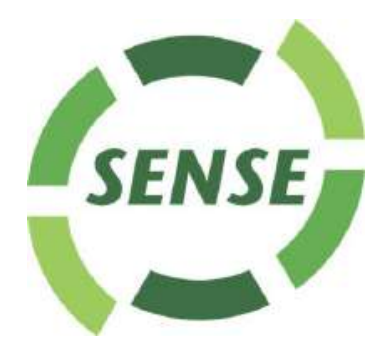

The SENSE Research School declares that Mr Torsten Starkloff has successfully fulfilled all requirements of the Educational PhD Programme of SENSE with a work load of $30 \mathrm{EC}$, including the following activities:

\section{SENSE PhD Courses}

- Environmental research in context (2013)

- Research in context activity: 'Writing reflection on the context, pitfalls and challenges of successful PhD research and writing of follow-up project proposal' (2017)

\section{Other PhD and Advanced MSc Courses}

- WOCAT Training within COST Action ES4011 'Desertification Hub', University of Bern (2013)

- Multi-scale assessment of vadose zone hydrology, Norwegian University of Life Sciences (2013)

- X-ray image processing and analysis, Swedish University of Agricultural Sciences (2014)

\section{Management and Didactic Skills Training}

- Supervising MSc student with thesis entitled 'Soil surface roughness measurements and erosion modelling' (2013)

\section{Oral Presentations}

- Applied comparison of the erosion risk models EROSION 3D and LISEM for a small catchment in Norway. Vannets vei I Landskapet-Hydrologiens Betydning for Miljøstatus Modellering, 20 November 2012, As, Norway

SENSE Coordinator PhD Education

Dr. Monique Gulickx 


\section{Propositions:}

1. For understanding processes at catchment scale, models are an essential tool, but their results are only as reliable as the knowledge the model user has of the area. (this thesis)

2. In terms of soil erosion, shallow snow packs can have a greater negative impact than thick stable ones.

(this thesis)

3. Drones will soon be a standard component, as an auger is today, in the field-toolbox of soil scientists.

4. Participants of congresses avoiding traveling by plane should be offered a reduction in congress fee.

5. A one-year internship at a farm should be a mandatory part of the education of soil scientists.

6. To maintain good quality research in the future, thoroughly documented 'failures' should become as publishable as successful experiments.

Propositions belonging to the thesis, entitled

'Winter hydrology and soil erosion processes in an agricultural catchment in Norway' Torsten Starkloff

Wageningen, 05 December 2017 